\title{
The power of energy
}

Synergies and trade-offs of achieving SDG7 targets in Sub-Saharan Africa - A model-based analysis

Anteneh G. Dagnachew 


\section{The power of energy}

Synergies and trade-offs of achieving SDG7 targets in Sub-Saharan Africa - A model-based analysis

Anteneh G. Dagnachew 
The power of energy: Synergies and trade-offs of achieving SDG7 targets in SubSaharan Africa - A model-based analysis

Anteneh G. Dagnachew, 2021

The research work reported in this thesis was carried out at the department of 'Climate, Air, and Energy' at PBL and the 'Energy and Resources' group of the Copernicus institute, at the faculty of geosciences, Utrecht university. The work benefitted from the funding by the Dutch Ministry of Foreign Affairs, through its Directorate-General of Trade and International Cooperation and the European Horizon 2020 research programme 'Linking Climate and Development Policies Leveraging International Networks and Knowledge Sharing CD-LINKS'.

ISBN: $\quad$ 978-94-6416-457-2

Printing: $\quad$ Ridderprint | www.ridderprint.nl

Layout and design: Sanne Kassenberg, persoonlijkproefschrift.nl

Cover design by: Ètienne Bruis, De Theater HAVO/VWO, Rotterdam 


\title{
The power of energy: \\ Synergies and trade-offs of achieving SDG7 targets in Sub- Saharan Africa - A model-based analysis
}

\author{
De kracht van energie: \\ Synergieën en trade-offs voor het behalen van SDG7 \\ doelstellingen in Sub-Sahara Afrika - Een modelanalyse \\ (met een samenvatting in het Nederlands)
}

\section{Proefschrift}

ter verkrijging van de graad van doctor aan de Universiteit Utrecht

op gezag van de rector magnificus, prof.dr. H.R.B.M. Kummeling, ingevolge het besluit van het college voor promoties in het openbaar te verdedigen op woensdag 7 april 2021 des ochtends te 10.30 uur

door

\section{Anteneh Getnet Dagnachew}

geboren op 17 oktober 1981 te Addis Abeba, Ethiopië 


\section{Promotor:}

Prof. dr. D.P. van Vuuren

\section{Copromotor:}

Dr. A. Hof 
"We each exist for but a short time, and in that time explore but a small part of the whole universe. But humans are curious species. We wonder, seek answers."

Stephen Hawking and Leonard Milodinow, The grand design, P.5

"You have to act as if it were possible to radically transform the world. And you have to do it all the time."

Angela Davis 


\section{Contents}

Abbreviations

1. Introduction

1.1. Background 2

1.2. Universal access in the context of SDGs 4

1.3. Energy system modelling and developing countries 7

1.4. Modelling synergies and trade-offs in the context of SSA 11

1.5. Main objective and research questions 15

1.6. Thesis outline 18

2. The role of decentralized systems in providing universal electricity access in Sub-Saharan Africa - A model-based approach

Abstract $\quad 22$

Highlights $\quad 22$

2.1. Introduction 23

2.2. Key factors determining the choice of different electrification $\quad 24$ systems

2.3. Electrification model and model runs 28

2.3.1. Choosing between electrification options 28

2.3.2. Generation technologies \& costs of electrification 31

2.3.3. Scenario Assumptions 34

2.4. Results 37

2.4.1. Electrification rates and total electricity demand 37

2.4.2. Electrification systems and electricity costs 38

2.4.3. Electrification investments 40

2.4.4. Sensitivity analysis $\quad 43$

2.5. Discussion and Conclusion $\quad 44$

$\begin{array}{ll}\text { 2.6. Acknowledgements } & 47\end{array}$

3. Trade-offs and synergies between universal electricity access and $\quad 49$ climate change mitigation in Sub-Saharan Africa

Abstract $\quad 50$

$\begin{array}{ll}\text { Highlights } & 50\end{array}$ 
3.1. Introduction 51

3.2. Methodology 53

3.2.1. The IMAGE-TIMER model 53

3.2.2. Scenario descriptions 55

3.3. Results 58

3.3.1. Electricity demand 58

3.3.2. Electricity production 61

3.3.3. Electricity prices and investments $\quad 69$

3.4. Discussion 71

3.5. Conclusions 73

3.6. Acknowledgements 75

4. Actors and governance in the transition toward universal and $\quad 77$ sustainable electricity systems in Sub-Saharan Africa

$\begin{array}{ll}\text { Abstract } & 78\end{array}$

$\begin{array}{ll}\text { Highlights } & 78\end{array}$

$\begin{array}{ll}\text { 4.1. Introduction } & 79\end{array}$

4.2. Methodology 80

4.2.1. Expert Workshops $\quad 81$

4.2.2. Stakeholder interviews $\quad 81$

4.3. Access to electricity: key actors and barriers 85

4.3.1. Actors in the governance of electricity supply 85

4.3.2. Barriers to off-grid (renewable) electrification 86

4.4. Results 89

4.4.1. Storylines 90

4.4.2. Institutional structure, actors and governance 92

4.4.3. Existing regulatory instruments to stimulate off-grid 99 systems 102

4.5. Discussion 102

4.6. Conclusion and policy implications 103

$\begin{array}{ll}\text { 4.7. Acknowledgements } & 104\end{array}$

$\begin{array}{ll}\text { 4.8. } & \text { Future work } \\ & 105\end{array}$ 
5. Scenario analysis for promoting clean cooking in Sub-Saharan

Africa: costs and benefits

$\begin{array}{ll}\text { Abstract } & 108\end{array}$

$\begin{array}{ll}\text { Highlights } & 108\end{array}$

$\begin{array}{ll}\text { 5.1. Introduction } & 109\end{array}$

5.2. Methodology 110

5.2.1. Current use of cooking fuel in SSA 111

5.2.2. Model description 112

5.2.3. Technology and cost assumptions 116

5.2.4. Scenario descriptions 118

5.3. Results 120

5.3.1. Cooking fuels and technologies $\quad 120$

5.3.2. Capital cost and fuel expenditure 122

5.3.3. Health impacts - Child mortality 124

5.3.4. Risk of deforestation 126

5.3.5. GHG emissions 128

5.4. Discussion 130

5.5. Conclusions 132

5.6. Acknowledgement 134

6. Integrating energy access, efficiency and renewable energy 137 policies in Sub-Saharan Africa: a model-based analysis

$\begin{array}{ll}\text { Abstract } & 138\end{array}$

$\begin{array}{ll}\text { Highlights } & 138\end{array}$

$\begin{array}{ll}\text { 6.1. Introduction } & 139\end{array}$

6.2. Methodology 140

6.2.1. Scenario descriptions 142

6.3. Results 144

6.3.1. Trends in access to clean fuels 144

6.3.2. Change in household final energy intensity 146

6.3.3. Renewable energy shares 148

6.3.4. Investment requirements of providing universal 149 access

6.3.5. Energy use related residential sector emissions 150 
6.4. Discussion 150

6.5. Conclusions 152

$\begin{array}{ll}\text { Acknowledgements } & 153\end{array}$

7. Synthesis and conclusions 155

$\begin{array}{ll}\text { 7.1. Introduction } & 156\end{array}$

$\begin{array}{ll}\text { 7.2. Synthesis of results } & 159\end{array}$

$\begin{array}{ll}\text { 7.3. Discussion } & 175\end{array}$

$\begin{array}{ll}\text { 7.4. Conclusions } & 179\end{array}$

7.5. Further research 182

$\begin{array}{ll}\text { 8. } & \text { References } \\ & 187\end{array}$

Annex A: Supplementary information - Chapter 2 204

Annex B: Supplementary information - Chapter 3 215

Annex C: Supplementary information - Chapter 4

Annex D: Supplementary information - Chapter $5 \quad 227$

Annex E: Supplementary information - Chapter $6 \quad 241$

$\begin{array}{ll}\text { Summary } & 247\end{array}$

Samenvatting $\quad 252$

वप⿴囗十丁S 257

$\begin{array}{ll}\text { Acknowledgements } & 261\end{array}$

Curriculum Vitae $\quad 263$

$\begin{array}{ll}\text { List of publications } & 264\end{array}$ 


\section{Abbreviations}

ALRI

BC

BL

BoS

CAPEX

CCS

\section{CD-LINKS}

CIF

$\mathrm{CO} 2$

DBE

DFID

DFID

ECG

EDL

EEP

EEU

ElectriFi

ENREP

EWURA
Acute Lower Respiratory

Infections

Black Carbon

Baseline

Balance of System

Capital Expenditures

Carbon Capture and

Sequestration

Linking Climate and

Development Policies-

Leveraging International

Networks and Knowledge

Sharing

Climate Investment Funds

Carbon Dioxide

Development Bank of

Ethiopia

Department for International

Development

Department for International

Development

Electricity Company of Ghana

Economical Distance Limit

Ethiopian Electric Power

Ethiopian Electric Utility

Electrification Financing

Initiative

Electricity Network

Reinforcement and

Expansion Project

Energy and Water Utilities

Regulatory Authority
FAO

FEC

GDP

GDP

GEDAP

GHG

GISMO

GTF

GW

HAP

$\mathrm{HH}$

HV

IAM

IDA

IEA

IMAGE

IRENA

$\mathrm{km}$

KWh

LCOE

LPG

LSEB

LV

MARKAL
Food and Agriculture

Organization

Final Energy Consumption

Gross Domestic Product

Gross Domestic Product

Ghana Energy Development

and Access Project

Greenhouse Gas

Global Integrated

Sustainability MOdel

Ghana Grid Company Limited

Global Tracking Framework

Giga watt

Household Air Pollution

Household

High Voltage

Integrated Assessment

Models

International Development

Association

International Energy Agency

Integrated Model to Assess

the Global Environment

International Renewable-

Energy Agency

Kilometre

Kilowatt hour

Levelized Cost of Electricity

Liquified Petroleum gas

Lagos State Electricity Board

Low Voltage

MARKet and Allocation 


\begin{tabular}{|c|c|c|c|}
\hline MEM & $\begin{array}{l}\text { Ministry of Energy and } \\
\text { Minerals }\end{array}$ & REMI & $\begin{array}{l}\text { Residential Energy Model - } \\
\text { India }\end{array}$ \\
\hline \multirow[t]{3}{*}{ MESSAGE } & Model for Energy Supply & $\mathbf{R R}$ & Relative Risk \\
\hline & $\begin{array}{l}\text { Strategy Alternatives and } \\
\text { their General Environmental }\end{array}$ & SDG & $\begin{array}{l}\text { Sustainable development } \\
\text { goal }\end{array}$ \\
\hline & Impact & SE4ALL & Sustainable Energy for All \\
\hline Mt & Mega ton & SEFA & Sustainable Energy Fund for \\
\hline MTF & Multi-Tier Framework & & Africa \\
\hline MV & Medium Voltage & SHS & Solar Home Systems \\
\hline \multirow[t]{2}{*}{ NEDCo } & Northern Electricity & SME & Small and medium \\
\hline & Distribution Company & & Enterprises \\
\hline \multirow[t]{2}{*}{ NERC } & Nigerian Electricity & SREP-IP & Scaling-up Renewable Energy \\
\hline & Regulatory Commission & & Investment Plan \\
\hline \multirow[t]{2}{*}{ NESI } & Nigeria Electricity Supply & SSA & Sub-Saharan Africa \\
\hline & Industry & SSP & Shared Socio-economic \\
\hline \multirow[t]{2}{*}{ NGO } & Non-Governmental & & Projection \\
\hline & Organization & TIMER & Targets IMage Energy \\
\hline \multirow[t]{2}{*}{ NREP } & National Rural Electrification & & Regional simulation model \\
\hline & Program & TWh & Tera watt hour \\
\hline OC & Organic Carbon & UA & Universal Access \\
\hline OPEX & Operating Expenditures & UA-CP & Universal Access - Climate \\
\hline \multirow[t]{2}{*}{ OSeMOSYS } & Open Source energy & & Policy \\
\hline & MOdelling SYStem & UA-NCP & Universal Access - No Climate \\
\hline PPP & Purchasing Power Parity & & Policy \\
\hline PV & Photovoltaic & UN & United Nations \\
\hline REA & Rural Electrification Agency & USD & United States Dollar \\
\hline REF & Rural Energy Fund & VRA & Volta River Authority \\
\hline REMG & $\begin{array}{l}\text { Residential Energy Model - } \\
\text { Global }\end{array}$ & WEM & World Energy Model \\
\hline
\end{tabular}





\section{Introduction}




\subsection{Background}

Access to energy is an important prerequisite for human development as the provision of energy services is closely interwind with the broader socio-economic development of a society. Access to electricity has been associated with increased literacy rates [4], improved health care, enhanced economic opportunities [5], and improvements in productivity [6]. Similarly, universal access to clean and modern energy for cooking can improve health, reduce mortality, reduce poverty, reduce GHG emissions, and protect the environment [7]. These benefits were acknowledged by the global community through the adoption of the Sustainable Development Goals (SDGs), of which SDG7 calls for universal access to modern energy by 2030.

At the moment, Sub-Saharan Africa (SSA) has one of the lowest access rates to modern energy in the world. Figure 1 shows electricity and clean cooking energy access levels in SSA. The lack of access to electricity in SSA blights the continent's economic and social prospects. In 2019, more than 600 million people (60\% of the population) in SSA had no access to electricity [8], and the total installed generation capacity in the region is less than that of the United Kingdom. IEA [9] identified low electrification rates as a significant constraint to economic growth in several African countries, more relevant than access to finance, bureaucracy or corruption. In order to achieve universal electricity access by 2030, an additional 500 million people have to be connected on top of what is achieved under business-as-usual. This requires major investments in generation capacity and transmission and distribution [10].
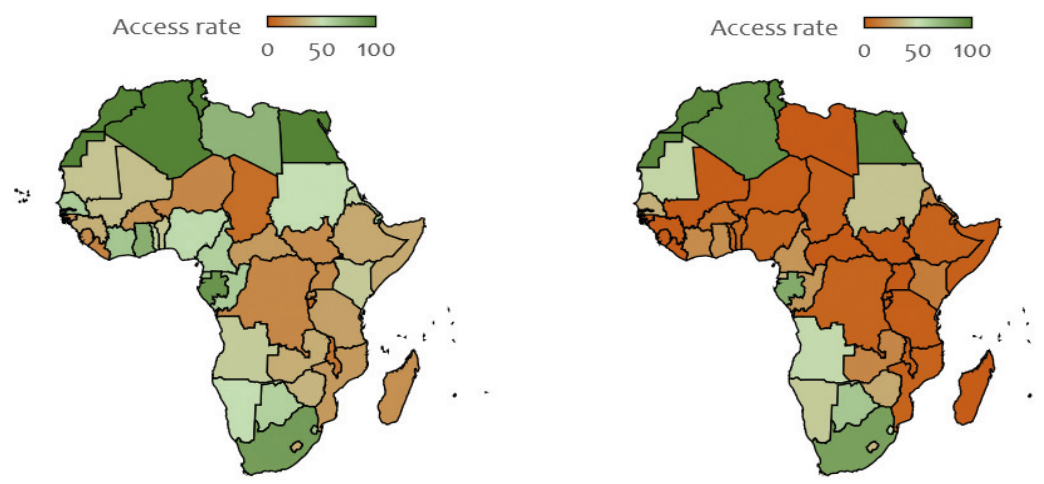

Figure 1: Access to electricity (left) and clean cooking energy (right) in SSA in 2015 [11] Note: Access rate for clean cooking energy for Libya is not available 
Access to clean and modern cooking energy is also a crucial component of sustainable development. However, despite efforts to promote universal access to clean and modern cooking, more than 850 million people ( $83 \%$ of the population) in the region relied on traditional biomass (wood, charcoal, dung, or agricultural residues) for cooking in 2018 - of which $80 \%$ using inefficient cookstoves or open fire. This leads to major health problems, as the inefficient and incomplete burning of solid biomass releases high levels of hazardous air pollutants, including carbon monoxide and fine particulate matter [12]. The resulting household air pollution (HAP) is linked to over 390 thousand premature deaths in SSA in 2017, disproportionately affecting women and children [13]. Moreover, cooking with traditional biomass contributes to deforestation and climate change.

Universal access to modern energy in SSA is unlikely to be met without policy intervention, especially since the expansion of access to electricity and modern fuel infrastructure has lagged behind population growth [7]. Still, innovations in decentralised energy technologies and rapid cost declines offer hope and opportunities for delivering universal electricity access in this decade. The challenge is enormous, however, especially for electricity planning and implementation, as a shift from the historical trend of the central grid as a sole electricity providing system to a variety of technology options that include on-grid and off-grid systems is needed. Similarly, providing universal access to clean and sustainable energy for cooking requires more than just promoting efficient biomass cookstoves. The transition requires weighing several fuel and technology options to determine the appropriate technology to provide access to modern energy for a given settlement at a given time. It involves analysing large sets of data, investigating the interaction between socio-economic factors and exploring the synergies and trade-offs of several parallel developments. At the same time, effective implementation of electrification plans calls for a wide range of interventions by various agencies, including governments, energy utilities, private-sector corporations, funding agencies, and developmental organizations at national and international levels.

Besides interactions between sector-specific policy measures, strategies to achieve universal energy access should consider possible synergies and trade-offs with other SDGs, including how they affect greenhouse gas emissions [14]. So far, lack of proper 
understanding and accounting of synergies and trade-offs between various policies has resulted in incoherent strategies, waste of resources, and delayed outcomes [15]. To this end, computer models, with their ability to compute interaction of various social, economic and environmental developments, are used as additional input to inform policy making. This thesis investigates pathways to achieving universal access to clean and modern energy in SSA and explores the interlinkages between universal access and various sustainable development targets including energy efficiency, renewable energy and climate change.

After this brief introduction on the role of energy in development and the current status in SSA, this chapter provides a brief overview of knowledge with respect to universal access to energy in the context of the SDGs (section 1.2), models and developing countries (section 1.3), the practice of modelling synergies and tradeoffs in the context of SSA (section 1.4), the objectives and the research questions (section 1.5), and the thesis outline (section 1.6).

\subsection{Universal access in the context of SDGs}

The SDGs are global goals adopted by all United Nations Member States in 2015 as a universal call to action to build a better and more sustainable future for all. The SDGs comprise 17 different goals with 169 targets and 232 indicators, which serves as a guide and monitoring mechanism to national and global efforts towards sustainable development. The 17 goals and their targets are integrated, indivisible and interlinked [16]. Hence, a silo-approach that focuses on a specific goal or sector will deliver sub-optimal results as it ignores the systemic nature of the challenges. Understanding the complex link between the SDGs and their targets is important to systematically assess how actions on one goal affect other development activities.

SDG7 aims to ensure access to affordable, reliable, sustainable and modern energy for all. It has three targets, i) to ensure universal access to affordable, reliable and modern energy services, ii) increase substantially the share of renewable energy in the global energy mix, and iii) double the global rate of improvement in energy efficiency, by 2030 [16]. Achieving these targets is important for almost all other SDG targets. Several studies have established the importance of the change in the 
energy system for other SDGs. Fuso Nerini, Tomei [17] found that 113 of the 169 SDG targets require actions to be taken concerning energy systems (see Figure 2). Based on expert surveys, van Soest, van Vuuren [18] show that key interactions exist across all SDGs. The results show SDG7 has high interaction with SDG13, medium interactions with SDG3, SDG8, SDG9, SDG11 and SDG12. It also shows low interactions with the rest of the SDGs (see Figure 2). The study shows that one or more targets in all SDGs are affected by decisions made concerning the energy systems. UN-DESA [19] also lays out the clear role of universal access to clean and modern energy to the achievement of other development goals. McCollum, Echeverri [20] assess the impacts that the kinds of energy solutions enumerated by SDG7 (renewables, efficiency, energy for the poor) could potentially have on various other SDGs, or vice-versa the effects that actions and policies in these other domains could have on the SDG7 targets. 


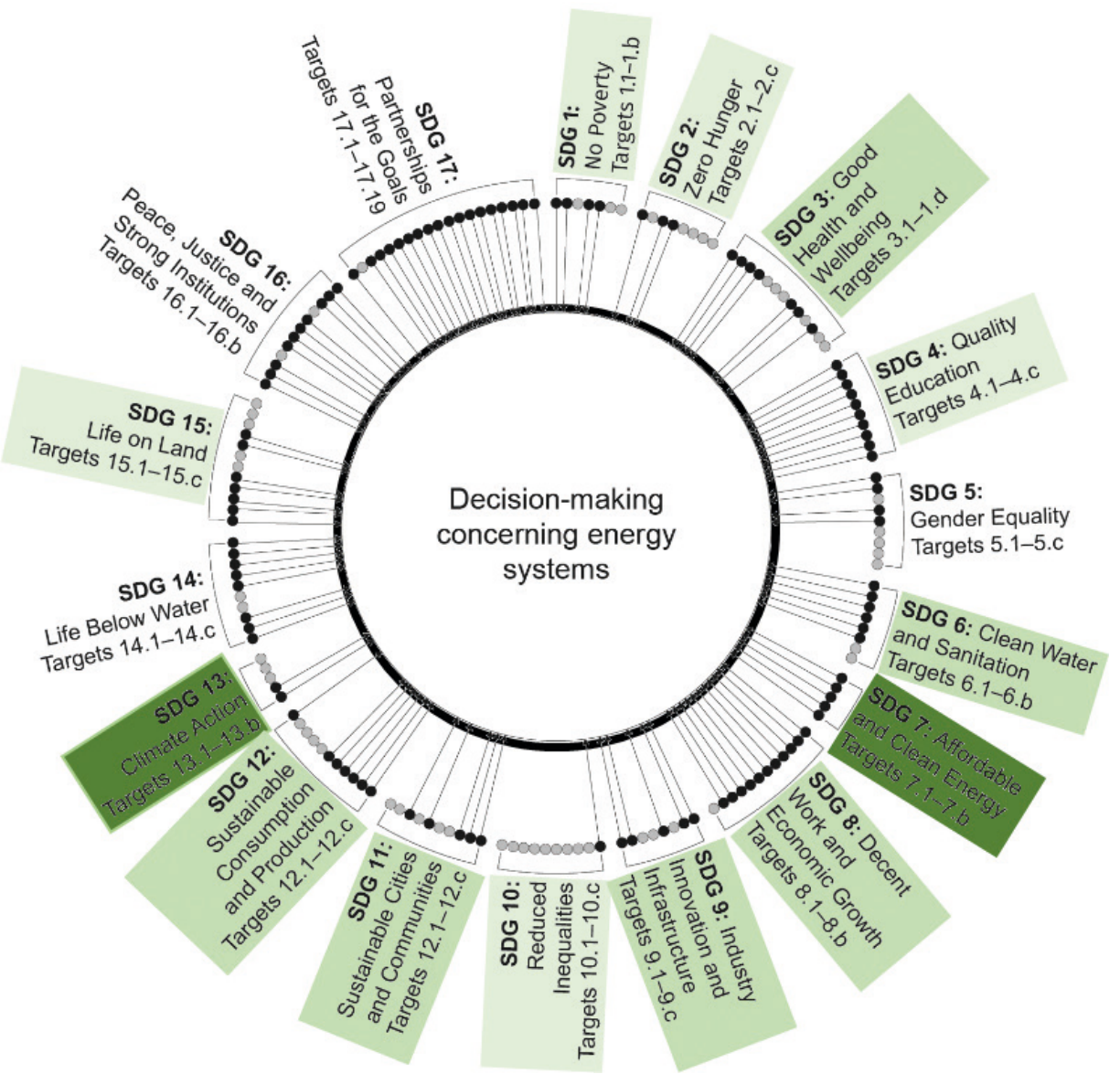

Figure 2: The importance of energy systems for the SDGs and their targets [17] and the importance of the interaction between SDG7 and other SDGs [18]

Note: Each dot represents a specific target recognized in the 2030 Agenda for Sustainable Development. The targets are grouped together under each associated SDG and they are ordered clockwise; for example, Target 1.1 in the diagram is represented by the leftmost circle in the group associated with SDG1. Targets highlighted black (and indicated with black lines) call for action in relation to energy systems. For example, all five targets in SDG7, all 10 targets in SDG4, 11 out of the 12 targets in SDG8, and 18 out of 19 targets in SDG17 require some kind of change in the energy system. Similarly, only 1 target in SDG10 (out of 10) and 2 out of 5 targets in SDG13 require action in the energy system to meet the targets. The green shade shows the level of interaction of SDG7, the darker the shade the stronger the interaction. 
Modern energy access is essential to achieve virtually all development goals, for instance, No poverty (SDG 1), Zero hunger (SDG 2), Good health and well-being (SDG 3), Quality education (SDG 4), Gender equality (SDG 5), Decent Work and Economic Growth (SDG 8), Sustainable Cities and Communities (SDG 11), Climate Action (SDG 13), and Life on Land (SDG 15) [21-23]. People who lack access to modern forms of energy are trapped in a reinforcing cycle with insufficient means to improve their living conditions and basic services [19], such as access to health care (targets 3.7 and 3.8), access to education (target 4.1), access to drinking water and sanitation (target 6.1), access to information (target 9.c) and access to adequate and safe housing (target 11.1), with important consequences on poverty in all its dimensions (target 1.2). They also spend a significant share of their income on expensive, unhealthy, unsafe, time consuming and inefficient forms of energy. Affordable and reliable access to modern forms of energy is the key to breaking this cycle.

There is a concern that achieving universal access to modern energy has a potential conflict with the target to reduce greenhouse gas emissions if that demand is not largely met by low-carbon energy sources [24]. At the same time, promoting renewables could result in energy price shocks for the poor if the costs of transition are not supported by pro-poor policies [25]. Another concern is that promoting bioenergy as a strategy for decarbonization could lead to higher food prices (and thus reduced access to affordable food for the poor) [25] as well as impact food security, land-based carbon stocks, and other environmental services [26]. Therefore, an integrated approach that takes advantage of the synergies and manage the trade-offs between and within the SDGs is a crucial component of sustainable development.

\subsection{Energy system modelling and developing countries}

Energy systems are crucial components of socio-economic systems and have several cross-disciplinary interactions with the economy, society, and the environment [27]. Energy system planning involves finding a balance between supply and demand while keeping the broader national and international development goals in mind. The balance depends on the objective of the planning exercise - minimize the annual cost of providing access, minimize the total investment requirement, ensure 
energy security, or improve the overall efficiency of the system. In the context of sustainable development goals, working out the best way to provide universal access to clean, modern and sustainable energy while minimizing the social, economic and environmental impacts is a key challenge that policy makers in SSA are facing. To inform the decision-making process, several organizations rely on analytical models. Models, in general, represent a simplified view of the real world while performing complex computations that replicate the interrelations of various factors simultaneously. Energy modelling is growing in importance as a tool to help provide robust underpinning to policy-making.

However, the majority of global energy modelling teams are located in industrialized countries, and none of them in Africa, according to the website of the IAMC (the Integrated Assessment Modelling Consortium). Hence, most of the energy systems models that are used in the context of developing countries are built in industrialised countries. The assumptions about energy systems of developing countries are mainly based on experience from the energy systems of industrialised countries [28]. This implies that, in these models, the future development of energy system in developing countries will replicate that of the industrialised countries [28]. However, the energy system characteristics of developing countries are considerably different than that of industrialized countries, as shown in Table 1. It is not only the energy system characteristics that are different for developed and developing countries, but also the central question that the models aim to address. The main question in developed countries is how to reduce emissions without affecting the energy services. In developing countries, the focus lies on providing access to modern energy for all and preferably with renewable energy. Though it is not possible to address all the characteristics of the developing countries' energy systems due to technical restrictions, data inconsistencies and complexity of the system, it is important to have models that adequately represent the main features of the system. 
Table 1: Characteristics of energy systems in developed and developing countries [28-31]

\begin{tabular}{|c|c|c|}
\hline Characteristics & $\begin{array}{l}\text { Energy systems in } \\
\text { developed countries }\end{array}$ & Energy systems in developing countries \\
\hline Supply \& demand & $\begin{array}{l}\text { Almost constant match } \\
\text { of supply and demand }\end{array}$ & $\begin{array}{l}\text { Supply shortages, sub-optimal power system } \\
\text { configurations }\end{array}$ \\
\hline $\begin{array}{l}\text { Transmission and } \\
\text { distribution losses }\end{array}$ & Low losses & High losses \\
\hline $\begin{array}{l}\text { Rate of electricity } \\
\text { access }\end{array}$ & $\begin{array}{l}\text { Almost complete } \\
\text { universal access }\end{array}$ & Considerable lack of access \\
\hline $\begin{array}{l}\text { Dominant energy } \\
\text { carriers }\end{array}$ & $\begin{array}{l}\text { predominance of } \\
\text { modern energy carriers }\end{array}$ & $\begin{array}{l}\text { predominance of traditional bio-fuels (charcoal, } \\
\text { firewood, agriculture residue, and dung) }\end{array}$ \\
\hline $\begin{array}{l}\text { Urban and rural } \\
\text { divide }\end{array}$ & $\begin{array}{l}\text { Structural premises in } \\
\text { urban and rural areas }\end{array}$ & Considerable urban-rural divide \\
\hline $\begin{array}{l}\text { Financing and } \\
\text { investment decisions }\end{array}$ & Adequate & Inadequate \\
\hline Subsidies & Adequate subsidies & Abused or inadequate subsidies \\
\hline $\begin{array}{l}\text { Utility company } \\
\text { financial situation }\end{array}$ & $\begin{array}{l}\text { well established } \\
\text { companies in semi- } \\
\text { regulated system }\end{array}$ & $\begin{array}{l}\text { Poor sector financing (due to tariffs below long- } \\
\text { term marginal costs of production or below average } \\
\text { operating costs, a poor revenue collection performance) }\end{array}$ \\
\hline $\begin{array}{l}\text { Extent of informal } \\
\text { economy }\end{array}$ & Low & Large informal economy, non-monetary transactions \\
\hline Economic structure & $\begin{array}{l}\text { Slow transition in the } \\
\text { past, stable }\end{array}$ & $\begin{array}{l}\text { Rapid change in economic structure (from agriculture } \\
\text { to modest industry and to service sector) }\end{array}$ \\
\hline
\end{tabular}

There are some studies on energy system modelling in SSA with their focus varying considerably. A Scopus search for (energy OR electrification OR electricity) AND modelling AND Africa gives 342 results; limiting the search topic to energy and environmental science narrows the results to 243 publications. The number of publications on energy system modelling for universal access in (parts of) SSA is even less, as many of the 243 studies address topics such as forecasting daily solarradiation, resource potentials, sizing of energy systems or viability of hybrid systems in a specific setting. Below, the top ten cited studies relevant for this thesis are discussed. 
Deichmann, Meisner [32], Parshall, Pillai [33] and Mentis, Howells [34]used spatial models to determine where off-grid systems are cost-effective alternative to centralized grid supply in SSA. These studies concluded that extension of the national grid is attractive under most geographic conditions while decentralized systems are competitive mostly in remote and rural areas. Zeyringer, Pachauri [35] analyse the cost-effective electrification solution for Kenya comparing grid extension with standalone PV systems using micro-data. They conclude that $17 \%$ of the population can be reached cost-effectively by off-grid systems till 2020, confirming the important role that decentralised PV plays in electrification. Winkler, Hughes [36] use the Markal energy model for mitigation analysis of the South African electricity sector under two scenarios that assume $27 \%$ and $50 \%$ of renewable electricity by 2050 . The result shows that technology learning can make a significant difference in renewable energy related investments as a mitigation strategy. van Ruijven, Schers [37] and Daioglou, van Ruijven [38] used bottom up simulation models to assess future trends in electrification in developing world regions including parts of SSA. The results demonstrate the high potentials of off-grid technologies in the region. Ouedraogo [39] developed a scenario-based model to analyse the current status of power generation and project the composition of the future generation profile under alternative scenarios. The results show a rapid increase in electricity demand, supply shortages and high emissions of GHGs. They conclude that the focus on renewable energy based systems is not the best option for sustainable electrification. Heinrich, Howells [40] use a partial equilibrium energy-environment-economic (E3) modelling approach that is extended by assigning cost penalties to non-cost attributes to force the model's least-cost objective function to better satisfy non-cost criteria. The study provides a framework for policymakers to generate a solution set for the power expansion problem that represents a range of solutions that each satisfies multiple objectives to a varying extent. Beck, Kempener [41] explores a new approach to planning and optimization of energy networks, using a mix of global optimization and agent-based modelling tools taking account of techno-economic, environmental and social criteria, and engaging explicitly with inherent network complexity in terms of the autonomous decision-making capability of individual agents within the network, who may choose not to act as economic rationalists. 


\subsection{Modelling synergies and trade-offs in the context of SSA}

The models used in the studies mentioned in the previous section address the complexity of energy planning in developing countries to a certain degree but have limited focus in terms of purpose, paradigm, geographic or time horizon. Present-day energy models could be improved to better represent the special characteristics of developing country energy systems [28]. Understanding these differences is crucial for an adequate representation of developing countries and scenario-making of the energy future. Specifically, the high reliance on traditional energy sources and the considerable urban-rural divide, together with the extensive data requirements of energy modelling, pose obstacles for several developing countries. Determining the requirements of the future energy infrastructure requires inputs of the assessment of the current and future energy demand patterns and trends.

The residential energy model of Daioglou, van Ruijven [38], the main tool for this research, is extended to partly address these unique characteristics of SSA. A simplified representation of the decision tree for choosing the least-cost electrification option for a settlement is presented in Figure 3, a detailed presentation of the model can be found in Figure 6. The electrification component is a multiyear bottom-up model that determines the least-cost electrification technology on $0.5^{\circ} \times 0.5^{\circ}$ grid-cell basis. The model distinguishes three electrification options: (a) extending the central grid; (b) mini-grid systems (photovoltaic panels, diesel generator, wind power, mini-hydro, and hybrid technologies); and (c) stand-alone systems (diesel generators and Solar Home Systems). Detailed cost components of the chosen electrification technologies such as the cost of high voltage (HV) lines, medium voltage (MV) lines, low voltage lines (LV), transformers, household connection and metering, diesel fuel per litre, diesel generators, solar panels, BOS, wind energy system, storage technologies, and associated recurring annual costs (operation and maintenance) are required by the model. These data are location-, scenario-, and time-dependent. 


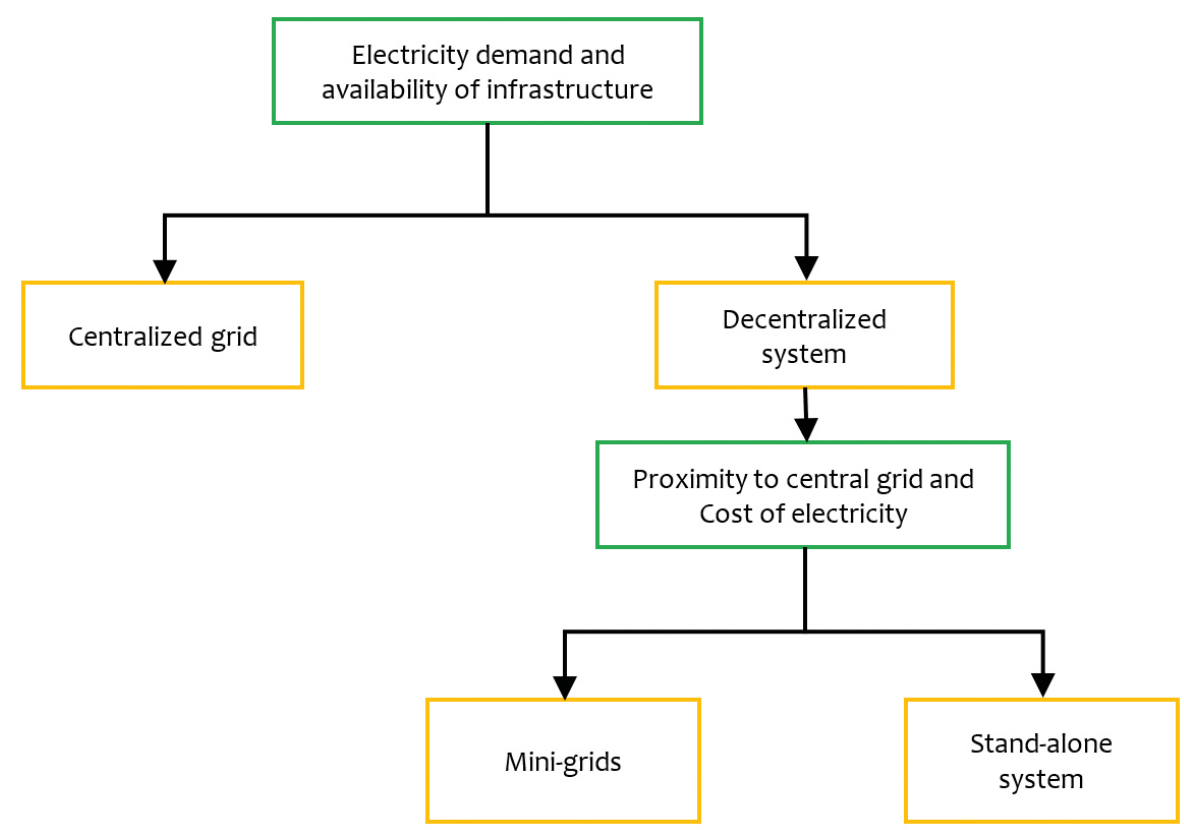

Figure 3: Simplified representation of decision-making model for choosing the least-cost options

The cost of electricity delivered from the different options is calculated based on a mix of local, national and regional data sets. Higher resolution grid-cell data is used for the urban and rural population size, the costs of electricity generation for different technologies, technical potentials of renewable energy sources, the distance of a grid-cell's population to existing high-voltage power lines, and population density (see Annex A for more on this). These data sets address some of the limitations of developed-country oriented models by incorporating unique local characteristics. The electricity access levels used to calibrate the model are based on country level data as reported by the World Bank [11]. Other data sets, such as the cost of transmission and distribution networks, transmission and distribution losses, interest rates, and household electricity demand, are based on regional information.

The priority of energy planning in SSA lies in rapidly increasing access and supply, rather than decarbonization. In line with this, a purpose-designed decision tree performs annual iteration to update technology allocations based on least-cost optimization. The model uses the levelized cost of electricity (LCOE) to make cost comparison across the different system and technology options. The total LCOE 
of a system is the combination of LCOEs of electricity generation, transmission system and distribution network. The transmission system is required only for the central grid, while both the central grid and mini-grid systems require a distribution network. Stand-alone systems are installed close to the load, so they require neither a transmission system nor a distribution network.

Similarly, the cooking energy system module of the Residential Energy Model-Global (REMG) is used to determine future energy demand and the role of different fuels and technologies for cooking (see Annex $D$ for more detail). Figure 4 demonstrates a simplified representation of the cooking fuel and technology choice model. A detailed version of the model can be found in Figure 27. The model is a bottom-up residential energy simulation model that describes the demand and supply of energy for different end-use functions. The future cooking energy demand is determined by focusing on the demand drivers like household size and household expenditure. The model also recognizes the impact of heterogeneity in income groups and urbanrural divisions on household energy demand. It incorporates various cooking energy solutions; traditional biomass cookstoves, improved biomass cookstoves, advanced biomass cookstoves, kerosene, LPG, natural gas, biogas and electricity.

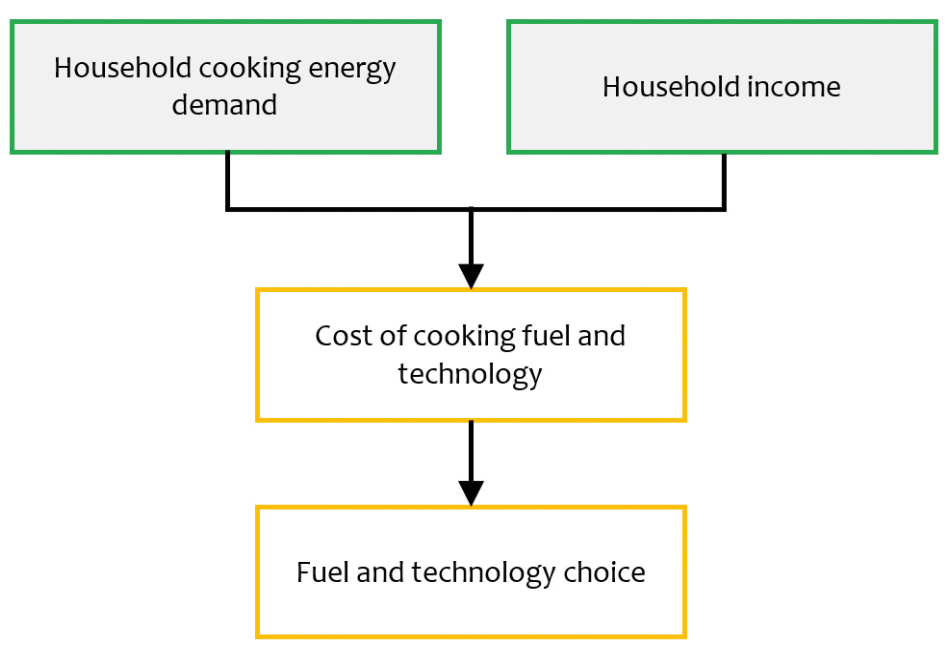

Figure 4: simplified representation of cooking fuel and technology choice 
Our model, like several previous models, neglects the roles of actors and institutions that are crucial in facilitating the universal access process. In a bid to address this shortcoming, we have conducted stakeholder interviews and workshops to identify barriers for electricity access and relevant actors, institutions, and regulations to facilitate the path towards universal access.

Both the electrification and cooking energy demand modules use GDP per capita as one of the main drivers for energy demand level and expenditure. The regional energy demand is determined for five income classes in rural and urban settlements. This way, we consider impact of income inequality between high and low income and between urban and rural settlements. The electrification model and the cooking energy system model are incorporated within the IMAGE model (presented in Figure 5). IMAGE is an Integrated Assessment Model (IAM) looking at future global environmental change [42]. The model links, within a single framework, main features of society with the biosphere and the climate system to assess sustainability issues such as climate change, biodiversity loss and human well-being. The model encompasses (i) the TIMER energy-system simulation model [2] that describes demand and supply of key energy carriers for 26 world regions, (ii) the IMAGE-Land Management model [43] that is used to determine potential biomass supply, and (iii) the GISMO health model $[44,45]$ that is used to determine the health impacts of household air pollution in SSA. 


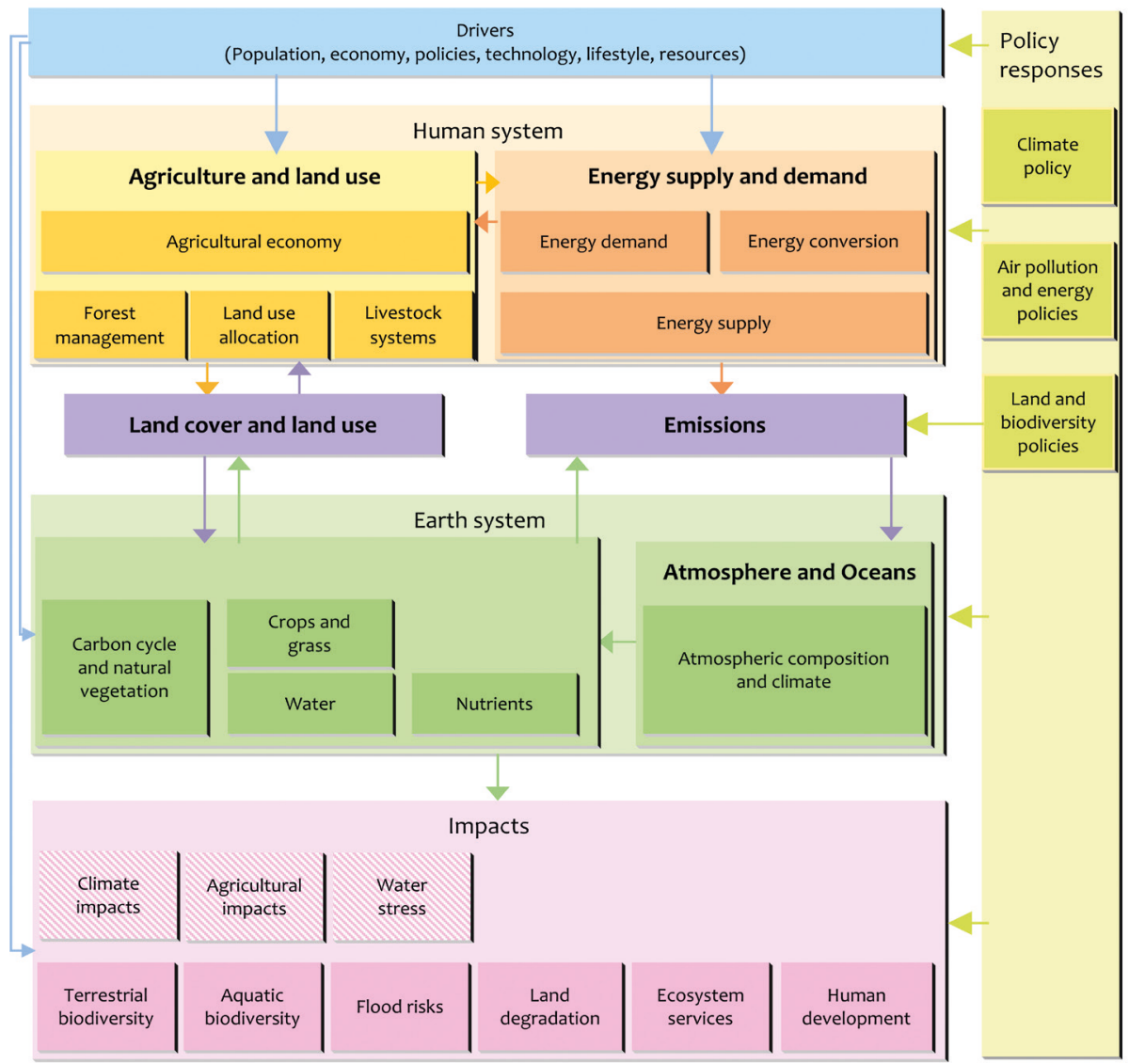

Figure 5: The IMAGE modelling framework [42]

\subsection{Main objective and research questions}

The overall aim of this thesis is to explore synergies and trade-offs of pathways to achieve SDG7 - Ensure access to affordable, reliable, sustainable and modern energy - using a purpose-designed least-cost energy access model that is integrated within an IAM. We will focus on all three components of SDG7: universal access to affordable, reliable and modern energy services, a substantial increase in the share of renewable energy in the global energy mix, and an improvement in energy efficiency. 
The thesis provides least-cost pathways and explores the technical, financial, social, and environmental implications of adopting various technologies for residential energy services. In addition, it identifies the roles of actors and institutions, and the role of regulations in the transition to universal electricity access in SSA. The emphasis of the thesis is to identify synergies and trade-offs between various policies, measures and institutions designed to facilitate the path to achieving SDG7.

In this context, the over-arching research question is "How can universal access to modern and sustainable energy in SSA be ensured while at the same time aiding other development goals?".

In the context of SSA, the two most critical aspects of achieving SDG7 are ensuring universal access to (i) reliable and affordable electricity and (ii) clean and modern fuels for cooking. The first provides the most important bridge into future development of the continent. The second relates to a major residential energy service in SSA that is currently leading to several local sustainability issues.

The over-arching research question is addressed by exploring four main research questions:

\section{What are the implications of different pathways towards achieving universal access} to electricity in Sub-Saharan Africa by 2030 on investments and climate change?

Historically, providing access to electricity to settlements has been done through incrementally extending the central grid. In SSA, this method has proven to be a slow, inefficient, and capital-intensive process that benefits the richest and those closest to existing infrastructure. However, with the rapid decline of renewable energy technologies and the innovations in mobile banking, there are several options of providing access to electricity to the poor and remote communities quickly and economically. These technologies have created new momentum around electrification, but their suitability varies by the location the settlement (population density, consumption levels, resource availability, infrastructure availability, etc.). In this context, assessing the investment needs of these technologies and the interlinkages with climate change provides valuable insight into policy-making 
and for advocacy. To answer the first main research question, the following subquestions are addressed:

1.1. What is the role of decentralised electrification systems in achieving the universal access target?

1.2. What are the synergies and trade-offs of universal access to electricity and climate change mitigation?

\section{Which actors and institutions are involved in the transition towards universal electricity access in SSA?}

Governments have been by far the most important player in power generation and transmission for the past century in SSA. The bureaucracy, lack of human and technical capacity, and corruption has stifled the development of the electricity sector in the region. The emergence of new distributed electrification technologies provides new opportunities, but also poses considerable technical, economic, sociocultural and political challenges. It requires a new way of electricity governance to accommodate the new players emerging as the result of the transition. To answer this question, we present a systematic analysis of institutional challenges and opportunities resulting from the emergence of distributed generation in the bid to provide universal access.

\section{What are the investment and expenditure needs and implications for health,} biodiversity, and climate of pathways towards universal access to clean and modern cooking in SSA?

Universal access to clean and modern cooking solutions is a crucial component of sustainable development as it is critical for several other SDGs and requires a multisectoral approach. Despite the international effort, there are still large numbers of households relying on polluting and dangerous fuels as primary source of cooking energy. Countries with high reliance on traditional methods of cooking need to design the right policies and to make a maximum impact with minimum-regret solutions. This requires an evaluation of the investment needs and expenditures of various cooking solutions, and identify synergies and opportunities with other development goals. 


\section{What are the synergies and trade-offs of integrating policies to achieve goals with} respect to access, efficiency and renewable energy in SSA?

Previous studies have explored the challenges of providing universal access to modern and sustainable energy, the energy efficiency potentials, and the renewable energy potentials separately. These three targets are complementary and the interaction between these factors could lead to a greater effect than the sum of the effects of individual measures. However, an integrated assessment of the magnitude of the synergies and trade-offs between these targets has barely been explored.

\subsection{Thesis outline}

Each chapter of this thesis is the result of a peer-reviewed research article. These articles are published as components of the thesis framework in order to achieve its objective.

Chapter 2 describes the purpose-designed model to explore the development in the SSA electricity sector in Baseline and Universal access scenarios. The results provide insight in the role of different systems and technologies in providing access to electricity in the region and associated investment requirements.

Chapter 3 explores trade-offs and synergies between achieving universal electricity access and climate change mitigation in SSA, using the IMAGE-TIMER IAM. For this purpose, the chapter analysed developments of indicators that describe demand, production, and costs of the future power system under various scenarios with and without climate change mitigation policies.

Chapter 4 provides relevant policy recommendations to facilitate the path towards universal electricity access in SSA regions by identifying the barriers for electricity access and relevant actors, institutions, and regulations through stakeholder interviews and workshops, with a focus on off-grid systems.

Chapter 5 presents several scenarios for the development of (clean) cooking solutions in SSA assuming specific policy options or specific transition pathways towards universal access by 2030. The scenarios consider historic developments, 
availability of fuels and infrastructure, required investments, and trade-offs and synergies related to health, biodiversity and climate change.

Chapter 6 informs planning and policy making by quantitatively exploring the interaction between universal access to modern energy services, enhanced energy efficiency and scaled-up deployment of renewable energy technologies. For that purpose, the chapter assesses a set of scenarios to analyse the interaction between these targets by using two Integrated Assessment Models (IAM), IMAGE \& MESSAGE, that are capable of analysing these synergies and trade-offs.

Chapter 7 synthesises the results of the previous chapters and provides an integrated discussion and conclusion.

Table 2: The intersection between the chapters (peer reviewed publications) and the research questions

\begin{tabular}{|c|c|c|c|c|c|}
\hline \multirow{2}{*}{ Research question } & \multicolumn{5}{|c|}{ chapter } \\
\hline & 2 & 3 & 4 & 5 & 6 \\
\hline $\begin{array}{l}\text { What are the implications of different pathways towards achieving } \\
\text { universal access to electricity in Sub-Saharan Africa by } 2030 \text { on } \\
\text { investments and climate change? }\end{array}$ & & & & & \\
\hline $\begin{array}{l}\text { What are the actors and institutions involved in the transition towards } \\
\text { universal electricity access in SSA? }\end{array}$ & & & & & \\
\hline $\begin{array}{l}\text { What are the investment and expenditure needs and implications for } \\
\text { health, biodiversity, and climate of pathways towards universal access } \\
\text { to clean and modern cooking in SSA? }\end{array}$ & & & & & \\
\hline $\begin{array}{l}\text { What are the synergies and trade-offs of integrating policies to achieve } \\
\text { goals with respect to access, efficiency and renewable energy in SSA? }\end{array}$ & & & & & \\
\hline
\end{tabular}



2. The role of decentralized systems in providing universal electricity access in Sub-Saharan Africa - A model-based approach 


\section{Abstract}

Poverty and lack of access to electricity are highly correlated. In SSA, one of the poorest regions in the world, two in every three people have no access to electricity. This chapter describes a purpose designed model to explore and project the development in the SSA electricity sector in Baseline and Universal access scenarios. The results provide insight in the role of different systems and technologies in providing access to electricity in the region and associated investment requirements. We project that Baseline developments do not lead to universal access to electricity, especially in Eastern Africa and the rural areas of SSA. The results show that central grid extension should be complemented with off-grid systems (mini-grid and standalone) to increase access in SSA. At the same time, the targeted level of consumption has large implications on the preferred electrification technology and associated investment requirements. For low levels of consumption, off-grid technologies are the most important technologies to increase access rate, while for high levels of consumption, extending the central grid is more economical. Total cumulative investment in the period 2010-2030 amount to 22 billion USD for low levels of consumption and exceed 2.5 trillion USD for high levels of consumption.

\section{Highlights}

- Baseline trends fall short of universal electricity access in SSA

- The preferred technology to increase access strongly depends on electricity demand

- Off-grid systems can provide access up to $65 \%$ of the newly electrified population

- There is a need for trade-off between targeted access rate \& consumption level

- Cumulative investment to achieve universal access could amount to 2.5 trillion USD

Published article: Dagnachew, A. G., Lucas, P. L., Hof, A. F., Gernaat, D. E. H. J., de Boer, H.-S., \& van Vuuren, D. P. (2017). The role of decentralized systems in providing universal electricity access in Sub-Saharan Africa - A model-based approach. Energy, 139, 184-195. https://doi.org/10.1016/j.energy.2017.07.144. 


\subsection{Introduction}

Access to electricity is crucial for human development [46]. Still, in SSA 621 million people (i.e. two in every three people) have no access to electricity [11]. The total generation capacity in SSA is just 90 gigawatts (GW), i.e. comparable to the total installed capacity of United Kingdom - a country with less than $7 \%$ of the population of SSA [47]. Moreover, electricity systems often function poorly with an unstable and unreliable electricity supply, low generation capacity, and low efficiency and high costs [48].

Through the adoption of the Sustainable Development Goals (SDGs), the global community has committed to achieving universal access to electricity by 2030 [16]. Scenario studies show that without dedicated policies, this target is unlikely to be reached [49]. Achieving the target would require a significant expansion of the grid and a strong increase in generation capacity [50]. In addition to central grid-extension, off-grid options, such as mini-grids and stand-alone systems, will be required to provide electricity to smaller or remote communities [51]. Energy models can help to evaluate the future challenges of achieving full electricity access. In particular, they can capture the complex interactions between various factors influencing future energy systems, such as long-term investments, operational planning, and electricity distribution.

Yet there are only few models that focus on African countries with their specific characteristics. A notable exception is Zeyringer, Pachauri [35] who developed a model to analyse cost-effective electrification solutions for Kenya, comparing grid extension with stand-alone Photovoltaic (PV) systems. Mentis et. al. also applied a GIS based methodology to inform electrification planning and strategies in Nigeria [52] and Ethiopia [53], taking into account grid extension, mini-grid and stand-alone electrification options. IEA [47] presented a projection and analysis of SSA's energy system to 2040, using its World Energy Model (WEM).

In this chapter, we use an extended stand-alone version of the rural electrification model developed by van Ruijven, Schers [37] to explore future developments in the electricity sector in SSA. The model was designed to assess the costs of rural electrification in developing countries, focusing on extension of the central grid to 
areas with no access to electricity. Unlike van Ruijven, Schers [37], who only looked at the central grid to provide access to electricity, the extended model includes eight off-grid electrification technologies (mini-grid and stand-alone options). Furthermore, van Ruijven, Schers [37] focused only on rural electrification, while the extended model allows assessing both rural and urban areas. This means that the extended model is able to evaluate a broad range of options for household electrification in both urban and rural areas. The model takes into account local characteristics, including population dynamics, resource availability and the prices of different technologies at a $0.5^{\circ} \times 0.5^{\circ}$ grid-cell. We used the model to address the following research questions:

1. What is the potential development in access to electricity and the related technology mix in SSA until 2030?

2. What is the role of decentralized systems in providing universal access to electricity in SSA in 2030?

3. How does changing the level of electricity consumption affect the technology mix and the required investment in the electricity sector?

The structure of the chapter is as follows. Section 2.2 presents the key strengths and weakness of the various electrification systems and the main factors determining the choice between these systems. Then, section 2.3 explains the methodology, including model structure, the different electrification technologies being considered, the methodology for calculating the costs of the different technology options and model assumptions. After that, section 2.4 presents model results for different scenarios, as well as a sensitivity analysis of the main model parameters. Finally, section 2.5 provides conclusions and discussion on model performance, policy implications and suggestions for further research.

\subsection{Key factors determining the choice of different electrification systems}

Almost all governments in developing countries are emphasizing the crucial role of electricity services for human development [33] and have put electrification as a development priority [54]. Traditionally, electrification in developing countries has 
been regarded as the responsibility of governments and has been implemented by national utilities with natural monopolies [55]. Governments have been focusing on extending the central grid to benefit from economies of scale [51]. However, the emphasis on the central grid, while overlooking alternative off-grid solutions has hampered a rapid spread of electricity infrastructure to large parts of developing countries [51]. As a result, despite substantial efforts at extending central grids, the electrification rate in SSA has barely kept up with population growth [56]. Diversification of electrification solutions could play an important role in increasing access, especially in rural SSA [51].

Broadly, three different electrification options can be considered: 1) central grid extension, 2) mini-grid systems, and 3) stand-alone systems (see Table 3). Even though both grid-connected and off-grid systems have their own advantages and disadvantages, in the end, the choice between these systems strongly depends on costs per kWh and associated maintenance requirements [57]. This is particularly the case for a lot of countries in SSA, given the limitations in financial resources and the presence of other competing priorities. 
Table 3: Definitions of electrification systems [58]

\begin{tabular}{|c|c|c|c|c|}
\hline Type & \multicolumn{2}{|c|}{ Definition } & Advantages & Disadvantages \\
\hline $\begin{array}{l}\text { On- } \\
\text { grid } \\
\text { system }\end{array}$ & \multicolumn{2}{|c|}{$\begin{array}{l}\text { All network or sub-grid or } \\
\text { generating systems that are } \\
\text { connected to the grid and run by } \\
\text { national utility }\end{array}$} & $\begin{array}{l}\text { High degree of reliability, } \\
\text { lower price per kWh } \\
\text { than other options when } \\
\text { population density and/ } \\
\text { or consumption is high }\end{array}$ & $\begin{array}{l}\text { High initial investment, } \\
\text { very high price per } \\
\text { kWh in low population } \\
\text { density or consumption } \\
\text { areas }\end{array}$ \\
\hline \multirow[t]{3}{*}{$\begin{array}{l}\text { Off- } \\
\text { grid } \\
\text { system }\end{array}$} & \multicolumn{4}{|c|}{$\begin{array}{l}\text { All distribution networks that are isolated from the main grid, supplied by independent } \\
\text { source(s) of power, and managed by any kind of operator. This includes both mini-grid and } \\
\text { stand-alone options. }\end{array}$} \\
\hline & $\begin{array}{l}\text { Mini- } \\
\text { grid } \\
\text { system }\end{array}$ & $\begin{array}{l}\text { System where all or a } \\
\text { portion of the produced } \\
\text { electricity (by any source) is } \\
\text { fed into a small distribution } \\
\text { grid that provides several } \\
\text { end-users with electricity } \\
\text { A mini-grid system can } \\
\text { be either isolated or } \\
\text { connected to the central } \\
\text { grid }\end{array}$ & $\begin{array}{l}\text { Enhance local level } \\
\text { ownership of operation } \\
\text { \& maintenance, social } \\
\text { control over electricity } \\
\text { theft, better reliability } \\
\text { than stand-alone, easy } \\
\text { adaptability, more } \\
\text { cost effective than } \\
\text { grid extension over } \\
\text { large distance, reduced } \\
\text { distribution loss }\end{array}$ & $\begin{array}{l}\text { Frequent technology } \\
\text { failure from lack of } \\
\text { maintenance, untested } \\
\text { technology, lack of local } \\
\text { skills for maintenance } \\
\text { Insufficient capacity } \\
\text { from poor assessment, } \\
\text { increasing demand, } \\
\text { seasonal resource } \\
\text { fluctuation, demand } \\
\text { management }\end{array}$ \\
\hline & $\begin{array}{l}\text { Stand- } \\
\text { alone } \\
\text { system }\end{array}$ & $\begin{array}{l}\text { Isolated power system } \\
\text { that usually supplies } \\
\text { one rural customer } \\
\text { without a distribution } \\
\text { grid (such as household, } \\
\text { community infrastructure, } \\
\text { battery charging station, } \\
\text { multifunctional platform, } \\
\text { water pumping station, etc.) }\end{array}$ & $\begin{array}{l}\text { User-managed on day } \\
\text { to day basis, blackouts } \\
\text { affect only one user }\end{array}$ & $\begin{array}{l}\text { Limited capacity, lack of } \\
\text { maintenance capacity } \\
\text { at household level, } \\
\text { seasonal resource } \\
\text { fluctuation }\end{array}$ \\
\hline
\end{tabular}

In addition to the costs of the electricity supply technologies themselves, the distance to the central power line, the population density, household electricity consumption, and resource availability are key determinants of the costs per kWh of electricity.

The distance of the area from existing power line is a crucial factor for choice of an electrification system. Delivering electricity through an established grid is cheaper than off-grid options. However, the cost of extending the grid to remote and low populated areas can be very high and the long distance transmission lines can 
experience high technical losses [59]. In this situation, off-grid systems could be an attractive option for areas that are located far from the central grid [37].

Population density is also a key determinant. Most rural communities (as well as many peri-urban areas) are characterized by low population density. The average population density in SSA in 2014 was 41 inhabitants per $\mathrm{km}^{2}$ (ranging from 3 in Namibia to 440 in Rwanda). In low population density areas, electricity distribution costs are shared by relatively few people, resulting in high costs for each unit of electricity consumed [60]. In such regions, off-grid options are relatively attractive, especially when the location is too remote to connect to the central grid.

Electricity consumption is another important determinant for the choice between electrification systems, as low levels of consumption imply high costs per KWh to cover the costs of transmission and distribution. Electricity consumption of any community depends on a number of factors ranging from income of consumers, tariff (price per kWh), cost of competing or substitute services, cost of appliances, socio-cultural factors and economic factors. Annual electricity consumption in SSA varies significantly between countries, ranging from $50 \mathrm{kWh}$ per capita in Niger, to 4600 kWh per capita in South Africa [11].

Finally, resource availability plays an important role in choosing the electrification system and technologies. The whole of SSA is richly endowed with renewable energy resources [32]. The potentials of wind and solar energy are assessed in detail by Hoogwijk [61], who estimated that the technical potential for solar energy in the region exceeds $100 \mathrm{PWh}$ per year. The highest potential for wind power is located in Eastern Africa - with over 300 times more potential capacity than the current electricity consumption - while other parts of SSA have limited potential for wind [61]. Likewise, the whole of SSA has significant potential for hydropower, with the ratio of 'available generation capacity' to 'technically feasible capacity' ranging from 8\% in Eastern Africa, to $19 \%$ in Western \& central Africa [62]. 


\subsection{Electrification model and model runs}

In order to look at the technology options for electrification and use the information on key determinants presented in section 2.2, we have extended the electrification model developed by van Ruijven, Schers [37] with eight off-grid electrification options. The model is designed to make projections for future electricity access rates, choice of electrification technology for rural and urban areas, and associated investment requirements under business-as-usual assumptions - as well as for achieving specific electricity access targets (such as universal access). The model can be used as a stand-alone tool (as used in this chapter), and it can also be integrated into a more comprehensive energy-system model.

\subsubsection{Choosing between electrification options}

The extended model is a multi-year bottom-up electrification model that determines the preferred electrification technology for a grid-cell based on the least-cost option. Figure 6 shows the model process in choosing the least-cost electrification technology for a given grid-cell. The model uses grid-cell data on cost of power generation (for different technologies), population density, cost of transmission and distribution networks, technical potentials of renewable energy sources, the distance of the grid-cell from an existing power line, and other socio-economic data. The data is used to project the cost of electrification and select the least-cost electrification technology from the following three electrification options:
a) extending the central grid,
b) mini-grid systems (photovoltaic (PV) panels, diesel generator, wind power, mini-hydro, and hybrid technologies), or
c) stand-alone systems (diesel generators and solar home systems - SHS).

The model makes two key decisions:

1. Central grid versus off-grid, and

2. Mini-grid versus stand-alone

These decisions are based on the cost of electricity at the grid-cell. The decision-making process is elaborated in section 2.3.1.1 and 2.3.1.2. In section 2.3.2, we discuss in detail the costs involved in the different electrification options and how these costs are calculated. 
Decision tree to determine the lowest-cost electrification system

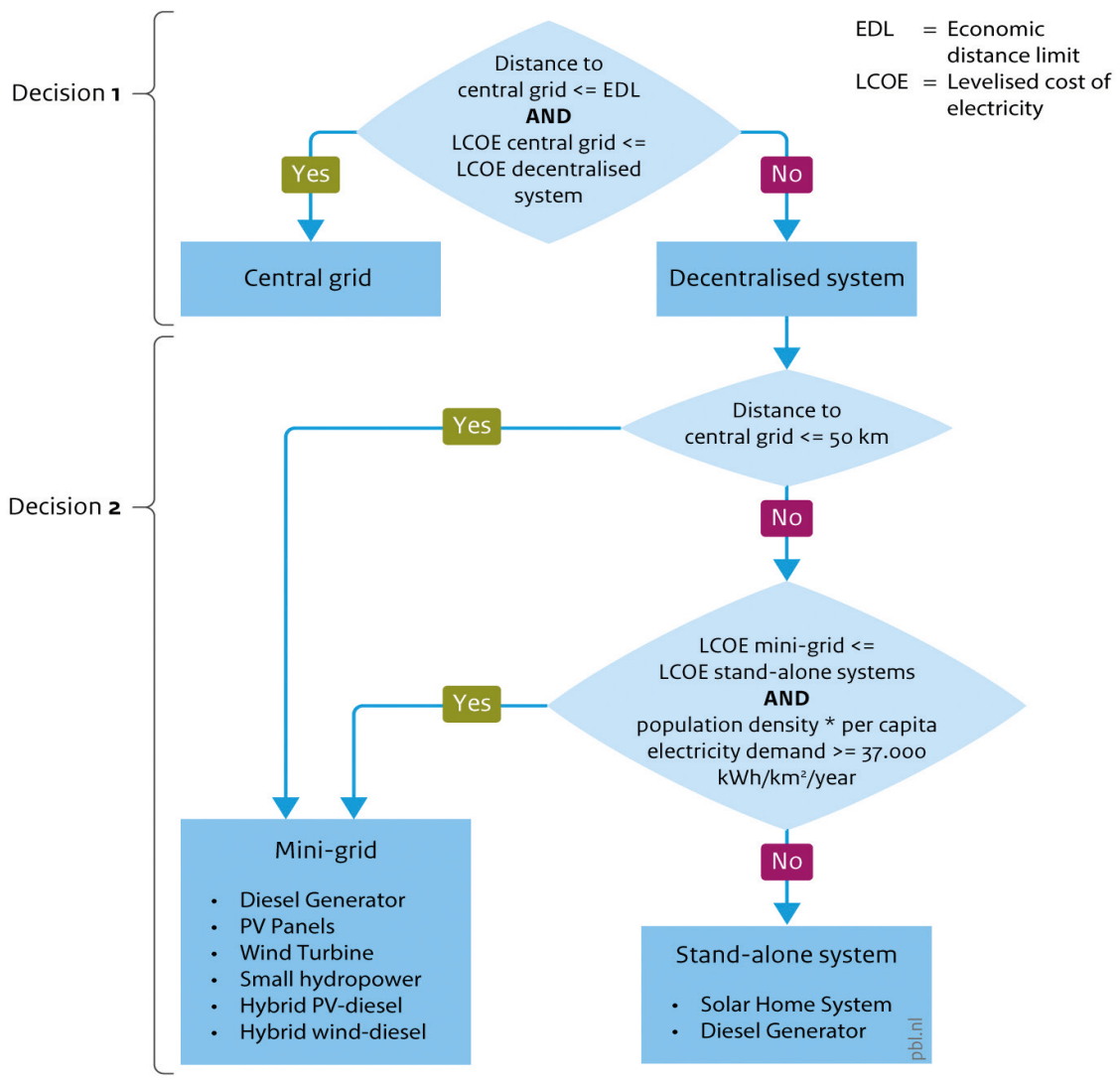

Source: PBL

Figure 6: Model decision-making process in choosing the least-cost options

\subsubsection{First decision: central grid versus off-grid options}

The first decision is made based on the cost of power generation and the distance of the area from existing power lines. If the central grid has lower power generation costs than the off-grid options, the choice between connecting to the central grid or providing off-grid options depends on the distance to the existing power line. Grid extension is not favourable if the distance from the power line exceeds a certain threshold value. This value is represented by the Economical Distance Limit (EDL) [63]. EDL is calculated according to the following formula:

$$
E D L_{c}=\frac{\left(L C O E_{\text {alt }, c}-L C O E_{c g}\right) * \sum_{t=\text { Baseyear }}^{\text {Baseyear }+ \text { Lifetime }} E_{t, c(t)}}{C_{H V \& M V, c}} \mathrm{~km}
$$




$$
\begin{aligned}
& L C O E_{c g} \text { and } L C O E_{\text {alt,c }} \text { are the levelized costs of electricity generation per grid- } \\
& \text { cell from centralized power plants and alternatives, } \\
& \text { respectively (USD per kwh) }
\end{aligned}
$$

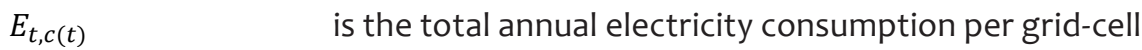

$$
\begin{aligned}
& \text { (kwh per year) at year } t \text {, and } \\
& C_{H V \& M V, c} \quad \text { is the cost of HV \& MV lines required to extend the grid to a } \\
& \text { grid-cell (USD per km) }
\end{aligned}
$$

As such, the EDL is the critical distance between households/communities and the main power lines for which the levelized costs per kWh of grid extension $\left(L C O E_{g e}\right)$ are greater than those for off-grid electricity supply [64]. If the distance to the existing power lines is smaller than the EDL, central grid extension is chosen as the electrification option. However, to reduce the revenue risk of a mini-grid, the model chooses central grid extension to provide access to electricity to the population within $50 \mathrm{~km}$ distance from the existing power line. Figure 7 shows the distance to existing power lines as of 2010, based on power line data of Open Street Maps [65] and Landscan population data [66]. The distance within each grid-cell is the population-weighted distance. First, the distance of every 30 " X 30 " gridcell centroid from existing power lines was determined. This distance was then aggregated to $0.5^{\circ} \mathrm{X} 0.5^{\circ}$ grid-cell using the population size as a weighting factor.

\section{Distance from central grid, 2010}

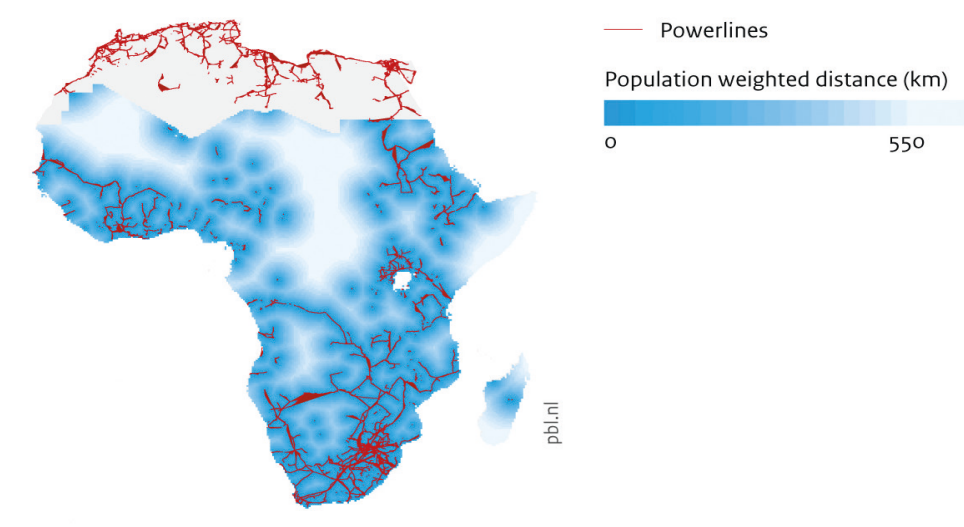

Source: PBL; OpenStreetMap 2015

Figure 7: Population-weighted average distance of the grid-cell centroid to the nearest existing power line (km) in 2010. Sources: population data [66] and power line data [65] 


\subsubsection{Second decision: mini-grid versus stand-alone options}

The second key decision is to identify the least-cost off-grid electrification option for a grid-cell. If the mini-grid or stand-alone option has a lower power generation cost than the central grid, the model determines which of the decentralized systems is the least-cost electrification option. This is based on i) the LCOE of the respective technologies, ii) population density, iii) the distance from the existing power lines of the grid-cell, and iv) household level of electricity consumption. If two or more of the following conditions are met, a stand-alone system is favoured to other systems, provided that it is also the cheapest: (i) the grid-cell has a population density less than 250 persons per $\mathrm{km}^{2}$ (equivalent to about 50 households per $\mathrm{km}^{2}$ ) [67], (ii) electricity demand is less than 150kWh per person per year [58], and (iii) the nearest power line is located further than 50km away, in which case there is less chance of the grid expanding to the area in the near future.

\subsubsection{Generation technologies \& costs of electrification}

The total annual and cumulative regional electrification investments are determined by aggregating required electrification investments of all grid-cells in a region. These investments depend on the cost of electrification, the projected population size, and the projected rate of electricity access at a grid-cell. The cost of electrification is the aggregate of the cost of four system components:

i. power generation cost,

ii. household wiring and metering cost,

iii. internal component cost: the cost of Low-Voltage (LV) \& Medium-Voltage (MV) distribution network, and

iv. external component cost: the cost of the required High-Voltage (HV) transmission lines and transformers.

For central grid extension, all four components are considered. For mini-grids, only i, ii and iii are relevant - and for stand-alone options, only i and ii are required.

A number of mini-grid and stand-alone options are considered in the model and are discussed in detail in Annex A. The levelized cost of electricity generation $\left(L C O E_{g e}\right)$ for all alternative technologies are calculated according to the following formula [68]: 


$$
L C O E_{g}=\frac{\sum_{i=1}^{m}\left[\text { Annuity }_{i} * I_{i}+C_{F C, i}+\beta_{i} I_{i}\right]}{\sum_{i=1}^{m} E_{i}}
$$

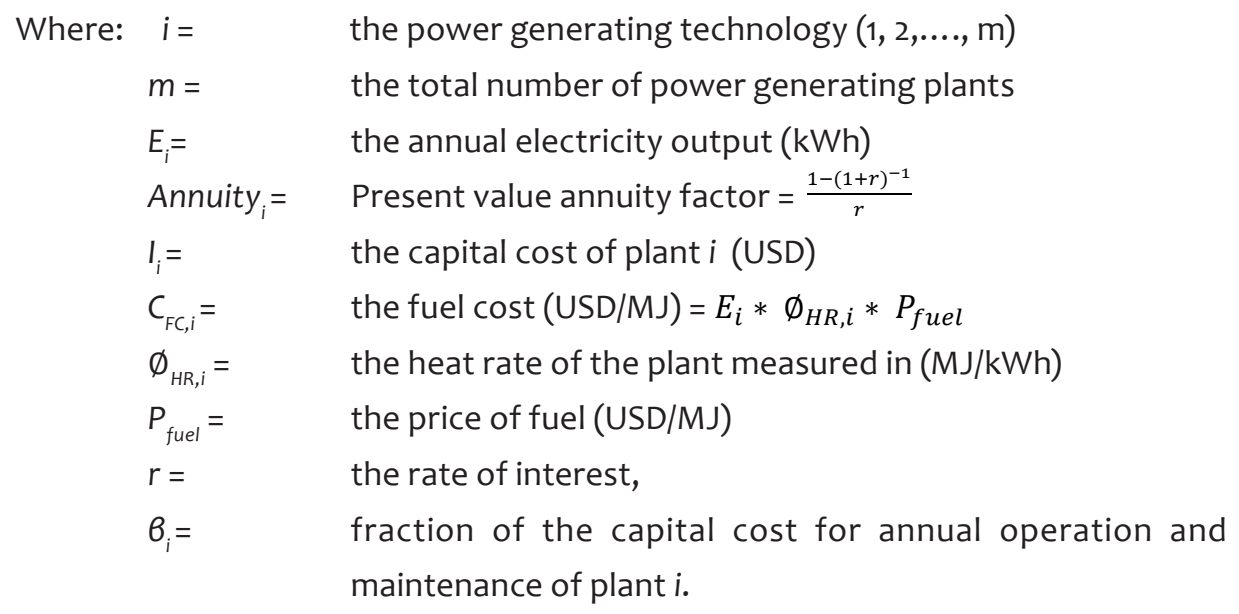

The capital cost $\left(I_{i}\right)$ includes the initial investment cost of power plants, including all components, replacement cost of the components, and the interest payment during construction.

The cost of distribution and household wiring and metering $\left(\operatorname{Inv_{\text {tot,c}}}\right)$ is calculated as follows:

$$
\ln v_{t o t, c}=\ln v_{w \& m, c}+\ln v_{i n t, c}+\ln v_{E x t, c}
$$

Where: $\quad \operatorname{In} v_{w \& m, c}$ is the cost of household wiring and metering for electrified households in a grid-cell (USD)

$\ln v_{\text {int,c }} \quad$ is the cost of the internal component of electrification for a grid-cell which includes the costs of low-voltage lines network for a grid-cell (USD)

$\ln v_{E x t, c} \quad$ is the cost of the external component of grid extension for a grid-cell which includes the costs of high-voltage and mediumvoltage lines and transformers (USD). 


$$
\operatorname{LCOE}_{\text {dis }, c}=\frac{\sum_{i=1}^{m}\left[\text { Annuity }_{i} * \operatorname{Inv}_{i, t o t, c}\right]}{\sum_{i=1}^{m} E_{i}}
$$

Formula 2 is used to calculate the cost of electricity generation for selected minigrid and stand-alone technologies, discussed in the next section. Formula 3 is used to calculate transmission and distribution costs for extending the central grid and mini-grid systems. The design and detail cost components of the transmission and distribution network is discussed in van Ruijven, Schers [37].

\subsubsection{Mini-grid options}

Mini-grids comprise a power generator and a low-voltage distribution network often serving a single community or small town. The most common technologies used for electrification with a mini-grid is the diesel generator, small hydro power, photovoltaics, wind power, and hybrid systems consisting of more than one of these technologies [69]. Mini-grids are not connected to the central grid. However, the ambitions and development policies of several countries in SSA to expand the central grid and central generation capacity implies that mini-grids are designed to facilitate future connectivity.

The model includes a range of mini-grid technologies:

1. diesel generator mini-grid

2. solar PV mini-grid

3. wind power mini-grid

4. small hydro power

5. hybrid PV-diesel generator

6. hybrid wind-diesel generator

The total capacity of the mini-grid technology $i$ at a grid-cell level $\left(\mathrm{MG}_{\mathrm{i}, \text { cap, },}\right)$ depends on the annual electricity consumption of the grid-cell $\left(E_{t, c}\right)$, the capacity factor of the technology $\left(\mathrm{CF}_{\mathrm{i}}\right)$, annual load hours, and the distribution loss (Loss $\mathrm{dis}_{\mathrm{is}}$ ):

$$
M G_{i, c a p, c}=\frac{E_{t, c}}{\left(C F_{i} * \text { Annual load hours }\right) *\left(1-\operatorname{Loss}_{\text {dis }}\right)}
$$


As mentioned above, the mini-grid technology also requires a distribution subsystem ( $\left(L C O E_{d i s, c}\right)$, which adds to the cost of the power plant. In line with van Ruijven, Schers [37], we assume that Single Wire Earth Return (SWER) wires are used for the distribution network. Therefore, the cost of distribution involves the internal cost and the cost of wiring and metering as discussed in formula 3, with no external cost component. For the hybrid mini-grid, low and medium penetration levels are chosen to reduce complexity of the system, as these are mature technologies [70]. High penetration systems may require advanced power control systems, as discussed in Hong, Ou [71] for micro-grid hybrid wind, photovoltaic, and fuel cell based power systems, and in Ou and Hong [72] for systems containing solar power, wind power, and a diesel-engine. Table 22, 23, 24 and 25 of Annex A present the specific parameters and assumptions for the mini-grid technologies considered by the model.

\subsubsection{Stand-alone options}

The stand-alone technology options are defined as decentralized systems in the form of a generator or solar home system (SHS) that can be adopted by individual households. A stand-alone system experiences less distance-related transmission losses. The capacity of the stand-alone technology $i$ for a household ( $\operatorname{StA} I_{i, c a p, c}$ ) depends on the annual electricity consumption of the household $E_{t, h h}$, the annual load hours, and the capacity factor of the technology $\left(\mathrm{CF}_{i}\right)$ :

$$
S t A l_{i, c a p, c}=\frac{E_{t, h h}}{\left(C F_{i} * \text { Annual load hours }\right)}
$$

In the model, two stand-alone technologies are included:

1. solar home systems (SHS)

2. diesel generator

Tables 26 and 27 in Annex A present the specific parameters and assumptions for these stand-alone technologies.

\subsubsection{Scenario Assumptions}

The model is used to explore two main scenarios: a baseline (BL) scenario and a universal access (UA) scenario. In the model, SSA is sub-divided in four regions: 
'Western and central Africa', 'Eastern Africa', 'Republic of South Africa' and 'the rest of southern Africa' (see Table 31 and Figure 43 of Annex A). The basic difference between the two main scenarios relates to the rate of regional electrification in 2030. In the BL scenario, the rate of electrification is based on business-asusual developments (with no new policies or targets), and is calculated by the electrification model discussed in van Ruijven, Schers [37]. This model projects the rate of electrification based on GDP per capita, population density and the urbanization rate. In the UA scenario, the SDG target of full access to electricity by 2030 is imposed for the whole of SSA. Moreover, in addition to the projected baseline level of electricity consumption, five illustrative variants of the UA scenario are included, with varying levels of consumption according to the Multi-Tier Framework (MTF), to demonstrate the impact of changing consumption on the electrification system and the required cost of electrification (see Section 2.3.3.2).

\subsubsection{Population and economic development}

The main inputs for the model are projections of drivers of energy demand, e.g. population, economic activity, rate of technology change, and urbanization rate. For the purpose of this chapter, these drivers are taken from the Shared Socioeconomic Pathway 2 (SSP2) as implemented in IMAGE [73]. SSPs provide narrative descriptions and quantifications of possible developments of the socioeconomic variables, mentioned above, that characterize challenges to mitigation and to adaptation [74]. SSP2 represents a middle-of-the-road scenario regarding population growth, economic growth, technology development and social acceptance for all energy conversion technologies. The population of SSA is projected to grow to over 1.3 billion in 2030, with the economy almost doubling during this period. The target population for each region is the projected population in 2030.

\subsubsection{Electricity consumption levels}

For both the BL scenario and the UA scenario, baseline household electricity consumption in 2030 is taken from the IMAGE implementation of the SSP2 scenario [75]. Electricity consumption level is provided for five different income classes, for both rural and urban households. Here, we only use the average levels of electricity consumption for urban and rural households, disregarding the income differences between individual households. 
For the UA scenario, we introduce five illustrative variants according to the aspired level of household electricity consumption, as household electricity consumption is one of the key factors for determining the electrification system (see Section 2.2). The different levels of electricity consumption per household are based on the MTF of the Global Tracking Framework (GTF) of the SE4ALL initiative [76], as summarized in Table 4. The levels used in our UA scenarios were set at the minimum consumption levels of the respective tiers. The MTF gives a minimum threshold of different levels of electricity consumption, based on the indicative hours of use for selected appliances. Therefore, the tiers do not accurately reflect the diversity of appliances actually used by the household, nor appropriately account for energy efficiency. Instead, the tiers address the intensity of access, capture the amount of energy services that electricity connections provide, and emphasize that access should be beyond the mere existence of connections. The variations in levels allow for exploring the impact of the level of electricity consumption on the electricity system and cost of electrification in the region. Moreover, the multi-tier measurement of energy access allows governments to set their own targets and ambitions depending on the local situation, such as its development status, the needs of its population, and the available budget [77]. For each variant, the level of electricity consumption is kept uniform for all households that have acquired access to electricity after 2010, while baseline levels of consumption were assumed for households that in 2010 already had access.

Table 4: Multi-Tier Framework for Access to Household Electricity Supply [78]

\begin{tabular}{|c|c|c|c|c|c|c|c|}
\hline & & Tier-0 & Tier-1 & Tier-2 & Tier-3 & Tier-4 & Tier-5 \\
\hline \multicolumn{2}{|c|}{ Annual consumption (kWh/Household) } & $<4.5$ & $\geq 4.5$ & $\geq 73$ & $\geq 365$ & $\geq 1,250$ & $\geq 3,000$ \\
\hline \multirow[t]{2}{*}{ Duration } & Minimum hours per day & & $4 \mathrm{hrs}$ & $4 \mathrm{hrs}$ & $8 \mathrm{hrs}$ & $16 \mathrm{hrs}$ & $23 \mathrm{hrs}$ \\
\hline & Minimum hours per evening & & $1 \mathrm{hr}$ & $2 \mathrm{hrs}$ & 3hrs & $4 \mathrm{hrs}$ & $4 \mathrm{hrs}$ \\
\hline
\end{tabular}




\subsection{Results}

\subsubsection{Electrification rates and total electricity demand}

\subsubsection{Baseline scenario}

A significant gap is projected between the $\mathrm{BL}$ electrification rate and universal access target in 2030, except for Republic of South Africa (Table 5). Furthermore, considerable differences are projected between regional electrification rates and between rural and urban electrification rates within the regions. Almost $90 \%$ of Republic of South Africa is projected to have access to electricity by 2030, while only $52 \%$ of the population in Eastern Africa is projected to have access. Likewise, nearly $75 \%$ of rural Republic of South Africa is projected to have access to electricity in 2030, while in Eastern Africa a mere $30 \%$ of the rural population is projected to have access. By 2030, an additional 550 million people are projected to have access to electricity in SSA. However, this still leaves 500 million people (more than $35 \%$ of the projected SSA population in 2030) without access to electricity.

The total regional electricity demand is projected to increase from 90TWh in 2010 to 270TWh in 2030 - an increase of over 180TWh. More than 140TWh of the increase is to accommodate households connected after 2010. Western \& central Africa accounts for more than $50 \%$ of the increase in residential electricity consumption in SSA.

Table 5: 2010 and projected 2030 regional population and electrification rate (BL scenario)

\begin{tabular}{|c|c|c|c|c|c|c|c|c|c|c|c|c|}
\hline \multirow[b]{3}{*}{ Region } & \multicolumn{6}{|c|}{2010} & \multicolumn{6}{|c|}{2030} \\
\hline & \multicolumn{3}{|c|}{$\begin{array}{c}\text { Total Regional } \\
\text { Population } \\
\text { (million) }\end{array}$} & \multicolumn{3}{|c|}{$\begin{array}{c}\text { Electrification } \\
\text { rate }\end{array}$} & \multicolumn{3}{|c|}{$\begin{array}{c}\text { Total regional } \\
\text { Population } \\
\text { (million) }\end{array}$} & \multicolumn{3}{|c|}{$\begin{array}{c}\text { Electrification } \\
\text { rate }\end{array}$} \\
\hline & Urban & Rural & Total & Urban & Rural & Total & Urban & Rural & Total & Urban & Rural & Total \\
\hline $\begin{array}{l}\text { Western \& } \\
\text { central Africa }\end{array}$ & 180 & 231 & 411 & $65 \%$ & $16 \%$ & $38 \%$ & 361 & 294 & 655 & $86 \%$ & $47 \%$ & $69 \%$ \\
\hline Eastern Africa & 63 & 198 & 261 & $54 \%$ & $12 \%$ & $23 \%$ & 135 & 267 & 402 & $96 \%$ & $30 \%$ & $52 \%$ \\
\hline $\begin{array}{l}\text { Republic of } \\
\text { South Africa }\end{array}$ & 31 & 19 & 50 & $88 \%$ & $56 \%$ & $76 \%$ & 42 & 17 & 59 & $94 \%$ & $75 \%$ & $88 \%$ \\
\hline $\begin{array}{l}\text { The rest of } \\
\text { southern } \\
\text { Africa }\end{array}$ & 47 & 89 & 136 & $52 \%$ & $6 \%$ & $22 \%$ & 98 & 113 & 211 & $82 \%$ & $33 \%$ & $56 \%$ \\
\hline
\end{tabular}




\subsubsection{Universal access scenario}

In the UA scenario, all SSA households have access to electricity by 2030. The average level of electricity consumption of households connected before 2010 is taken from the baseline projection, while the average electricity consumption of all households connected after 2010 is determined by either the baseline projection or the five tiers, with the five tiers used for illustrative purposes. The projected baseline level of electricity consumption lies somewhere between Tier-3 and Tier-4 levels, while Tier-1 is considerably below, and Tier- 5 is significantly above, the projected baseline level of consumption (see Table 6). Total residential electricity demand in 2030, at baseline level of consumption, is projected to reach 330TWh (with 195TWh for households connected after 2010). The tier-based projection shows total electricity demand in SSA ranging from 140TWh for Tier-1 (with 1.1TWh for households connected after 2010), to 920TWh in Tier-5 (with 785TWh for households connected after 2010).

Table 6: Total residential electricity demand in the UA scenario, including the illustrative variants in 2030

\begin{tabular}{llll}
\hline $\begin{array}{l}\text { Scenario } \\
\text { Variant }\end{array}$ & $\begin{array}{l}\text { Average level of electricity } \\
\text { consumption of households } \\
\text { connected after 2010 }\end{array}$ & $\begin{array}{l}\text { Projected SSA total residential } \\
\text { electricity demand for } \\
\text { households connected after 2010 }\end{array}$ & $\begin{array}{l}\text { Projected SSA } \\
\text { total residential } \\
\text { electricity demand }\end{array}$ \\
\hline $\begin{array}{l}\text { UA- Baseline } \\
\text { consumption }\end{array}$ & $\begin{array}{l}\text { Baseline level of } \\
\text { consumption }\end{array}$ & 195TWh & 330TWh \\
Tier-1 & $4.5 \mathrm{kWh} / \mathrm{HH} /$ Year & 1.1TWh & 140TWh \\
Tier-2 & $73 \mathrm{kWh} / \mathrm{HH} /$ Year & $18 \mathrm{TWh}$ & 155TWh \\
Tier-3 & $365 \mathrm{kWh} / \mathrm{HH} /$ Year & $95 \mathrm{TWh}$ & 230TWh \\
Tier-4 & $1250 \mathrm{kWh} / \mathrm{HH} /$ Year & $327 \mathrm{TWh}$ & 460TWh \\
Tier-5 & $3000 \mathrm{kWh} / \mathrm{HH} / \mathrm{Year}$ & $785 \mathrm{TWh}$ & 920TWh \\
\hline
\end{tabular}

\subsubsection{Electrification systems and electricity costs}

Figure 8 shows the least-cost electrification system for each grid-cell in the UA scenario, including the five illustrative variants. At baseline level of consumption (which is between Tier-3 and Tier-4), projections show that $85 \%$ of the newly connected population in SSA will be connected to the central grid. At Tier-1 level of consumption, the electrification system is dominated by decentralized systems providing access to nearly $65 \%$ of the newly connected population in the UA scenario. In this scenario, in which all newly connected households are assumed to consume 
4.5 kWh per HH per year, stand-alone systems and mini-grids provide access to $50 \%$ and $15 \%$, respectively of the newly connected population. However, at the higher levels of consumption of Tier-4 or Tier-5, the economies of scale changes in favour of extending the central grid. As a result, at Tier- 5 level of consumption, the central grid takes the lion's share of the electricity system, providing access to nearly $95 \%$ of the newly connected population (more than one billion people), while around 80 million people are connected through stand-alone systems.

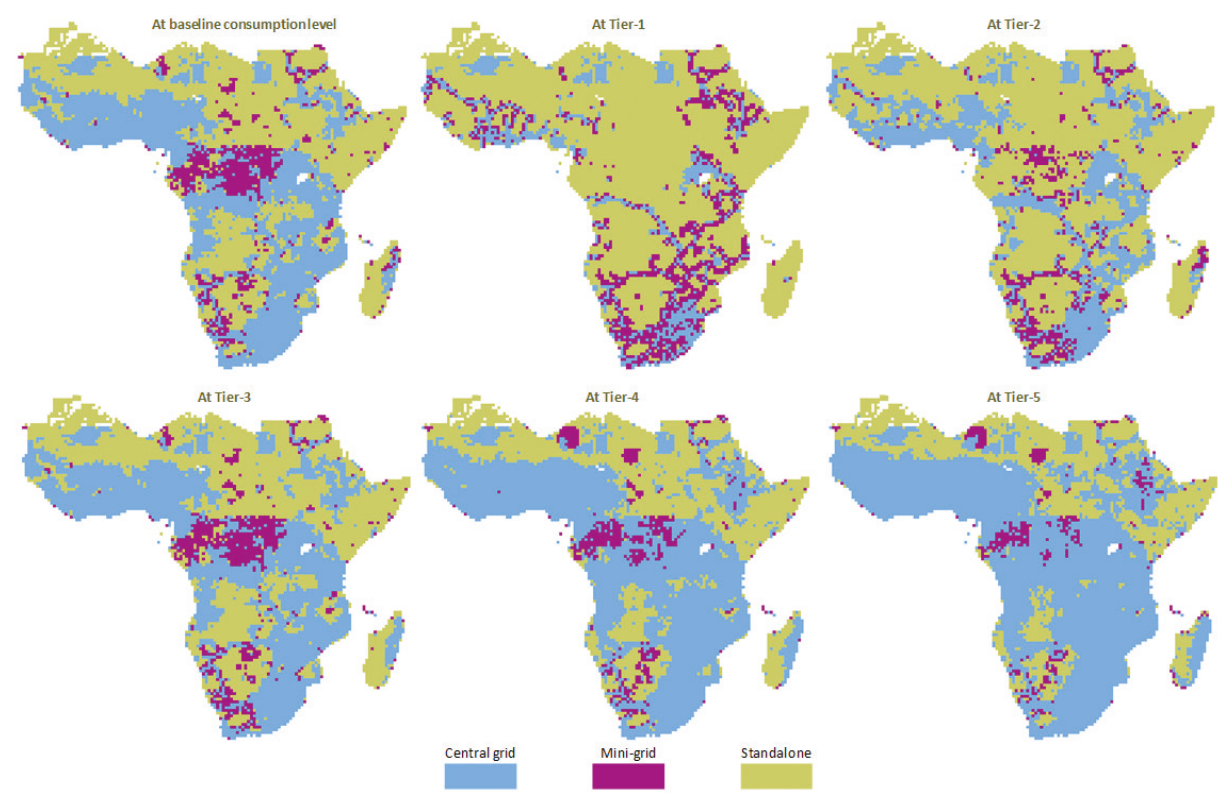

Figure 8: The least-cost electrification system in 2030 for UA Scenario and the illustrative variants

Figure 9 shows the share of the different systems in the BL scenario and the UA scenario, together with the illustrative variants (with consumption increasing from Tier-1 to Tier-5) in SSA in 2030. Under BL scenario, it is projected that the central grid provides access to more than $80 \%$ of the newly connected population, with the rest of the population getting access to electricity with mini-grid and stand-alone systems. For Tier-1 level of consumption, $80 \%$ of the stand-alone systems are solar home systems, providing access to $40 \%$ of the newly connected population. For Tier-5 level of consumption, $90 \%$ of the stand-alone systems are solar home systems (SHS), providing access to less than $5 \%$ of the newly connected population. 


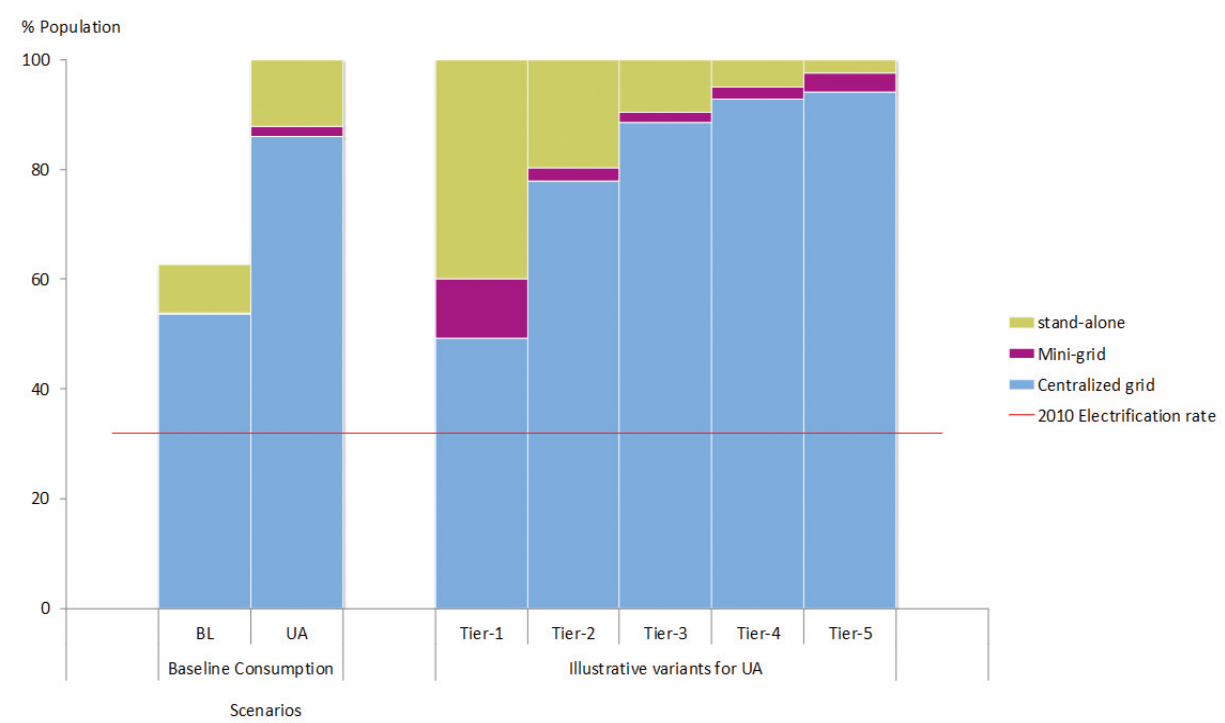

Figure 9: Population distribution by system in 2030 for the BL scenario and UA scenarios, including illustrative variants

The projections show that the cost of electricity generation from a solar PV minigrid starts from USD 0.09 per KWh in 2030, with the lowest LCOE in Eastern Africa and the highest in the Republic of South Africa. The LCOE for wind powered minigrid starts from USD 0.11 per KWh in 2030, the cheapest being in Western \& central Africa and the most expensive in Southern Africa. When there is enough technical potential available, mini-hydro is able to provide least-cost options in some parts of the region, with the LCOE starting from USD 0.14 per kWh. Eastern Africa and part of Western \& central Africa have the highest hydropower potential, hence the lowest electricity generation cost. PV-Diesel Generator and Wind-Diesel hybrid systems also provide a very cost-effective electrification option in some parts of SSA. The LCOE of PV-Diesel hybrid mini-grid starts from USD 0.16 per kwh, whereas the cost of Wind-Diesel Generator mini-grid system starts from USD 0.15 per kwh. Extending the central grid to some remote low-density areas is projected to cost as high as USD 200 per KWh in 2030.

\subsubsection{Electrification investments}

Figure 10 shows total 2010-2030 cumulative investment requirements in the BL scenario and the UA scenario, together with the five illustrative variants. The cumulative investment is the capital expenditure required to provide households 
access to electricity. It does not include recurring annual costs such as fuel costs and operation and maintenance costs. Cumulative investments in the BL scenario are projected to amount to USD 310 billion, an annual average of USD 16 billion. Under the BL scenario, more than $95 \%$ of the investment is projected to go toward extending the central grid. The highest cumulative investment is projected in Western \& central Africa, as a large number of the population in that region is projected to get access by 2030, while the cumulative investment in Republic of South Africa is projected to be the lowest, since a large proportion of the population already has access to electricity.

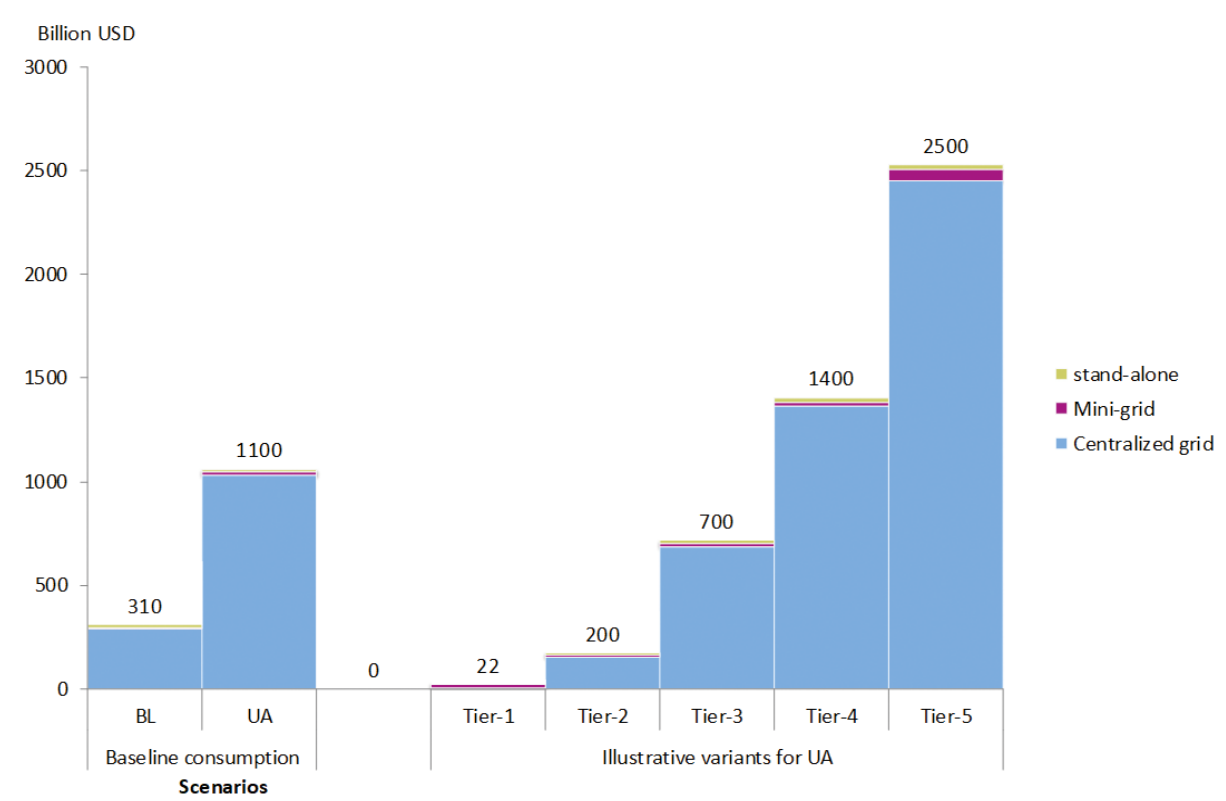

Figure 10: 2010-2030 cumulative investments in the BL scenario and the five UA variants

The cumulative investment requirements for the UA scenario at baseline level of consumption is projected to exceed USD 1000 billion, with $95 \%$ of the investment projected to go toward extending the central grid. The cumulative investment requirements in the UA illustrative variants differ significantly between the lowest and the highest aspired levels of electricity consumption, with USD 22 billion at Tier-1 level of consumption, and USD 2500 billion at Tier-5 level of consumption. The Tier-1 requirement is much lower than the investments required in the $B L$ scenario, due to the BL scenario having a much higher projected level of consumption. In other 
words, we project that full electricity access, at relatively low levels of consumption, could be achieved at lower costs than the projected costs required in the BL scenario, in which full access to electricity is not yet achieved.

The investment distribution of the different technologies at Tier-1 and Tier-5 levels of consumption is shown in Figure 11. At Tier-1 level of consumption, decentralized systems are projected to require more than $75 \%$ of the total investment, while the rest goes toward extending the central grid. At Tier-5 level of consumption, on the other hand, more than $95 \%$ of the cumulative investment goes toward extending the central grid. At Tier-2 and Tier-3 level of consumption, the share of the decentralized system in the required cumulative investment is only $10 \%$ for Tier-2, and $5 \%$ for Tier- 3 .
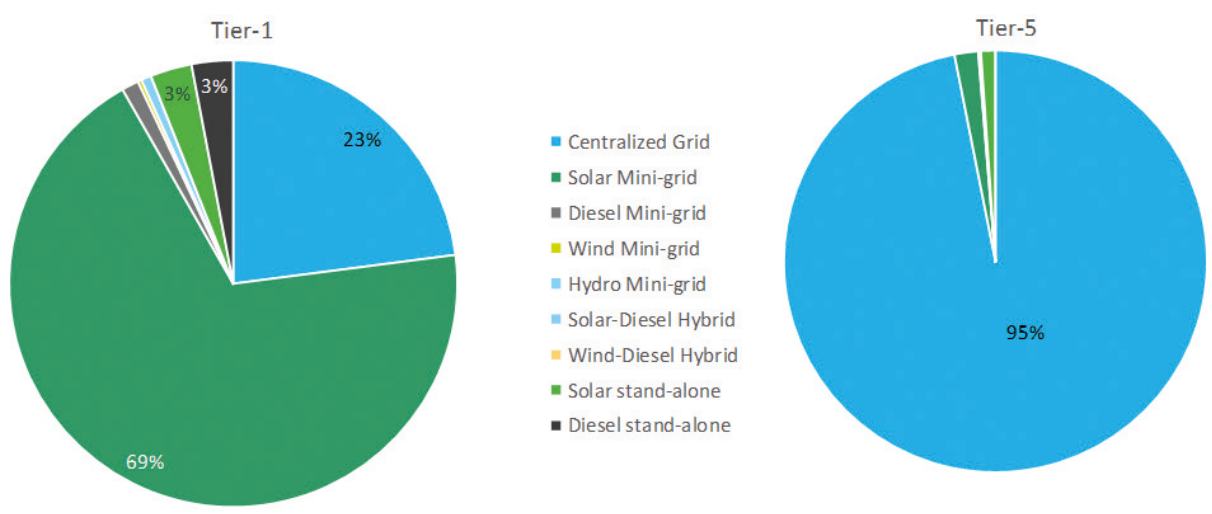

Figure 11: 2010-2030 cumulative investment distribution at Tier-1 (left) and Tier-5 (right) illustrative level of consumption

Our projections of required investments are in the same order of magnitude as other studies. van Ruijven, Schers [37] estimates that, in order to extend only the central grid, an investment of USD 180-320 billion between 2010 and 2030 is required to achieve the universal access target for rural SSA. Their estimates are based on consumption levels of $65 \mathrm{kwh}$ per $\mathrm{HH}$ and $420 \mathrm{kwh}$ per $\mathrm{HH}$, which can be related to Tier-2 and Tier-3 of the MTF. Their estimates are somewhat higher for the lowest level of consumption, and marginally lower for the highest level of consumption, than in our projections (which are USD 115 and USD 360 billion). The higher estimates by van Ruijven, Schers [37] for low levels of consumption can be explained by the fact that extending the grid at the lowest level of consumption is quite expensive. 
At higher levels of consumption, the reason is that the estimated capital costs for grid extension in van Ruijven, Schers [37] are lower than reported in most recent literature, resulting in lower estimates than our study.

\subsubsection{Sensitivity analysis}

Several studies use different estimates for the cost of diesel fuel and transmission and distribution network. See, for example, Deichmann, Meisner [32] for study on Kenya, Fuso Nerini, Broad [67] for study on Ethiopia and Nigeria, and Kemausuor, Adkins [63] for study on Ghana. Therefore, a sensitivity analysis was conducted to assess if the model results are sensitive to the assumptions regarding costs of diesel fuel and the transmission and distribution network, using the ranges of Fuso Nerini, Broad [67] and Deichmann, Meisner [32] as the lowest and highest estimates, respectively (see Table 7).

Table 7: High and low values for transmission and distribution network costs in Sub/Saharan Africa [32, 67]

\begin{tabular}{|c|c|c|c|}
\hline \multicolumn{2}{|c|}{ Parameter } & Low value & High value \\
\hline \multicolumn{2}{|c|}{ Diesel fuel } & USD 0.5 per litre & USD 0.8 per litre \\
\hline \multicolumn{4}{|c|}{ Electricity network costs } \\
\hline$a$ & HV transmission lines (132 kV line) & USD 28000 per km & USD 90000 per km \\
\hline$b$ & MV transmission lines ( $33 \mathrm{kV}$ line) & USD 9000 per km & USD 23000 per km \\
\hline c & LV transmission lines & USD 5000 per km & USD 10600 per km \\
\hline$d$ & Transformers & USD 5000 per km & USD 35000 per km \\
\hline e & Metering and wiring & USD 100 per HH & USD 250 per $\mathrm{HH}$ \\
\hline
\end{tabular}

The cost of diesel has very little impact on the share of decentralized and centralized electrification systems for all levels of electricity consumption. However, the costs of the network components have a visible impact on the share of the different electrification systems at low levels of consumption, and a relatively smaller effect at higher levels of consumption. In the UA scenario, at the lowest level of consumption, off-grid systems provide access to $75 \%$ of the newly connected population, which is 10\%-points (equal to 110 million people) higher than the share that assumes the low costs. At the highest level of consumption, the share of the decentralized systems is $7 \%$ of the newly connected population for the low value of the costs estimates, 
and $9 \%$ for the high value of costs estimates. In other words, at high network costs, decentralized systems are projected to provide access to an additional 20 million people than provided for at lower network costs.

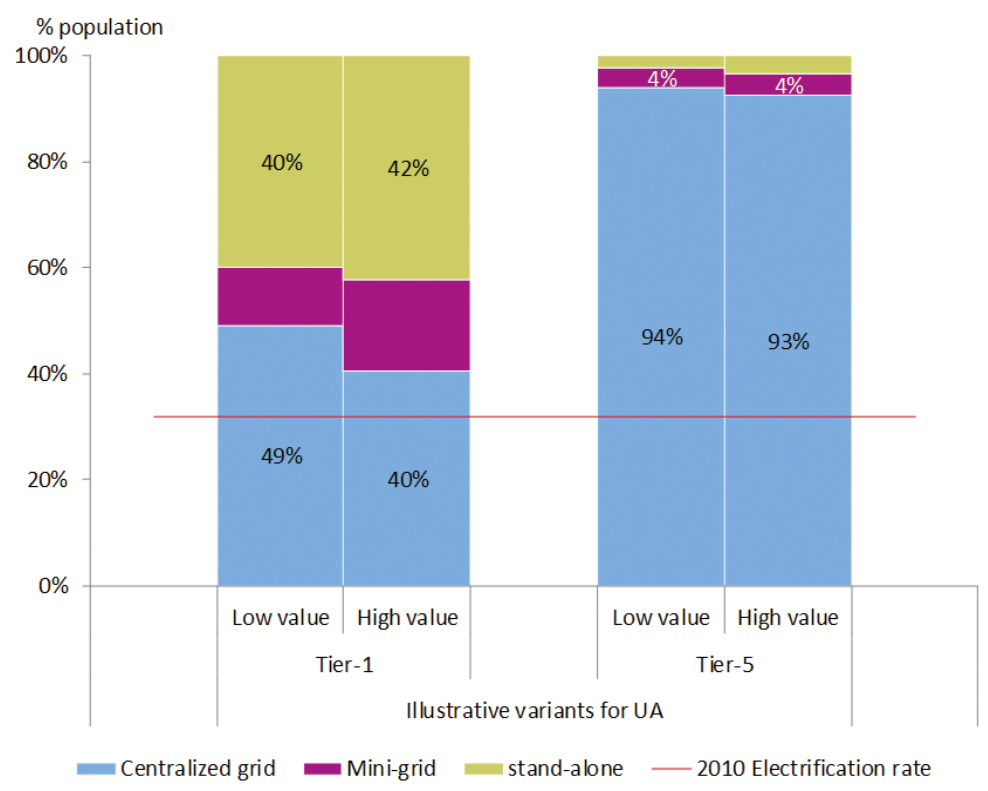

Figure 12: The impact of high transmission and distribution cost on the share of the electrification systems

The 2010-2030 cumulative investment requirement shows considerable increase at high costs of transmission and distribution. The projected cumulative investment for achieving the universal access target at the highest network costs is USD 55 billion for Tier-1 level of consumption (increasing from USD 22 billion at lowest network cost), and USD 8 trillion at the Tier-5 level of consumption (increasing from USD 2.5 trillion at lowest network cost). The investment requirements of the BL scenario are also projected to increase to nearly USD 600 billion (increasing from USD 310 billion at lowest network cost).

\subsection{Discussion and Conclusion}

This chapter discusses an extended model that allowed exploration of the technology and financial developments for electricity access in SSA. More specifically, the model 
was used to explore future developments in the region's electricity sector, the technologies that will play a role, and investment requirements in different scenarios up till 2030. The model's results provide insight in the role of decentralized systems in achieving universal electricity access in SSA. In our analysis, we highlight the need for long term planning to address both the rapidly changing prices of various technologies and the increasing level of electricity consumption.

At the same time, it is important to understand the scope and limitations of the model and scenario assumptions:

1. With the aim of providing an overview of the role of different technologies in achieving universal electricity access and the associated investments, we have used a simple homogenous network design as discussed in van Ruijven, Schers [37]. Different network designs could result in different cost estimates.

2. For this chapter, the focus was on the cumulative electricity consumption at grid-cell level, and not the different level of consumption of households. We assumed regional average urban and rural levels of electricity consumption, irrespective of the differences in income levels between individual households. Therefore, we recommend further research to explore the effects of linking the different levels of consumption to the different income categories in urban and rural areas.

3. The MTF is used to demonstrate the impact of different levels of household electricity consumption on the technology mix, and on the investment needed to provide insight to planners and policy makers on the resources required. It is unlikely that in the short term everyone in SSA will reach Tier-5 level of consumption, considering that the average level of consumption at BL scenarios is projected to be much closer to Tier-3.

4. Climate policies will impact on the choice of electrification technologies and the total cost of electrification. We have not addressed this issue in this chapter, but recommend further research.

5. The model is specifically designed to explore and project the developments in the SSA electrification system. At the current time, it has not been applied to other regions; however, it could be modified to study other regions, such as developing Asia. 
The following conclusions can be drawn from the scenario analysis.

There is a significant gap between the projected electricity access rate in the BL scenario, and the target to provide universal access to electricity. By 2030, more than 550 million additional people are projected to have access to electricity in SSA, compared to 2010 levels. This still leaves over 500 million people without electricity access. The lowest levels of access are projected in Eastern Africa and in rural areas.

The model projections show a significant increase in total residential electricity consumption in most scenarios in SSA in 2030. For the baseline level of consumption, this is the result of rapid population growth and economic development projected in the SSP2 Scenario. For the tier-based variants, the electricity consumption is more illustrative, as it is determined by the targeted tier level. Tier-5 would lead to an enormous increase in electricity consumption in SSA, where the electricity consumption is projected to be $30 \%$ more than the current residential electricity consumption of China. The increase in most of the scenarios will inevitably have a serious consequence on the regions' electricity-related emissions, depending on the chosen energy source.

The technology mix for providing full access to electricity strongly depends on the targeted level of electricity consumption. Renewable mini-grid technologies are projected to have an especially large potential in providing universal access to electricity in SSA. At low levels of consumption, off-grid systems are projected to provide access to nearly $65 \%$ of the newly electrified population, with solar mini-grids and solar stand-alone technologies playing important roles. Large parts of rural SSA are sparsely populated, this makes extending the central grid only attractive at high levels of electricity consumption. At Tier-5 level of consumption, nearly $95 \%$ of the newly electrified population is projected to have access through the central grid. These results are sensitive to the cost of the transmission and distribution network. At high transmission and distribution cost, off-grid systems will play an even bigger role in providing electricity connection in SSA.

Achieving the universal access target in 2030 requires the integration of off-grid electrification options within the electrification systems. Extending the central 
grid requires a significant upfront investment and is not economically feasible at low levels of consumption and/or low population density. Decentralized systems, on the other hand, can be implemented with relatively low initial investment, gradually scaling up the capacity as the level of consumption increases. This involves a tradeoff between the initial investment and the level of electricity consumption, but with potentially lower costs over the long term as consumption increases. Therefore, there needs to be an emphasis on long term planning, and a strategy to integrate the stand-alone and mini-grid systems into the central grid, whilst providing for the increasing levels of consumption. Assuming that high levels of electricity consumption will not be achieved for all households in 2030, mini-grid and offgrid electrification options play a significant role in achieving universal access to electricity.

The level of ambition in achieving universal access to electricity also has a significant implication on the cumulative investment required in the region. The analysis shows the need to balance the trade-off between the target electricity access rate and the level of consumption to provide for. While providing electricity access to the entire region at Tier-1 level of consumption is projected to cost around USD 22 billion, doing the same at Tier-5 level of consumption requires more than USD 2.5 trillion. It is projected to cost USD 310 billion to provide electricity access to nearly $65 \%$ of the SSA population at baseline levels of consumption, while it is projected that a little over half of that cost would suffice to provide access to everyone at Tier-2 level of consumption. As shown in the sensitivity analysis, these prices could be much higher at high transmission and distribution costs.

\subsection{Acknowledgements}

The research presented in this chapter was funded by the Dutch Ministry of Foreign Affairs, through its Directorate-General of Trade and International Cooperation. The work also benefitted from the funding of the European Horizon 2020 research programme as part of the CD-LINKS project (Linking Climate and Development Policies-Leveraging International Networks and Knowledge Sharing) under grant agreement No 642147. 

3. Trade-offs and synergies between universal electricity access and climate change mitigation in Sub-Saharan Africa 


\section{Abstract}

Access to electricity services is fundamental to development, as it enables improvements to the quality of human life. At the same time, increasing electricity access can have notable consequences for global climate change. This chapter analyses trade-offs and synergies between achieving universal electricity access and climate change mitigation in SSA, using the IMAGE-TIMER integrated assessment model. For this purpose, we analysed developments in a number of indicators that describe demand, production, and costs of the future power system under various scenarios with and without climate change mitigation policies. The results show that, achieving universal electricity access requires an annual investment of USD 27-33 billion until 2030 on top of baseline investment. There is a strong synergy in emissions reduction and investment savings, particularly driven by the regions' efficiency improvements of household appliances (the purchase of efficient appliances and the efficient use of the appliances). On the other hand, climate mitigation policies are projected to increase the cost of electricity per kWh, depending on fossil fuel share in the mix. Therefore, we conclude that, climate policies will need to be combined with complementary policies- e.g. pro-poor tariffs, fuel subsidies, and cross subsidization- to protect the poor from increasing electricity prices.

\section{Highlights}

- This chapter looks at electricity access and climate change mitigation in SSA

- Climate change impacts of universal electricity access are small

- Carbon pricing increases electricity prices but stimulates efficiency improvements

- Universal electricity access requires annual investment of USD 27-33 billion

- The impact of external climate change mitigation policies on SSA is modest

Published article: Dagnachew, A. G., Lucas, P. L., Hof, A. F., \& van Vuuren, D. P. (2018). Trade-offs and synergies between universal electricity access and climate change mitigation in Sub-Saharan Africa. Energy Policy, 114, 355-366 


\subsection{Introduction}

Ensuring access to affordable, reliable, sustainable and modern energy for all is one of the Sustainable Development Goals (SDG7) [16] and is also acknowledged by the Paris Agreement as an important need [79]. The key rational behind the emphasis on energy access is that access to modern energy services is fundamental to development [80]. Access to electricity, for instance, allows the use of appliances like mobile phones, radios and fans, while lighting provides extra hours to study or work. Still, over 1.2 billion people did not have access to electricity in 2013; more than half of which live in SSA [81]. Achieving SDG7 thus requires SSA countries to expand electricity access substantially, especially since population is projected to grow rapidly. However, the goal of increasing electricity access is coupled to other SDGs and societal goals, including mitigation of climate change [82]. This is also explicitly recognized by SDG7, which, next to universal access to modern energy sources, also includes targets on renewable energy and energy efficiency.

There are a number of possible trade-offs between providing access to electricity and climate policy. One such trade-off is that increasing electricity access could contribute to greenhouse gas emissions, both directly by increasing energy consumption, and indirectly by promoting economic growth [83]. Several studies have shown that the direct impact of providing electricity access is relatively small: These studies typically find an increase in emissions of around 2-4\% (See for instance van Vuuren, Nakicenovic [82] and UN-OHRLLS [84] for studies at the global scale, Pachauri [85] for India, and Sanchez and Tozicka [86] on South Africa). The reason is that additional energy consumed by poor households is expected to be very small compared to the average consumption, while the newly gained access contributes significantly to human development. The indirect impact from promotion of economic growth is more uncertain and more difficult to assess, and will most likely be a long-term effect. Another possible trade-off is that policies aimed at climate change mitigation can negatively impact energy access by increasing energy prices. For instance, several studies have shown that mitigation policies could slow down the switch from traditional biomass to modern fuels for cooking and heating [38, 87, 88].

To the best of our knowledge, there are no studies in literature that specifically explore the relationships between climate mitigation policies and electricity access 
in SSA. This study addresses these omissions by analysing the impact of mitigation policies on electricity access in SSA, as well as the impact that achieving universal electricity access in SSA has on global climate change. Furthermore, most existing studies on electricity access in SSA [32, 50, 89] assume a fixed minimum level of electricity consumption for all households, neglecting the dynamic process where electricity consumption increases with growing wealth. In this study, we assess the impact of different electricity consumption levels for urban and rural households and various income layers. As such, the main research question of this article is:

What are key synergies and trade-offs between improving electricity access and climate mitigation in SSA?

As a continuation of our previous work [10], which addresses the effect of various levels of electricity consumption on installed capacity and investment, this chapter presents the interaction between universal electricity access and climate change mitigation efforts. We focus on a number of indicators that describe demand, production, and costs of future developments in the power system in SSA under several scenarios. The scenarios differ with regard to electricity access targets and implementation of climate mitigation policy. We have used the Integrated Assessment Model (IAM) IMAGE-TIMER [90], including the electrification model described in Dagnachew, Lucas [10] and the household electricity demand model described in Daioglou, van Ruijven [38]. This model is particularly suited to the analysis, as it combines a detailed electrification model containing several ongrid and off-grid electrification options, with an IAM that takes into account the synergies and trade-offs with (global) climate mitigation policies. The choice between electrification systems (grid, mini-grid and stand-alone) is based on local data about socio-economic characteristics, and potentials and prices of various offgrid technologies (solar PV, wind power, mini-hydro, diesel generators).

The structure of the rest of the chapter is as follows: section 3.2 presents the methodology employed in this chapter, where the model and the scenarios are described; section 3.3 presents the results using the indicators listed above; section 3.4 presents a brief discussion on the model performance and results and uncertainties, and section 3.5 provides conclusions on policy implications and suggestions for further research. 


\subsection{Methodology}

\subsubsection{The IMAGE-TIMER model}

The IMAGE model is an integrated assessment model looking at future global environmental change [42]. It represents interactions between society, the biosphere and the climate system to assess sustainability issues such as climate change, biodiversity loss and human well-being. In this chapter, we use the energysystem simulation model (TIMER), a sub-model of the IMAGE framework [2, 75]. We focus on household electrification, using the electrification sub-model described in Dagnachew, Lucas [10] and the household electricity demand sub-model described in Daioglou, van Ruijven [38].

TIMER describes the demand and supply of 12 different energy carriers for 26 world regions. In the model, SSA is divided into four regions: 'western \& central Africa', 'eastern Africa', 'Republic of South Africa', and 'the rest of southern Africa' (see Annex A). Key issues that TIMER addresses are transitions to more sustainable energy supplies; exploitation of energy resources to meet future demand; and the potential role of the energy conversion sector and individual technologies, particularly in power production, in achieving a more sustainable energy system. In choosing energy supply carriers, TIMER uses a multi-logit approach that selects predominantly the cheapest energy technologies, but assigns a market share to technologies that have somewhat higher costs as well, taking into account heterogeneous local characteristics where relevant. In some exceptions, optimization algorithms are used for simplification. In order to represent climate policy in the model, a 'carbon price' is introduced to induce a shift towards lowcarbon technologies. Key mitigation options include increasing the share of nuclear power and renewables, equipping fossil-fuel technologies with Carbon Capture and Sequestration (CCS), improving energy efficiency, and reducing non- $\mathrm{CO}_{2}$ greenhouse gas emissions. More detail on the assumptions and parameters of the TIMER model can be found in van Vuuren, van Ruijven [2].

Household electricity demand is determined for five income classes, for both rural and urban households, based on the demand for different energy services. The household demand model projects the electricity demand by looking at the specific end-use function (i.e. cooking, appliances, and lighting) and their drivers (population, 
floor space, appliance ownership, appliance efficiency, weather, and electricity price) and relating these functions to economic development. Empirical data shows that household electricity consumption correlates positively with income, which is used in the model, taking into account appliance ownership [38]. Next to income, total household electricity consumption is determined by appliance efficiency. Change in appliance efficiency is driven by two mechanisms: global autonomous improvement towards a theoretical maximum, and regional improvement stimulated by regional energy prices. Increasing electricity price, for example due to carbon tax, stimulates efficiency improvement, hence, a decrease in household electricity consumption. Subsequently, the investments in different end-use technologies (and fuel types) to fulfil demand depend on their relative costs (although some services like lighting and appliances can only be fulfilled by electricity).

Part of the household demand model is the electrification sub model. This model, discussed in detail in Dagnachew, Lucas [10], is integrated within the TIMER model, to allow analysis of trade-offs and synergies between electricity access and climate change mitigation (Figure 13). The model is designed to assess future developments in household electricity access and the role of different technologies. The model determines the least-cost electrification technology (grid-based, mini-grid or standalone) per grid-cell, based on the lifetime cost of generation, transmission and distribution of each technology and the consumption density ( $k W h$ per $\mathrm{km}^{2}$ area) of the respective grid-cell, under various policy assumptions (see Annex B). The model also calculates the associated investment requirements. The model operates at a $0.5^{\circ} \times 0.5^{\circ}$ grid-cell basis and takes key characteristics of the electricity sector into account. Off-grid electrification technologies include mini-grids based on diesel generators, mini-hydro, solar, wind (the last two potentially in combination with a diesel generator), and stand-alone systems based on solar power or diesel generators. The model uses exogenous data on population density [66], distance from existing high-voltage power lines [65] and endogenous data on resource availability [61], regional electricity prices, and the costs of individual electrification technologies for central grid, mini grid and stand-alone systems. 
Synergies and trade-offs between electricity access and climate change mitigation

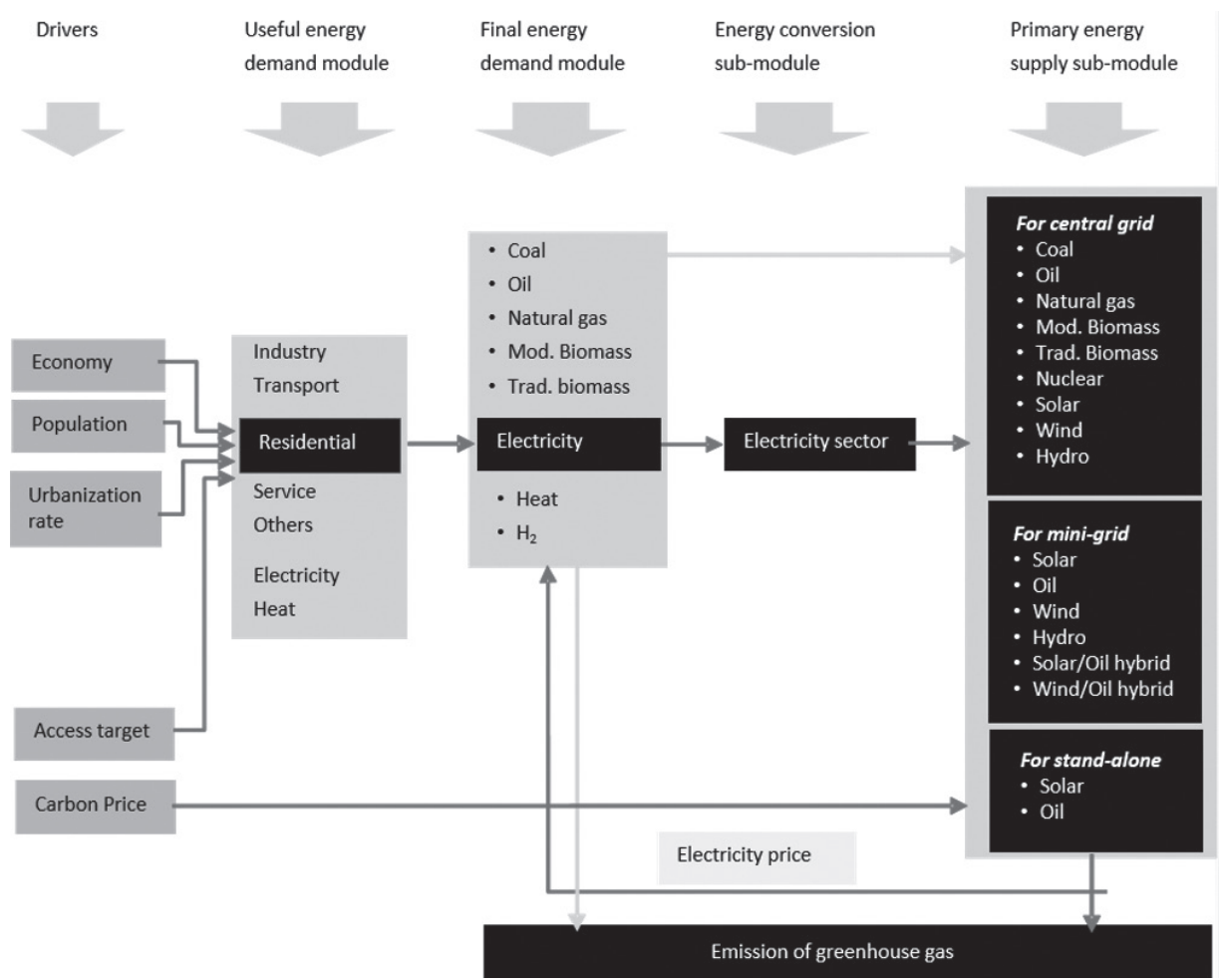

Figure 13: The SSA electrification model integrated in TIMER Model (modified from van Vuuren, van Ruijven [2])

\subsubsection{Scenario descriptions}

Four scenarios are used in this chapter to assess the impact of climate mitigation policy on achieving the universal access target, and vice versa: a baseline scenario $(B L)$, a universal electricity access scenario without climate policy (UA), a universal access scenario with global climate mitigation policy imposed in all regions (UA-CP), and a universal access scenario with global climate mitigation policy where SSA is exempted from carbon price (UA-NCP). Table 8 provides a short description of these four scenarios. 
Chapter 3

Table 8: Scenario names and descriptions

\begin{tabular}{|c|c|c|c|c|c|}
\hline \multirow{2}{*}{$\begin{array}{l}\text { Scenario } \\
\text { name }\end{array}$} & \multirow[t]{2}{*}{ Abbreviation } & \multirow[t]{2}{*}{ Description } & \multicolumn{2}{|c|}{ Model implementation } & \multirow[t]{2}{*}{ Objective } \\
\hline & & & Access rate & Carbon price & \\
\hline Baseline & $B L$ & $\begin{array}{l}\text { - A business-as- } \\
\text { usual path } \\
\text { - No measures are } \\
\text { taken to increase } \\
\text { electricity or } \\
\text { improve supply }\end{array}$ & $\begin{array}{l}\text { - Endogenous } \\
\text { - Varies by } \\
\text { region }\end{array}$ & - None & $\begin{array}{l}\text { To explore and } \\
\text { explain how the } \\
\text { electricity sector } \\
\text { would evolve without } \\
\text { additional policies } \\
\text { and interventions }\end{array}$ \\
\hline $\begin{array}{l}\text { Universal } \\
\text { access }\end{array}$ & UA & $\begin{array}{l}\text { - Universal access } \\
\text { for all households } \\
\text { based on a least- } \\
\text { cost option }\end{array}$ & $\begin{array}{l}\text { - Exogenous } \\
-100 \%\end{array}$ & - None & $\begin{array}{l}\text { To understand the } \\
\text { impact of providing } \\
\text { universal electricity } \\
\text { access by } 2030 \text { on the } \\
\text { electricity sector }\end{array}$ \\
\hline $\begin{array}{l}\text { Universal } \\
\text { access } \\
\text { with } \\
\text { mitigation } \\
\text { policy for } \\
\text { all }\end{array}$ & UA-CP & $\begin{array}{l}\text { - Universal access } \\
\text { for all households } \\
\text { based on a least- } \\
\text { cost option } \\
\text { - Stringent global } \\
\text { climate mitigation } \\
\text { policy in all regions, } \\
\text { including SSA }\end{array}$ & $\begin{array}{l}\text { - Exogenous } \\
-100 \%\end{array}$ & $\begin{array}{l}-43 \text { USD/tCO2 } \\
\text { in } 2020, \\
\text { increases } \\
\text { to } 110 \text { USD/ } \\
\text { tCO2 in } 2030 \\
\text { - All regions }\end{array}$ & $\begin{array}{l}\text { To explore the impact } \\
\text { of global climate } \\
\text { mitigation policies on } \\
\text { the electricity sector } \\
\text { and eventually on } \\
\text { the universal access } \\
\text { target }\end{array}$ \\
\hline $\begin{array}{l}\text { Universal } \\
\text { access } \\
\text { with } \\
\text { mitigation } \\
\text { policy for } \\
\text { all but SSA }\end{array}$ & UA-NCP & $\begin{array}{l}\text { - Universal access } \\
\text { for all households } \\
\text { based on a least- } \\
\text { cost option } \\
\text { - Stringent global } \\
\text { climate mitigation } \\
\text { policy in all regions } \\
\text { except SSA }\end{array}$ & $\begin{array}{l}\text { - Exogenous } \\
-100 \%\end{array}$ & $\begin{array}{l}-43 \mathrm{USD} / \mathrm{tCO} 2 \\
\text { in } 2020, \\
\text { increases } \\
\text { to } 110 \mathrm{USD} / \\
\text { tCO2 in } 2030 \\
\text { - SSA is } \\
\text { exempted }\end{array}$ & $\begin{array}{l}\text { To investigate the } \\
\text { impact of imposing } \\
\text { climate policy in the } \\
\text { rest of the world on } \\
\text { achieving universal } \\
\text { access in SSA }\end{array}$ \\
\hline
\end{tabular}

The scenarios are all based on the exogenous assumptions and projections of the drivers of energy demand (e.g. population growth, economic development, rate of technology change, and rates) of the Shared Socioeconomic Pathways (SSPs), as implemented in IMAGE [91]. The SSPs provide narrative descriptions and quantifications of possible developments of socio-economic variables that characterize challenges to mitigation and to adaptation [74, 92]. Here we use the IMAGE implementation of the SSP2 scenario because it represents a 'middleof-the-road scenario' regarding population and economic growth (Table 9). As household electricity access and demand is strongly dependent on these variables, 
it can also be viewed as 'middle-of-the-road' regarding baseline access rates and demand levels. Both technology development and social acceptance for all energy conversion technologies are assumed to be 'middle-of-the-road'. In SSP2, the SSA population is expected to grow from 860 million in 2010 to over 1.3 billion in 2030, with the economy almost doubling during this period (see Kc and Lutz [93], Dellink, Chateau [94]). Table 9 shows the socio-economic drivers in 2010 and in 2030, under the SSP2 scenario (Annex B provides a comparison of these drivers with other SSPS).

Table 9: Socio-economic data under SSP2 scenario [93-95]

\begin{tabular}{|c|c|c|c|c|c|c|}
\hline \multirow{2}{*}{ Region } & \multicolumn{2}{|c|}{$\begin{array}{l}\text { Population } \\
\text { (million) }\end{array}$} & \multicolumn{2}{|c|}{$\begin{array}{l}\text { GDP per capita } \\
\text { (USD/cap) }\end{array}$} & \multicolumn{2}{|c|}{$\begin{array}{c}\text { Urban population } \\
(\%)\end{array}$} \\
\hline & 2010 & 2030 & 2010 & 2030 & 2010 & 2030 \\
\hline World & 6920 & 8323 & 9891 & 17389 & $51 \%$ & $60 \%$ \\
\hline SSA & 864 & 1329 & 1979 & 3721 & $37 \%$ & $48 \%$ \\
\hline Western \& central Africa & 417 & 656 & 1586 & 3400 & $44 \%$ & $55 \%$ \\
\hline Eastern Africa & 260 & 403 & 1228 & 2406 & $24 \%$ & $33 \%$ \\
\hline Republic of South Africa & 50 & 59 & 9252 & 16407 & $62 \%$ & $72 \%$ \\
\hline The rest of southern Africa & 137 & 211 & 1943 & 3682 & $35 \%$ & $46 \%$ \\
\hline
\end{tabular}

In the BL scenario, electrification rates are determined endogenously to the model, based on GDP per capita, population density, and urbanization rate. In the three UA scenarios, full electricity access in SSA by 2030 is imposed exogenously to the model. In the UA scenarios, access to electricity increases from the regions' 2010 levels, to $100 \%$ in 2030 . In the UA-CP scenario, a global mitigation policy in the form of a price on carbon emissions is applied. The carbon price trajectory is taken from the IMAGE implementation of the SSP2-2.6 scenario, and amounts to $43 \mathrm{USD} / \mathrm{tCO}_{2}$ in 2020 , increasing to $110 \mathrm{USD} / \mathrm{tCO}_{2}$ in 2030 [96]. The carbon price increases the preference for renewable energy carriers and induces energy efficiency measures, and should therefore be interpreted as a universal stimulus for cost-effective climate polices. In practice, a similar strategy can be targeted through other policy measures, such as specific energy efficiency policies. Such policies can have different effects on energy access and these effects are not assessed in this chapter. In the UA-NCP scenario, the same carbon price trajectory as in the UA-CP scenario is used, but SSA is exempted from the global carbon 
price. This scenario is added to test how sensitive the results are to developed countries taking the lead in international climate policy. It also allows exploring the extent to which external climate policy would indirectly impact electrification decisions in SSA.

\subsection{Results}

This section presents the results on key indicators that describe the demand, production, and costs of the electricity system, as summarized in Table 10. We describe the results in more detail in Section 3.3.1, 3.3.2 and 3.3.3.

Table 10: Matrix showing the results of our analysis under different scenarios in 2030

\begin{tabular}{|c|c|c|c|c|c|c|}
\hline \multirow[b]{2}{*}{ Scenarios } & \multicolumn{2}{|l|}{ Demand } & \multicolumn{2}{|l|}{ Production } & \multicolumn{2}{|l|}{ Costs } \\
\hline & $\begin{array}{l}\text { Population } \\
\text { with } \\
\text { access to } \\
\text { electricity } \\
(\%)\end{array}$ & $\begin{array}{l}\text { Total } \\
\text { residential } \\
\text { electricity } \\
\text { demand } \\
\text { (TWh) }\end{array}$ & $\begin{array}{l}\text { Share of } \\
\text { low- carbon } \\
\text { technologies in } \\
\text { the electricity mix } \\
\text { (\%)' }\end{array}$ & $\begin{array}{l}\text { CO2 emission } \\
\text { from } \\
\text { residential } \\
\text { electricity use } \\
(\mathrm{Mt})\end{array}$ & 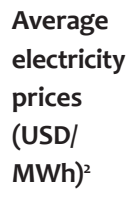 & $\begin{array}{l}\text { Cumulative 2010- } \\
2030 \text { investments } \\
\text { in production, } \\
\text { transmission and } \\
\text { distribution (billion USD) }\end{array}$ \\
\hline$B L$ & 63 & 266 & 46 & 31 & 55.4 & 313 \\
\hline UA & 100 & 330 & 45 & 39 & 56.3 & 970 \\
\hline UA-CP & 100 & 270 & 67 & 13 & 85.8 & 840 \\
\hline UA-NCP & 100 & 330 & 45 & 39 & 56.1 & 976 \\
\hline
\end{tabular}

\subsubsection{Electricity demand}

\subsubsection{Electricity access}

Based on the assumed continuation of the historic correlation between electricity access and GDP per capita, population density, and urbanization rate in the model [38], the BL scenario shows a considerable increase in the percentage of the population with access to electricity. In total, more than 550 million people are projected to have gained access in SSA by 2030. However, this leaves about 515 million people without access to electricity. Eastern Africa will have the highest proportion of people without access to electricity by 2030 , followed by the rest of southern Africa, western and central Africa, and the Republic of South Africa.

1 Shows the average share of all four regions

2 Shows the average electricity price of the four regions 


\subsubsection{Household electricity consumption}

The average annual household electricity consumption in 2010 was under $350 \mathrm{kWh}$ in all Sub-Saharan regions, except for the Republic of South Africa. The projected annual growth in electricity consumption between 2010 and 2030 ranges from $2 \%$ per year in the Republic of South Africa, to 6\% in eastern Africa. Figure 15 shows the resulting projected average levels of electricity consumption (of those households that have access to electricity) for urban and rural households in 2010 (left), and in 2030 (right), for the five income quintiles under baseline assumptions. In the UA scenario, the same level of household electricity consumption as in the BL scenario is assumed - but with more households having access. The introduction of climate mitigation policy leads to significant efficiency improvements in consumption, resulting in a total electricity saving of around $20 \%$ by 2030 in the UA-CP scenario, relative to the UA scenario (Table 10). Figure 14 demonstrates the electricity consumption per capita under UA and UA-CP scenarios. In all the scenarios, the appliance ownership per household is the same. Thus, the decrease in electricity consumption under UA-CP scenario implies a notable improvement in appliance efficiency attributed to the purchase of efficient appliances and the efficient use of the appliances. Under the UA-NCP scenario, where SSA is exempted from the carbon price, no significant efficiency improvements are projected.

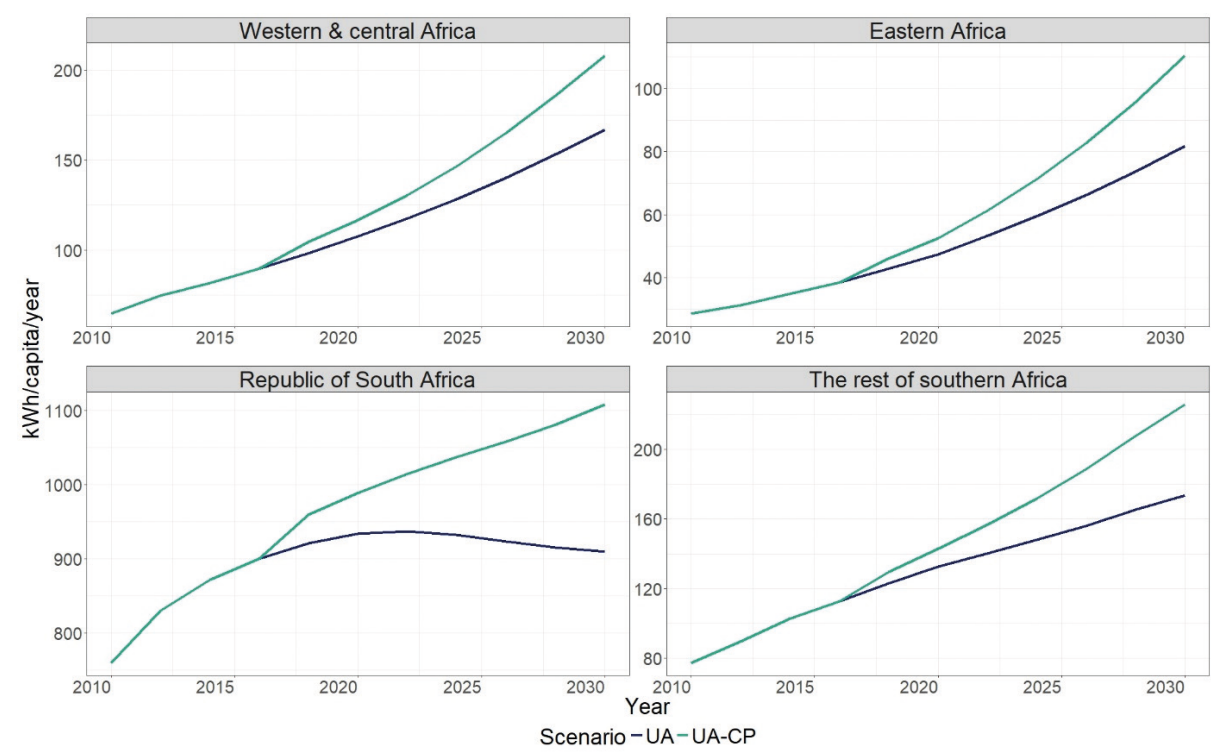

Figure 14: Electricity consumption per capita per year under UA and UA-CP scenarios 
The World Bank MTF has been introduced to communicate different levels of ambition with regard to electricity access, including household consumption levels [76]. Thus, it provides a useful comparison to our projected consumption levels. The MTF distinguishes electricity consumption levels ranging from very low (Tier 1, i.e. $\geq 4.5 \mathrm{kWh}$; which allows the use of very low-power appliances such as light bulbs and phone charging), to medium (Tier $3 \geq 365 \mathrm{kWh}$, which allows the use of low-power appliances such as TV, fan and lowpower refrigeration), to very high (Tier $5 \geq 3000 \mathrm{kWh}$, which allows the use of high-power appliances such as refrigerators and air conditioners). Average electricity consumption levels are projected to be around Tier-3 in eastern Africa by 2030, while in western \& central Africa, and in the rest of southern Africa, it reaches levels halfway between Tier-3 and Tier-4 (with large differences in household electricity consumption between income groups). The Republic of South Africa has the highest projected consumption levels, with around Tier- 5 in urban areas and between Tier- 4 and Tier- 5 in rural areas. The large differences between regions can be illustrated by the projection that the highest income group in eastern Africa consumes less electricity than the lowest income group in the Republic of South Africa. Earlier studies used household consumption levels of $250 \mathrm{kWh}$ and $500 \mathrm{kWh}$ per household per year for new connections in rural and urban areas, respectively, in their analyses, which is in between Tier-2 and Tier-3 [81, 97].

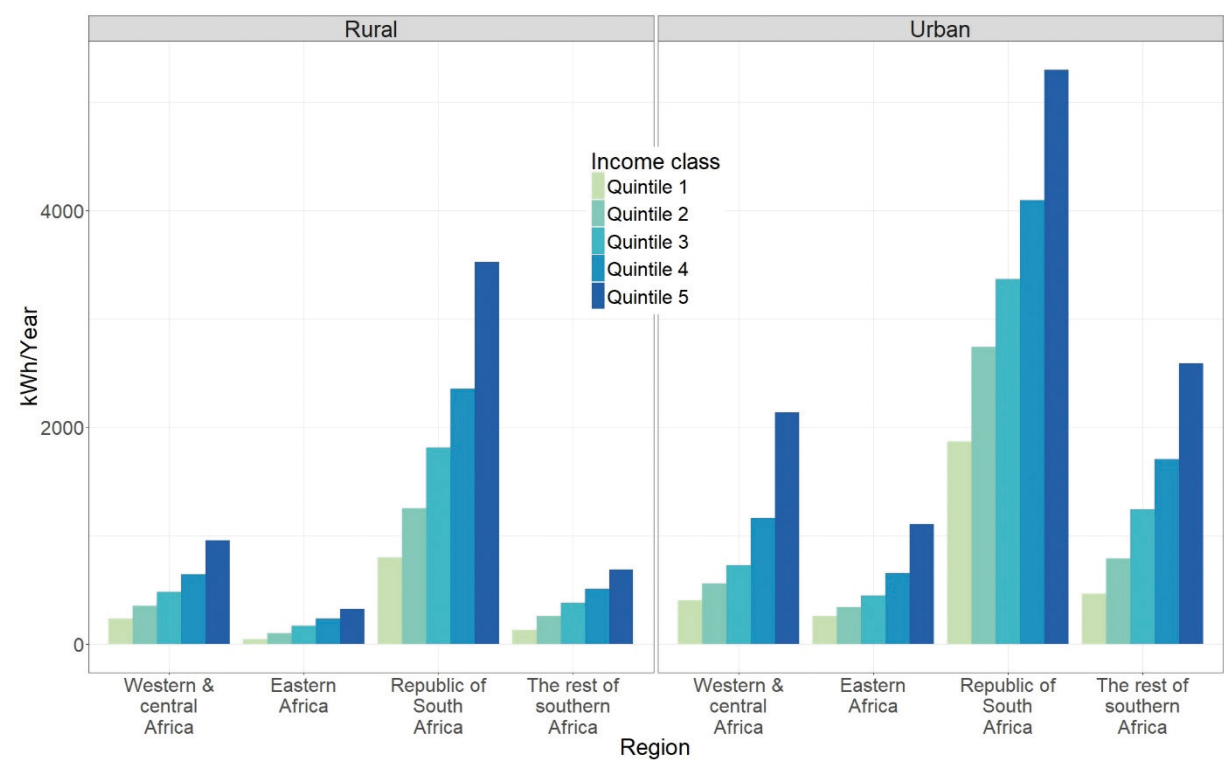

Figure 15: Rural and urban annual household electricity demand projections for 2030 under the SSP2 scenario 


\subsubsection{Total residential electricity demand}

Stark population growth, significant increase in electricity access and increasing levels of household electricity consumption push up total residential electricity demand in the region. Even without achieving the universal access target, total residential electricity demand in the $B L$ scenario is projected to increase from 90 TWh in 2010 to almost 270 TWh in 2030 (Table 10). This implies an average annual growth rate of nearly 6\% between 2010 and 2030. In the UA scenario, electricity demand reaches $330 \mathrm{TWh}$ (Table 10). This is $23 \%$ more than in the BL scenario, raising the annual growth in electricity demand to $7 \%$.

While the rural population is projected to account for $52 \%$ of the total population in 2030 , in the $\mathrm{BL}$ scenario it represents $85 \%$ of the population without access to electricity. In this context, it is important to reiterate that household electricity demand in rural SSA is much lower than in urban areas under all scenarios. As a consequence, the associated increase in electricity demand in urban areas still accounts for $40 \%$ of the total.

The efficiency improvements resulting from global climate policy almost completely offset the additional electricity generation needed for achieving universal access in the UA scenario. The electricity demand for the additional connections under UA-CP is projected to be 21 TWh less than what is projected under the UA scenario, while providing the same energy services.

\subsubsection{Electricity production}

The electricity mix and related $\mathrm{CO}_{2}$ emissions largely depend on the electricity system (on-grid, mini-grid or stand-alone) and the prices of different energy carriers.

\subsubsection{Least-cost electrification system}

SSA is characterized by a large number of sparsely populated rural settlements, where many households have a very low income and hence low levels of electricity consumption. Under these circumstances, off-grid systems - including minigrids and stand-alone systems - could play a vital role in providing electricity access at reasonable cost. However, extending the transmission and distribution infrastructure to cities and communities, for which on-grid electrification is cost- 
effective, also brings the grid closer to relatively remote communities, thereby increasing the cost-effectiveness of grid connection compared to off-grid systems. Therefore, the timing of electrification of a grid-cell affects the choice of the technology: every time a grid-cell gets access through the main power line, another grid-cell gets closer to the central grid. Targeting universal access changes, the dynamics of the electrification process, due to the increasing number of people that will get access every year, and the higher rate of learning of new technologies.

Out of the 550 million people gaining access by 2030 in the BL scenario, only $16 \%$ (95 million people) gain access through off-grid systems. An important reason is that, according to the model projections, $90 \%$ of the SSA population is concentrated on just $45 \%$ of the region's land area. This, together with the growing electricity demand, largely favours the central grid. Moreover, most of the people gaining access under BL scenario live in urban areas.

In the UA scenario, off-grid electrification systems are projected to be the least-cost option for close to $7 \%$ of the additional connections, i.e. nearly 15 million people, bringing the total number of people connected to off-grid systems to 110 million (Table 11 and Figure 16). In parts of eastern Africa (South Ethiopia, Somalia, South Sudan and Madagascar) and central Africa (Chad, Central African Republic and Democratic Republic of Congo), people live relatively dispersed and household electricity demand is much lower than in the other regions, favouring off-grid systems.

Climate policy stimulates expansion of renewable energy-based off-grid systems, as a consequence of both higher fossil fuel prices and decreasing consumption levels due to considerable efficiency improvements (see Figure 14). Therefore, 10 million more people are connected via off-grid systems in the UA-CP scenario than under UA scenario. In the UA-NCP scenario, climate policy outside of SSA could influence the African electricity system through inducing faster learning of low-carbon technologies and through lower fossil fuel prices (as a result of reduced demand in other regions as a consequence of climate policy). Our results show the first effect to be slightly stronger than the second one, and therefore there are slightly more people ( 2 million) connected by off-grid systems in the UA-NCP scenario than in 
the UA scenario. In all scenarios, the majority of the people connected through off-grid systems live in eastern Africa (almost 60\%) and western \& central Africa (30\%) (Table 11).

Table 11: Total number of population connected with on-grid and off-grid system under BL, UA, UA-CP and UA-NCP scenarios in 2030 (in millions)

\begin{tabular}{|c|c|c|c|c|c|c|c|c|c|c|}
\hline \multirow{2}{*}{$\begin{array}{l}\text { Scenario } \\
\text { Variant }\end{array}$} & \multicolumn{2}{|c|}{$\begin{array}{c}\text { Western \& } \\
\text { central Africa }\end{array}$} & \multicolumn{2}{|c|}{ Eastern Africa } & \multicolumn{2}{|c|}{$\begin{array}{l}\text { Republic of } \\
\text { South Africa }\end{array}$} & \multicolumn{2}{|c|}{$\begin{array}{c}\text { Rest of } \\
\text { southern Africa }\end{array}$} & \multicolumn{2}{|c|}{ SSA } \\
\hline & On-grid & Off-grid & On-grid & Off-grid & On-grid & Off-grid & On-gric & Off-grid & On-grid & Off-grid \\
\hline$B L$ & 428 & 27 & 150 & 57 & 52 & 0 & 107 & 10 & 737 & 94 \\
\hline UA & 622 & 33 & 336 & 66 & 59 & 0 & 200 & 10 & 1217 & 109 \\
\hline UA-CP & 619 & 36 & 333 & 69 & 58 & 1 & 198 & 12 & 1208 & 118 \\
\hline UA-NCP & 622 & 33 & 336 & 66 & 59 & 0 & 198 & 12 & 1215 & 111 \\
\hline
\end{tabular}
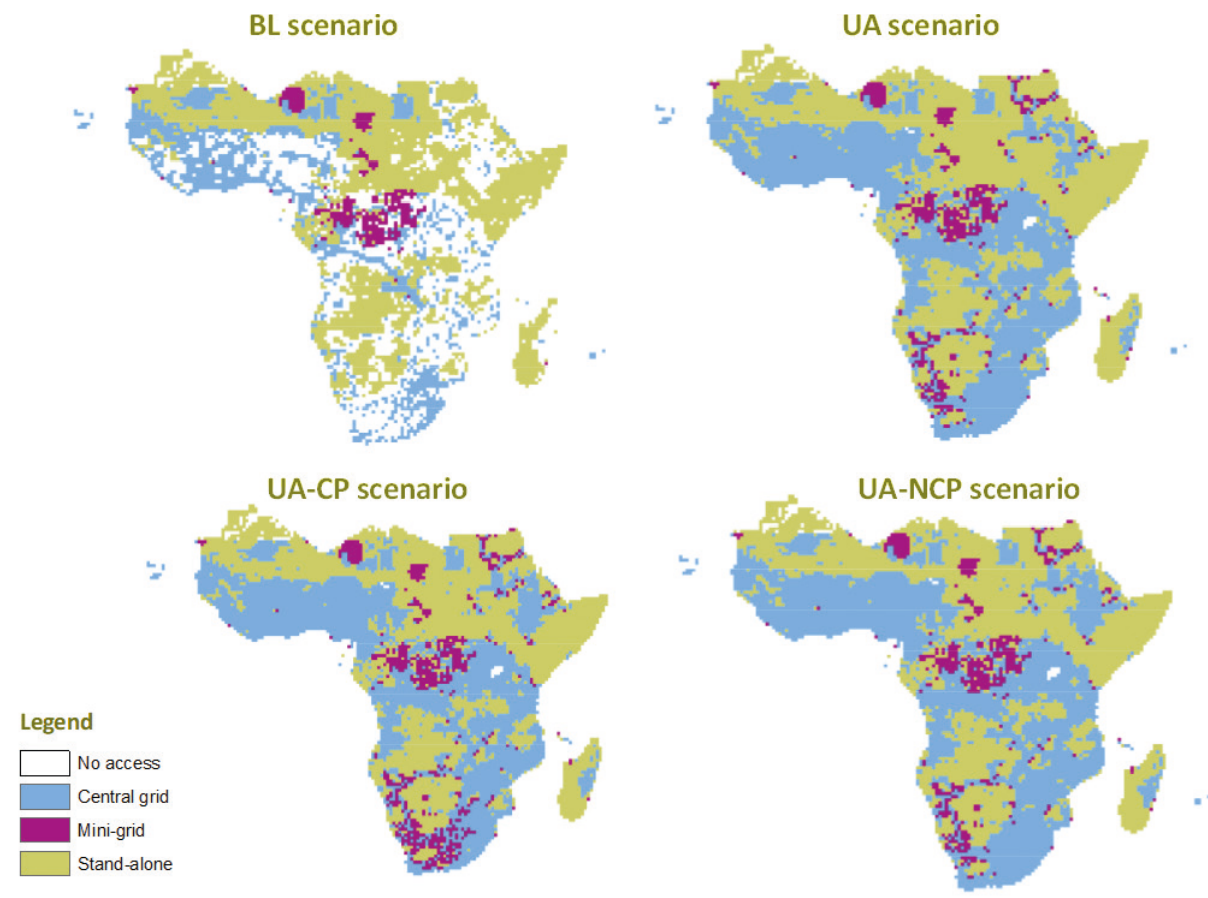

Figure 16: Least-cost electrification systems under BL, UA, UA-CP and UA-NCP scenarios 
The production from stand-alone diesel generators is projected to be $70 \%$ lower in the UA-NCP scenario than in the UA scenario (Figure 17). At the same time, the UA-NCP scenario includes more solar mini-grids, solar home systems, and diesel minigrids. Urban areas show an increase of mainly solar mini-grids, while in rural areas solar mini-grids, diesel mini-grids and solar home systems all increase. In the UA-NCP scenario, climate policy induces barely any additional efficiency improvements in SSA. In this scenario, the renewable energy developments in other regions lead to a slight increase in the share of PV mini-grids in all regions (and a slight decline in central generation). Wind power and PV-diesel hybrid plants become increasingly competitive with diesel mini-grids, but are still projected to be the least-cost options for as few as approximately 100 thousand people in eastern Africa. The share of diesel stand-alone systems is much higher than under the UA-CP scenario, but slightly lower than under the UA scenario.

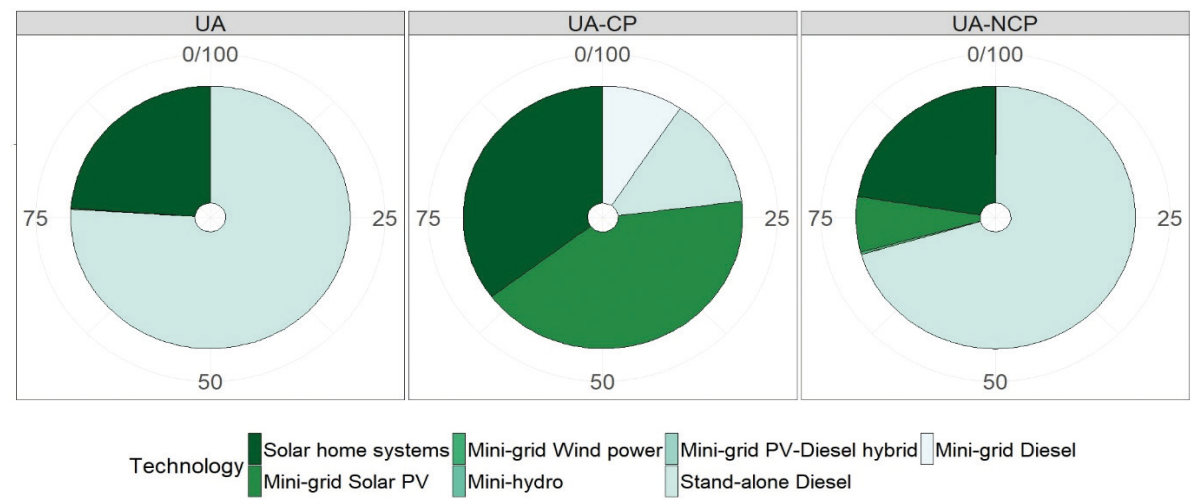

Figure 17: Sources of electricity for off-grid systems for the additional connections in \%MWh by source

\subsubsection{Electricity mix}

The electricity mix is largely determined by the relative costs of different technologies. Costs of renewable power generation technologies, particularly solar and wind, have decreased significantly over the last decades, largely driven by innovation in technology and policy [98]. The model projections show a continuation of this trend, with solar and wind in particular becoming increasingly competitive with fossil fuels over the coming decades. The cost of wind energy is low, especially in eastern Africa, where the largest single wind power project in Africa, the Lake Turkana Wind Power project, is being built. Hydropower and coal-based electricity 
production remain cheap, while prices of oil and gas-based electricity production are projected to increase over time (Figure 18).

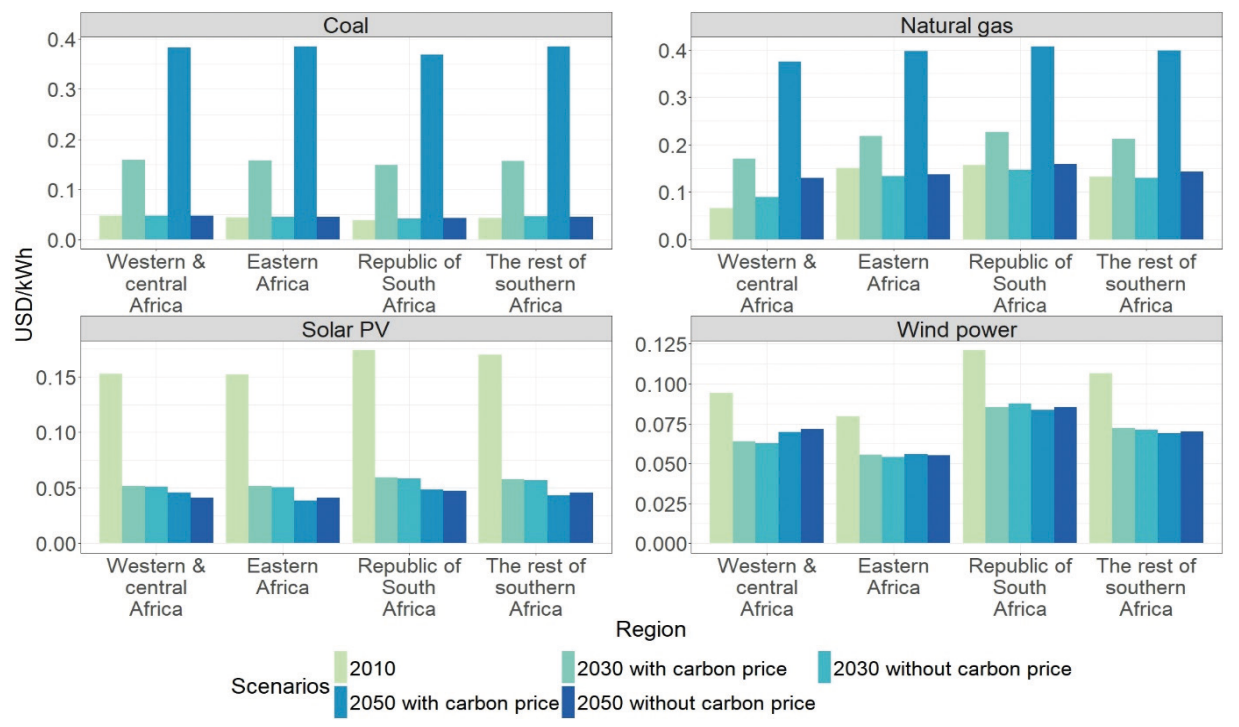

Figure 18: LCOE of electricity generation from selected energy carriers

In the UA scenario, additional on-grid generation capacity is mostly the scaling-up of existing capacity (see Figure 19). For western \& central Africa, this is primarily based on natural gas and hydropower, reflecting the abundance of these resources. In eastern Africa over $65 \%$ of the additional capacity is projected to come from renewable energy sources, with hydropower being by far the largest electricity source by 2030, which is especially due to high shares of hydropower in Ethiopia, Tanzania, Kenya and Uganda. Natural gas (driven by recent discoveries in Tanzania) and geothermal (particularly in Ethiopia and Kenya) are also projected to play significant roles in the region. The Republic of South Africa continues to rely primarily on coal. Finally, the rest of southern Africa is projected to rely mainly on coal and hydropower in 2030. As a result, the share of renewable energy in the total electricity mix is projected to decrease in all regions except the Republic of South Africa by 4-6 percentage-points (see Figure 19). Only in the Republic of South Africa is there little change in the electricity mix, as the projected extra electricity demand is relatively low, and the energy mix is already dominated by coal. 
In the UA-CP scenario, the changes in electricity mix resulting from global climate policy varies between the regions. Coal is projected to decrease significantly in the energy mix in all regions. Furthermore, while total electricity production from renewable energy sources does not change much in absolute terms, its share increases. The share of natural gas as a fuel for combined-cycle power plants also increases, as i) its carbon content is lower than coal and ii) it can be efficiently used for balancing fluctuating renewable resources. The model also projects a significant increase in nuclear energy, especially in the Republic of South Africa. Several countries in SSA have considerable uranium reserves and the Republic of South Africa has two nuclear power plants currently providing approximately $5 \%$ of its total electricity use. Overall, the global carbon price pushes SSA onto a renewable energy pathway. In eastern Africa, where the renewable energy share is already high, it is projected to reach almost $100 \%$ in 2030 , from $58 \%$ in 2010 . In the Republic of South Africa, the share of low-carbon fuel is also projected to increase significantly, reaching 45\% in 2030 (including nuclear), starting from 6\% in 2010. Carbon Capture and Storage (CCS) also plays a role in reducing emissions from coal-fired, natural gas-fired and biomass power plants. In western \& central Africa, and in the rest of southern Africa, the global carbon price offsets the projected decline in the renewable energy share in the UA scenario, when no global carbon price is applied.

Under the UA-NCP scenario, the electricity mix changes only slightly relative to the UA scenario. In western \& central Africa, the share of coal, solar PV and wind decline marginally (0.5\%, $1.3 \%$ and $1.7 \%$, respectively), while the share biomass increase by $14 \%$. The electricity mix in eastern Africa remains more or less similar to the UA scenario except for a marginal decline in the share of solar PV (1.2\%) and wind (1.6\%), which is compensated by an increase in hydro power. In the Republic of South Africa solar PV (15\%) and wind power capacity (40\%) show a decline, while oil and natural gas increase by $1 \%$ and $2.5 \%$, respectively. A slight decline in natural gas-fired plants (2\%), solar PV (1\%) and wind power capacity (2.5\%) in the rest of southern Africa is balanced by a marginal increase in production from nuclear (1\%) and hydro power plants ( $1 \%)$. 


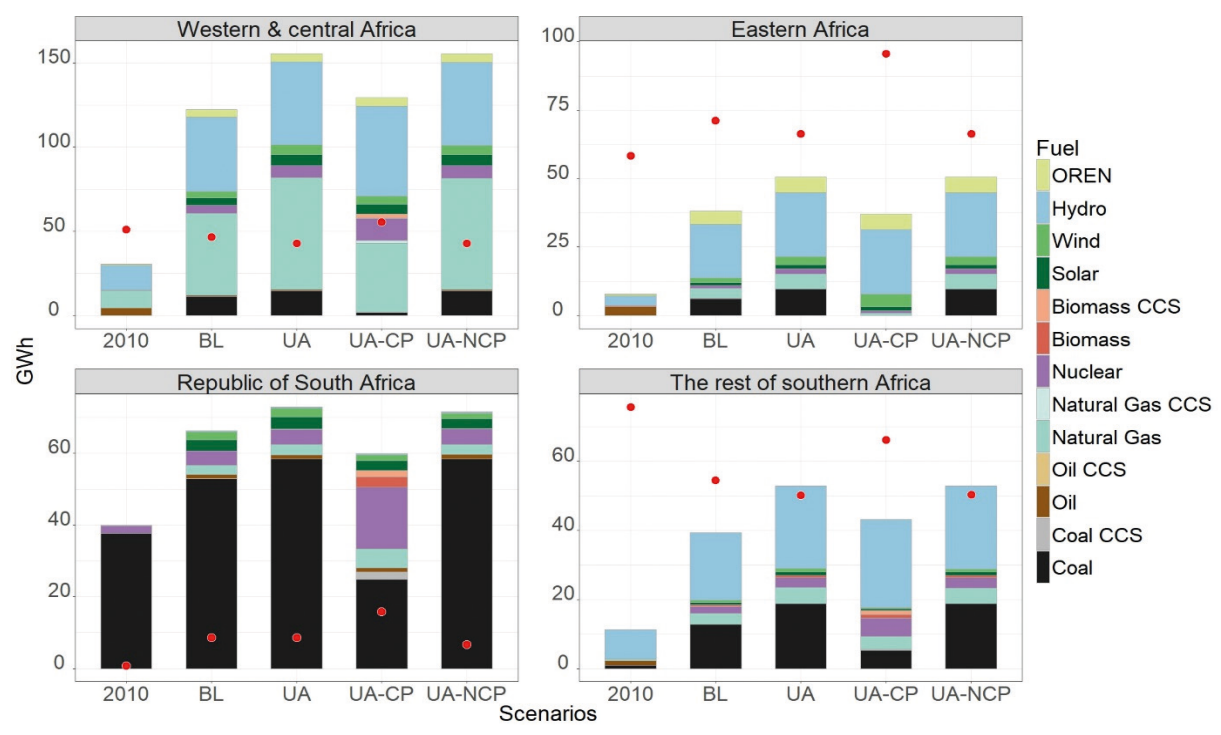

Note: $\mathrm{CCS}=$ carbon capture and storage

Figure 19: Total generation mix for the residential electricity demand in 2030 (the red dots show the share of renewable energy in the mix)

\subsubsection{3. $\mathrm{CO}_{2}$ emissions}

In 2010, residential $\mathrm{CO}_{2}$ emissions from electricity accounted for around $25 \%$ of total electricity-related $\mathrm{CO}_{2}$ emissions in SSA and only around $0.5 \%$ of global electricityrelated $\mathrm{CO}_{2}$ emissions, of which two-thirds is from the Republic of South Africa. Driven by the rapid increase in residential electricity demand, total residential electricity-related $\mathrm{CO}_{2}$ emissions in the $\mathrm{BL}$ scenario are projected to increase from $14 \mathrm{Mt}$ in 2010, to $31 \mathrm{Mt}$ in 2030, which amounts to an increase of $4 \%$ per year (Figure 20). Despite this relatively large increase, the share of SSA in global electricity-related emissions is projected to remain very small: $0.7 \%$ in 2030. As a consequence of the fuel switch and the use of more efficient coal and gas-powered power plants, the carbon intensity of the central grid is projected to decrease in western \& central Africa, and in the Republic of South Africa, somewhat mitigating the increase of $\mathrm{CO}_{2}$ emissions. In the rest of southern Africa, a growing use of coal increases the carbon intensity in the region.

Achieving the universal access target will inevitably result in an increase in electricityrelated residential emissions. Indeed, the projections show that providing electricity access to an additional 500 million people results in an emission increase of $8 \mathrm{Mt}$ 
$\mathrm{CO}_{2}$, i.e. $27 \%$ on top of the 2030 value in the $\mathrm{BL}$ scenario. This increase is negligible, as it is only around $0.2 \%$ of the global electricity-related emissions. Besides, access to electricity could also provide climate benefits that are not accounted for in this study. For example, switching from kerosene to electric lighting could reduce related climate forcing with a factor 10, due to the avoided black carbon emission [99].

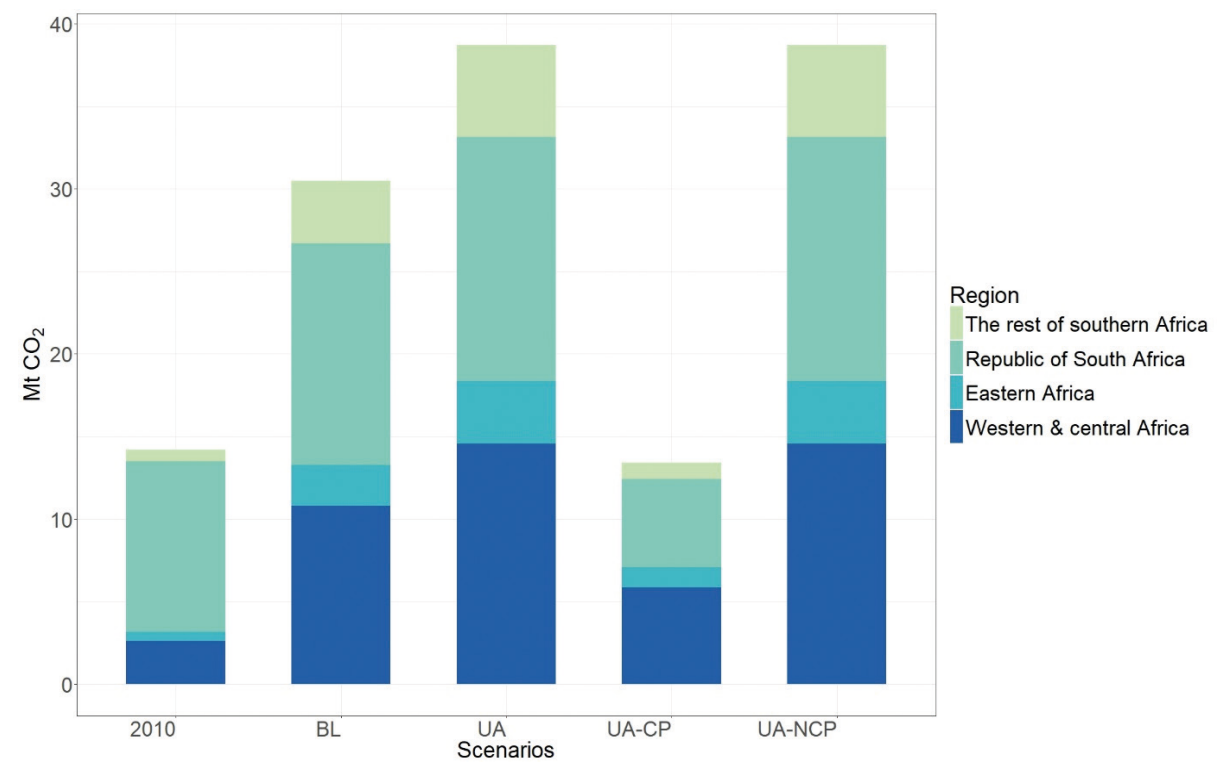

Figure 20: Electricity related $\mathrm{CO}_{2}$ emissions from the residential sector in SSA under $\mathrm{BL}, \mathrm{UA}, \mathrm{UA}-\mathrm{CP}$ and UA-NCP scenarios in 2030

Under the UA-CP scenario, the shift to low-carbon energy sources and efficiency improvements results in a total $\mathrm{CO}_{2}$ emissions reduction of $65 \%$ in 2030 , relative to the UA scenario, bringing total residential emissions from electricity to below 2010 levels. This scenario shows that emissions peak around 2020, followed by a rapid decline. Under UA-NCP scenario, on the other hand, electricity-related emissions from the residential sector are almost the same as under the UA scenario. The slight increase in the share of renewable technologies in western \& central Africa and in the rest of southern Africa, together with some efficiency improvements in power generation and transportation, result in only a marginal decrease in electricityrelated $\mathrm{CO}_{2}$ emissions from the residential sector. 


\subsubsection{Electricity prices and investments}

\subsubsection{Electricity prices}

Climate mitigation policies are projected to result in higher electricity prices in all regions, with higher increases in regions with large shares of fossil fuels in their electricity mix (Figure 21). Eastern Africa has the highest share of low-carbon electricity generation and, therefore, the carbon price leads to the lowest electricity price increase of the four regions ( $25 \%$ by 2030 , compared to the UA scenario). In the rest of southern Africa, mitigation policies will increase the price by nearly $40 \%$, due to a strong dependency on natural gas (which is the primary source of electricity, particularly in Angola, Mozambique and Tanzania). In western \& central Africa, the carbon price is projected to increase the electricity price by $35 \%$ in 2030 , relative to the UA projection. This again reflects the dominance of fossil fuel in the electricity mix, which is affected by carbon price. The Republic of South Africa is most affected by the carbon price, due to the strong dominance of coal in its electricity mix. In the UA-CP scenario, the projected electricity price shows an annual average increase of $5 \%$ between 2010 and 2030, leading to an electricity price in 2030 that is more than twice the level of the price without a carbon price. The UA-NCP scenario has almost identical electricity prices to the UA scenario, showing that the carbon price in the rest of the world has a negligible effect on electricity prices in SSA.

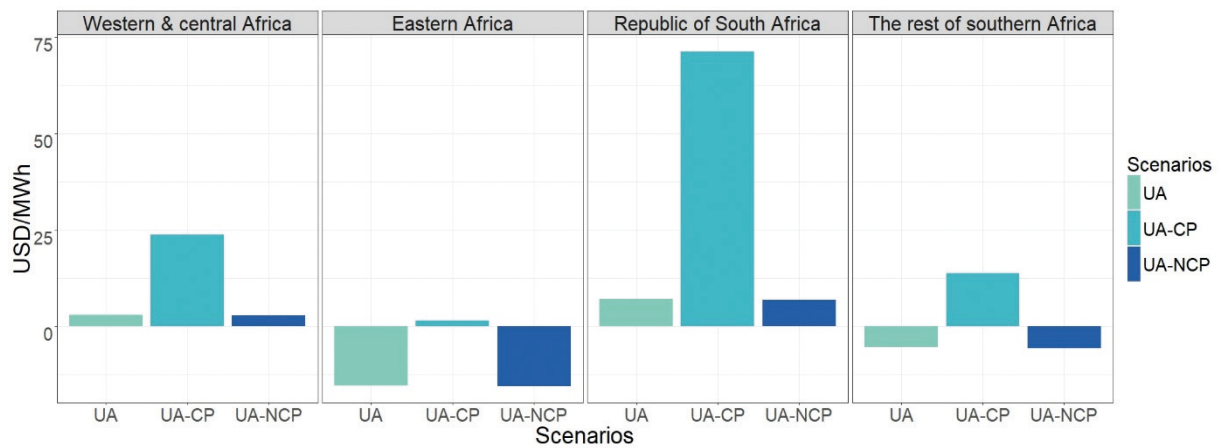

Figure 21: Projected change in average electricity prices under UA, UA-CP, and UA-NCP scenarios in 2030 relative to 2010

\subsubsection{Electrification investments}

The projected expansion in installed capacity and transmission and distribution infrastructure in all scenarios require large investments. Under the BL scenario, the 
total cumulative investment of 2010-2030 is projected to be around USD 310 billion, equivalent to an average of USD 16 billion per year (Figure 22). This is approximately twice the current level of annual infrastructure investment [100]. The increase is mostly a result of the anticipated growth in electricity demand during this period. Recurring costs, such as for fuels and operation and maintenance, are projected to average USD 5 billion per year. The highest investment requirements by far are for western \& central Africa, where 55\% of the newly connected population lives. The region requires investments for the refurbishment of existing power plants, significant capacity addition to meet the growing electricity demand, and an extension of the transmission and distribution infrastructure for more than $50 \%$ of the newly connected population. In contrast, total investment requirements in the Republic of South Africa are relatively low. The country already owns an extensive high-power grid with a large share of the population already connected; hence, the projected investments are mostly for expansion of generation capacity.

Achieving the universal access target will require significant further expansion of installed capacity, as well as transmission and distribution infrastructure. In the UA scenario, to provide electricity access to the additional population, a projected cumulative investment of USD 660 billion, or USD 33 billion per year, is required between 2010 and 2030, on top of the projected investments in the BL scenario. These investment requirements include expanding generation capacity and extending transmission and distribution infrastructure. They do not include funding requirements for capacity development, such as research and development, planning, and policies and regulations, which could also be significant. The bulk of this investment ( $85 \%$ ) goes to upgrading and extending the transmission and distribution infrastructure, reflecting the severe lack of transmission and distribution networks and inefficiency of the system. A study by IEA [81] also confirms the need for large investment in the transmission and distribution system. More than half of the additionally connected population in western \& central Africa require an extension of high and medium voltage transmission and distribution infrastructure, which is associated with large investment costs. In eastern Africa, around $20 \%$ of the additional connected population requires an extension of the high and medium voltage transmission and distribution infrastructure. 


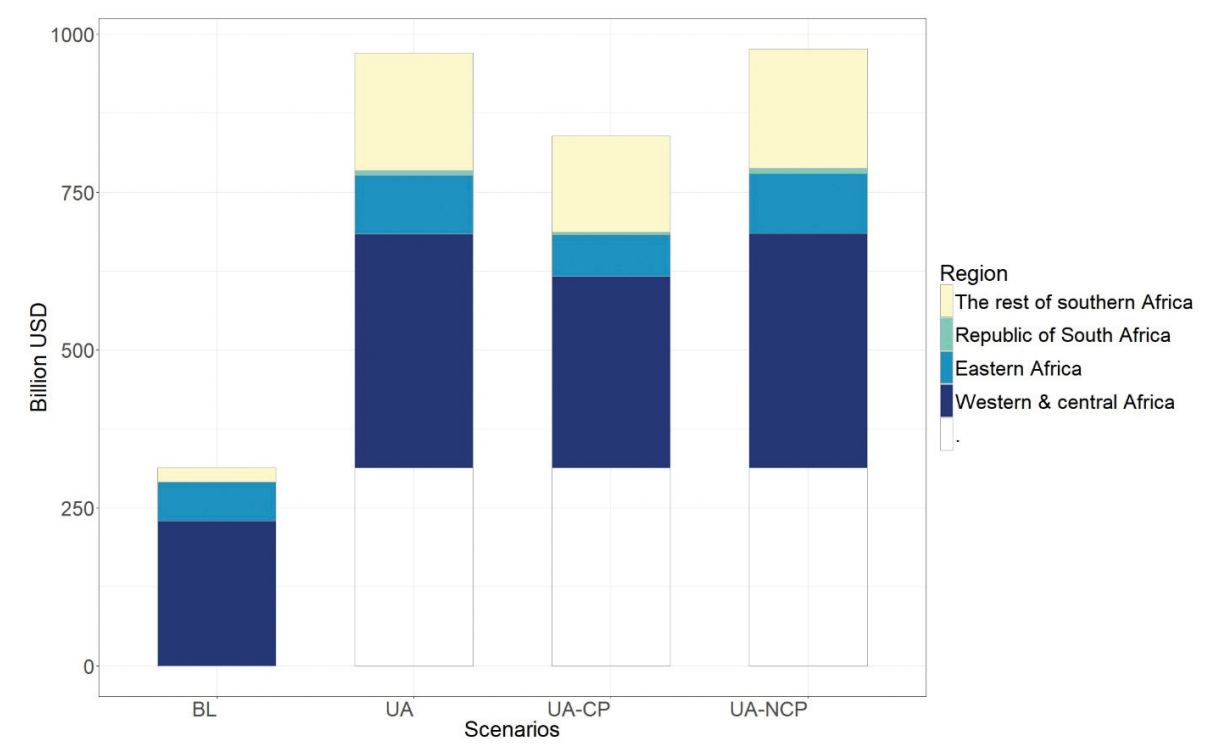

Figure 22: 2010-2030 cumulative investments for electricity access in various scenarios

In the UA-CP scenario, the additional investment requirement for generation capacity and transmission and distribution infrastructure by the additional connected population is projected to be around USD 27 billion per year (Figure 22). This is 20\% less than what is required under UA scenario, which can be explained by the efficiency improvements in household appliances and electricity production (see section 3.3.1.2) The UA-NCP scenario requires almost the same level of investment as in the UA scenario, since household consumption, generation, and transmission and distribution systems are largely similar. The marginal increase in cumulative investment is the result of the shift from diesel generators to wind and solar mini-grids, and solar home systems, which have higher initial investment costs (but lower running costs). These investment requirements do not include the costs of climate change mitigation policies that will add to the investment requirements of the UA-CP scenario.

\subsection{Discussion}

Our results are reflections of the model dynamics, the data input and the scenario designs. We acknowledge that there are large uncertainties in our model projections. Different socio-economic projections (population size, population density, household size, income) might result in different magnitudes of emissions, investments, or 
different energy mixes. The same is true about network design, learning rates of new technologies, fuel prices, technology deployment, price elasticity, etc. Moreover, the model results are a simplification of the real-world situation.

The model uses high-resolution data on a $0.5^{\circ} \times 0.5^{\circ}$ grid-cell for population size, population density, renewable energy potentials and renewable energy prices. This allows a more detailed representation of demand density, energy resource potentials and technology prices than when only regional dynamics are considered. The model chooses from a number of electrification technologies, which, in addition to the central grid, include mini-grids based on diesel, hydro, solar, and wind (eventually in combination with diesel); and stand-alone systems, based on solar and diesel. Data on diesel prices, electricity prices, household size, household electricity consumption and generation mix are more aggregated at regional levels. This means that we miss important local differences. For example, diesel prices vary significantly between oil producing countries and oil importing countries, while in our model they are grouped within the same region.

Due to data restrictions, we assume that everyone that has access to electricity in 2010 is connected to the central grid. If the share of existing off-grid connections is considerable, it might lead to different dynamics in the electricity system. Furthermore, we have not addressed the roughness of the terrain in selecting the electrification system or technology. Similarly, differing costs for transmission and distribution networks can be found in the literature $[32,67]$. The transmission and distribution costs used in our model are at the lower estimates of the literature. Higher transmission and distribution costs will mostly likely lead to higher shares of off-grid systems.

A comparison of our results to those of other studies shows that our projection of additional annual investment requirements of USD 33 billion to achieve the universal access target is significantly higher than the USD 19 billion estimated by IEA [59], but within the range of USD 20-50 billion projected by IRENA [101]. Bazilian, Nussbaumer [50] estimate that the additional cost of achieving universal electricity access will amount to USD 740 billion between 2011 and 2030, based on an annual average electricity consumption of $1285 \mathrm{kWh}$ per capita in 2030, which is considerably higher than our estimates. This gap can be explained by differences between the models in household electricity consumption, household size, cost of technologies, and shares of 
off-grid technologies in the electricity system. Our estimates of the number of people without access under baseline developments is similar to the estimate by the IEA [81]; 515 million people by 2030 and 530 million people by 2040, respectively. Similarly, our projections for residential electricity demand show an annual average growth rate of $6 \%$ and $7 \%$ between 2010 and 2030 under BL and UA scenarios, respectively. This is quite similar to the estimate of $6 \%$ between 2010 and 2040 projected by IEA [81]. The same report also shows an average annual growth rate of household electricity consumption of $2-7 \%$, depending on the region, which is similar to our estimate of $2-6 \%$. The two models also agree that the bulk of the investment requirement goes to expansion of the transmission and distribution system in the region.

The synergy between climate mitigation and universal electricity access are largely the result of projected household appliance efficiency improvements. The projected household appliance efficiency depends on two consumer actions: the purchase of efficient appliances and the efficient use of the appliances. Together with an increase in electricity prices, energy-efficiency improvements result in a huge reduction in household electricity consumption. In reality, other measures promoting energy efficiency, such as appliance energy performance standards and labelling (probably complementing carbon price), might achieve the same result. Besides, we have not addressed the rebound effect of improved appliance efficiency and related market failures.

The analysis of resource requirements for achieving the universal access target in SSA are indicative estimates and are by no means precise figures, but are instead intended to indicate the order of magnitude of the efforts and resources that will be needed if the target is to be met. The identified synergies and trade-offs between climate mitigation policies and universal access to electricity in SSA are robust to the above-mentioned uncertainties.

\subsection{Conclusions}

In this chapter, we have used the IMAGE-TIMER integrated assessment model to analyse trade-offs and synergies between climate mitigation policies and achieving universal electricity access in SSA. The analysis focused on differences in electricity demand, production, and costs under four different scenarios, focusing on several 
key indicators. Three of the scenarios target universal access to electricity by 2030: one without specific climate mitigation policy; another with global coordinated climate policy in the form of a carbon price; and a third, with global coordinated climate policy that exempts SSA from carbon prices. Our model does not address the spill overs (co-benefits or adverse effects) of climate mitigation policies on other sectors of the regional economy, nor the institutional requirements and the financing of universal electricity access in the region, which is a different topic altogether. From the model results, we draw the following conclusions:

The increase in $\mathrm{CO}_{2}$ emissions due to achieving universal electricity access is small compared to global $\mathrm{CO}_{2}$ emissions. Current electricity-related residential $\mathrm{CO}_{2}$ emissions in SSA are very low, due to low levels of electricity access and low consumption levels. Without climate policies, achieving universal electricity access in SSA considerably increases emissions relative to baseline development. However, the increase in emissions from providing universal access to electricity in SSA is negligible relative to global emissions, and it barely influences global climate change. Furthermore, climate mitigation policy could offset the projected increase, due to efficiency improvements and a shift to low-carbon energy sources.

Synergies between climate mitigation policy and universal access to electricity relate to efficiency improvements and declining renewable technology prices. SSA could benefit from a globally coordinated climate mitigation policy through efficiency improvements in household appliances and learning in renewable energy technologies, which seem mutually reinforcing. Renewable electricity generation technologies based on off-grid systems are becoming increasingly competitive with fossil fuel-based energy systems. In remote, low-density settlements, off-grid systems (mostly stand-alone) in particular play an essential role in reaching the poorest and most isolated populations (also known as the 'last-mile' challenge). This provides an opportunity for SSA to decarbonize the electricity system, ensure sustainable development, establish energy security, and avoid fossil fuel lock-in in the long term, while at the same time avoiding billions of USD in energy-system investments.

Achieving universal electricity access in SSA requires at least a tripling of the current annual electricity-system investments of 8 billion USD. Our model projections show 
that the annual cost of providing universal electricity access between now and 2030 in SSA ranges from USD 27 billion with climate policies, to USD 33 billion without climate policies. Efficiency improvements in household appliances could lower the investment requirements for achieving universal access (by $20 \%$, in our model). The regions' energy potential is neither evenly distributed, nor always located close to demand centres; hence the bulk of the investment requirement in all scenarios is projected to go to expansion of the transmission and distribution system. The annual investment of USD 27 to USD 33 is a significant amount, but it probably understates the full costs of universal electricity access in the most electricity-poor region in the world, due to large uncertainties resulting from lack of data and other challenges, such as political will and corruption that are difficult to model. Besides, these investments do not include the cost of climate change mitigation policies which will increase the investment requirements under UA-CP scenario.

A global carbon price results in increases in electricity prices. Climate mitigation policy, in this study imposed by a global uniform carbon price, is projected to increase the cost of electricity per kWh that will undoubtedly affect the poor. The price increase is especially large in regions with a high share of fossil fuels in their electricity mix. However, according to several studies, currently, the poor pay more for alternative (and mostly polluting) electricity sources, while being hindered from connecting to existing power lines by high connection fees. Moreover, replacing kerosene and candle lighting by electricity improves household health and safety considerably, while at the same time providing higher quality and quantities of light. To facilitate access by the poor, climate mitigation policies can also be combined with complementary policies, such as free basic electricity, low consumption low tariff, cross subsidization, etc., specifically designed to protect the poor from increasing electricity prices.

\subsection{Acknowledgements}

The research presented in this chapter was funded by the Dutch Ministry of Foreign Affairs, through its Directorate-General of Trade and International Cooperation. The work also benefitted from the funding of the European Horizon 2020 research programme as part of the CD-LINKS project (Linking Climate and Development Policies-Leveraging International Networks and Knowledge Sharing) under grant agreement No 642147. 

4. Actors and governance in the transition toward universal and sustainable electricity systems in Sub-Saharan Africa 


\section{Abstract}

Sub-Saharan Africa faces several challenges that hamper the effort to provide universal electricity access. The challenges are not the result of lack of energy resources but rather the result of governance and institutional problems as well as lack of capital to meet the high investment requirement. This study aims to provide relevant policy recommendations to facilitate the path towards universal electricity access in SSA. We do this by identifying the barriers for electricity access and the relevant actors, institutions, and regulations using desk research, stakeholder interviews and expert workshops. The results show that the absence of overall plans and approaches and lack of clarity in policies are the main challenges for the sector. Setting standards for electricity products, such as solar panels, could help to reduce the problem of counterfeit poor-quality products. A broader participation of non-governmental actors is needed to increase the speed of electrification. This requires innovative revenue schemes, financial and fiscal incentives and elimination of market distortions. More generally, we conclude that stable and consistent policy frameworks and improved coordination between actors, are crucial to accelerate electrification in the region.

\section{Highlights}

- Deeper governance and institutional problems hinder universal electricity access

- The chapter explores the roles of actors and institutions for universal access

- Institutional reforms need to stimulate innovation in technology \& business models

- Clear technical standards and certification for off-grid technologies are crucial

- Improved coordination between actors could increase the synergy of programs

Published article: Dagnachew, A. G., Hof, A. F., Roelfsema, M. R., \& van Vuuren, D. P. (2020). Actors and governance in the transition toward universal electricity access in Sub-Saharan Africa. Energy Policy, 143. https://doi.org/10.1016/j.enpol.2020.111572. 


\subsection{Introduction}

Several governments in developing countries have emphasized the crucial role of electricity for human development [33] and have, therefore, put electrification as a development priority [54, 55, 102]. Despite this, most business-as-usual or current policy projections do not expect the absolute number of people with no access to electricity to decline significantly between now and $2030[8,10]$. Sub Saharan Africa (SSA) represents a primary example of this: while more than 600 million people in SSA did not have access to electricity in 2010, in 2018 that number had barely declined [8].

The challenges in SSA are not the result of lack of energy resources. The region has ample fossil and renewable energy resources to meet the demand. Recoverable oil resources will be sufficient for the next 100 years, coal for over 400 years and gas for about 600 years [81], while the region as a whole has also abundant potential for solar, wind and hydropower $[61,101]$. Rather, the challenges are a result of governance and institutional problems, as well as lack of capital to meet the high investment requirement. Monopoly [103], corruption [104] and inefficient management [105] are some of the challenges mentioned in the literature. As a result, the energy system functions poorly with an unstable and unreliable electricity supply, low generation capacity, low efficiency, inadequate investment, high costs and often prices that are too low to cover costs $[48,106]$.

Several studies have examined the governance of the electricity system and the energy transition in SSA countries. Power, Newell [107] studied the involvement of Brazil, India and China in the transfer of renewable energy technologies and their overall significance in the energy systems of Mozambique and South Africa. Newell and Phillips [108] explored the theoretical and practical challenges of energy transition in Kenya through an account of the political economy of energy transitions and the ways in which they are constrained and enabled by neo-liberalization processes. Baker, Newell [109] discussed the governance and financing of clean energy transition in South Africa by analysing the struggle over competing energy visions, infrastructures and political agendas. Winkler [110] examined various policy options for promoting renewable electricity and the implementation challenges in South Africa (however, without addressing the individual actors or their networks). 
The above-mentioned studies all focused on actors and processes either in their current status or in the context of the transition towards a low-carbon energy system. This chapter, on the other hand, focuses on a transition towards universal electricity access, while taking the regional socio-economic differences into consideration. More specifically, the aim of this study is to provide relevant policy recommendations to facilitate the path towards universal electricity access by identifying the barriers and relevant actors, institutions, and regulations for universal electricity access in different regions in SSA. Given the crucial role that they play in providing universal access to electricity, the focus of the study specially lies in off-grid systems. Our analysis is based on a desk research, workshops and expert interviews in the case study countries Ghana, Nigeria, Ethiopia, and Tanzania. The desk research was aimed at providing a broad picture of governance of electricity systems in SSA and provided input to the workshops. The workshops aimed to narrate possible pathways for electrification in SSA, identify the actors and explain their role in the system. The results of the workshops were also used to structure the interviews and further analysis.

The rest of the chapter is organised as follows. Section 4.2 provides the methodology used for the expert workshops and stakeholder interviews employed in the casestudy countries. Section 4.3 presents a general discussion of important aspects related to actors involved in the governance of electricity supply, with special focus on barriers for off-grid electrification in SSA. It thereby provides a general framework to structure and analyse the results. Section 4.4 discusses the results in terms of alternative electrification storylines, institutional structure and actors, and regulatory instruments. Section 4.5 presents the discussion, followed by conclusion and policy recommendations in section 4.6.

\subsection{Methodology}

We first conducted a desk research to identify the relevant actors in electricity governance and identify barriers that hinder the expansion of decentralised systems in developing countries. This provided the basis for the expert workshops that were organised to develop a set of narratives for electricity production and governance in SSA. These narratives were then used as context for the stakeholder interviews 
and the analysis. The results from the stakeholder workshops and the stakeholder interviews were used to provide relevant policy recommendations.

\subsubsection{Expert Workshops}

Three workshops were held in the Netherlands and in Ethiopia to create qualitative storylines that describe the roles of different actors in the transition to sustainable and universal electricity access in SSA (see section 4.4.1 for results). The expert workshops involved several experts who are familiar with the region's electricity sector and included policy makers, researchers, financers, modellers, energy service providers, Non-Government Organizations and the private sector. The narratives describe the main characteristics of the possible future evolution of the electricity sector in the region. These serve as the context for stakeholder interviews, to understand the barriers, and identify the gaps in governance of the sector in the region. The list of organizations involved in the workshops is presented in Annex $C$.

The aim of the first workshop was to explore various storylines for electricity production and governance together with other modellers and researchers. The purpose of the second and third workshops was to further develop the storylines and complement the quantitative pathways presented in Dagnachew, Lucas [10] and Dagnachew, Lucas [14] with qualitative storylines that describe the roles of different actors in the transition to sustainable and universal electricity access in SSA. In these two workshops, we employed the world-café model to create a hospitable space, encourage everyone's contribution, and connecting diverse perspectives on the issue. At the end of the third workshop, key actors and their roles were identified, as well as driving forces and key uncertainties. These served as the basis for storylines that were developed to structure and validate stakeholder interviews and to narrate possible future paths for the region's electricity sector. The storylines show how old and new actors and their roles could evolve in the future.

\subsubsection{Stakeholder interviews}

The storylines provide the structure and the context for the stakeholder interviews. The aim of the interviews was to identify existing actors, institutions and regulations and their interactions in Nigeria, Ghana, Ethiopia, and Tanzania as narrated in the storylines. Stakeholder interviews were conducted for different electrification 
projects (see Annex C for list of interviewees and interview questions). In addition to the central grid, we identified off-grid projects through iterative discussions with experts, where large numbers of off-grid electrification projects are being implemented. The selected countries capture the diversity in population size, economic development, natural resource availability, and governance culture. The choice is also influenced by the ease of access to local information. The list of organizations participated in the interview is presented in Annex C.

A total of 100 interviews were conducted between August and October 2017. After identifying the projects, actors including national governments, regional/ state governments, local governments, key financial institutions, civil society organizations, academic institutions and the private sector were approached for interviews. The interviews were semi-structured open-ended, and were based on pre-determined questions, which allowed stakeholders to share the requested information (Annex C presents the interview questions). In developing the question, we tried to identify the most appropriate way to obtain the necessary information together with local experts, given the cultural context. The interview questions were tested with non-priority stakeholders in each country.

The initial process resulted in a long list of actors involved in the sector and we prioritised the ones that play a crucial role in the sector. For this, we consulted at least one expert in each country with good knowledge of the electricity sector, its actors, and the power of those actors to influence policy. Following that, we applied snowball sampling to identify and include actors deemed important by respondents. The snowballing helped to identify actors that play important roles in centralized and decentralised systems. This process provided an extensive list of actors in the electricity sector in the countries under consideration.

We conducted interviews with stakeholders of three types of electrification projects in each country: the central grid, a mini-grid system, and a stand-alone system. The projects were selected based on discussions and recommendations from local experts. Below, the projects/systems are briefly introduced. 


\subsubsection{Central grid projects}

Ghana has a total installed capacity of about 4.4 GW, coming from hydropower and fossil fuel-based thermal plants [111]. Volta River Authority (VRA) generates the bulk of the electricity. The transmissions network in Ghana is owned and operated by the Ghana Grid Company Limited (GRIDCo), while Electricity Company of Ghana (ECG) and Northern Electricity Distribution Company (NEDCO) dominate the distribution of electricity. The interview is conducted with stakeholders in Accra, Ghana.

The total installed electricity capacity in Nigeria is $12.5 \mathrm{GW}$, mostly coming from fossil-based thermal plants and hydropower. However, mostly, only half this capacity is available [112]. The Nigerian Electricity Regulatory Commission (NERC) is an independent regulatory body responsible for the technical and economic regulation for the Nigeria Electricity Supply Industry (NESI). NESI consists of six generation companies, one transmission company and eleven distribution companies. Stakeholders in Lagos Mainland were chosen for the interview.

Ethiopia has an installed capacity of $4.2 \mathrm{GW}$ [113], of which $90 \%$ consisting of hydropower. The rest of the capacity consists of wind and fossil fuel-based thermal plants. The Ethiopian Electric Power (EEP) is responsible for constructing and administration of power generation plants, high voltage transmission lines, substations and whole sale of electricity. The Ethiopian Electric Utility (EEU) is responsible for the power distribution and the operation of power transmission lines of $\leq 66 \mathrm{kV}$ within the national power grid. The interviews were conducted with stakeholders in Addis Ababa, Ethiopia.

Tanzania has $1.6 \mathrm{GW}$ installed capacity. The majority of the electricity (>1 GW) is produced from thermal plants, with the remainder consisting of hydro (561 MW) and other renewables [114]. Despite repeated attempts to reform the sector, it still lacks sustained commitment to private sector investment. The Ministry of Energy and Minerals (MEM) is responsible for overall energy policy formulation, while an independent regulatory agency, the Energy and Water Utilities Regulatory Authority (EWURA), dictates the regulation of the sector. The interviews are conducted with stakeholders in Arusha, Tanzania. 


\subsubsection{Mini-grid projects}

In Nigeria, a natural gas based mini-grid system - the mainland independent power project - to alleviate the problem of frequent power interruption was selected. This project with a capacity of $8.8 \mathrm{MW}$ was established by the Lagos state government and provides electricity to 12,000 residents in Lagos Mainland. The project consists of a public-private partnership between the Mainland Power Limited (part of Lagos state government), the CET Energy (a private energy group managing the system), and Skye Bank that financed the project. In Ethiopia, a diesel powered mini-grid that supplies electricity to a rural settlement in Gambella was selected. The system has 6 MW of installed capacity and serves 20,000 residents. In Ghana, the Ghana Energy Development and Access Project (GEDAP) was selected. This project implemented a total of five solar PV and wind powered mini-grids with a total capacity of $200 \mathrm{~kW}$, supplying around $650 \mathrm{kWh}$ of electricity per day. In Tanzania, we chose the JUMEME Rural Power Supply (JUMEME) project in Bwisya Village of Mwanza Region. The projects consist of a $60 \mathrm{kWp}$ solar PV and a 33-kVA diesel generator hybrid minigrid system built with the financial support from the Sustainable Energy Fund for Africa (SEFA).

\subsubsection{Stand-alone projects}

The stand-alone projects were all related to solar home systems. In Nigeria, the Lagos Solar project was selected, which consists of a partnership between Lagos State Electricity Board (LSEB) and Solar Nigeria, which is financed by UK Department for International Development (DFID). The project provides access to electricity to schools and health centres in rural and peri-urban areas of Lagos State. In addition to providing half of the required investment, LSEB provides training programmes to locals on operation and maintenance of the system. In Ethiopia, the Solar Energy Foundation project, which operates under the rural electrification programme and targets households in remote rural areas with heavy reliance on kerosene lamps, was chosen. The foundation works together with governments, NGOs, training institutes and solar home system manufacturers in Ethiopia. In addition to providing finance, it also provides trainings for locals in operation and management of the system. In Ghana, the Ghana National Rooftop Solar Programme was selected as an interesting case to study stand-alone electrification in the country. In 2015, the Ministry of Energy through the Energy Commission launched the programme as an integral 
part of the government strategy to expand access to electricity. The programme consists of a capital subsidy on solar systems to help make solar affordable for the average Ghanaian. The National Rural Electrification Program (NREP) of Tanzania is a government program that aims to expand rural electrification by working together with the private sector. Mobisol provides large productive-use solar home systems under this program, combining them with mobile technology and a 36-month micro finance scheme.

\subsection{Access to electricity: key actors and barriers}

This section presents a general framework of actors and institutions involved in electricity governance based on the conducted desk research. We also introduce known barriers to off-grid electrification systems that are deemed crucial to provide access to electricity in remote, low density settlements. The findings are used to structure the workshops and stakeholder interview as well as for framing of the analysis.

\subsubsection{Actors in the governance of electricity supply}

Governance issues are often cited as being the root cause of electricity access problems. Governance in the energy sector refers to the actors, institutions and processes that shape how decisions are made in the process of providing energy services [115]. It involves a broad spectrum of actors connected to energy infrastructure and energy services. These actors include (local and national) governments, NGOs, civil society groups, corporations, residents, as well as new actors.

The actors involved in the governance of the electricity sector are strongly influenced by the technical setting of the electricity system [116]. In general, there are two approaches to electrification: a centralized (on-grid) track and a decentralized (mini-grid and off-grid) track, though they might have their own variants. These tracks of electrification can be defined based on the type of technology used and the institutions involved [117]. Centralized tracks rely on electricity generation at large-scale centralized facilities and subsequent distribution through a transmission network with the government as the main actor. In this system, electrification is 
undertaken by national governmental entities such as the state-owned national utility, a rural electrification agency (REA), or the ministry of energy, acting alone or together with the extension of the national grid as the main route for increasing access [117]. Decentralized tracks often refer to systems that generate electricity at or near demand sites and do not require significant distribution networks. These are usually implemented through non-governmental entities such as cooperatives, community user groups, or a smaller private sector [118].

Integrating decentralized electrification technologies within the energy system could play an important role in increasing access, especially in rural SSA [51]. However, the policy, financial and institutional challenges of renewable energy based decentralized systems are quite different to those of centralized systems, calling for new and innovative modes of governance [116].

\subsubsection{Barriers to off-grid (renewable) electrification}

Off-grid electrification systems are crucial in providing access to electricity, especially to the rural poor $[10,14,119]$. However, off-grid systems face various barriers for penetration in developing countries [120-122]. The barriers discussed below are strongly related to the roles taken by electricity system actors, their organizational capacity, and the level of coordination between them. Below, we shortly discuss these barriers, with Figure 23 providing the summary.

\subsubsection{Market failure}

In many countries, government-owned utilities still control electricity production, transmission and distribution. This results in a highly controlled energy sector with restricted access to technology and a lack of competition. High transaction costs and missing market infrastructure have been mentioned as barriers to renewable energy based decentralized systems [120]. In addition, lack of information about new technologies results in uncertainty about the quality and efficiency of decentralized energy technologies. Lack of information among the stakeholders has been cited in many studies $[120,123]$ as one of the barriers to the successful dissemination of decentralized systems. Consumers perceive new technologies to be more expensive than traditional systems and involve more financial and investment risks. 


\subsubsection{Market distortion}

Fossil fuel use has large negative external effects related to human health, ecosystem decline and climate change. In most developing countries, these negative external effects are not internalised in their costs. On the contrary, there are often large public subsidies, both implicit and explicit, channelled in favour of fossil energy sources [124]. This distorts investment decisions by significantly lowering energy prices from fossil fuel resources. Furthermore, unequal tax burdens on fossil fuel and renewable energy industries and lack of incentives for renewable energy technologies are barriers for small- and medium-scale decentralized energy systems $[125,126]$.

\subsubsection{Economic and financial barriers}

It is difficult for developers to obtain long-term credits for off-grid projects with acceptable conditions [127]. One reason is the small scale of many decentralized renewable energy projects. Many large financial institutions are unwilling to consider small projects as investing in utility-scale projects offers better returns from loans and lower transaction costs. At the same time, microfinancing institutions offer loans at very high interest rates that scare off small scale investors. High risk perceptions, which can be influenced by factors such as policy design, sudden policy changes, permitting procedures etc., make investment in decentralized electricity options unattractive to private investors. This hinders access to finance from the private sector [128]. There are few multilateral and bilateral initiatives that provide financial resources for renewable energy projects, such as the UN SEFA, the IRENA Africa clean energy corridor, the U.S. Power Africa initiative, the Climate Investment Funds (CIF), and the EU's Electrification Financing Initiative (ElectriFi). However, the investments that these initiatives generated have been far below needs [129]. Moreover, the initiatives are fragmented, causing overlaps, inefficiencies and overall higher transaction costs [130].

\subsubsection{Institutional barriers}

Regulatory and institutional barriers can impede deployment of off-grid technologies. Lack of clear national strategies for the energy sector, uncertainties surrounding subsidies (continuation or phase-out) and government support of both renewable energy technologies as well as fossil-based energy technologies 
strengthens reluctance of the private sector to invest in decentralized systems. Similarly, uncertainties in grid extension plans and regulatory requirements, and lack of coordination and cooperation within and between institutes and stakeholders involved in the sector also present challenges for private investors. Experience in India shows that extension of the central grid to rural areas have often led to end-users abandoning the use of micro/mini grids [127]. Hence, most developing countries require a significant amount of regulatory and financial reforms to remove such institutional barriers.

\subsubsection{Technical barriers}

Technical or technological barriers generally include barriers associated with resource, technology and skill attributes. New technologies and systems are seldom on an equal footing with established technologies. There is a lack of knowledge and skills for designing, commissioning and operating decentralized renewable energybased power plants. Inappropriateness of the identified technology, poor design, and lack of community training on the operation and maintenance of the equipment have been mentioned as barriers to the dissemination of renewable energy based decentralized systems [120].

\subsubsection{Social, cultural and behavioural barriers}

When appropriate community education is missing, communities may develop negative perceptions about the functioning of the new technology [120]. Moula, Maula [131] recognise social acceptance as an important issue shaping the widespread implementation of renewable energy technologies and argue that 'social attitudes' need to change for radical implementation of renewable energy technologies. 


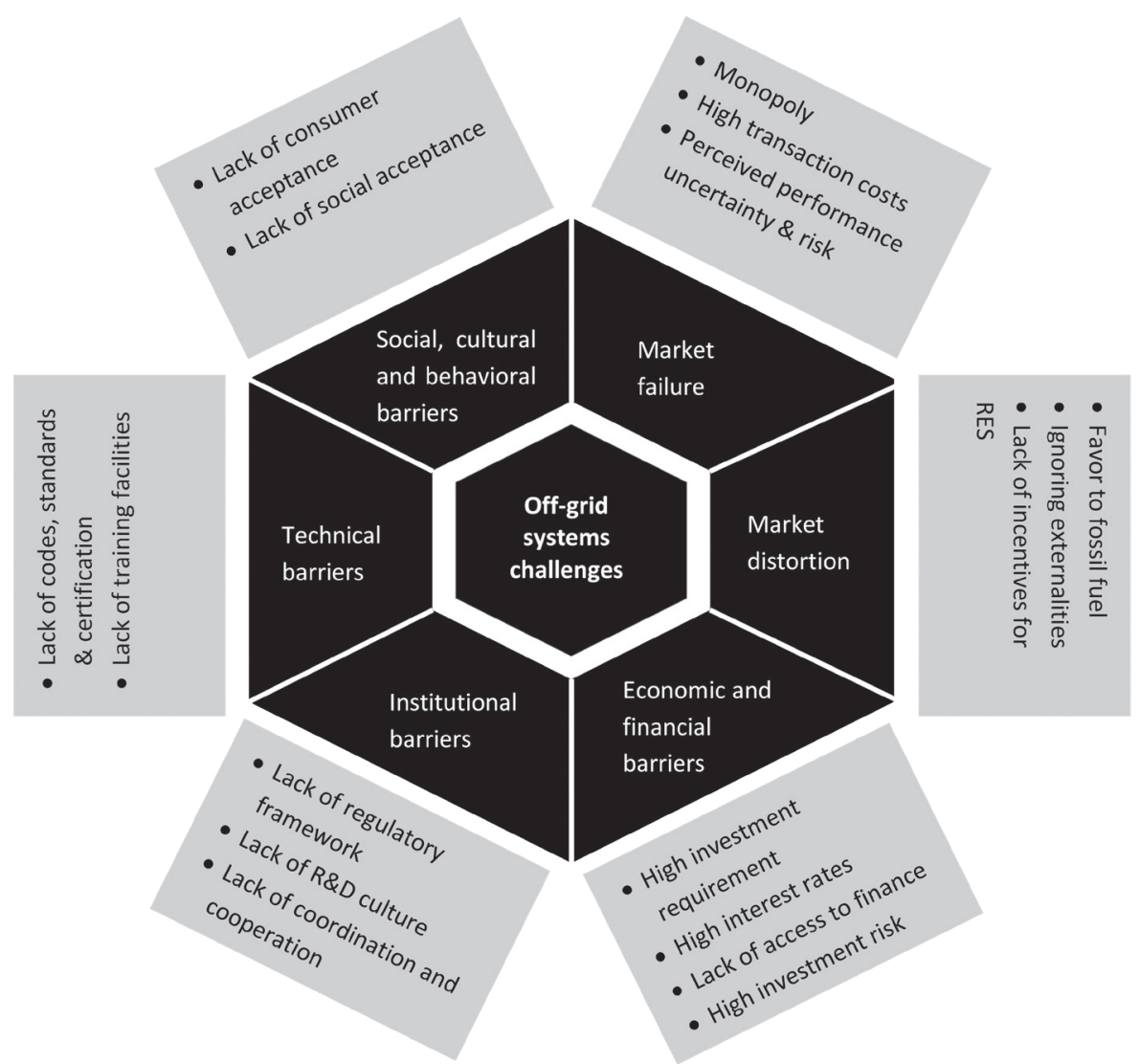

Figure 23: Barriers to off-grid electrification in developing countries (Source: authors' compilation)

\subsection{Results}

This section presents the result of our study. First, the storylines which were developed during the expert workshops are discussed. Then, the findings of the stakeholder interviews related to institutional structure, actors and regulatory instruments in the electricity system are provided. As mentioned before, the storylines describe how the role of actors and institutions could evolve in the future. They help identify the actors, institutions and regulations that are crucial where the development of decentralized systems is at the heart of the strategy to provide universal access to electricity. Then, in combination with the current state of affairs as established through the interviews, we identify the gaps and draw down relevant policy recommendations to facilitate the path towards universal electricity access in SSA. 


\subsubsection{Storylines}

Based on results from the interactive discussion of the three workshops, four alternative storylines for the electricity production and governance in SSA were developed. The workshop participants identified the drivers of change and their interactions in the electricity system in SSA. The main characteristics of the storylines are organized along two axes: governance structures and electrification systems. The governance axis represents the hierarchy of decision making, the electrification system axis the dominance of large-scale on-grid systems or smallscale off-grid options. These storylines help to understand the causal relationships within the electricity system and envision various ways of future developments in the system.

\subsubsection{Storyline-1: Top-down governance and centralized electricity production}

In this storyline, large scale on-grid systems are preferred and electrification occurs primarily through extension of the centralized grid. Electricity supply is based on the notion that state-owned monopolies or a few large utility companies provide electricity infrastructure services and distribution. Overarching strong top-down governance institutions are the norm, and the process is led by the government through organizations such as state utilities, electrification agencies or energy ministries. The national government provides rules and regulation to create a good competitive market. The private sector is given the opportunity to engage in large-scale production. Financing is (currently) not a major obstacle, as financing a few large-scale investments is generally easier than financing many smaller-scale investments. Development banks and the central government play an important role in providing or facilitating access to financing. The role of NGOs is limited to agenda setting and providing an overview of the process.

\subsubsection{Storyline-2: Top-down governance and decentralized electricity production}

Decentralized off-grid options provided through specialized institutes such as rural electrification agencies are dominant in providing access to electricity, through market development involving private sector and others. Large donor organizations like the World Bank and the African Development Bank play a central role in 
providing loans and financial support through the rural electrification agencies to alleviate financial barriers. Finance is organized for the whole electricity chain and financial activities are clustered. NGOs assist in capacity building, including productive end-use promotion, standardization and certification processes. Finally, other top-down actors that are not directly involved in the energy sector, like the World Health Organization (WHO), play important roles in providing leadership, shaping the research agenda, and setting norms and standards for health-related key electricity access indicators. In this storyline, the electrification process harnesses local entrepreneurial talent (mostly as operators) and benefits from a strict governmental control.

\subsubsection{Storyline-3: Bottom-up governance and decentralized electricity production}

In this storyline, decentralized systems (mini-grid and standalone) are preferred. Electrification is basically a community driven model and it is generally carried out through nongovernmental entities such as cooperatives, community user groups, or private entrepreneurs. To overcome potential social and cultural barriers, the needs of the electricity service user are put central and the focus is on energy services and their components. The process is inclusive, involving every stakeholder from beginning to end. This system stimulates social innovations and requires a decentralized multi-layered governance system - addressing both institutional and technical barriers. The role of the government is mainly on setting standards and regulation. But this requires capacity building within government offices and sharing experiences of best practices. Governments promote and lead the initiative to adopt new technologies and to provide confidence to the private sector through regulation, incentives and guarantees. NGOs and academia have important roles in conducting research and case studies, pilot and demonstration projects, and lead stakeholder discussions. They also take part in building local capacity, awareness creation, networking and experience sharing. However, they do not provide free money to the community, as this will distort the market and undermine ownership. The private sector is the service provider and collaborates with other stakeholders to develop innovative financing mechanisms and business models. The government provides collateral for households with difficulty to acquire financing. The community is the owner of the technology. 


\subsubsection{Storyline-4: Bottom-up governance and centralized electricity production}

Large scale on-grid systems are preferred. Electrification is generally carried out through nongovernmental entities such as cooperatives, community user groups or private entrepreneurs. Full-service contracts are delivered by (local) SME's. Their deployment especially requires strong organization of local communities. The national government has an enabling and facilitating role in creating a long-term perspective, by putting it on the national agenda and by creating a fair market. The local government role is to protect the community interest, make sure there are quick solutions and take care of monitoring of the project. NGOs, together with business and academia, are involved in doing research \& case studies and conduct pilot \& demonstration projects. They also take part in awareness creation. These projects are especially relevant for creating confidence and making sure good quality, locally fit technologies are used. Users are willing to accept the system but require reliability/security of the service. Financing can be arranged by upscaling micro-finance or by setting up local cooperation.

\subsubsection{Institutional structure, actors and governance}

Through interviews with stakeholders, the important actors involved in centralized and decentralized electrification programs in the four countries were identified. While the type and roles of actors differ by country and by project, governments have a strong presence in all the cases. Table 12 presents the key characteristics of the case-study countries relevant for understanding current electrification levels and for the choice of electrification systems. 
Table 12: Key characteristics of the case-study countries in 2016 [11]

\begin{tabular}{lllll}
\hline & Nigeria & Ghana & Ethiopia & Tanzania \\
\hline Sub-region & $\begin{array}{l}\text { Western \& } \\
\text { central Africa }\end{array}$ & $\begin{array}{l}\text { Western \& } \\
\text { central Africa }\end{array}$ & $\begin{array}{l}\text { Eastern } \\
\text { Africa }\end{array}$ & $\begin{array}{l}\text { Southern } \\
\text { Africa }\end{array}$ \\
\hline Population (million) & 186 & 28 & 102 & 56 \\
GDP (current USD in billion) & 405 & 55 & 74.3 & 49.8 \\
GDP per capita PPP (current USD) & 5867 & 4294 & 1735 & 2787 \\
Urban population (\% of total) & 49 & 55 & 20 & 32 \\
Access to electricity (\% total population) & 58 & 78 & 27 & 16 \\
Rural access to electricity (\% rural population) & 39 & 63 & 12 & 4 \\
Population density (people/km²) & 204 & 124 & 102 & 63 \\
\hline
\end{tabular}

\subsubsection{Actors in the on-grid (centralized) system}

Table 13 presents the main actors and institutions involved in governing the current electricity sector in the case-study countries. 


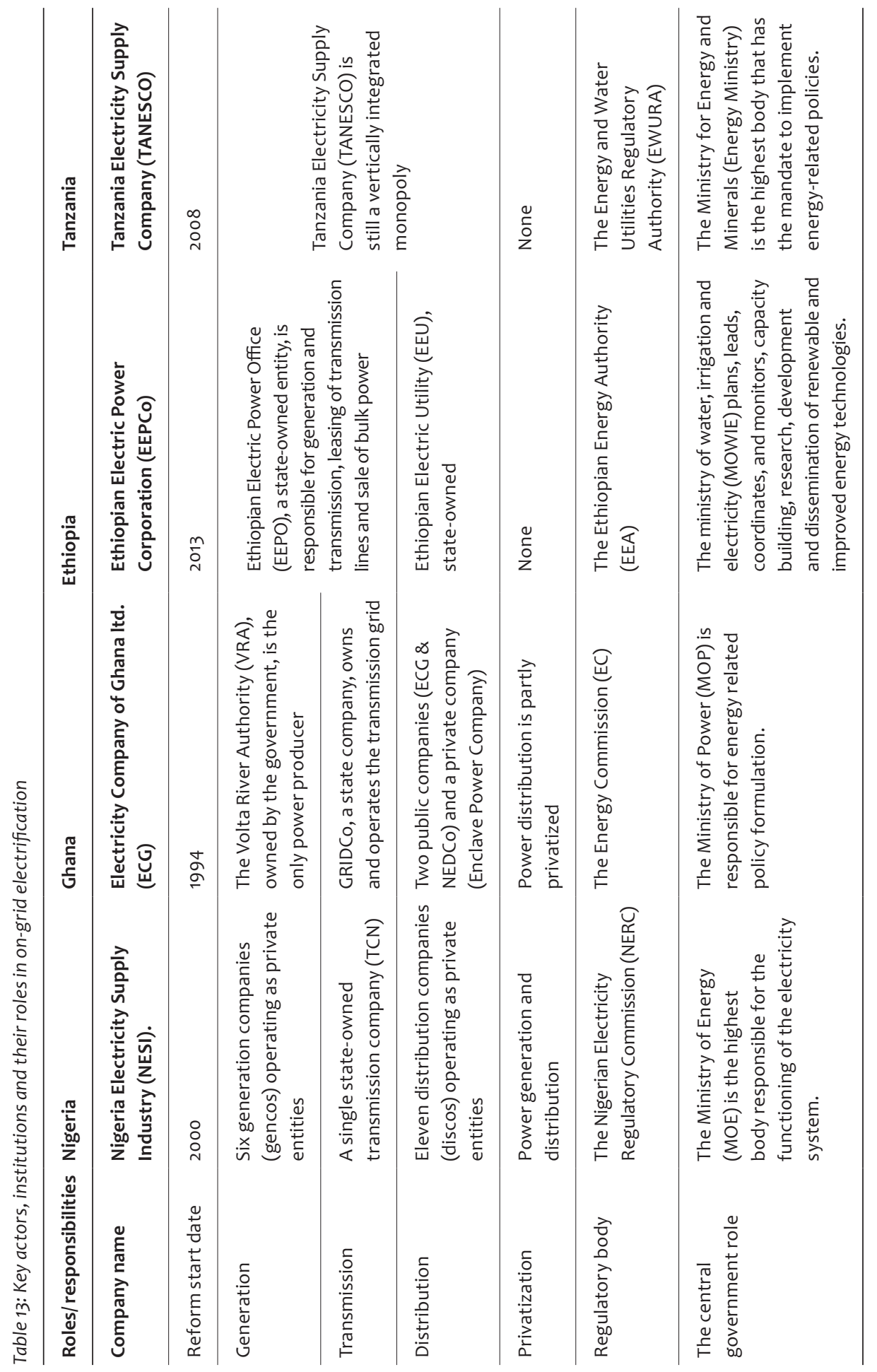


Generally, electrification has been a supply driven process taken by a single public utility with a top-down governance. In all our case-study countries, the electricity sector is quite similar to the system described under storyline-1 but it is going through a reform process. However, the timing and extent of these reforms differ by country. Most are still stuck in the initial stages of reforms, which in practice implies unbundling of generation, transmission, and distribution. Nigeria is the only country where power generation within the central grid is privatised. To decrease financial risks for power generation companies, the Nigerian Bulk Electricity Trading Plc (NBET) was established as a credible off-taker (as part of the power purchase agreement (PPA)). Power distribution in Nigeria is fully privatised with 11 private companies involved in distribution. Ghana's Enclave Power Company is a private sector involved within the country's central grid system with responsibility to distribute for the Free Economic Zone. In Ethiopia and Tanzania, all components of the central grid are owned and operated by the government. The sector in all four countries is characterized by big loses in transmission and distribution that results in a sector wide revenue gap, increasing the risk for private sector participation. Other problems of the electricity sector, as identified by the actors themselves, include insufficient generation capacity, old and damaged transmission components, lack of human resource capacity, power theft, limited revenue, lack of stakeholder collaboration, lack of consumer awareness on energy efficiency, and poor-quality products. Figure 24 presents a simplified structure of the on-grid electricity system and its actors in the case-study countries. 


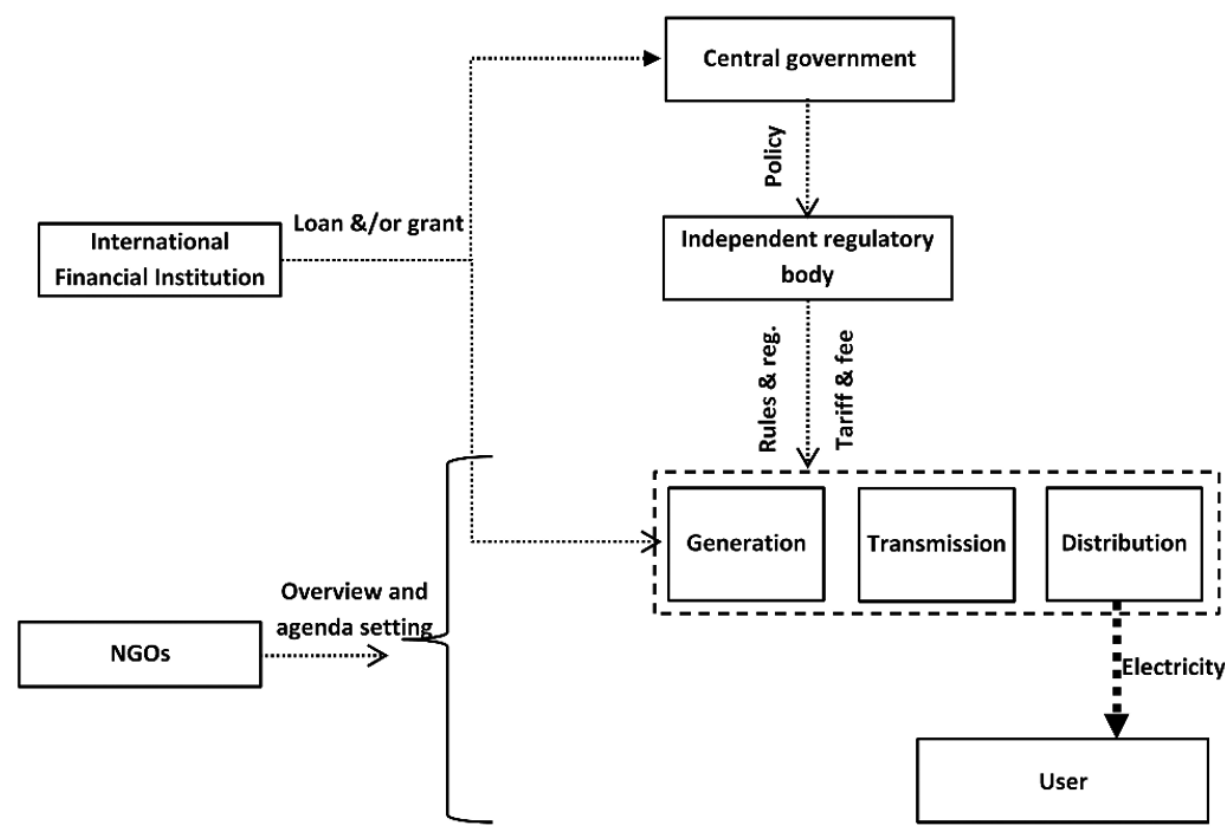

Figure 24: Simplified institutional structure of on-grid electrification

\subsubsection{Actors in the off-grid (decentralized) systems}

New actors continuously emerge to fill the gap in the off-grid electrification system in the region. The private sector is gradually growing into the off-grid electricity market, but the institutional and financial capacity problems persist in all case-study countries. Table 14 presents the main actors, institutions and their roles in off-grid electrification in the case-study countries. 
Table 14: Key actors, institutions and their roles in off-grid electrification

\begin{tabular}{|c|c|c|c|c|}
\hline $\begin{array}{l}\text { Roles/ } \\
\text { responsibilities }\end{array}$ & Nigeria & Ghana & Ethiopia & Tanzania \\
\hline $\begin{array}{l}\text { Access to } \\
\text { working } \\
\text { capital }\end{array}$ & $\begin{array}{l}\text { The Central Bank of } \\
\text { Nigeria }\end{array}$ & $\begin{array}{l}\text { The World Bank is } \\
\text { the main source of } \\
\text { finance }\end{array}$ & $\begin{array}{l}\text { - Development } \\
\text { Bank of Ethiopia } \\
\text { (DBE) } \\
\text { - Rural Electrifica- } \\
\text { tion Fund (REF) } \\
\text { - The Carbon Initia- } \\
\text { tive for Develop- } \\
\text { ment (Ci-Dev) }\end{array}$ & $\begin{array}{l}\text { Rural Energy } \\
\text { Agency } \\
\text { (REA), African } \\
\text { Development Bank } \\
\text { (AfDB) through } \\
\text { SEFA }\end{array}$ \\
\hline $\begin{array}{l}\text { Training and } \\
\text { capacity } \\
\text { building }\end{array}$ & $\begin{array}{l}\text { The Lagos Energy } \\
\text { Academy (LEA) and } \\
\text { the National Power } \\
\text { Training Institute } \\
\text { of Nigeria (NAPTIN) } \\
\text { provide hands-on } \\
\text { vocational training } \\
\text { to young specialists } \\
\text { in the Power Sector } \\
\text { Value Chain }\end{array}$ & $\begin{array}{l}\text { NGOs together with } \\
\text { government pro- } \\
\text { vide trainings for } \\
\text { locals on operation } \\
\text { and maintenance of } \\
\text { the system }\end{array}$ & $\begin{array}{l}\text { - Addis Ababa } \\
\text { University (AAU) } \\
\text { and Selam } \\
\text { Vocational } \\
\text { Training assist } \\
\text { in research and } \\
\text { capacity building. } \\
\text { - NGOs are involved } \\
\text { in capacity building } \\
\text { of public institutes }\end{array}$ & $\begin{array}{l}\text { National and } \\
\text { international } \\
\text { development } \\
\text { organisations and } \\
\text { NGOs (i.e. AfDB, } \\
\text { GIZ, SNV, the World } \\
\text { Bank, etc.) }\end{array}$ \\
\hline $\begin{array}{l}\text { Advocacy and } \\
\text { awareness }\end{array}$ & $\begin{array}{l}\text { Council for } \\
\text { Renewable } \\
\text { Energy Nigeria } \\
\text { provides a forum } \\
\text { for discussion } \\
\text { and promotes the } \\
\text { use of renewable } \\
\text { energy technology } \\
\text { for off-grid } \\
\text { electrification }\end{array}$ & $\begin{array}{l}\text { NGOs are engaging } \\
\text { with local people } \\
\text { and creating } \\
\text { awareness }\end{array}$ & $\begin{array}{l}\text { - The Ethiopian } \\
\text { Alternative } \\
\text { Energy Promotion } \\
\text { and Development } \\
\text { Centre } \\
\text { - Solar Energy } \\
\text { Development } \\
\text { Association } \\
\text { (SEDA-E) }\end{array}$ & $\begin{array}{l}\text { Tanzania } \\
\text { Renewable Energy } \\
\text { Association } \\
\text { (TAREA) works } \\
\text { to bring actors } \\
\text { together } \\
\text { to promote } \\
\text { accessibility } \\
\text { and use of } \\
\text { renewable energy } \\
\text { technologies }\end{array}$ \\
\hline Subsidies & $\begin{array}{l}\text { The UK Department } \\
\text { for International } \\
\text { Development } \\
\text { (DFID) provides } \\
\text { fund for co- } \\
\text { financing }\end{array}$ & $\begin{array}{l}\text { The Government of } \\
\text { Ghana }\end{array}$ & $\begin{array}{l}\text { - The Solar Energy } \\
\text { Foundation (SEF), } \\
\text { an NGO, covers } \\
75 \% \text { of the cost } \\
\text { of a solar home } \\
\text { system for rural } \\
\text { households. } \\
\text { - REF also provides } \\
\text { capital subsidy } \\
\text { of } 20-30 \% \text { of the } \\
\text { investment costs to } \\
\text { renewable energy } \\
\text { project developers. }\end{array}$ & $\begin{array}{l}\text { Rural Energy } \\
\text { Agency and Fund } \\
\text { (REA/F) }\end{array}$ \\
\hline
\end{tabular}


Chapter 4

Table 14: Key actors, institutions and their roles in off-grid electrification (continued)

\begin{tabular}{|c|c|c|c|c|}
\hline $\begin{array}{l}\text { Roles/ } \\
\text { responsibilities }\end{array}$ & Nigeria & Ghana & Ethiopia & Tanzania \\
\hline $\begin{array}{l}\text { The role of } \\
\text { government }\end{array}$ & $\begin{array}{l}\text { National energy } \\
\text { policy, rules and } \\
\text { regulations }\end{array}$ & $\begin{array}{l}\text { Sets the rules and } \\
\text { regulations, facili- } \\
\text { tated the process } \\
\text { and co-financed the } \\
\text { program }\end{array}$ & $\begin{array}{l}\text { Policy and regulation, } \\
\text { capacity building } \\
\text { and demonstration } \\
\text { projects }\end{array}$ & $\begin{array}{l}\text { National energy } \\
\text { policy, regulations, } \\
\text { licensing \& } \\
\text { enforcement }\end{array}$ \\
\hline $\begin{array}{l}\text { The private } \\
\text { sector }\end{array}$ & $\begin{array}{l}\text { The global off-grid } \\
\text { lighting association } \\
\text { (GOGLA) is involved } \\
\text { in electrification } \\
\text { with business } \\
\text { models ranging } \\
\text { from 'consumer } \\
\text { buying the service' } \\
\text { to 'consumer } \\
\text { buying the product' }\end{array}$ & $\begin{array}{l}\text { Installation, } \\
\text { operation, and } \\
\text { maintenance of } \\
\text { renewable energy } \\
\text { systems }\end{array}$ & $\begin{array}{l}\text { Supply off-grid } \\
\text { electrification } \\
\text { technologies }\end{array}$ & $\begin{array}{l}\text { - JUMEME provides } \\
\text { solar-diesel hybrid } \\
\text { mini-grids } \\
\text { - Mobisol, Off-grid } \\
\text { Electric Tanzania } \\
\text { Ltd. (ZOLA) are in- } \\
\text { volved in providing } \\
\text { solar energy service } \\
\text { through pay-as-you- } \\
\text { go models }\end{array}$ \\
\hline $\begin{array}{l}\text { The role of the } \\
\text { community }\end{array}$ & & $\begin{array}{l}\text { On-site support } \\
\text { including facilitation } \\
\text { and labour }\end{array}$ & & \\
\hline
\end{tabular}

There is a growing number of household and community energy producers (and consumers) in all case-study countries. Rural electrification agencies are established in the countries with the mandate to facilitate rapid rural electrification engaging producer-consumers and the private sector. They identify suitable locations and technologies for electrification, advise on tariffs, allocation of subsidies, provide grants, and execute projects. However, most of the actors interviewed expressed their doubts about the possibility of meeting the universal electricity access targets with the current effort. The national electricity policies require better institutional settings and human capacity, as well as greater collaboration between the various actors. Lack of clear policies and targets, institutional barriers (most of all corruption), weak stakeholder collaboration and lack of finance are the four obstacles mentioned repeatedly by respondents for expansion of decentralized systems to provide access. Moreover, lack of institutional capacity, lack of accountability, and high transaction cost are obstacles to progress in the sector. Poor quality counterfeit products (generic solar panels, as they are called by the locals) are also taking advantage of the lack of standards for new technologies 
reinforcing social barriers. In Ethiopia, the electricity tariffs are amongst the lowest in the world, hindering private sector participation. In addition, the public sector is not communicating with the private sector, which results in sub-optimal outcomes. There is no clear role for donors and NGOs. Figure 25 presents a simplified structure of the off-grid electricity system and its actors in the case-study countries.

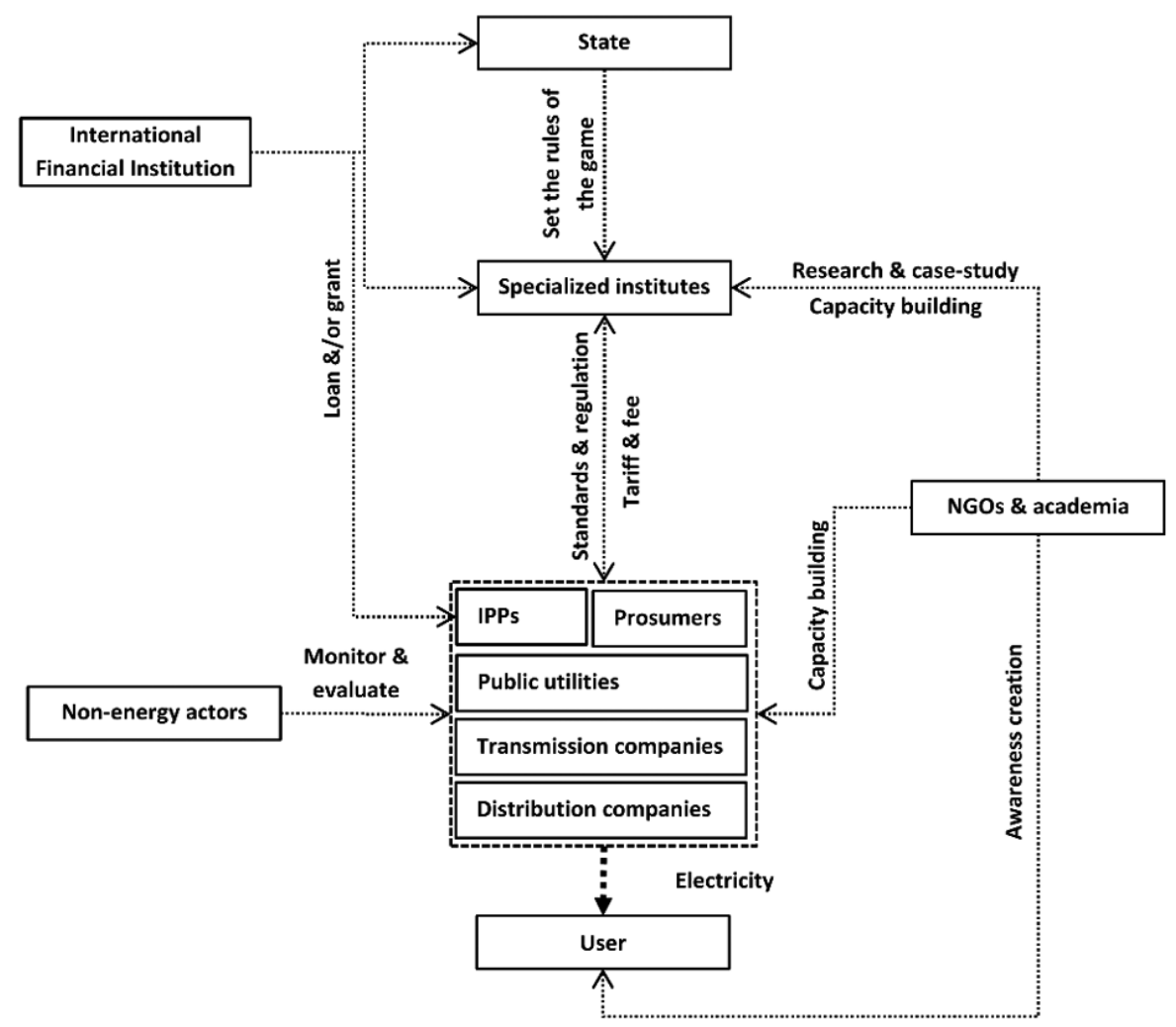

Figure 25: Simplified institutional structure of off-grid electrification systems

\subsubsection{Existing regulatory instruments to stimulate off-grid systems}

The case-study countries have developed several regulatory instruments to address the barriers listed in Section 4.3.2, including financial incentives (e.g. start-up grant, loan guarantee), fiscal incentives (e.g. exemption of import duty and/or value added tax), and elimination of market distortions (e.g. reducing fossil fuel subsidies) (see Table 15). Government grants are often provided to reduce the relatively high costs of renewable energy technologies that are still unaffordable for many consumers. 
Capital subsidy is one of the most widely adopted policy instruments to help off-grid projects overcome the initial investment barrier. In Ethiopia, the Solar Energy Foundation (SEF) provided $75 \%$ of the fund for a solar home system in rural settlements while the rest of the investment was covered by the beneficiary. The government of Ethiopia also provides duty exemptions for importing solar power related equipment. In Ghana, the government subsidized the cost of PV modules up to 500 Watt to beneficiaries of the national rooftop solar program, whereby the beneficiary purchases the rest of the balance of system (BoS) components such as batteries, inverter and charge controller. Several banks have expressed interest in providing loan facilities for the purchase of BOS components. Solar PV projects in Nigeria and Tanzania receive tax exemptions to soften the burden of the initial investment.

In some cases, special funds were set up to broaden financing channels for offgrid projects, and preferential interest rates were provided for loans for off-grid renewable energy development to deal with economic and financial barriers. In Tanzania, the Rural Energy Fund (REF) was established to provide grants to developers of rural energy projects and to utilities for rural grid distribution investments. In Ghana, the Scaling-up Renewable Energy Investment Plan (SREPIP) under the Climate Investment Fund provides large loans for renewable energy projects. Similarly, in Ethiopia, the Development Bank of Ethiopia (DBE) that, in partnership with the International Development Association (IDA) under the Electricity Network Reinforcement and Expansion Project (ENREP) of the World Bank, is providing working capital loans to private sector providers and microfinance to households. Solar crowdfunding is a new financing mechanism in which investment funds in solar systems are raised from individual investors through the internet, such as TRINE in Tanzania and Uganda. Operating \& maintenance subsidies are seen as essential to sustain the project operations over a long period, particularly in the case of extremely remote areas with a poor ability to pay. Micro-finance to rural households for Solar-Home-Systems has been successfully implemented in Ethiopia. Table 15 presents the different regulatory measures implemented or being implemented in the case-study countries to address some of the challenges to wider deployment of renewable energy based decentralized systems discussed in section 4.3.2. 


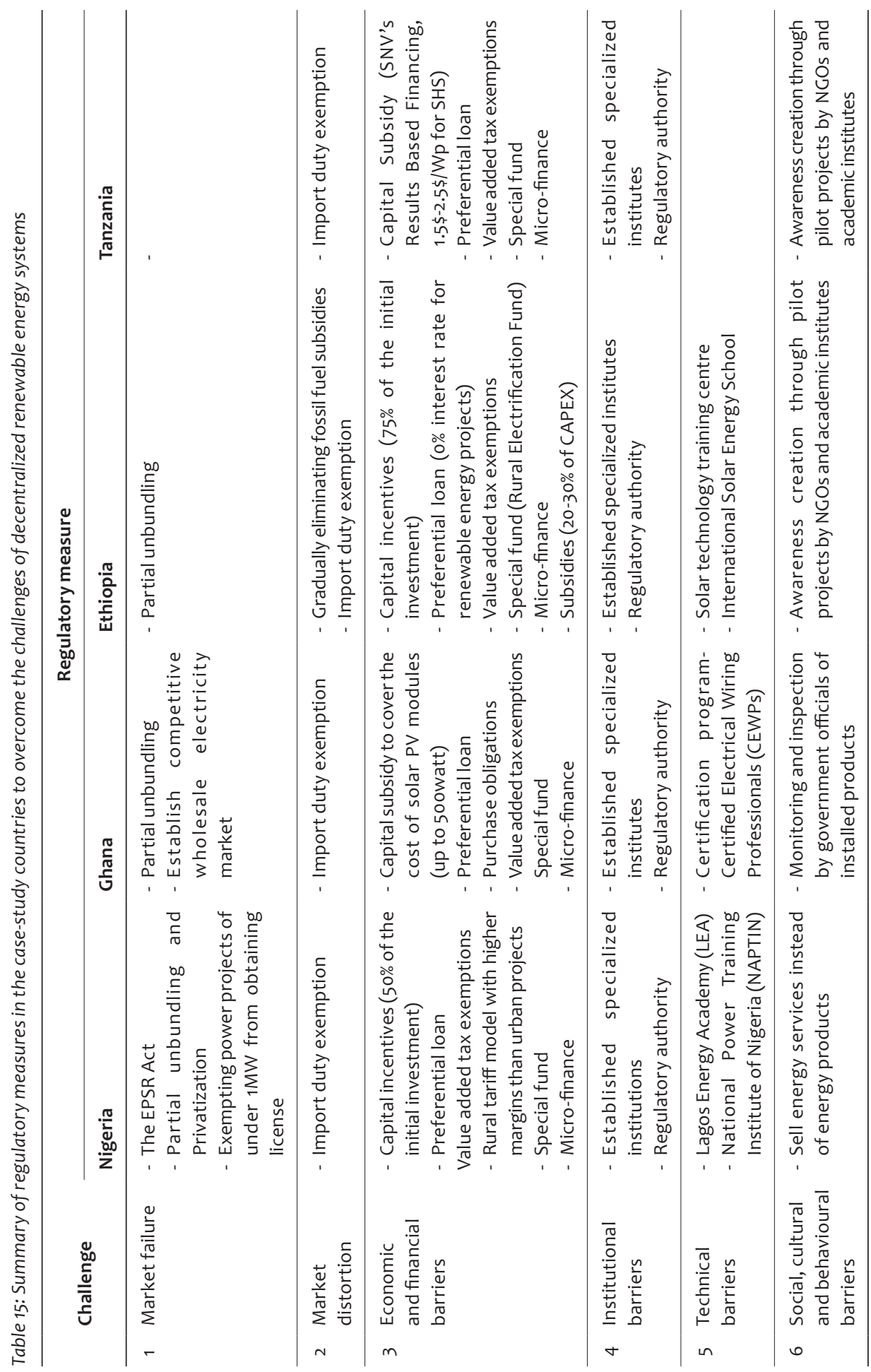




\subsection{Discussion}

In this chapter we aimed to provide relevant policy recommendations to facilitate universal electricity access in SSA. Our approach combined desk research, iterative discussions with experts, and stakeholder interviews in four case-study countries. First, an overview of the institutional transformation required to tackle the barriers to wider deployment of decentralized electrification systems has been generated. Next, a set of alternative storylines was developed in expert workshop to explore the evolving role of old and new actors in the electricity system. We also identified the relevant actors and explored their perspectives on the challenge for universal electricity access and the role of decentralized systems in SSA. Finally, we have identified regulatory measures in the case-study countries that are implemented to overcome these barriers. We have not explored if these measures are economically optimal solutions, nor what their effects on other sectors of the economy could be.

Despite the social and economic differences of our case-study countries, there is little difference in the development of the power sector. In all the case-study countries, the system is similar to what is described under storyline-1: structured top-down with little room for new players. This system has not been able to increase access at the scale required to achieve the universal access target. A slow transformation to what is described under storyline-2 takes place to accommodate new actors and their resources. However, the pace of this transformation has been very slow. While generation, transmission and distribution are unbundled in all countries, it is only in Nigeria where power generation within the central grid is privatised. Decentralized off-grid options provided through specialized institutions such as rural electrification agencies are growing in importance in all countries. These institutions facilitate the expansion of the systems through market development involving private sector and other stakeholders. Several regulatory instruments are employed by governments to tackle the barriers for increasing access to electricity, ranging from financial incentives to restructuring of the electricity governance at all levels.

Considering the urgency of the matter, bottom-up decentralized electrification is ideal for accelerating universal access to electricity in poor rural areas. However, the institutional structure still lacks incentives for innovations in technology and business model to improve access at the speed required to achieve the universal 
access target. The regulatory agencies not only have limited capacity but also lack political independence. In most cases, there is no clear role for community organizations, donors, academic institutions and NGOs. Despite the ongoing reform, institutional and economic barriers will, at least in the short and medium term, hinder the progress in renewable energy technology deployment and, hence, universal electricity access in SSA.

From the desk research and stakeholder interviews, we identify lack of overarching plans and approaches, lack of clarity in policies, and counterfeit products as major barriers that imped the expansion of decentralized systems. In addition, high upfront costs for consumers, a lack of access to finance for the private sector and consumers, a lack of awareness about renewable energy technology, lack of standards for new technologies, lack of coordination and cooperation between various actors, and high transaction costs are also identified as common barriers. Previous studies show that, if universal electricity access is to be achieved, much is expected from distributed renewable energy generation. This need for and the potentials of renewable energy technologies to achieve universal electricity access is recognized by private and public actors alike, but realizing the potential requires a much more radical change in the institutional settings of the energy sector in SSA.

\subsection{Conclusion and policy implications}

From our desk study, expert workshops and stakeholder interviews, we draw the following conclusion and policy recommendations:

\section{Upscaling off-grid systems requires stable and consistent policy frameworks and} clear technical standards and certification for new technologies. The results of the desk research and the stakeholder interviews demonstrate that the absence of overall plan and approach, lack of clarity in policies, and counterfeit products are the most common barriers shared by public and private actors and consumers. Achieving universal electricity access requires better collaboration and coordination between stakeholders to align data, finance and governance efforts. In our casestudy countries, however, the public sector lacks sufficient capacity (as observed in rural electrification agencies) to design policies, establish standards and monitor 
the process. Therefore, improved coordination between actors could increase the synergy of the various electrification programs and save resources.

Achieving universal access to electricity through the integration of off-grid systems requires innovative revenue schemes, financial and fiscal incentives and elimination of market distortions. Addressing the financial capacity problem identified by the interviewees requires a broader participation of non-governmental actors. Private sector participation in both the central and decentralised systems in our casestudy countries is limited. Increasing participation of non-governmental actors requires differentiated financing schemes, such as public private partnerships, participation of community-interest companies, and low-profit and for-benefit corporations working together. Stable and transparent policies and government support are important to encourage the private sector. At the same time, lowering the transaction cost by making reliable data for weather, household consumption, and ability to pay readily available, could stimulate the private sector participation.

Stakeholders could facilitate low interest loans to stimulate the development of decentralized electricity systems, but at the risk of leading to corruption. As showed by the results of the stakeholder interviews, fiscal incentives are the preferred stimulation package by governments of our case-study countries. These incentives represent a major component of public policies to stimulate off-grid electrification. All the case-study countries provide exemptions for import tax and value-added tax for renewable energy technologies. Providing loans at preferential interest rates compared to the market can help stimulate access to electricity and the dissemination of renewable energy technology. However, these instruments are not yet well developed and can lead to corruption and inefficient bureaucracies.

\subsection{Acknowledgements}

The authors would like to thank Prof.dr.ir. Eefje H.W.J. Cuppen (Professor of Governance of Sustainability at Leiden University) who provided valuable contribution to the research methodology. We are also grateful for Professor Peter Newell (Professor of International Relations at the University of Sussex) and Professor Harriet Bulkeley (professor in the Department of Geography at 
the University of Durham) for their participation in the workshops, their valuable comments to the content of this chapter and the contribution of their 'The Rising Powers' project to this article. We also thank Paul L. Lucas (senior researcher at PBL Netherlands Environmental Agency) for his comments in the earlier versions of the chapter that greatly improved the final product.

The research presented in this chapter was funded by the Dutch Ministry of Foreign Affairs, through its Directorate-General of Trade and International Cooperation. The work also benefitted from the funding of the European Horizon 2020 research programme CD-LINKS [grant agreement No 642147].

\subsection{Future work}

The next step is to translate the qualitative storylines and the governance instruments identified in this chapter to a quantitative simulation model. 



\section{Scenario analysis for promoting clean cooking in Sub-Saharan Africa: costs and benefits}




\section{Abstract:}

Nearly 900 million people in SSA rely on traditional biomass (wood, charcoal, dung, or agricultural residues) for cooking. This has major health consequences, as inefficient and incomplete combustion of traditional biomass is associated with high levels of hazardous air pollutants. In this chapter, we present several scenarios for the development of (clean) cooking solutions in SSA assuming specific policy options or specific transition pathways towards universal access by 2030. The scenarios consider historic developments, availability of fuels and infrastructure, required investments, and trade-offs and synergies related to health, biodiversity and climate change. For this purpose, we use the IMAGE modelling framework, where the global energy model TIMER (specifically the household energy model REMG), the IMAGE-LandManagement model, and the GISMO health model form integral parts. The results show that, in the absence of coordinated actions, enabling policies and scaled-up finance, the number of people in SSA relying on traditional biomass cookstoves could amount to $660-820$ million by 2030 (50-60\% of the population). Phasing out traditional biomass has considerable social, environmental and economic benefits, and could lead to lower total fuel expenditures. However, investments in cookstoves need to be quadrupled relative to baseline.

\section{Highlights}

- Baseline trends leave a billion people without access to modern cooking fuels

- Phasing-out traditional biomass may lead to lower total cost of cooking

- Clean cooking solutions could save the lives of 100 thousand children in 2030

- Harvesting biomass for cooking increases the risk of local forest degradation

- Halting the use of traditional biomass cuts emissions from cooking by at least half

Published article: Dagnachew, A. G., Hof, A. F., Lucas, P. L., \& van Vuuren, D. P. (2020). Scenario analysis for promoting clean cooking in Sub-Saharan Africa: Costs and benefits. Energy, 192, 116641. 


\subsection{Introduction}

Nearly 900 million people in SSA rely on traditional biomass (wood, charcoal, dung, or agricultural residues) for cooking [132]. This has major health consequences, as inefficient and incomplete combustion of traditional biomass is associated with high levels of hazardous air pollutants, including carbon monoxide and fine particulate matter [12]. The evidence links household air pollution (HAP) from cooking with solid fuels to over 390 thousand premature deaths in SSA in 2017, 35\% of the deaths occurring amongst children under 5 years of age [13].

The use of fuelwood and charcoal also exerts a large pressure on local and regional environments, including deforestation, forest degradation and destruction [133, 134], and soil degradation and erosion [135]. In addition, residential biomass burning contributes to climate change through black carbon emissions [136] and, when the biomass used is harvested unsustainably, through net $\mathrm{CO}_{2}$ emissions [137]. Shifting to clean cooking fuels and technologies therefore has both social and environmental benefits, which is internationally recognized through Sustainable Development Goal (SDG) target 7.1 (achieving universal access to affordable, reliable, and modern energy services).

Long-term targets require decision-making that considers plausible future outcomes and their potential implications. Model-based scenarios can be used for this, informing policymakers how a transition to clean cooking solutions could take place. Some studies have already explored scenarios for clean cooking access in various regions. Pachauri, van Ruijven [138] assess investments requirements and impacts of achieving universal access to clean-combusting cooking fuels and stoves by 2030 using two alternative modelling frameworks. Cameron, Pachauri [87] quantified the costs of supporting policies to make universal access to clean cooking affordable in South Asia. Fuso Nerini, Ray [139] compare various cooking solutions on the basis of 'levelized cost of cooking a meal' in Nyeri County, Kenya. Pachauri, Rao [140] use a model to simulate future pathways of clean cooking uptake and the outlook for achieving SDG 7.1 in Guatemala, Honduras and Nicaragua. Although these studies looked at access to clean cooking in various scales and contexts, the possible development routes for clean cooking in SSA, one of the regions where the use of traditional fuels is prevalent, have not been sufficiently explored. This 
study addresses that gap by exploring several policy options and pathways towards universal access to clean cooking solutions in SSA, and analyses the consequences of these options and pathways for cookstove and fuel costs, health, wood demand, and emissions. In addition to providing long- and short-term policy insights, the study contributes to existing academic literature by assessing the synergies and trade-offs between various SDGs in the context of universal energy access in SSA.

In this chapter, we present two sets of scenarios for promoting cooking solutions in SSA. In the first set, specific policy measures are introduced to analyse the effectiveness and consequences of these policies. In a second set, the scenarios are set up in such a way that access to clean cooking solutions for all households in SSA is achieved by 2030 using a back-casting method. This set of scenarios provides insight into the requirements and consequences of achieving certain predefined targets for clean cooking. The scenarios are developed using the IMAGE framework [42]. More specifically, extended versions of the residential sector end-use models REMI [141] and REMG [38] within the IMAGE framework are used. The scenarios consider historic developments and the availability of fuels and infrastructure, and show required expenditures in both capital (i.e. cookstoves) and fuels, impacts on child health, wood demand, and greenhouse gas emissions. The main objective of this scenario analysis is to provide insight in to the role of different cooking technologies, the investment needs and the fuel cost in achieving universal access to clean cooking in SSA, as well as to assess the consequences of different scenarios for biodiversity, health, and the climate.

The chapter is organised as follows. Section 5.2 provides the methodology, including the main assumptions on costs of and emissions from fuels \& technologies included in the study and the scenario descriptions, followed by section 5.3 that presents the results. Section 5.4 contains the discussion and section 5.5 concludes with policy recommendations.

\subsection{Methodology}

Our study relies on the IMAGE model [42] and its sub-models to provide an integrated and systemic view on modern cooking solutions. This section discusses the current 
situation, the different modules used in our analysis, the most relevant technology costs and socioeconomic assumptions, and presents a description of the scenarios.

\subsubsection{Current use of cooking fuel in SSA}

In SSA nearly 900 million people relied on solid biomass as their primary cooking energy source in 2016 (Figure 26). Nearly a quarter of that was charcoal, the rest being firewood (73\%), dung (2\%) or crop residue ( $1 \%$ ), mainly used in inefficient stoves or traditional three-stone fires. This is a decline of a meagre $3 \%$-points since 2000 [119]. The use of traditional biomass is particularly dominant in poor rural settlements because of either its low cost, sometimes collected for free [142], the lack of available alternatives [143], or cultural factors (e.g. preferences and taste) [144]. After biomass, kerosene is the second most prevalent fuel used for cooking in SSA, particularly in urban areas. In 2016, $12 \%$ of the urban and $4 \%$ of rural households in SSA used kerosene as the main cooking fuel. In the same year, LPG was the primary cooking fuel for $10 \%$ of SSA urban households. LPG and natural gas are barely used in rural areas, mainly due to lack of distribution systems [145] and the relatively high and fluctuating price of the fuel in combination with very low-income levels [146]. Finally, electricity, the cleanest cooking solution with respect to HAP, is primarily used in Southern Africa.

There are similarities and considerable differences between the sub-regions (Figure 26). The share of traditional biomass cookstove use is similar between western \& central Africa and eastern Africa, and slightly lower in the rest of southern Africa. Kerosene has a relatively large share in western \& central Africa and the Republic of South Africa, improved cookstoves are more prevalent in eastern Africa, and electricity is used often in southern Africa. The share of LPG is the largest in the rest of southern Africa. 


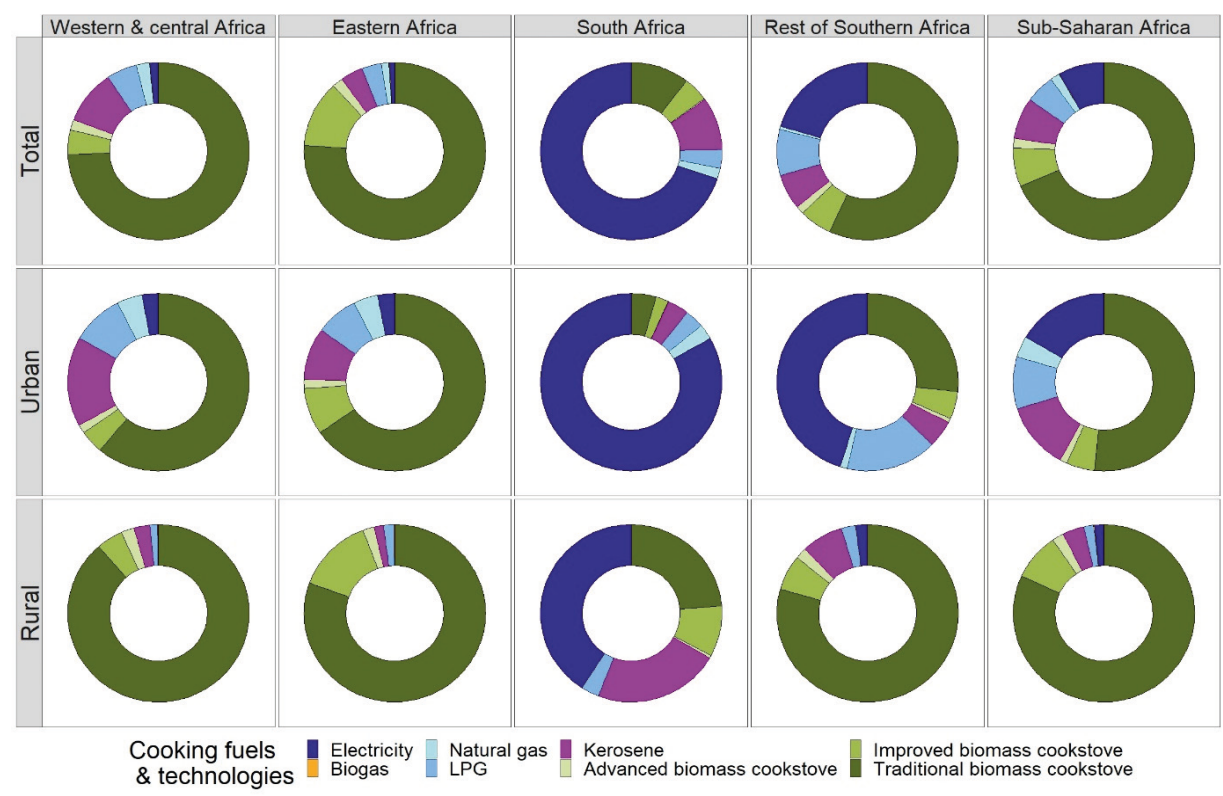

Figure 26: Regional cooking energy mix in 2016 in SSA [147, 148]

\subsubsection{Model description}

For the scenarios analyses the IMAGE 3.0 integrated assessment modelling framework [42] is used, which includes the TIMER energy-system simulation model [2], IMAGE-LandManagement [43] and the GISMO health model [44, 45]. The IMAGE framework is a suite of simulation models that together represent interactions between society, the biosphere and the climate system to assess sustainability issues such as climate change, biodiversity loss and human well-being. The model includes a detailed description of the energy and land-use system and simulates socio-economic and environmental parameters on a geographical grid of 30 by 30 min or 5 by $5 \mathrm{~min}$ (around $50 \mathrm{~km}$ and $10 \mathrm{~km}$ at the equator, respectively), depending on the specific variable. The IMAGE 3.0 modelling framework has been used in similar studies in the past and the results are published in peer reviewed articles $[38,43,149-152]$.

The TIMER model describes demand and supply of key energy carriers for 26 world regions [2]. Important issues that can be addressed with the model include transitions to modern and sustainable energy supplies, energy access, future 
demand projections, the role of the energy conversion sector and various energy technologies in achieving a more sustainable energy system, and computing emissions of greenhouse gases related to energy conversion.

The mix of cooking fuels and technologies is determined with REMG, which is part of the TIMER model [38]. REMG is a stylized bottom-up simulation module, which describes energy demand for cooking (and other residential end-use functions such as water heating, space heating, space cooling and appliance use ) [38] (Figure 27). The model describes household energy demand and the fuel mix for five income classes, for both rural and urban households. Cooking energy demand is primarily driven by population size and household income (Figure 27). The cooking fuel and technology options include: mineral coal, traditional biomass (in combination with traditional and improved cookstoves), modern biomass (in combination with advanced cookstoves), kerosene, LPG, biogas, natural gas and electricity. The model uses a capital vintage model for the stock of stoves. Shares of different stoves in the cooking energy mix are the result from additional purchases and depreciation after the technical lifetime. The cooking technology mix serves as input to the other modules to determine the capital cost, the fuel expenditure, the health impact and the environmental impact.

The capital costs and annual fuel expenditure are determined based on the market shares of the different cooking technologies and their efficiencies. Market shares of purchases are determined using perceived costs of different cooking technologies with a multinomial logit allocation. It thereby assigns the largest market share to the cheapest energy technologies, while technologies that have higher costs get lower shares, considering heterogeneous local characteristics where relevant. The perceived costs include monetary and non-monetary costs. The monetary costs are the sum of the capital costs and the operating (fuel and maintenance) costs. The annualized capital costs are determined by the cost of the cooking technology and accessories and consumer discount rates. The discount rates are higher for lowincome households and decrease with income. The non-monetary costs represent the fact that fuel choice is not only the product of economic factors alone; especially in poorer households where cultural aspects, lack of awareness on advantages of cleaner fuels, and the opportunity cost of traditional biomass play important roles. It 
is assumed that the non-monetary costs for traditional fuels (i.e. biomass, kerosene) increase with income. More details on REMG are presented in Annex D.

GISMO is used to determine the health impacts of the cooking energy mix in the different scenarios. The health model describes the causal chain between health-risk factors, morbidity and mortality, based on a multi-state approach, distinguishing risk exposure, disease incidence and death [44, 45]. The GISMO model is used to assess future developments in child mortality attributable to HAP, focussing on acute lower respiratory infections (ALRI). The model is updated to total ALRI incidence and mortality data and technology specific of the Global Burden of Disease study 2017 [13]. Exposure specific Relative Risk (RR) ${ }^{1}$ are used to relate the use of specific cooking technologies to increased risk of ALRI incidence and death [13] (see Table 16). Important inputs for these calculations are the household cooking energy mix from REMG, age-specific population projections and per capita GDP projections.

IMAGE-LandManagement model [43] is used to determine potential biomass supply. The demand for fuelwood relative to the potential supply from natural regrowth is an indicator for the risk of additional deforestation. The total wood supply (ton dry matter/year) is determined based on the potential growth of stems and branches in natural vegetation, excluding projected natural area, cropland, grazing land or built-up areas. Demand for wood is calculated based on the cooking energy mix for the different scenarios, a wood-to-charcoal conversion efficiency of 20\%, a wood-tofirewood conversion efficiency of $100 \%$, and the energy content of energy carriers as given in Table 17.

1 RR ratios indicate the increased risk of illness or mortality while exposed to a certain risk factor, as compared to a situation with no increased risks (i.e. no household air pollution, $R R=1$ ). 


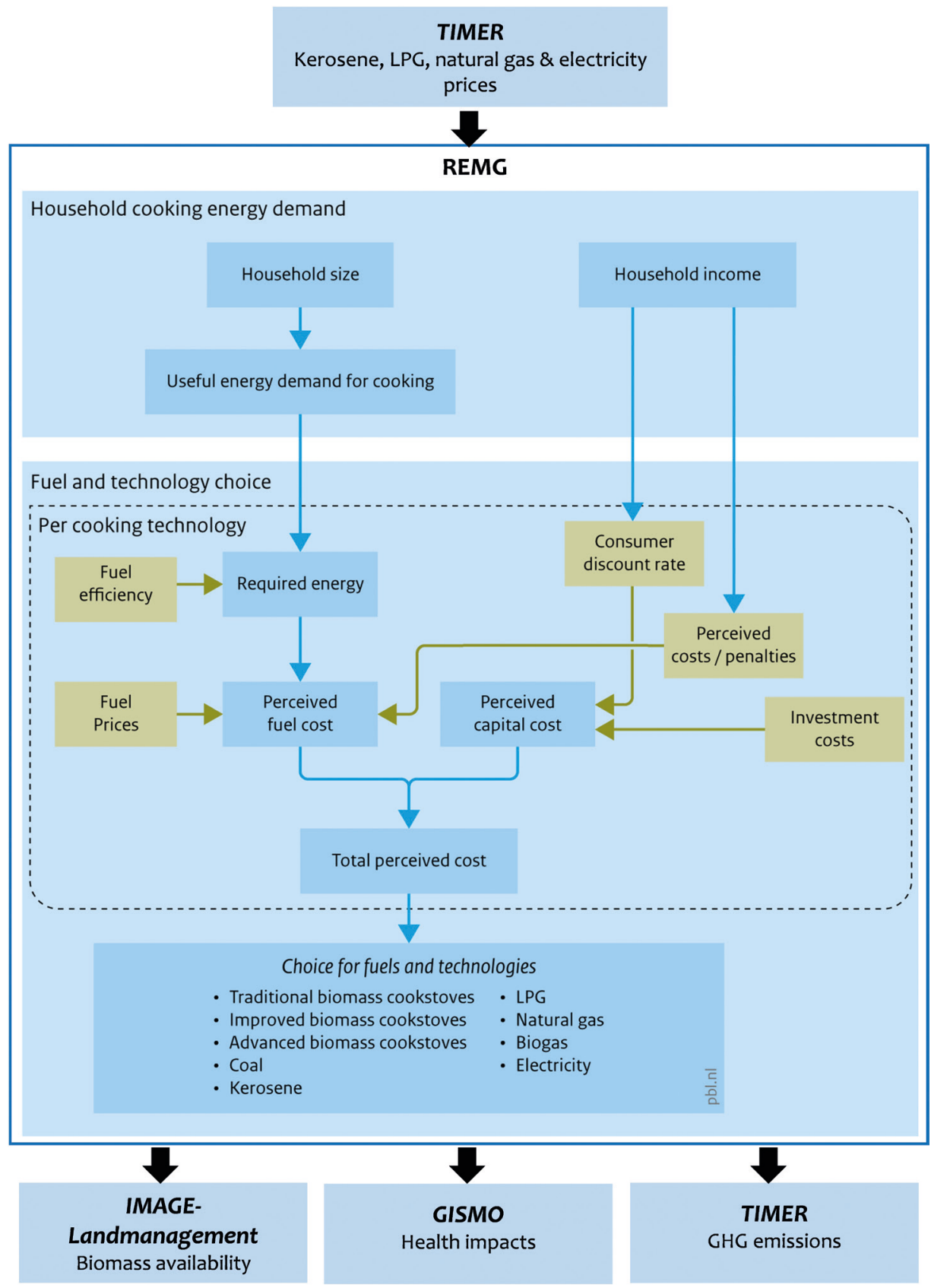

Figure 27: Cooking fuel and technology choice drivers in REMG and interaction with other sub-models (adapted from Daioglou et al., 2012) 


\subsubsection{Technology and cost assumptions}

Here we summarize most important assumptions on technology performances and cost. These assumptions are based on previous studies. A detailed description of the assumptions and their respective sources can be found in Annex D. The most important assumptions in the REMG model are the useful energy demand for cooking, and current and future costs of fuels and cookstoves, which together with household per capita income levels, determine the choice for cooking technologies in the model.

The amount of useful energy needed for cooking is an important assumption for determining the technology choice, which in turn, determines associated capital investments and fuel expenditures. The amount of energy that a household requires for cooking has been the subject of numerous studies. However, large difference are found in the estimates, ranging from $0.36 \mathrm{MJ} /$ capita/meal [153] to $6 \mathrm{MJ} /$ capita/ meal [154]. Daioglou, van Ruijven [38] found no statistically significant relationship between energy for cooking and income or geographical region. Hence, a constant value of $3 \mathrm{MJ} /$ capita/day (the literature mean) of useful energy for all households and regions is used. To address this uncertainty, we have presented the impact of useful energy demand on the cooking energy mix in SSA in Annex D (from which it can be concluded that the shares of cooking technologies and fuels are not sensitive to the level of useful energy needed).

Table 16 presents assumed current and future average capital cost (stove and accessory costs) and the annual average operating cost (fuel and maintenance costs) of the cooking fuel and technology combinations included in the model. These costs can differ per region and settlement. The values provided in the table are averages across the whole of SSA.

Other important assumptions include the conversion efficiencies of the fuels and technology related to $\mathrm{PM}_{2.5}$ concentrations (see Table 16). The conversion efficiencies determine secondary energy demand (e.g. amount of wood for traditional biomass), and thereby the operating cost as well as potential environmental consequences. Technology related 24-hour $\mathrm{PM}_{2.5}$ concentration determine exposure to HAP and are used to calculate related child mortality due to ALRI. For the conversion efficiencies, average field values are used for 2015, which improve linearly to maximum laboratory 
levels in 2050 as given in Table 6 of Kaygusuz [155] and figure 11.2 of World Bank [156]. For average $\mathrm{PM}_{2.5}$ concentrations, the average values reported in figure 11 of World Bank [156] is used in 2015, linearly declining to the lowest value in 2050.

Table 16: Assumptions on Conversion efficiencies [155, 156], health effects [156], and average costs [157-159].

\begin{tabular}{|c|c|c|c|c|c|c|c|c|c|}
\hline \multirow[t]{2}{*}{ Fuel } & \multirow[t]{2}{*}{ Cookstove technology } & \multicolumn{2}{|c|}{$\begin{array}{l}\text { Conversion } \\
\text { efficiency } \\
(\%)\end{array}$} & \multicolumn{2}{|c|}{$\begin{array}{c}\text { 24-hour PM2.5 } \\
\text { concentrations } \\
\left(\mu \mathrm{g} / \mathrm{m}_{3}\right)\end{array}$} & \multicolumn{2}{|c|}{$\begin{array}{c}\text { Capital } \\
\text { cost (USD) }\end{array}$} & \multicolumn{2}{|c|}{$\begin{array}{l}\text { Average annual } \\
\text { operating cost } \\
\text { (USD)2 }\end{array}$} \\
\hline & & 2015 & 2030 & 2015 & 2030 & 2015 & 2030 & 2015 & 2030 \\
\hline Traditional & Traditional cookstove & 12 & $14^{3}$ & 500 & 500 & 0.5 & 0.5 & 91 & 69 \\
\hline biomass & Improved cookstove & 30 & 33 & 200 & 150 & 25 & 20 & 35 & 28 \\
\hline $\begin{array}{l}\text { Modern } \\
\text { biomass }\end{array}$ & Advanced cookstove & 40 & 47 & 75 & 60 & 65 & 51 & 108 & 84 \\
\hline Mineral Coal & Improved coal cookstove & 25 & 25 & 200 & 150 & 25 & 25 & 62 & 72 \\
\hline Kerosene & Kerosene stove & 35 & 44 & 50 & 40 & 20 & 20 & 271 & 223 \\
\hline LPG & Single burner & 50 & 58 & 20 & 10 & 55 & 39 & 159 & 139 \\
\hline Natural gas & Gas stove & 50 & 57 & 0 & 0 & 55 & 39 & 103 & 82 \\
\hline Biogas & Gas stove \& digester & 40 & 50 & 0 & 0 & 550 & 430 & 9 & 8 \\
\hline Electricity & Electric/induction & 75 & 86 & 0 & 0 & 70 & 55 & 246 & 198 \\
\hline
\end{tabular}

Finally, the GHG emissions from mineral coal, biomass, kerosene, LPG, and natural gas are calculated based on the emission factor given in Table 17. and the total energy input required to produce the desired amount of useful energy. For electricity, the GHG emissions are calculated based on the required secondary energy input and the regional baseline projections of emissions from electricity production (that includes efficiency and transmission losses). For biomass cookstoves, it is assumed that the net $\mathrm{CO}_{2}$ emissions at the point of combustion of fuelwood is zero if it is sustainably harvested. Based on the estimates from FAO [160], we assume that a third of the fuelwood is harvested unsustainable and hence adds $\mathrm{CO}_{2}$ emissions to the atmosphere. In this study, we consider the most important GHG emissions that include $\mathrm{CO}_{2}, \mathrm{CH}_{4}, \mathrm{~N}_{2} \mathrm{O}$, black carbon (BC) and organic carbon (OC).

2 Data includes interpolations

3 Traditional biomass cookstove includes various self-made cookstoves ranging from three-stone fire to basic mud stoves, and we assume that the use of three-stone fire declines in the future 
Chapter 5

Table 17: Energy content and emission factors of cooking fuels [161, 162]

\begin{tabular}{lll}
\hline Fuel & Energy content & CO $^{2}$ emission factor \\
\hline Mineral Coal & $46 \mathrm{MJ} / \mathrm{kg}$ & $238 \mathrm{~kg} / \mathrm{GJ}$ \\
Firewood, air dried (15\% moisture) & $16 \mathrm{MJ} / \mathrm{kg}$ & $217 \mathrm{~kg} / \mathrm{GJ}$ \\
Charcoal & $30 \mathrm{MJ} / \mathrm{kg}$ & $218 \mathrm{~kg} / \mathrm{GJ}$ \\
Kerosene & $43 \mathrm{MJ} / \mathrm{kg}$ & $126 \mathrm{~kg} / \mathrm{GJ}$ \\
Liquefied Petroleum Gas (LPG) & $45.5 \mathrm{MJ} / \mathrm{kg}$ & $67 \mathrm{~kg} / \mathrm{GJ}$ \\
Natural gas & $38 \mathrm{MJ} / \mathrm{m}^{3}$ & $56 \mathrm{~kg} / \mathrm{GJ}$ \\
Bio-gas & $22.8 \mathrm{MJ} / \mathrm{m}^{3}$ & $4 \mathrm{~kg} / \mathrm{GJ}$ \\
Electricity & $3.6 \mathrm{MJ} / \mathrm{kWh}$ & $70-250 \mathrm{~kg} / \mathrm{GWh}^{2}$ \\
\hline
\end{tabular}

\subsubsection{Scenario descriptions}

The scenarios have been designed based on iterative discussions with relevant stakeholders that include governments, practitioners, aid organizations and the private sector ${ }^{4}$. Two sets of scenarios are assessed: policy scenarios and target scenarios (Table 18).

Table 18: Names and descriptions of the scenarios for SSA

\begin{tabular}{|c|c|c|}
\hline Scenario set & Scenario name & Short description \\
\hline $\begin{array}{l}\text { Baseline } \\
\text { scenario }\end{array}$ & Baseline & $\begin{array}{l}\text { Reference scenario without specific policies to stimulate clean cooking } \\
\text { under SSP2 socio-economic projections. }\end{array}$ \\
\hline \multirow{3}{*}{$\begin{array}{l}\text { Policy } \\
\text { scenarios }\end{array}$} & $\begin{array}{l}\text { Cookstove } \\
\text { subsidy }\end{array}$ & $\begin{array}{l}\text { A } 50 \% \text { subsidy on the retail prices of improved and advanced cookstoves, } \\
\text { but no subsidy on fuel. }\end{array}$ \\
\hline & $\begin{array}{l}\text { Biogas digester } \\
\text { subsidy }\end{array}$ & A $50 \%$ subsidy on the retail price of biogas digesters. \\
\hline & $\begin{array}{l}\text { Enhanced fuel } \\
\text { distribution }\end{array}$ & $\begin{array}{l}\text { A fraction of LPG and (liquid) natural gas required for cooking is } \\
\text { provided by infrastructure support or subsidy ( } 40 \% \text { in urban areas and } \\
100 \% \text { in rural areas), leading to lower gaseous fuel prices for the final } \\
\text { consumer (by on average } 20-30 \% \text { for LPG and by } 30-50 \% \text { for natural gas). }\end{array}$ \\
\hline
\end{tabular}

4 The scenarios have been discussed at the clean cooking forum 2017 in Delhi, at SNV during a cooking experts meeting, and a Dutch SPARK meeting in The Hague. 
Table 18: Names and descriptions of the scenarios for SSA (continued)

\begin{tabular}{lll}
\hline Scenario set & Scenario name & Short description \\
\hline & $\begin{array}{l}\text { Notraditional } \\
\text { cookstoves }\end{array}$ & $\begin{array}{l}\text { A complete phase out of solid biomass in combination with } \\
\text { traditional cookstoves and kerosene cookstoves by } 2030 .\end{array}$ \\
Target & Modern fuel & A complete phase out of solid biomass, kerosene and mineral coal by 2030. \\
scenarios & $\begin{array}{l}\text { Electric } \\
\text { cooking }\end{array}$ & $\begin{array}{l}\text { A complete phase out of solid biomass, kerosene and mineral coal by } \\
2030 \text { and households cooking on electricity will use } 50 \% \text { less energy } \\
\text { due to changes in cooking behaviours. LPG, natural gas and biogas will } \\
\text { remain as cooking options. }\end{array}$ \\
& &
\end{tabular}

Note: extended description of the scenarios can be found in Annex D.

The policy scenarios have been designed to assess the effect of specific policy interventions that stimulate the adoption of cleaner cooking fuels/technologies. Specifically, the following policies are assessed: a biomass cookstove capital subsidy, a biogas digester capital subsidy, and a modern fuel (LPG and natural gas) distributions system subsidy.

The target scenarios are designed to show different pathways to achieve the SDG target of universal access to clean and modern cooking energy in SSA. These scenarios arise from the need for radical measures to meet the SDG7 target of achieving universal access to clean and modern energy. We consider low-emission biomass cookstove, such as improved and advanced biomass cookstoves, transitional technologies that are beneficial to health and the environment. As such, we examined two overall pathways: a complete phase out of traditional biomass cookstoves by 2030 (No traditional cookstoves) and a complete phase-out of solid biomass (Modern fuel) by 2030. Additionally, for the latter pathway we have developed a scenario in which we assumed a change in cooking behaviour (a switch to pre-cooked food or low energy intensive diet) for all households that cook on electricity - leading to a 50\% reduction in final energy use (Electric cooking).

All scenarios are based on the SSP2 socio-economic pathway that assumes medium projections for population growth, urbanization and economic development. In 2030, SSA population is projected to grow to more than 1.3 billion [93], average GDP per capita to more than USD 3700 [94], and urbanization to nearly 50\% [95]. The sensitivity of socio-economic drivers on baseline developments is analysed in Annex D. 


\subsection{Results}

This section provides the results for policy scenarios and target scenarios relative to the SSP2 baseline results. The scenarios are discussed in terms of future developments in the use of cooking fuels and technologies, related fuel and capital cost of stoves and accessories, and their implications on child mortality, the risk of forest degradation and deforestation, and GHG emissions. The results presented in this chapter focus on 2030, the target year for the SDGs. However, for the policy scenarios, we found that the progress after 2030 is interesting as well. Projections to 2050 are therefore presented in Annex D.

\subsubsection{Cooking fuels and technologies}

The baseline projection shows a moderate switch away from traditional cookstoves by 2030 .The share of the population relying on traditional biomass cookstoves declines from $70 \%$ in 2016 to $55 \%$ in 2030 (in absolute numbers increasing from 700 to 730 million people) under the baseline. This scenario leaves over a billion people without access to modern cooking solutions (i.e. biogas, LPG, natural gas and electricity).

The policy scenarios lead to lower shares of traditional biomass use but none of them lead to achieving the SDG target. In the Enhanced fuel distribution and Cookstove subsidy scenarios, about 150 million less people cook with traditional biomass cookstoves by 2030 relative to baseline (see Figure 28), leaving 580 million people relying on traditional biomass cookstoves. The effect of a biogas digester subsidy on traditional cookstoves use is minimal by 2030, the results show that the increase of biogas use is relatively small in the short term (as the investment requirement remains large even with the subsidy) and that it mainly replaces LPG and improved and advanced cookstoves.

Under the baseline scenario, $20 \%$ of the population cooks with modern fuels by 2030. The Enhanced fuel distribution scenario shows a higher share of modern fuels, with $30 \%$ of the population cooking on LPG or natural gas. As expected, the share of modern fuels in the Cookstove subsidy does not differ much from baseline, but the use of improved and advanced cookstoves is about twice as high as in the 
baseline. The shares of kerosene and electricity do not differ significantly between the baseline and policy scenarios.

After 2030, traditional biomass cookstoves use declines, mainly replaced by improved biomass cookstoves and LPG (see Annex D). This rapid decrease can be attributed to i) efficiency improvements of modern fuel-based technologies and improved and advanced cookstoves, ii) urbanization, and iii) the increase in household income. The impact of biogas subsidies also become considerable as household income increases and the price of digesters declines. The specific policies to promote clean cooking will accelerate the trend.

The target scenarios imply a strong deviation from the baseline, as more than half the population in SSA needs to transition to modern fuels. In the No traditional cookstoves scenario, more than half the population cook on biomass (either on improved or advanced cookstoves) and around a quarter use LPG in 2030, the rest covered with biogas, natural gas and electricity. In the Modern fuel scenario, an even more rapid transition is required. By 2030, liquid and gaseous fuels are used by $75 \%$ of the population. Biogas and electricity provide the rest of the population with clean cooking energy. If behavioural change for those households cooking on electricity is assumed (leading to a 50\% lower energy demand as they switch to per-cooked food or less energy intensive diet), the results change considerably: the share of electricity in the cooking energy mix is projected to increase to more than $55 \%$ by 2030 , as shown under the electric cooking scenario. This is due to the low annual energy demand and hence low fuel expenditure for electricity. The energy saving gained from cooking behaviour change is in addition to the autonomous efficiency improvement shown in Table 16. 


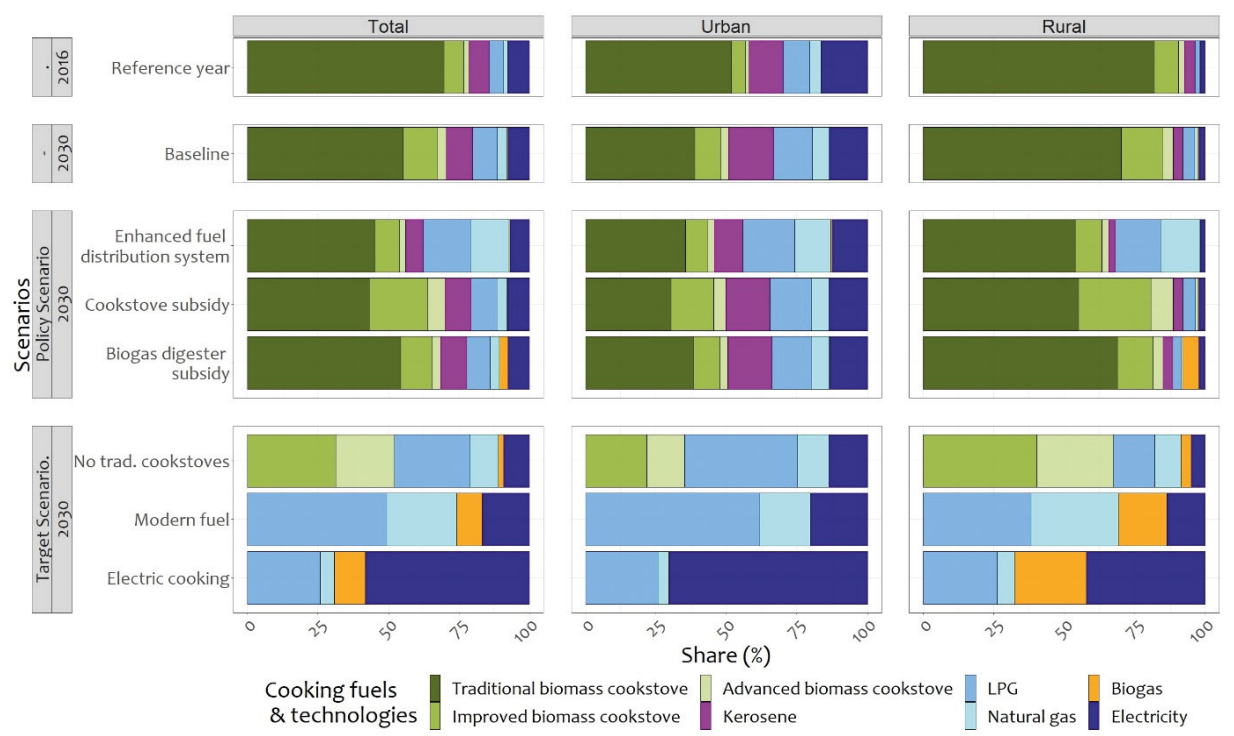

Figure 28: Cooking energy mix in SSA

\subsubsection{Capital cost and fuel expenditure}

The annual fuel expenditure for cooking outweigh the annual capital cost by far, both in the baseline and in the policy and target scenarios (Figure 29). In 2016, total annual fuel expenditure in SSA was about USD 23 billion, equalling USD 112 per household. Traditional biomass dominated the fuel expenditures with USD 14 billion (assuming average cost of USD 0.03 per kilogram for charcoal and firewood), followed by kerosene and electricity. In the baseline scenario, by 2030, total annual fuel cost is projected to increase to around USD 30 billion, equalling USD 100 per household. Most of the policy scenarios show similar total fuel expenditures as baseline by 2030, which is a direct consequence of small changes in fuel mix (see Figure 28). The only major difference is found in the Enhanced fuel distribution scenario, which shows a much higher expenditure in gaseous fuels, displacing biomass, kerosene, and also electricity. However, in this scenario, governments or other stakeholders facilitating access to modern fuel bear $10 \%$ of the fuel cost. The target scenarios show larger differences. Phasing out traditional cookstoves and kerosene leads to much lower average annual fuel cost, as more efficient biomass cookstoves are used and kerosene is expensive. However, if all biomass use is phased out (as in the modern fuel scenario), total fuel cost is projected to increase, as the cheap biomass used in improved cookstoves is being replaced by more expensive gaseous fuels 
and electricity. The electricity scenario shows lower annual fuel expenditure than most of the scenarios because of the lower energy use of the households cooking on electricity.

The total annual capital cost in the baseline scenario is 600 million USD in the period 2016-2030, equalling 2 USD per household. In the Cookstove subsidy scenario, the capital cost is projected to be only slightly higher than in the baseline. This is because traditional cookstoves are mostly replaced by improved cookstoves (see Figure 28), which are still relatively cheap compared to the modern cookstoves. The Biogas digester subsidy scenario does lead to much higher capital cost than in the baseline, because of the relatively high capital cost of biogas digesters. In the period 20162030, about a third of total capital cost consist of purchases of biogas digesters, even though the share of biogas in the energy mix is very small. The Enhanced fuel distribution scenario projects a small increase in capital cost compared to the baseline, mainly because the relatively expensive biogas digesters are replaced by LPG and natural gas. The target scenarios show considerably higher capital cost than the baseline in 2030, although in absolute terms the numbers remain low. In the No traditional cookstoves scenario, the capital cost is almost three times as high as in the baseline (1.6 billion annually) in the period 2016-2030. In the Modern fuel scenarios, the capital cost is four times as high as in the baseline in the same period. The capital expenditure under electric cooking scenario is similar to the modern fuel scenario as electric cookstoves replace both the expensive biogas digesters and the relatively cheaper options of LPG and natural gas cookstoves.

By 2030, no traditional biomass cookstoves scenario shows the lowest total cost, followed by the Electric cooking, Cookstove subsidy and Biogas digester subsidy scenarios. All these scenarios show lower annual cost for cooking than in the baseline. The Modern fuel scenario shows higher cost, especially due to relative high costs for gaseous fuels and electricity. The Enhanced fuel distribution scenario has the highest total cost of the three policy scenarios. This is due a very high share of gaseous fuels in this scenario, replacing cheaper options as a consequence of the fuel distribution enhancement. As a significant share of the cost will be paid for by public money in setting up the distribution network, the cost for the households are in fact the lowest of all policy scenarios. This implies that a large sum of public 
money is needed to enhance fuel distribution (about USD 3 billion by 2030). The capital expenditure in the period 2030-2050 in baseline and policy scenarios is four times the investment in the previous period driven by a rapid growing population and switches to LPG, natural gas and biogas cookstoves. More detail on projections after 2030 is presented in Annex D.

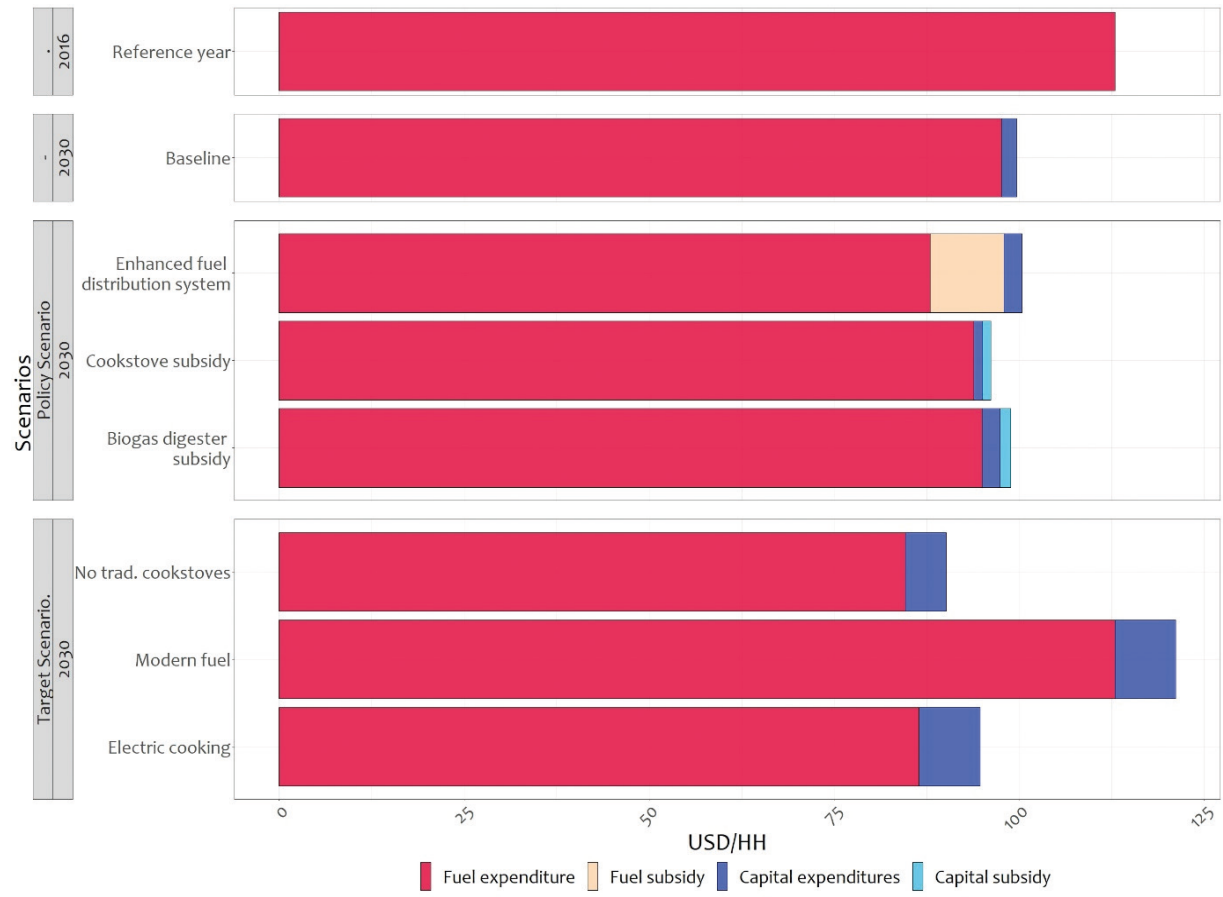

Figure 29: Household annual cooking fuel and capital expenditure in SSA

\subsubsection{Health impacts - Child mortality}

In 2010 in SSA, HAP was estimated to be responsible for more than $40 \%$ of total ALRI deaths in children under 5 [13]. In the baseline scenario, attributable child mortality reduces from around 225 thousand in 2016 to 135 thousand in 2030 (see Figure 30). The policy scenarios only show modest improvements in child mortality by 2030, as the share of biomass use on traditional stoves remains high. Furthermore, the reduction in the relative risk when switching from a traditional cookstove to an improved cookstove is only small, even though the concentration levels decrease substantially. Only the Enhanced fuel distribution scenario shows 
significant improvements (around 20\% relative to baseline), as biomass, mostly used in combination with a traditional stove, is partly replaced by LPG and natural gas with 90-99\% less $\mathrm{PM}_{2.5}$ emissions compared to open wood fires.

The three target scenarios show much higher impacts on child mortality. Currently, improved biomass stoves are in the range of Tier 0-2 emission standards and advanced biomass stoves in Tier 2-3. Only well-performing fan gasifiers and, to a lesser extent, natural-draft gasifier stoves approach the emission levels of LPG [156]. When phasing out the use of traditional biomass stoves, attributable mortality is reduced by around 50\% by 2030, compared to baseline levels. Also phasing-out biomass use in combination with improved and advanced cookstoves reduces attributable child mortality with 95-99\%, with a higher emphasis on HAP-free electric cooking further reducing attributable child mortality.

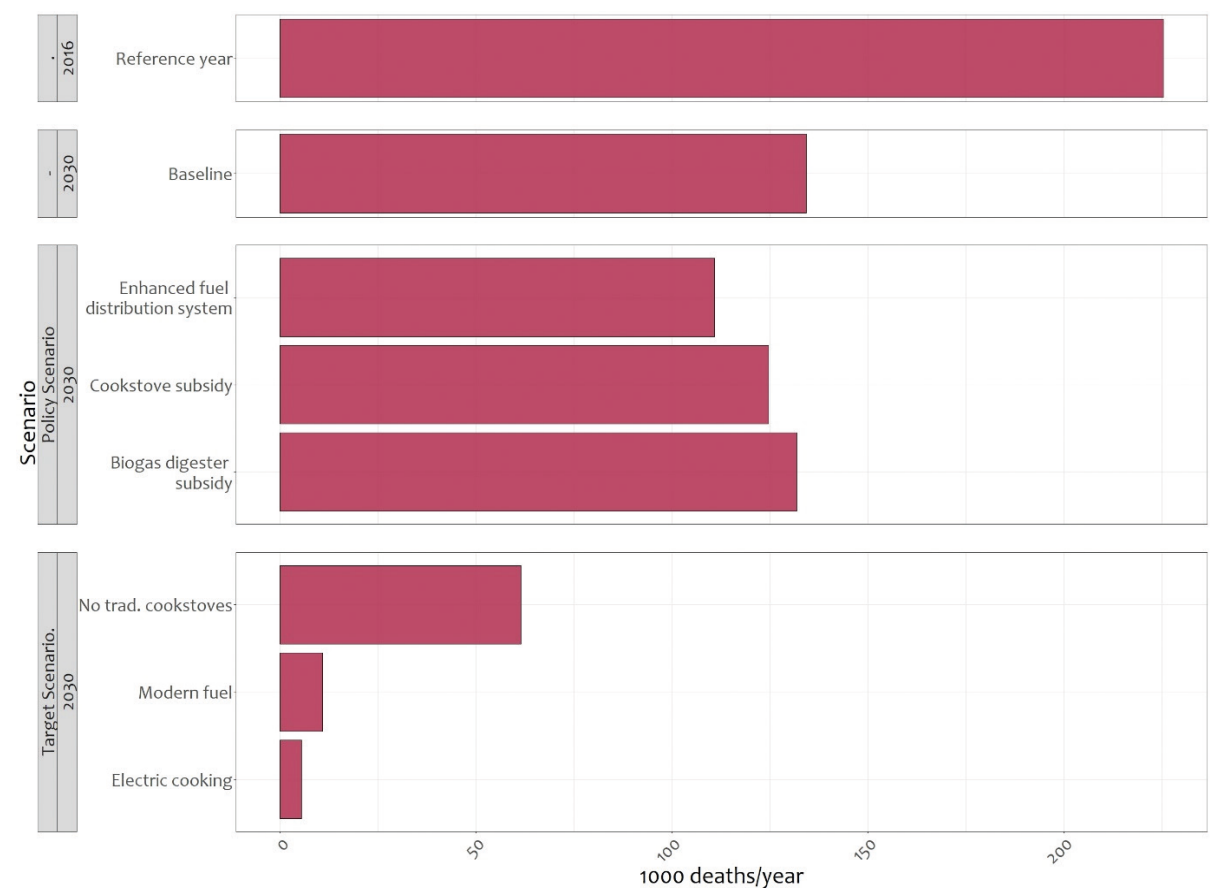

Figure 30: ALRI child death attributable to household air pollution in SSA 


\subsubsection{Risk of deforestation}

In 2016, the fuelwood demand in SSA was 498 million tons (203 million tons for charcoal and 295 million tons for firewood). In the baseline, the total demand for wood remains relatively constant in the short term (485 million tons, see Figure 31) and declines to 200 million tons by mid-century driven by a shift away from biomass and efficiency improvements due to i) shifts towards more efficient cookstoves and fuels, and ii) efficiency improvements of stoves themselves (see Figure 47 of Annex D). The policy scenarios show a slight decrease in fuelwood demand by 2030 , especially the Enhanced fuel distribution and Cookstove subsidy scenarios, which show a 12 and $17 \%$ decrease in fuelwood demand compared to baseline, respectively.

The target scenarios show a much higher impact on fuelwood demand. Phasing out traditional cookstoves implies that fuelwood demand (148 million tons) could be $70 \%$ less than the projected demand in the baseline by 2030 . This is despite the still strong dependence on biomass in the baseline by 2030 , as the shift from traditional to the more efficient improved and advanced cookstoves already leads to a much lower demand for wood.

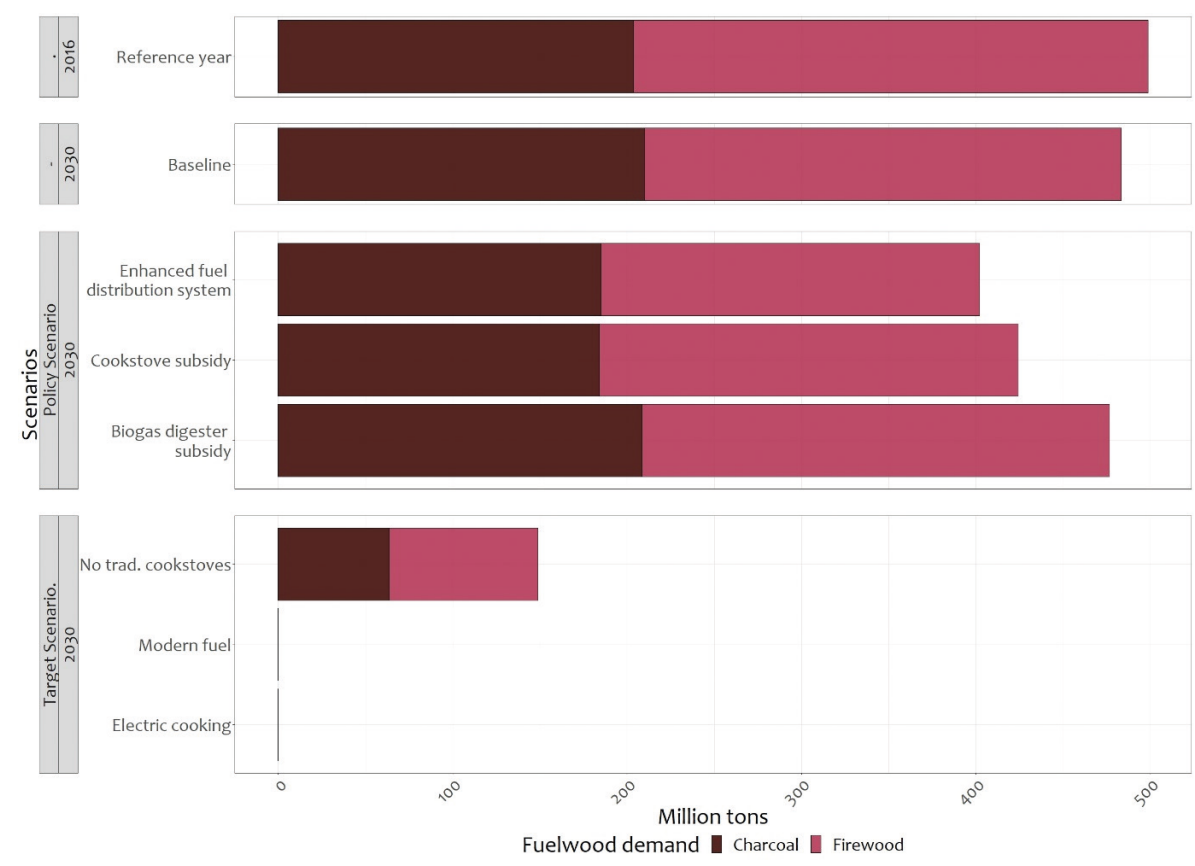

Figure 31: Fuel-wood demand for charcoal and firewood in SSA 
Natural biomass production is estimated at 1340 million tons in 2015 and 1100 million tons in 2030. This is much higher than the projected demand in all scenarios (Figure 32) and thus does not necessarily have to lead to increased deforestation. These findings are in line with those of Santos, Dekker [163], who concluded that the cumulative global supply of net primary production remains higher than the global demand for biomass. We have taken a more conservative approach, by taking into consideration only the potential growth of stems and branches in natural vegetation, instead of all net primary production. We still found that for SSA as a whole, total potential supply is much larger than the projected demand for wood. However, this conclusion only holds under the assumption that biomass is sustainably harvested - which implies that the harvesting method is more important for reducing deforestation than the absolute demand for fuelwood. Moreover, on a more local level wood demand may be higher than supply. This is shown in Figure 32. The potential supply of biomass is concentrated in the Congo Basin, the southwestern part of West Africa, south-west Ethiopia and parts of Madagascar, while demand for fuelwood demand is highly concentrated in high population density settlements in eastern and western Africa (Figure 32). Burundi, Rwanda, and large parts of Uganda and Nigeria face high local deficits due to their low-standing biomass. Similarly, Kenya, Ethiopia, Malawi, Burkina Faso and Ghana also show some local deficit areas. In these parts, the No traditional cookstove scenario leads to much lower local deficits than the other scenarios where biomass is used. 


\section{Biomass demand and supply for household cooking, 2030}

Demand under Baseline scenario

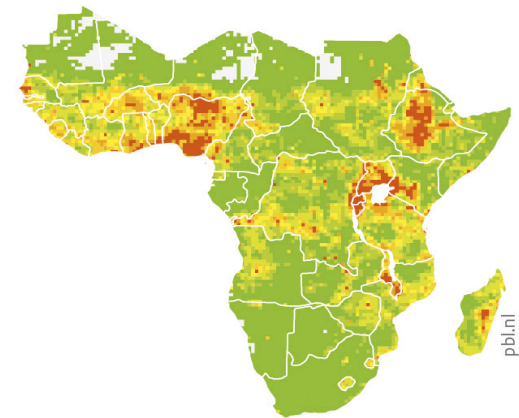

Supply under Baseline scenario

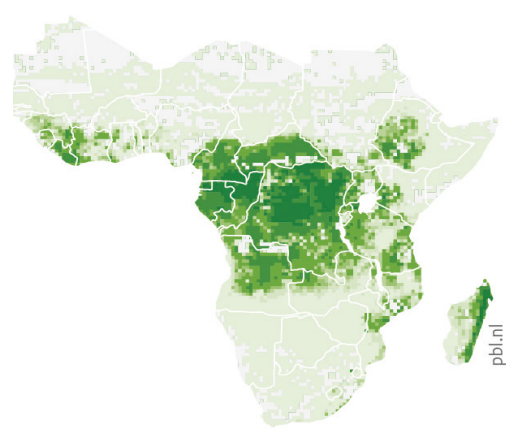

Source: PBL
Demand under No traditional cookstove scenario
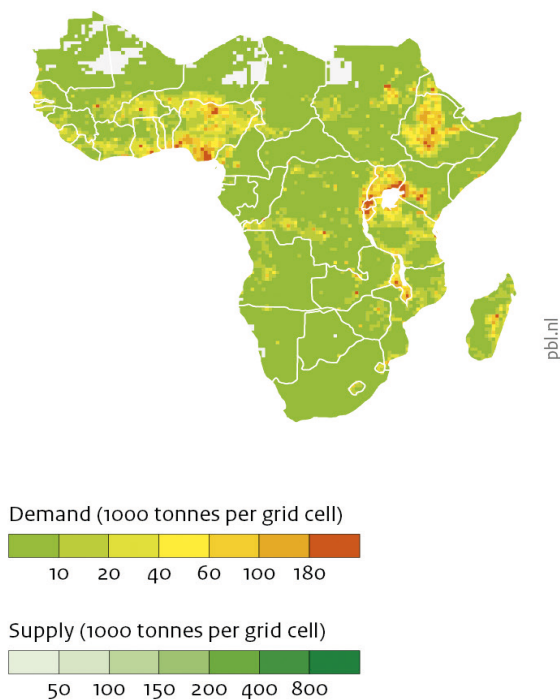

No demand or supply

Figure 32: Fuelwood demand and potential supply in 2030

\subsubsection{GHG emissions}

The displacement of traditional cookstoves with more efficient biomass or modernfuel cookstoves can reduce cooking-related GHG emissions considerably. In 2016, total GHG emissions from cooking in SSA amounted to $600 \mathrm{Mt} \mathrm{CO}_{2}$ e (Figure 33), which is almost equal to total $\mathrm{CO}_{2}$ emissions of Canada. By far the largest share (75\%) came from the burning of solid biomass in traditional cookstoves. In the baseline, GHG emissions are projected to decline slightly towards $540 \mathrm{Mt} \mathrm{CO}_{2} \mathrm{e}$ in 2030 due to efficiency improvements in cleaner biomass and modern fuel cookstoves (despite a 35\% increase in cooking energy demand). The policy scenarios Enhanced fuel distribution and Cookstove subsidy result in a $7 \%$ and $14 \%$ emission reduction by 2030 relative to Baseline, respectively as inefficient traditional cookstoves are replaced by either more efficient gas stoves or by more efficient biomass stoves. 
The Biogas digester subsidy scenario does not lead to significant net changes in GHG emissions by 2030 , as the subsidy mainly affects cooking technologies in the long term. The emissions from biomass burning are based on the assumption that a third of the biomass is non-renewable [160]. Some studies provide higher estimates to how much of the biomass is unsustainably harvested $[164,165]$ which would imply an even higher effect of switching to modern fuels on greenhouse gas emissions. The target scenarios show a strong effect on emissions already in the short term, as the inefficient traditional cookstoves are completely phased out by 2030 . The reductions compared to baseline in the target scenarios range from $42 \%$ in the No traditional cookstove scenario to $64 \%$ in the Modern fuel and Electric cooking scenarios. As shown in a previous study by Dagnachew, Lucas [14], the emissions from household electricity use could decline further if electricity is produced from low-carbon energy sources.

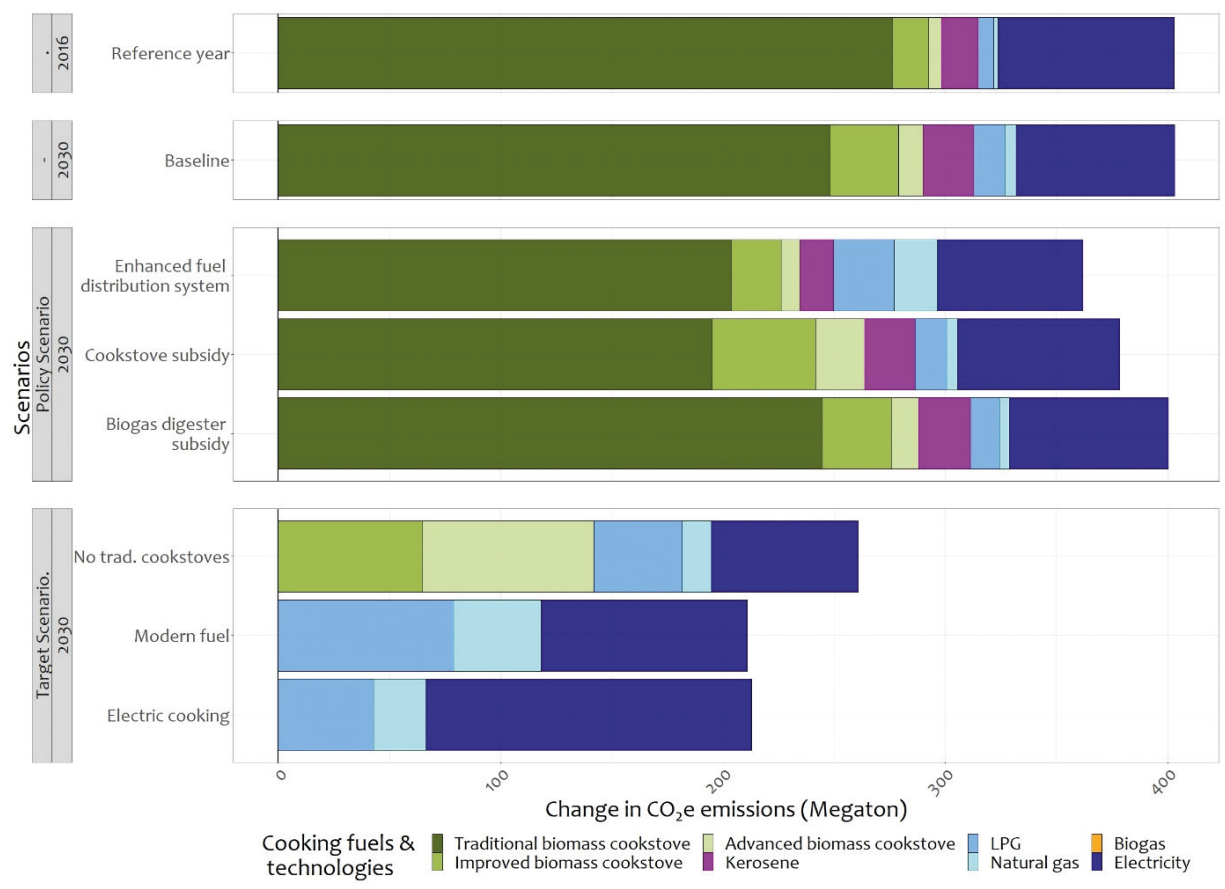

Figure 33: GHG emissions from household cooking 


\subsection{Discussion}

There are a number of caveats in our analysis. First of all, our results are based on historical relationships between various drivers and cooking fuel and technology choice. Several studies show that monetary value of fuel [166], household income [143] and infrastructure [167] indeed play an important role in the choice of cooking technology. However, these relationships might change over time.

Second, our model does not include all factors that influence technology choice. Factors like household-head gender [168], household-head age [169], cultural preferences [170], education [171] and technical aspects of the cookstoves [144, 172, 173] also play roles in cooking fuel and technology choices. Our model does not explicitly address the role of these determinants.

Third, cooking fuel choice is not a binary process. Our analysis is based on the households' choice for a primary fuel for cooking. However, empirical studies [174] show that households do not wholly abandon one fuel in favour of another, but rather modern fuels are slowly integrated into energy-use patterns, resulting in a mix of traditional and modern cooking fuels; a phenomenon referred to as 'fuelstacking'. Due to data limitations and the resulting complexity of the model, we do not capture this phenomenon in our model.

Fourth, availability of data is limited. The results of the analysis are driven by the underlying data, which is collected from several sources that often use various methodologies and inconsistent definition of variables. Besides, the purchase costs, fuel prices, and stove performance could differ locally and could have potential implications on fuel switching.

Finally, long-term projections are surrounded by many uncertainties, amongst others by socio-economic drivers like population growth, urbanization and economic development. In this study, we focussed on a specific set of assumptions regarding population, income, lifestyle and fuel prices. Obviously, these factors are inherently uncertain. The SSP scenarios cover a wider set of assumptions than only SSP2. To explore the impact of these uncertainties we show the results for the cooking energy mix for SSP1 and SSP3 in Annex D. The sensitivity analysis shows that 
in the short term, the results are not sensitive to socioeconomic assumptions and energy demand, but in the long term (2050), they are. However, the total biomass demand varies from 450 to 520 million tons and emissions from 380 to $430 \mathrm{MtCO}_{2}$ eq depending on the chosen SSP. Additionally, the model projections and our analysis neither cover the implementation nor the financing of these scenarios.

The results of our study is in line with the results reported in the IEA energy access outlook 2017 [119]. The IEA projection shows that, by 2030, 900 million people are without clean cooking access in SSA under the new policy scenario. Our projection shows very close estimate of 895 million by 2030 under the baseline scenario. The outlook also projects that the cost of providing universal clean cooking access in SSA by 2030 amounts to USD 1.7 billion per year, which is in the range of our estimate (USD 1.6 to 2.4 billion per year).

This study also shows the benefits of clean and modern energy access on health and the environment. According to our projection, universal access to clean and modern cooking energy could save the lives of up to hundred thousand children in 2030. It also considerably reduces deforestation and forest degradation and contributes to the reduction of up to $340 \mathrm{Mt} \mathrm{CO}_{2}$ emissions by 2030. However, the transition can be hampered by the cost of purchasing a modern stove. Addressing this issue requires emphasis on innovative business models and scaling-up of micro-finance with special focus on the low-income population. Even after purchasing the stove, the continued and proper use of the stove can be hindered by high fuel cost for modern technologies. Hence, the focus on accessibility and affordability of modern fuels is crucial to harness the full benefits of the transition. At the same time, the results of this study highlight that if health and environmental cost of traditional fuels and technologies are internalized, the cost competitiveness of modern cooking solutions could increase significantly. As such, the challenges of universal access to clean and modern energy relate to broader socio-economic factors. 


\subsection{Conclusions}

In this chapter, we present two sets of scenarios for promoting cooking solutions in SSA, either focusing on specific policy measures or imposing the universal access target. With the above caveats in mind, we can draw the following conclusions from our analysis:

Neither the baseline nor any of the policy scenarios analysed lead to achieving SDG7.1 on clean cooking in SSA. Unless radical improvements are made with respect to the affordability and efficiency of clean cooking technologies, as well as an exceptionally rapid installation of modern fuel infrastructure, traditional biomass (firewood and charcoal) will have a significant share (67\% in our scenario) in the cooking energy mix for decades to come. Neither the baseline nor any of the policy scenarios come close to achieving SDG7.1 in SSA. Improved and advanced biomass cookstoves could therefore play an important role as interim-solutions in the transition, especially in rural areas.

Phasing out traditional biomass use may lead to lower total cost of cooking. The average total household costs for the no traditional cookstove scenario and electric cooking scenario are lower than those projected under the baseline and the policy scenarios. Given that the annual fuel cost is several times higher than the average annual capital cost, saving on fuel (either by changing to more efficient biomass cookstoves or by using less useful energy for cooking) will lead to large reductions in cost (up to $17 \%$ lower according to our results). At the same time, initial capital cost, though relatively low, is often one of the biggest barriers for the poorest households without stable and reliable income in SSA [12, 175]. This implies that policies facilitating access to modern fuels, access to finance, and stimulate innovative business cases could help in the transition to clean and modern cooking solutions.

The transition to clean and modern cooking fuels and technologies could save the lives of 100 thousand children in 2030. Children under 5 years of age in SSA are disproportionately affected by HAP. Reducing the use of solid biomass, mineral coal and kerosene has considerable benefits on health and well-being. Our analysis shows that, while eliminating the use of traditional cookstoves could reduce child 
mortality attributed to HAP from pneumonia by $50 \%$ in 2030 compared to baseline, completely halting the use of solid biomass for cooking could reduce it by $99 \%$. This requires investment in awareness raising and communication of the negative sideeffects of traditional biomass use, scaling-up innovative finance models for poor households, as well as financial and technical support for businesses.

Eliminating traditional cookstoves or halting the consumption of solid biomass all together can help save 335-485 million tons of fuelwood annually by 2030 . The inefficiency in combustion of biomass in traditional biomass cookstoves is such that eliminating the use of traditional cookstoves could save up to 335 million tons of fuelwood. Halting the consumption of solid biomass entirely could save up to 485 million tons of fuelwood. Under baseline assumptions, the total biomass demand in SSA is well below total biomass production. However, by 2030 , several parts in western Africa and eastern Africa could experience pressure due to higher demand for fuelwood than the local production capacities. The transition towards clean and modern fuels could therefore provide environmental benefits tackling forest degradation, deforestation, soil erosion, and other natural resource impacts resulting from fuelwood collection.

Even when assuming that the biomass is largely harvested sustainably, resulting in very limited $\mathrm{CO}_{2}$ emissions, switching to modern fuels could lead to a decrease in greenhouse gas emissions. Eliminating traditional cookstoves could save 225 Mt $\mathrm{CO}_{2}$ e from avoided emissions by 2030, while halting the use of biomass entirely or cooking behaviour change could save $340 \mathrm{Mt}$ of $\mathrm{CO}_{2} \mathrm{e}$ (equivalent to a third of the total $\mathrm{CO}_{2}$ emissions in Africa in 2016). This is due to the low efficiency of biomass stoves and the fact that biomass burning emits $\mathrm{CH}_{4}, \mathrm{~N}_{2} \mathrm{O}$, and $\mathrm{BC}$ that have higher climate impacts than $\mathrm{CO}_{2}$. The avoided emission could be higher with higher proportion of unsustainably harvested biomass.

Efforts to achieve universal access to clean cooking solutions could be integrated within broader poverty alleviation and economic development policies. A transition towards clean cooking solutions can contribute to achieving a range of SDGs. In this study, we have discussed significant synergies with improving child health (SDG3), reducing greenhouse gas emissions (SDG13) and reducing deforestation, 
land degradation and biodiversity loss (SDG15). Coordinating initiatives and policies aiming to provide clean cooking solutions with policies and programs for (rural) education, health, universal access to electricity, climate change mitigation, environmental programs and industrialisation could increase synergies between the programs, facilitate the transition and bring the SDGs closer to realisation. Actions and programs could also explicitly consider gender and social aspects to address existing gender gaps in energy access.

\subsection{Acknowledgement}

The research presented in this chapter was funded by the Dutch Ministry of Foreign Affairs, the Netherlands, through its Directorate-General of Trade and International Cooperation. The work also benefitted from the funding of the European Horizon 2020 research programme, European Union, as part of the CD-LINKS project (Linking Climate and Development Policies-Leveraging International Networks and Knowledge Sharing) under grant agreement No 642147. 
Scenarios for universal access to clean cooking 



\section{Integrating energy access, efficiency and renewable energy policies in Sub- Saharan Africa: a model-based analysis}




\section{Abstract}

The role of energy in social and economic development is recognized by sustainable development goal 7 that targets three aspects of energy access: ensure universal access to affordable, reliable and modern energy services, substantially increase the share of renewable energy, and double the global rate of improvement in energy efficiency. With the projected increase in population, income and energy access in Sub-Saharan Africa, demand for energy services is expected to increase. This increase can be met through increasing the supply while at the same time improving households' energy efficiency. In this chapter, we explore the interactions between the three SDG7 targets by applying two Integrated Assessment Models, IMAGE and MESSAGE, that incorporate socio-economic heterogeneity of the end-user. The results of the study depict the synergistic relationships between the three SDG7 objectives. Relative to pursuing only the universal access target, integration of all three targets could i) reduce residential final energy consumption by up to $25 \%$, enabling the use of mini-grid and stand-alone systems to provide better energy services, ii) cut annual energy-use-related residential emissions by a third, and iii) lower energy related investments by up to $30 \%$ to save scarce finance.

\section{Highlights}

- Simulating residential demand needs a detail study of socio-economic heterogeneity

- Efficient biomass cookstoves are essential elements of the energy transition in SSA

- Integration of policies stimulates the expansion of energy services at a lower cost

- Energy efficiency supports the expansion of renewable-based distributed systems

- Integrated policies reduce the annual residential GHG emissions by a third in 2030

Published article: Dagnachew, A. G., Poblete-Cazenave, M., Pachauri, S., Hof, A., van Ruijven, B., \& van Vuuren, D. (2020). Integrating energy access, efficiency and renewable energy policies in Sub-Saharan Africa: a model-based analysis. Environmental Research Letters. 


\subsection{Introduction}

Ensuring universal access to affordable, reliable, sustainable and modern energy is one of the Sustainable Development Goals (SDG) [16] and is also acknowledged as an important objective by the Paris Agreement [176]. SDG7 covers three aspects of energy access: (1) ensure universal access to affordable, reliable and modern energy services, (2) increase substantially the share of renewable energy in the global energy mix, and (3) double the global rate of improvement in energy efficiency [16]. A growing number of countries have implemented policies to achieve these targets. However, these policies are often not coordinated or coherent, and usually different organizations take the lead on access, efficiency and renewable energy.

Using more efficient appliances helps to provide energy services to more consumers [177-180]. Effective efficiency interventions can also lower generation costs, reduce peak demand, reduce the need for fuel imports, and increase the value of decentralized systems [8, 10]. The growing use of end-use appliances could increase demand and, in particular, peak loads. This can be managed by introducing high-efficiency end-use appliances, allowing energy-service providers to save on investments in new capacity. Similarly, where decentralized generation is in place, energy efficiency enables consumers to derive greater benefit from the electricity supplied. Clear synergies among the targets exist, but just how important these interactions are is as yet uncertain.

While there are several studies investigating the interlinkages between various SDGs $[17,181]$, the interactions among the three SDG7 targets has hardly been explored, and particularly not for developing regions, such as sub-Saharan Africa (SSA). Despite having a considerable renewable energy potential [61], SSA is a region with the largest energy access deficit globally. This situation is not expected to improve much without new policies [8]. A key question therefore is how to achieve the SDG7 goals in SSA given the interactions among these three targets. The main questions that we aim to answer here is:

"What are the synergies and trade-offs between universal access to clean and modern energy, higher energy efficiency, and increased renewable energy deployment?" 
To answer this question, we develop a set of model-based scenarios that quantitatively investigate these interactions. We employ two Integrated Assessment Models (IAMs), IMAGE [42] and MESSAGE [182, 183], with a focus on the residential sector. We distinguish between end-use services related to space heating, space cooling, water heating, cooking, lighting and other household appliance use. Existing international and national energy statistics and balances are still quite aggregate and provide data by fuel source but not by end-use. Determining energy by end-use services therefore requires either scaling-down aggregate national data or scalingup from detailed household survey data sources. The two models employ these two different approaches to better reflect the uncertainty in end-use energy data.

So far, future scenario assessments have focused on total regional or sectoral energy demands and related emissions. However, simulating residential energy demand in the context of the SDGs requires a detailed study of the end-uses energy supplies and socio-economic heterogeneity in peoples' access to these services. This is critical, particularly in developing countries, for capturing the differences in circumstances and preferences across rich and poor in rural and urban settlements as the challenge is not just mitigating energy-use-related residential emissions, but also addressing access, affordability and local environmental concerns. Both IMAGE and MESSAGE, have the capability to incorporate socio-economic heterogeneity on the end-user's side. We consider differences across settlement patterns (urban and rural) and household incomes.

The chapter is organized as follows: we present the methodology in section 6.2, followed by the results in section 6.3. Section 6.4 presents the discussion and section 6.5 the conclusions.

\subsection{Methodology}

The two IAMs we employ here have very distinct model architectures, ways of incorporating socio-economic heterogeneity, and assumptions regarding how demand is determined and availability of supply options. Annex E provides detailed descriptions of the model structures, data inputs and assumptions. Both models have been used in numerous scientific publication and further descriptions of the 
models and their application can be found in [38, 43, 149-152] for IMAGE-TIMER and [140, 184-187] for MESSAGE-Access. Here, we only discuss some of the significant differences in the models that help explain the results that follow.

In IMAGE-TIMER, energy demand is simulated based on changes in population size, GDP and urbanization and demand is closely coupled to the overall IMAGE system-dynamics model. Multinomial logit functions are used to determine fuel and appliance choices for heterogeneous households by distinguishing between rural and urban regions and five income quintiles in each. The model captures competition between various supply technologies to meet required energy demands at leastcost. MESSAGE-Access, on the other hand, uses a simulation based structural approach to estimate household appliances and energy demand within the framework of an indirect utility maximization model. In contrast to IMAGE-TIMER, in MESSAGE-Access appliance choices and energy demands are estimated bottomup directly employing microdata from national household surveys. Heterogeneity in socio-economic circumstances is captured through simulating the entire population distribution jointly considering variations in household size, income and rural or urban location. We compare and contrast these very different modelling approaches in this work so as to better capture uncertainties arising from differences in model structure and data.

Another major difference between the two models is how useful energy demand for cooking is estimated. IMAGE-TIMER assumes a constant useful energy demand, implying that efficiency improvements will reduce the average per capita demand. This assumption is based on literature, e.g. Ang [188] finds that energy demand for cooking is not income elastic and the level of useful energy consumption per person is fairly constant over time. Similarly, Daioglou, van Ruijven [38] found no statically significant relationship between region, income and useful energy demand for cooking. MESSAGE- Access on the other hand, uses estimates of useful energy demand for cooking directly from microdata. Household survey data from several SSA countries reveal differences in the useful energy demand for cooking by income level and location. Thus, in MESSAGE-Access, cooking energy demand can rise if the rebound effect is stronger than the efficiency gains leading to higher energy consumption per capita. 
A third significant difference is in how bullish they are in their assumptions regarding the availability of cleaner stoves and fuels in the future. Given its nature as a datadriven household demand model, as long as households are able to afford fuels and stoves at the given prices, costs and budget constraints, MESSAGE-Access assumes no limitation in supply to households, with the exception of electricity that requires a connection for use. With an increase in income over time, households are therefore able to afford more efficient cookstoves in MESSAGE-Access. In IMAGE-TIMER, in contrast, the progress towards cleaner cooking solutions are assumed to be limited by historic relationships between access and GDP.

Fourth, MESSAGE-Access considers investments requirements in energy production, and appliance and stove acquisition only, and, unlike IMAGE-TIMER, excludes investments in electricity transmission and distribution.

\subsubsection{Scenario descriptions}

The baseline scenario is based on the SSP2 projection of the Shared Socioeconomic Pathways (SSP). The SSPs describe the future evolution of key aspects of society that together imply a range of challenges for mitigating and adapting to climate change [73, 189]. SSP2 represent a world where social, economic, and technological trends follow 'the-middle-of-the-road' path and do not shift markedly from historical patterns. To explore the impact and interactions between the three SDG7 targets, we design four additional scenarios as described below. Table 19 presents data for relevant indicators in the reference year and the most recent data. The targets and indicators for the scenario analysis are discussed in Annex E.

Table 19: Input data for various indicators in 2010 \& 2018

\begin{tabular}{lcccccc}
\hline \multicolumn{1}{|l}{$\begin{array}{c}\text { Indicator Residential } \\
\text { FEC } \\
\text { (PJ/year) }\end{array}$} & $\begin{array}{c}\text { Population } \\
\text { (Million } \\
\text { people) }\end{array}$ & $\begin{array}{c}\text { Household } \\
\text { energy } \\
\text { intensity } \\
\text { (GJ/ capita) }\end{array}$ & $\begin{array}{c}\text { Share of Renewable } \\
\text { energy in FEC (\%), the } \\
\text { bracket shows the share } \\
\text { excluding trad. biomass }\end{array}$ & $\begin{array}{c}\text { Population with access } \\
\text { in 2018 (\%) }\end{array}$ \\
\hline 2010 & 9163 & 879 & 10.4 & $88(9)$ & 33 & 15 \\
2018 & 10665 & 1080 & 9.9 & $81(14)$ & 45 & 29 \\
\hline
\end{tabular}


In the Universal access scenario (UNIV-ACC), all households get access to electricity and clean cooking by 2030. The efficiency improvements and renewable energy adoption follow the BASELINE trend. In the IMAGE-TIMER, household electricity demand is based on historical relationships between income and energy demand as discussed in van Ruijven, Schers [37]. In MESSAGE-Access, electricity demand is based on the bottom-up estimations from national surveys considering the 2030 projected income and population distribution. Clean cooking solutions include improved and advanced biomass-cookstoves ${ }^{1}$, LPG, (liquid) natural gas, biogas, and electricity.

The Universal access and energy efficiency scenario (ACC-EFF) achieves both the energy efficiency and universal access target by 2030. Based on the results of previous studies [190-192], a target improvement in household appliance efficiency by 2030 is imposed, in combination with the universal access target. This development happens independent of the renewable energy target that follows the BASELINE trend. Annex E presents targets for household efficiency improvements.

In the Universal access and renewable energy scenario (ACC-REN), the access target is achieved along with the renewable energy target. For our analysis, we exclude traditional biomass from renewables because it is unclear what percentage of traditional biomass should be considered renewable owing to unsustainable harvesting practices $[160,164,165]$. Besides, the dominance of traditional biomasscookstove use in large parts of SSA inflates the shares of renewable energy if traditional biomass would be included. Moreover, substituting inefficient biomasscookstoves with modern forms of renewables-based cookstoves would result in a decline in the shares of renewable sources in FEC. Efficiency improvement under this scenario follows the BASELINE trend.

The final scenario is the Universal access, energy efficiency and renewable energy scenario (ACC-REN-EFF), in which universal access to clean and modern energy is accompanied by improved energy efficiency and a higher share of renewables in the energy system. Table 20 provides a summary of the scenarios.

1 MESSAGE-Access only has two classes of biomass cookstoves, traditional and improved. 
Table 20: Scenario framework

\begin{tabular}{|c|c|c|c|c|}
\hline \multirow[t]{2}{*}{ Scenario } & \multirow[t]{2}{*}{ Description } & \multicolumn{3}{|c|}{ Targets achieved } \\
\hline & & $\begin{array}{l}\text { Universal } \\
\text { access }\end{array}$ & Efficiency & $\begin{array}{l}\text { Renewable } \\
\text { energy share }\end{array}$ \\
\hline $\begin{array}{l}\text { BASELINE } \\
\left(\mathrm{SSP}_{2}\right)\end{array}$ & $\begin{array}{l}\text { Autonomous efficiency improvements, business-as- } \\
\text { usual Renewable energy technology deployment } \\
\text { and business-as-usual energy access rates }\end{array}$ & $\mathrm{x}$ & $\mathrm{x}$ & $\mathrm{x}$ \\
\hline UNIV-ACC & $\begin{array}{l}\text { Universal access to clean and modern energy } \\
\text { is achieved under autonomous efficiency } \\
\text { improvements and business-as-usual Renewable } \\
\text { energy technology deployment }\end{array}$ & 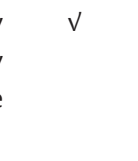 & $x$ & $\mathrm{x}$ \\
\hline ACC-EFF & $\begin{array}{l}\text { Universal access and enhanced energy efficiency } \\
\text { improvement policies under business-as-usual } \\
\text { Renewable energy technology development }\end{array}$ & $\checkmark$ & $v$ & $\mathrm{x}$ \\
\hline ACC-REN & $\begin{array}{l}\text { Universal access and renewable energy target are } \\
\text { achieved under business-as-usual energy efficiency } \\
\text { developments }\end{array}$ & $v$ & $\mathrm{x}$ & $v$ \\
\hline ACC-EFF-REN & $\begin{array}{l}\text { Universal access, enhanced efficiency improve- } \\
\text { ments, and doubling the rate of Renewable energy } \\
\text { technology deployment policies }\end{array}$ & $v$ & $v$ & $v$ \\
\hline
\end{tabular}

\subsection{Results}

\subsubsection{Trends in access to clean fuels}

The number of people without access to electricity remained constant between 2010 and 2016, at about 600 million [8], as the electrification rate was similar to the population growth. The number of people lacking access to clean cooking fuels has increased between 2010 and 2018 as the rate of progress was outpaced by population growth [193]. IMAGE-TIMER and MESSAGE-Access show a considerable improvement in access to both electricity and clean cooking in BASELINE. However, this still falls short of the universal access target. The rapid pace of population growth, the modest increase in income, inadequate infrastructure investment, and the high cost of acquiring and operating modern fuel cookstoves limit the progress. IMAGE-TIMER projects that $80 \%$ of those who use biomass continue to depend on traditional stoves in 2030. MESSAGE-Access, on the other hand, projects that, 
with declining cost of technologies and increasing income, $80 \%$ are able to afford switching to more efficient biomass cookstoves by 2030. These are still not advanced cookstoves, thus the health benefits are limited. Around 350 million people use either gas or electric stoves for cooking in 2030 under BASELINE, however the share of these two differ across the models (Figure 34). These results are in line with those from the IEA [193] that estimate that 530 million people will lack access to electricity in the Stated policy scenario (scenario based on current and announced policies).

The UNIV-ACC scenarios reach the universal access targets by definition. The way full access is achieved, however, differs between the scenarios. In IMAGE-TIMER, electricity, natural gas, LPG and biogas play roles together with improved and advanced biomasscookstoves. In MESSAGE-Access, clean cooking is provided primarily through advanced biomass-cookstoves and electricity, with LPG playing a limited role. Under UNIV-ACC, 600-800 million people rely on solid biomass, mostly charcoal and pellets, for cooking in improved and advanced cookstoves. Increased efficiency, improved consumer awareness, innovative financial schemes and reliable supply of modern fuels could further increase the attractiveness of electric and gas cooking. IEA [193] projections also shows that 600 million people rely on solid biomass in improved cookstoves under the Africa Case scenario (built on the visions of Agenda 2063 [194]).

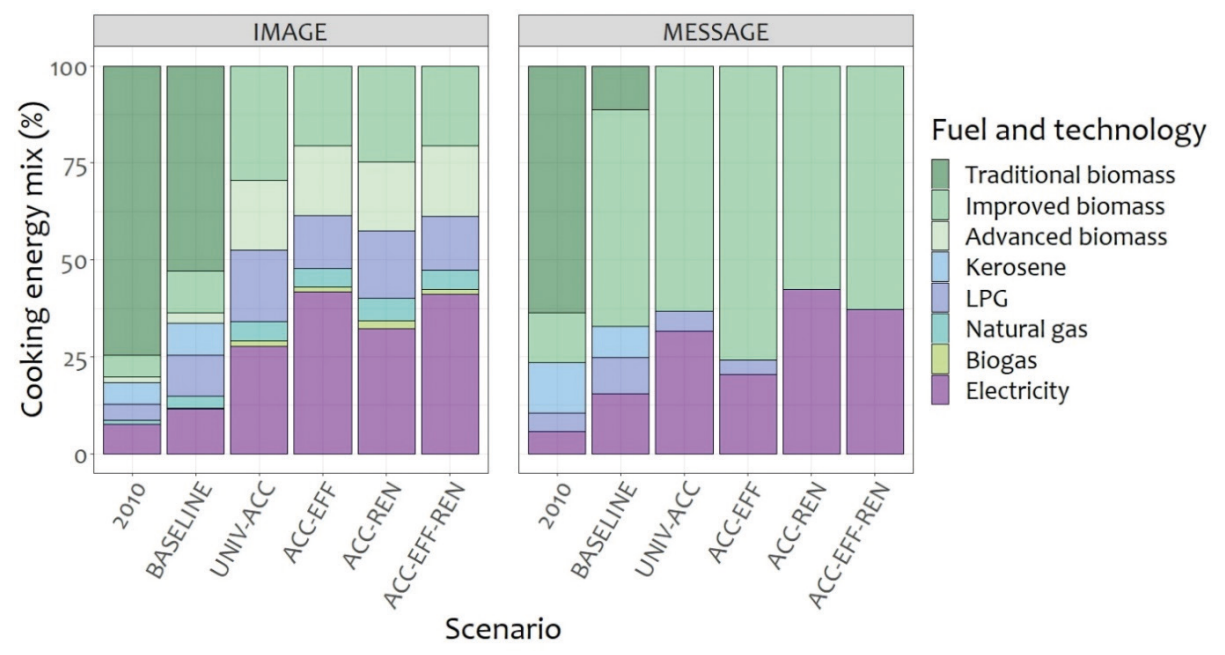

Figure 34: Cooking energy $\mathrm{mix}^{2}$ in 2010 and 2030

2 Biomass includes both firewood and charcoal use 


\subsubsection{Change in household final energy intensity}

Household useful energy consumption is projected to increase as more households get access to electricity and the ownership of appliance grows. That increase was very small between 1990 and 2010, as FEC increased by around 80\% and population by $70 \%$. The dominant energy use in the residential sector in SSA in this period was cooking and this will remain so in the coming decades.

Under BASELINE, FEC per capita remains constant in IMAGE-TIMER (see Figure 35). This can be explained by the rapid efficiency improvement in cooking technologies, a switch from traditional to modern fuels, and constant useful energy demand for cooking. MESSAGE-Access projects a $60 \%$ increase in per capita energy consumption by 2030 relative to 2010 , driven mostly by large increases in the uptake of appliances and some increase in cooking energy demand.

In UNIV-ACC, a complete phase-out of traditional biomass-cookstoves and a growing share of modern fuels in the cooking energy mix result in lower energy demand in IMAGE-TIMER. In contrast, in MESSAGE-Access, the efficiency gains are countered by a growing energy demand. As a result, total residential FEC under UNIV-ACC scenario declines (10MJ/capita) in IMAGE-TIMER but more-than doubles in MESSAGE-Access (29 MJ/capita) relative to 2010 (13 MJ/capita). FEC declines by around 10\% relative to 2010 in the Africa Case in IEA [193] amid efficiency improvements and the rapid displacement of (traditional) biomass in cooking.

Additional energy efficiency improvements in ACC-EFF provide large savings with a potential to reduce per capita energy consumption by $6-25 \%$ relative to UNIVACC. These savings are achieved by implementing efficient technologies that are already available on the market. Specifically, for IMAGE-TIMER, the largest efficiency gain comes from the halting of traditional biomass-cookstoves. The total saving in electricity consumption under ACC-EFF could reach up to 290 TWh by 2030 , which brings down peak load allowing lower system capacity requirements for decentralised renewable-based energy systems. Both models show lower energy demand per capita under ACC-EFF-REN relative to UNIV-ACC reflecting the synergetic relationships of the targets. 
With increasing income from 2010 to 2030, there is already a large shift from traditional biomass use to improved biomass use in MESSAGE-Access in BASELINE (Figure 34). Cooking energy demand remains similar between UNIV-ACC and ACC-EFF as the large efficiency gains together with rapid decline in price makes improved cookstoves a better alternative to modern fuels. IMAGE-TIMER show additional saving in cooking in ACC-EFF relative to UNIV-ACC driven by large gains from rapid efficiency improvements in biomass and modern fuel cookstoves.

The additional efficiency gain in ACC-EFF-REN can be as high as $25 \%$ relative to UNIV-ACC. However, in MESSAGE-Access, the savings made in cooking energy are countered by strong growth in appliance ownership. Specifically, the percentage of households possessing basic appliances such as televisions, and refrigerators doubles between 2010 and 2030. For other appliances with very low penetration in 2010, such as air conditioners or washing machines, there is a sizeable six-fold increase. In IMAGE-TIMER, ownership of appliances remains low as the average GDP per capita PPP remains under 4000 USD in SSA (excluding the Republic of South Africa).
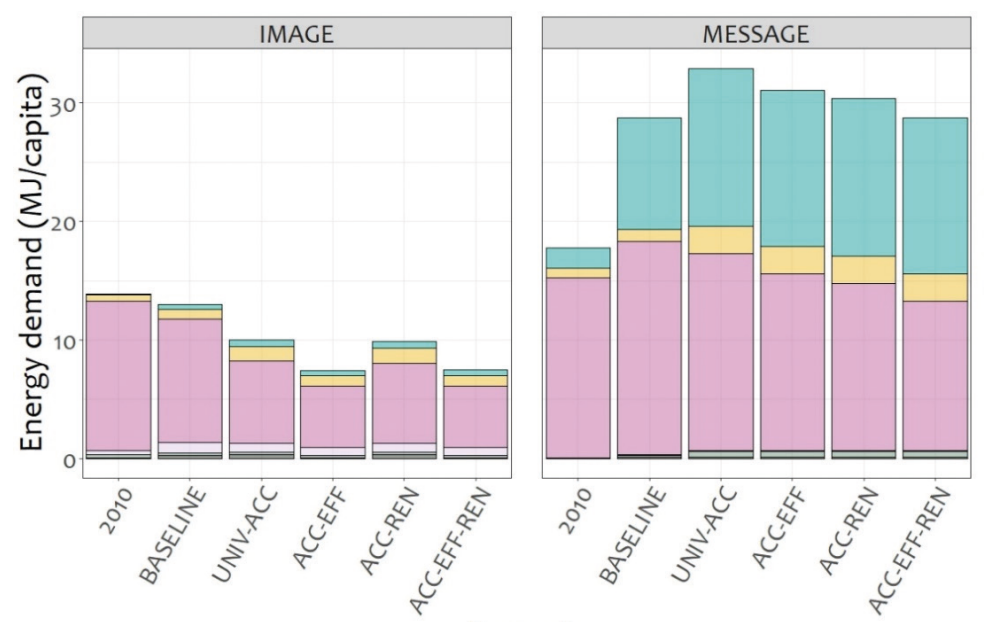

Scenario

Figure 35: Per capita FEC for residential end-use services in 2010 and 2030 


\subsubsection{Renewable energy shares}

The other SDG7 target is to substantially increase the share of renewable energy, i.e. solar, wind, geothermal, hydropower, bioenergy and marine sources, in FEC. Figure 36 shows the electricity mix and renewable energy shares in FEC. The energy system in SSA is dominated by bioenergy, with the exception of the Republic of South Africa. The rapid decline in cost of renewable energy technologies associated with accelerated global deployment has made them a cost-effective option for energy access in SSA. Under BASELINE, the share of renewables in the electricity mix increases from $24 \%$ in 2010 to $36-54 \%$ by 2030 . Renewables as a share of final cooking energy use is projected to decline under BASELINE. Two factors explain this. The first is the efficiency gain in modern renewable energy technologies (including renewable electricity) and the second is the increasing share of gas replacing traditional biomass in cooking.

In ACC-REN, renewable energy shares increase by 5-35\%-points relative to BASELINE. Electricity generation from solar and wind show large increase (26-40\%), starting from a low base of a combined 1\% in 2010. In ACC-EFF-REN, SSA's renewable energy share in electricity generation reaches $70-75 \%$ in 2030. Efficient appliances enable the deployment of solar home systems at a faster pace resulting in higher shares of renewable energy in this scenario.

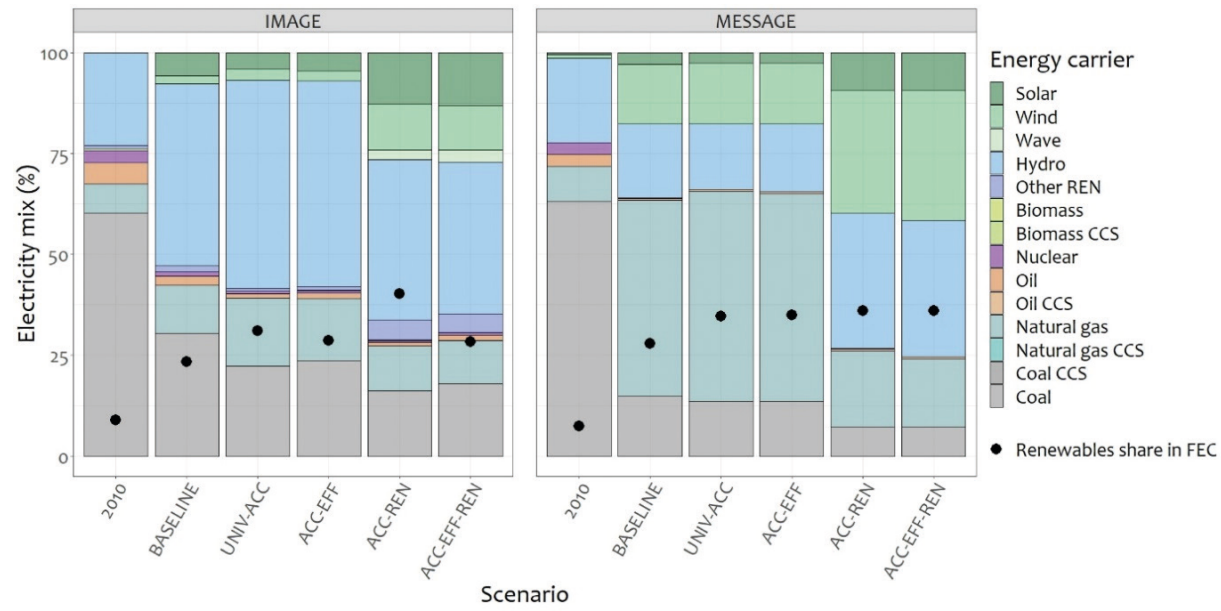

Figure 36: Electricity generation mix and renewable energy shares in FEC in 2010 and 2030 
Under BASELINE, where there is no radical change in technological innovation or infrastructure development, solid biomass accounts for around two-third of the cooking energy demand in 2030. Electricity provides $11-16 \%$ of the cooking energy demand. With the assumption that $27-34 \%$ of the traditional biomass is harvested sustainably, we can conclude that $23-30 \%$ of the final energy used for cooking in SSA comes from renewable energy sources, including renewable-energy based electricity. To improve access to cleaner cooking solutions, avoid household air pollution related mortality and reduce emissions, cleaner cooking fuels and technologies such as efficient biomass-cookstoves, LPG and natural gas play a considerable role together with electricity and biogas. The share of renewable energy in cooking energy mix under ACC-EFF-REN scenario is between 64\% (in IMAGETIMER) and 90\% (in MESSAGE-Access) including the use of biomass in improved and advanced cookstoves.

The RE share in FEC (excluding traditional biomass) under BASELINE reaches near $25 \%$ in 2030 , a similar projection as in the Stated policy scenario of IEA [193]. In UNIVACC, renewable shares are 22-31\% in 2030, with IEA's Africa Case projection coinciding with the higher end of the range.

\subsubsection{Investment requirements of providing universal access}

BASELINE investments in electricity and clean cooking infrastructure is projected to be 11-19 billion USD annually between 2015 and 2030. Universal access requires an additional annual investment of 14-37 billion USD, as shown in Figure 37. ACC-EFF has lower investment requirements compared to UNIV-ACC. In IMAGE-TIMER, the lower investment requirement in ACC-EFF is a result of the high energy savings associated with increased appliance efficiency. When highly efficient appliances are used, the capacity requirements for off-grid systems reduce considerably, hence, reduce the capital cost of stand-alone and mini-grid systems. The relatively low household energy demand also leads to higher share of off-grid systems reducing required investments in transmission and distribution. ACC-REN benefits from lower renewable energy prices amid large-scale deployment of renewable energy technologies.

ACC-EFF-REN has a total investment requirement of 14-28 billion USD a year on average. The synergy between energy efficiency and renewable energy is 
demonstrated by the large avoided investment (up to 31\%) in ACC-EFF-REN relative to UNIV-ACC. Higher renewable energy shares coupled with radical efficiency improvements reduces peak energy demand, hence lower capacity requirements. The electrification process largely favours renewable-based distributed systems, reducing grid losses and fuel transportation costs. The lower electricity demand together with the declining cost of renewable energy technology results in a combined saving of up to a hundred billion USD by 2030. However, it also means that, even in the scenario with the lowest investment needs for universal access, a near-doubling of the BASELINE investment is required.

\subsubsection{Energy use related residential sector emissions}

Total residential energy-use-related emissions in 2010 amounted to $560 \mathrm{Mt} \mathrm{CO}_{2} \mathrm{e}$, including emissions from non-renewable biomass burning for cooking (Figure 37). Under BASELINE, residential GHG emissions grows by an annual average rate of $1-1.8 \%$ between 2010 and 2030 as growing energy demand counters autonomous efficiency improvements. The avoided emission in UNIV-ACC amounts to $23-26 \%$ compared to BASELINE owing to the halt in the use of traditional biomass-cookstoves. MESSAGEAccess shows a higher GHG emission in ACC-EFF than UNIV-ACC as higher efficiency and lower prices make charcoal a more attractive option than low emission fuels such as natural gas and electricity. Higher reduction in GHG emissions is achieved in ACC-EFF-REN through the increased implementation of decentralized electrification technologies (as a result of lower demand density), elimination of traditional biomass-cookstoves, increased deployment of improved and advanced biomasscookstoves, and faster transition to modern fuel cookstoves. GHG-emissions in IMAGE-TIMER are in general higher than MESSAGE-Access as it considers that a third of the biomass is produced unsustainably resulting in a net-emission.

\subsection{Discussion}

This chapter analyses synergies and trade-offs between universal access to clean and modern energy, higher energy efficiency, and increased renewable energy deployment in SSA. Using two distinct model frameworks allows us to capture uncertainties arising from different model structures and data on energy by enduse, which has so far been rarely explored in the literature. 


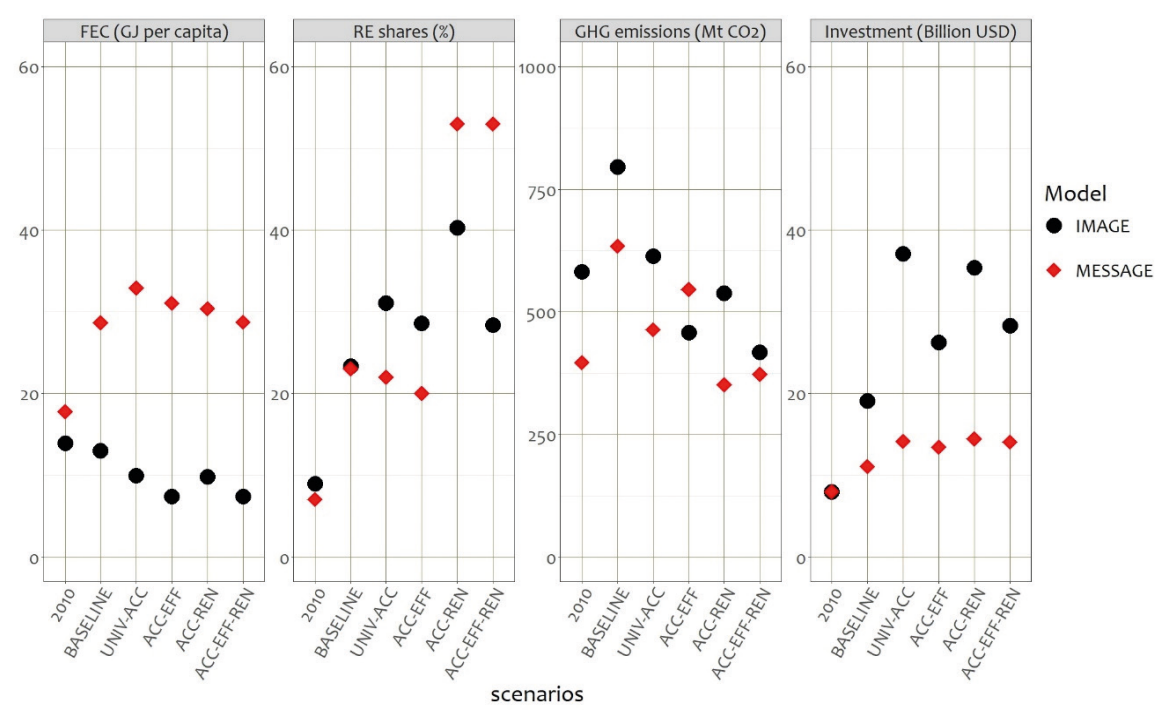

Figure 37: Final energy consumption, GHG emission, investment and renewable energy share in 2010 and 2030

Figure 37 summarises the results. Overall, the results depict the synergistic relationships between the three targets, so that our integrated scenario results in a lower FEC, lower GHG emissions, and lower investment needs relative to pursuing only the universal access target. This overall trend is consistent in the results from both models employed. There are, however, also important differences between the models, which reflect the methodological differences between the models and limitations in the availability of reliable historic data on energy by end-uses.

In this work, our focus is on household energy demand and does not consider demand for productive uses or other sectors of the economy. If those are considered, the demand density could increase, improving the financial viability of on-grid electrification. However, the decision to include or not include productive uses requires a trade-off between having access to electricity through quick and cost-efficient systems for low-demand density settlements that don't meet the needs of most productive appliances, and high-quality on-grid connections that can provide electricity for productive uses but are slow to arrive, unreliable, and at times expensive. Our analysis also does not address any existing institutional, governance or financial barriers for energy efficiency or for renewable energy technology deployment. Literature suggests that these can be significant and future work could explore these barriers and means to overcome them in depth. 


\subsection{Conclusions}

The results of our analysis provide some policy-relevant insights and conclusions, which we discuss here.

Our results show that integrating energy access, energy efficiency and renewable energy policies has several benefits. Integration stimulates the expansion of energy services while reducing the investment requirements and the impact on the climate. Higher energy efficiency improvements allow for providing a wide range of services with distributed systems, while distributed renewable energy expansion reduces conversion and transmission losses. Policies to expand generation and transmission capacities should consider efficiency improvements to avoid unnecessary extra capacity and save large amounts of hard needed finance. As end-use energy requirements decrease, the opportunity for low-energy density renewable sources to meet energy needs increases; thus, targets to increase the renewable share of total energy consumption can be achieved more expeditiously with added energy efficiency measures. With lower cost of end-use service delivery, money saved can be used to finance additional efficiency improvements and/or in the deployment of renewables.

There is a large potential for efficiency improvement in SSA despite the relatively low level of energy consumption. Cooking in SSA is a very energy intensive end-use activity driven by the widespread use of inefficient traditional biomass-cookstoves. Similarly, air conditioners, refrigerators, and other household appliances sold in SSA are typically far less efficient than most available units on the market. Largescale deployment of the best available technology (efficient household appliances and equipment) could help deal with the growing demand for residential energy services in SSA. This can also enable the use of mini-grid and stand-alone systems to provide energy beyond lamps and radios, to meet demands for cooling, heating, and electric cooking services. It also creates opportunities for companies and consumers alike while decreasing the need for expensive peak capacity. This, however, requires designing and enforcing of national standards and labelling for household appliances and equipment efficiency. 
The energy saving achieved through integration of policies leads to lower investment requirements for energy access and considerably lower energy related residential emissions by $\mathbf{2 0 3 0}$. The saving achieved in FEC result in lower requirements for energy supply while helping households reduce their energy expenditure. The average annual capital investment for energy infrastructure and annual operation and maintenance expenditure could be up to $30 \%$ lower compared to the UNIV-ACC scenario. Similarly, integrating the three policies could reduce the annual energy-use-related residential emissions by a third relative to the UNIV-ACC scenario. The emission reduction is largely attributed to the efficiency improvements in biomass-cookstoves and a switch to modern fuels, including LPG, natural gas and electricity, for cooking. However, providing access through the deployment of more efficient technologies can be more expensive. Thus, targeted policies, innovation, and financing will be needed to achieve wide-scale deployment of efficient equipment and appliances.

\section{Acknowledgements}

The research presented in this chapter was mainly funded by the European Horizon 2020 research programme, European Union, as part of the CD-LINKS project (Linking Climate and Development Policies-Leveraging International Networks and Knowledge Sharing) under grant agreement No 642147. The work also benefitted from funding by the Dutch Ministry of Foreign Affairs, the Netherlands, through its Directorate-General of Trade and International Cooperation. 



\section{Synthesis and conclusions}


The first part of this Chapter (7.1 and 7.2) summarizes the main findings of the study in the context of the research questions presented in the first chapter. The second part (7.3 and 7.4) presents a more general discussion and conclusion on synergies and trade-offs, the modelling of the interactions, and the caveats of the modelling exercise. Finally, we present some recommendations for further research (7.5).

\subsection{Introduction}

Access to electricity and clean cooking solutions are important prerequisites for human development. This was acknowledged by the global community through the adoption of the SDGs, in which SDG7 call for universal access to electricity and clean cooking solutions by 2030. Currently, more than 600 million people in SSA have no access to electricity, the total installed generation capacity in the region is less than that of the United Kingdom, and over 900 million people rely on traditional biomass for cooking.

Based on relationships between electricity access on the one hand and GDP per capita, population density, and urbanization rate on the other, model projections show that, if historical trends continue, about 515 million people still lack access to electricity in 2030. Eastern Africa is projected to have the highest proportion of people without access to electricity by that date (48 percent), followed by southern Africa without the Republic of South Africa (44 percent), western and central Africa (31 percent), and the Republic of South Africa (12 percent). Access to electricity is especially lagging in rural areas, which are projected to account for 85 percent of the population without access by 2030. Similarly, with continuation of historical trends, over 700 million people are projected to rely on traditional biomass for cooking in 2030, resulting in the mortality of over 135 thousand children under the age of 5 .

Ensuring access to modern and sustainable energy is a crucial component of sustainable development and it is acknowledged as a policy priority in several countries in SSA. While there are no doubts that providing access should be the priority, it should be pursued in the context of mitigating climate change. This is being facilitated by innovations in decentralised renewable energy technologies, rapid cost declines, and innovative market mechanisms. Decentralized systems also 
bring a new dimension to traditional energy system planning, which increases the importance of energy models in informing long-term strategic planning. Modelbased scenario analysis offers insight to possible development pathways, and their cost and benefits in the context of sustainable development.

Due to capacity limitations in SSA, most of the existing scenario studies employ models developed for industrialised country energy systems and they look at isolated developments in a country or part of the region. This study provides the development of the SSA's energy system in the context of global climate change using a custom-designed household energy access model embedded within the integrated assessment model IMAGE. Over the years, this research employed various versions of the household energy access model and applied several scenarios for universal access to electricity and clean cooking solutions. The scenarios were based on the exogenous assumptions and projections of the drivers of energy demand (e.g., population growth, economic development, rate of technology change, and urbanization rates) of the Shared Socioeconomic Pathways, as implemented in IMAGE. The model also used data on costs of power generation by different technologies, the costs of cooking by various cooking fuels and technologies, population density, costs of transmission and distribution, technical potentials of renewable energy sources, the distance of population settlements from existing power lines, and other infrastructure availability.

This thesis explores how universal access to modern and sustainable energy in SSA can be ensured in the broader development context as outlined by the sustainable development goals framework. We approach this challenge in four stages. First, we explore the cost and benefits of several pathways to universal access to electricity in the region. We did this by looking at least-cost technology choices based on different levels of household electricity consumption. The consumption levels are based on the Multi-Tier Framework (MTF) of the Global Tracking Framework (GTF) of the SE4ALL initiative as well as baseline consumption levels based on historical observations. MTF gives a minimum threshold of electricity consumption levels for households ranging from $4.5 \mathrm{kWh} /$ year at Tier-1 to $1250 \mathrm{kWh} /$ year at Tier-5. Given the wide regional scope of the thesis, the purpose of the MTF is to show how different levels of ambition for levels of energy consumption can impact the technology 
choice and the investment requirement, hence, the feasibility of achieving the target. While MTF provides a multidimensional measurement for energy poverty, we acknowledge that it implicitly measures energy access through ownership and usage of a set of appliances. As such, it fails to recognize the role of cultural norms and consumer preferences on energy service needs and appliance choices, as discussed in section 7.3 .

We also look at the interactions between universal access to electricity and climate change mitigation. Providing universal access to electricity in SSA requires substantial expansion of power generation capacity and transmission and distribution networks. There are a number of possible co-benefits and trade-offs between providing access to electricity and climate policy. To assess key synergies and trade-offs between electricity access and climate change mitigation, we analyse the developments of indicators that describe demand, production, and costs of the future power system under various scenarios with and without climate change mitigation policies. In an attempt to simulate the impact of climate change mitigation policies on universal electricity access, we use a global carbon price as a proxy for a stringent climate policy. Carbon price can have several unintended consequences and does not necessarily represent the actual policy instrument. In the real world, other policy instruments can be implemented to stimulate a shift towards lowcarbon energy systems. It is, however, very important that associated trade-offs are thoroughly explored and, often, these instruments need to be complemented by other policies.

Second, we investigate the roles of actors and institutions involved in the transition towards universal electricity access in Sub-Saharan Africa, with an emphasis on the roles of the public and the private sectors in expanding decentralised systems. In general, like several previous studies, our models neglect the roles of actors and institutions that are crucial in facilitating the universal access process. In a bid to address this shortcoming, we provide relevant policy recommendations to facilitate the path towards universal electricity access in SSA by identifying the barriers for electricity access and relevant actors, institutions, and regulations through stakeholder interviews and workshops, with a focus on off-grid systems. 
Third, we explore the costs and benefits of the pathways towards universal access to clean and modern cooking in SSA. Universal energy access is not only about electricity; access to clean cooking solutions is also an important component that touches various aspects of SDGs. To address this objective, we present several scenarios for the development of (clean) cooking solutions in SSA assuming specific policy options or specific transition pathways towards universal access by 2030. The scenarios consider historic developments, availability of fuels and infrastructure, required investments, and trade-offs and synergies related to health, biodiversity and climate change.

Finally, we look at the synergies and trade-offs of integrating access, efficiency and renewable energy policies in SSA. In addition to the impact of SDG7 on other SDGs, it is also important to investigate the interactions between the targets of SDG7 itself. The analysis informs planning and policy making by quantitatively exploring the interaction between universal access to modern energy services, enhanced energy efficiency and scaled-up deployment of renewable energy technologies. For that purpose, we assess a set of scenarios to analyse the interaction between these targets by using two Integrated Assessment Models, IMAGE \& MESSAGE, that are capable of exploring these synergies and trade-offs.

\subsection{Synthesis of results}

7.2.1. What are the implications of different pathways towards achieving universal access to electricity in Sub-Saharan Africa by 2030 on investments and climate change?

Chapter 2 and Chapter 3 studied the role of various technologies in addressing lack of access to electricity and the co-benefits and trade-offs between access and climate change mitigation. Access to electricity can be achieved through the extension of the central grid or through decentralised systems that are largely based on renewable energy. In this study we have looked at the role of various technologies, centralised and decentralised, in providing access to electricity in SSA based on varying levels of electricity consumption and with and without climate mitigation policy. 
There are considerable differences in electricity consumption between regions and between urban and rural settlements in SSA and this is projected to remain under the current trend. Currently, there are large differences in electricity consumption between regions, between urban and rural areas, and between income classes. While the average annual household electricity consumption in most of SSA in 2010 was under $350 \mathrm{kWh}$, in the Republic of South Africa it was over $2300 \mathrm{kWh}$. But there are also very large differences within countries and regions, i.e. between urban and rural areas and between income quintiles, as shown in Figure 38. These differences in household energy consumption are partly a result of lack of access to electricity, but also important for strategies to increase electricity access as the choice of options to increase electrification depends on the consumption density (electricity consumption per area).

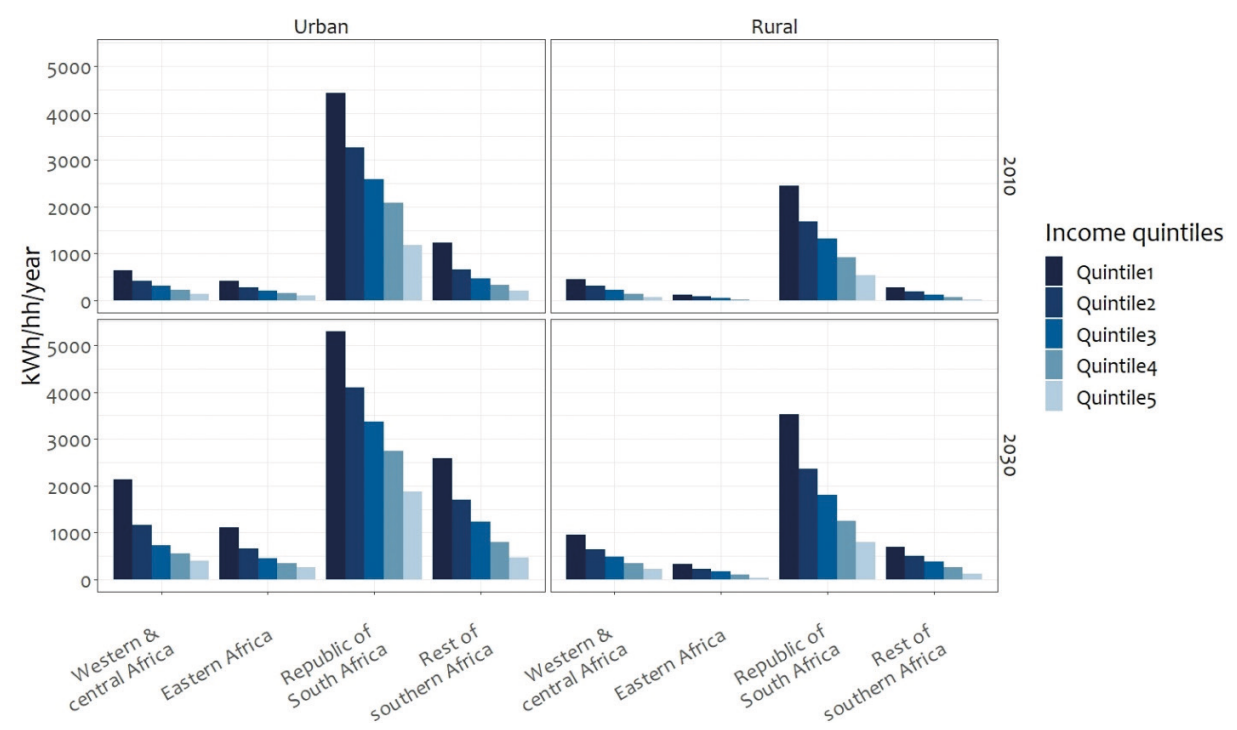

Figure 38: Regional differences in annual household electricity consumption, 2010 and 2030

Figure 38 shows household electricity consumption in SSA by settlement type and income class. Q1 represents the highest income quintile in a settlement whereas Q5 represent the lowest income class. 
Off-grid systems could play an important role by complementing the central grid to achieve universal access to electricity in SSA. The least-cost option to increase electrification depends on the consumption density (electricity consumption per area), the distance to available grid infrastructure and available local potential. For our default assumptions regarding these factors, access to central grid is the leastcost option to provide access for 85 percent of the newly connected population in SSA. For over a 100 million people, however, access through off-grid systems is more attractive even in our default case. However, if electricity demand remains low and/ or the costs of decentralized renewable energy technologies keep declining, it could even be attractive to connect a much higher share of the population through off-grid systems. If governments target a minimum level of access in which households get enough power to light two bulbs and charge mobile phones, off-grid systems could provide access to nearly 65 percent of the newly connected population (see Figure 39). Especially in poor, sparsely populated rural settlements in SSA, off-grid systems - including mini-grids and stand-alone systems - could play a vital role in providing electricity at a reasonable cost. At the moment, unfortunately, the electricity sector pays little attention and lacks the institutional capacity to accommodate off-grid systems at the scale required to provide access to low-density, low-demand and remote communities.

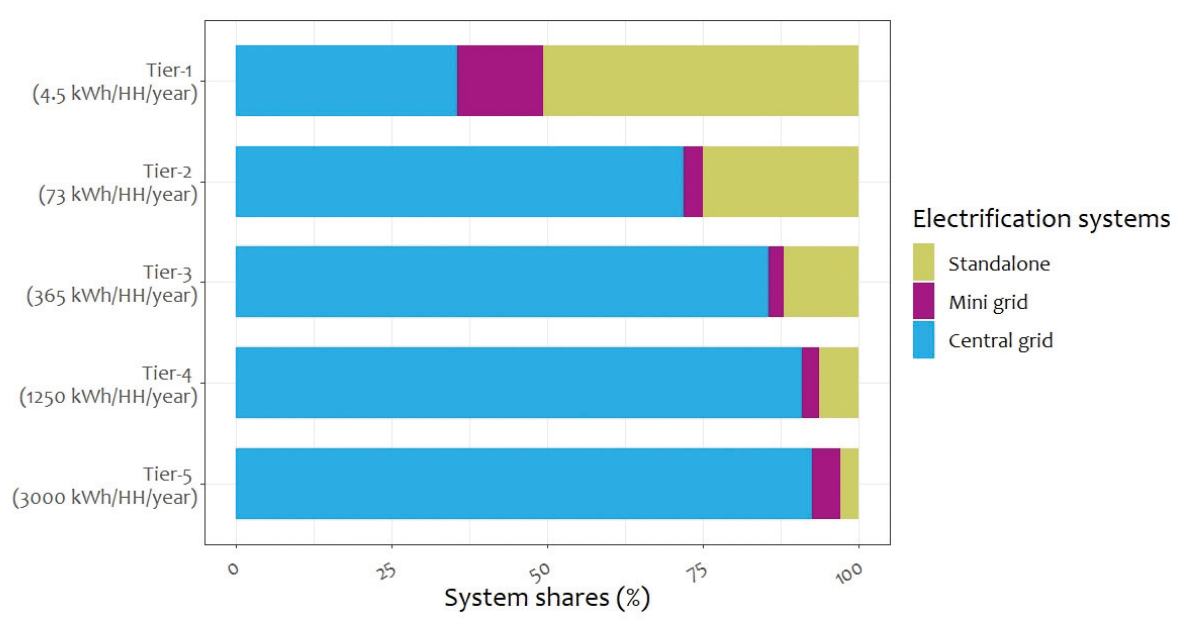

Figure 39: System shares of tier-1 (the lowest demand) and tier-5 (the highest demand) for new connections after 2010 
Figure 39 shows that mini-grid and stand-alone systems provide access to $65 \%$ of the newly connected population at lowest level of consumption in the Multi-Tire Framework. However, if higher ambition levels are targeted, centralised grid is the preferred technology for over $92 \%$ of the newly connected population.

\section{Energy efficiency can be an important component of the strategy to achieve} universal access to electricity in SSA by 2030. Increasing energy efficiency, an important strategy for climate change mitigation by reducing consumption, shows a synergetic relationship with accelerating universal access to electricity. If climate change mitigation policies are introduced globally, including SSA, a 20 percent saving in total residential consumption by 2030 could be achieved. This means that SSA would need 21 terawatt hours less capacity to serve the additional connections while providing the same level of energy services. Reducing the peak load helps to improve the reliability of the system and to avoid investments in unnecessary capacity expansion while the money saved could be used to expand access.

Strategies to increase access to electricity interact with the global ambition to mitigate greenhouse gas emissions. In 2010, residential $\mathrm{CO}_{2}$ emissions from electricity accounted for around 25 percent of total electricity-related $\mathrm{CO}_{2}$ emissions in SSA and only around 0.5 percent of global electricity-related $\mathrm{CO}_{2}$ emissions. Without climate policy, additional on-grid generation capacity mostly consists of scaling up existing capacity. Hence, achieving the universal access target will result in an increase in emissions of $24 \mathrm{Mt}$ of $\mathrm{CO}_{2}$, which is three times the 2010 level of energy use related residential emissions. Globally, this increase can be considered negligible, as it is only around 0.2 percent of the projected global electricity-related emissions in 2030, but it would put SSA on a pathway of a fossil-fuel based electricity system. Climate policy can significantly impact the electricity mix by relatively increasing the share of renewable energy-based generation. This does not only reduce emissions but also stimulates energy security. In that case, the use of coal is projected to decrease significantly. The share of natural gas for combined-cycle power plants, however, could increase, as it can efficiently be used to balance fluctuating renewable resources. Climate policy could also lead to a significant increase in nuclear energy in our scenario, especially in the Republic of South Africa. The shift to low-carbon energy sources and efficiency improvements due to carbon pricing helps to avoid 
65 percent of the projected electricity related $\mathrm{CO}_{2}$ emissions of 2030 in our climate policy scenario.

\section{Climate mitigation policies could lead to higher electricity prices, although this can} be mitigated by additional policies. This is an important trade-off as an increase in electricity prices could impact the poor unless climate mitigation is complemented with pro-poor policies. Eastern Africa will be the least affected as its electricity mix is dominated by renewable energy. Still, the price in this region is projected to be 25 percent higher under the scenario with climate policy than under the scenario without it. In the Republic of South Africa, the model projects a 120 percent increase in the electricity price due to the strong dominance of coal in the electricity mix. To overcome this trade-off, climate policy could be complemented with pro-poor policies, such as free basic electricity, low consumption low tariff, cross subsidization, etc., specifically designed to protect the poor from increasing electricity prices.

\section{Total annual investments for universal electricity access could reach 110 billion} USD, depending on the targeted level of electricity consumption. Achieving universal electricity access will require a significant further expansion of installed capacity as well as transmission and distribution infrastructure. The required capital investment is projected to be in the range of US\$22 - 110 billion per year, between 2010 and 2030, on top of investments projected under the baseline scenario of US\$16 billion (Figure 40). Of this investment, 85 percent would go to upgrading and extending the transmission and distribution infrastructure, reflecting the severe lack of such networks and the inefficiency of the system. As a result of rapid efficiency improvements, climate policy could make it cheaper to meet the universal electricity access target. The efficiency improvements will lead to lower additional investment requirements for generation capacity and transmission and distribution infrastructure for the additional connected population (US\$27 billion a year, compared to US\$33 billion a year without a climate policy under baseline levels of electricity consumption). 


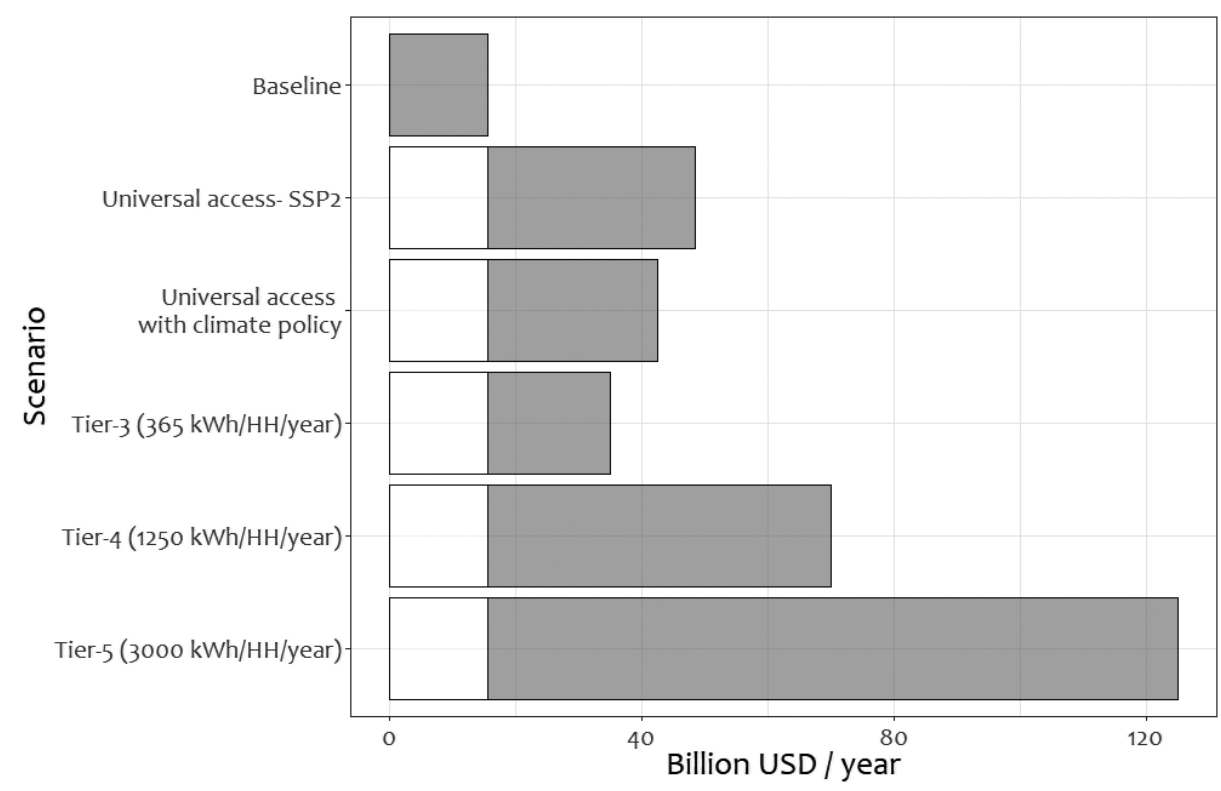

Figure 40: Additional annual investments for universal electricity access compared to the baseline trend, 2010-2030

Figure 40 presents the projected annual investment for universal access in various household consumption and climate policy scenarios in SSA. The level of annual household electricity consumption in Baseline, Universal access-SSP2 and Universal access with climate policy scenarios is based on historical observation of consumption levels associated with a given GDP per capita level. The Tier-3 to Tier-5 consumption levels are annual household consumption levels as defined in the MTF of the Global Tracking Framework (GTF) of the SE4ALL initiative. The average household consumption in SSA lies between Tier-3 and Tier-4, while in Southern Africa it lies between Tier-4 and Tier-5.

\subsubsection{Which actors and institutions are involved in the transition towards universal electricity access in SSA?}

SSA has vast fossil and renewable energy resources, but it is the region with the highest electricity access deficit in the world. Several studies show that the access challenge is a result of governance and institutional problems, as well as lack of capital to meet the high investment requirement. The current governance structure is associated with corruption and inefficient management of several utilities over 
long periods of time that prohibited infrastructure development at scale and pace required to provide universal access to electricity. As a result, the region's energy system functions poorly, with an unstable and unreliable electricity supply, low generation capacity, low efficiency, inadequate investment, high costs, and prices that have often been too low to cover costs.

Existing model-based studies do not address the role of governance in facilitating universal access to electricity and policy instruments to tackle barriers for expansion of off-grid systems that are crucial for universal access. The role of actors and institutions in expanding electricity access is the main topic covered in chapter 4 based on desk research, expert workshops and stakeholder interviews. In addition to investigating the existing institutional structure and its limitations, the chapter presents four storylines for the electricity sector with actors playing different roles. The storylines form combinations of extreme forms of governance structures (topdown vs bottom-up) and electrification systems (centralised vs decentralised). In reality, several combinations of governance structure and electrification system are possible. In this thesis, we chose to look at the extreme scenarios since the model assigns one system for each grid-cell and the economies of scale (the consumption density) plays a very important role in determining the choice of the system.

The study is conducted in four case study countries in SSA: Nigeria, Ghana, Ethiopia and Tanzania that together represent over a third of SSA's population. Table 21 summarises the role of various actors in decentralised electrification systems in the four countries. 


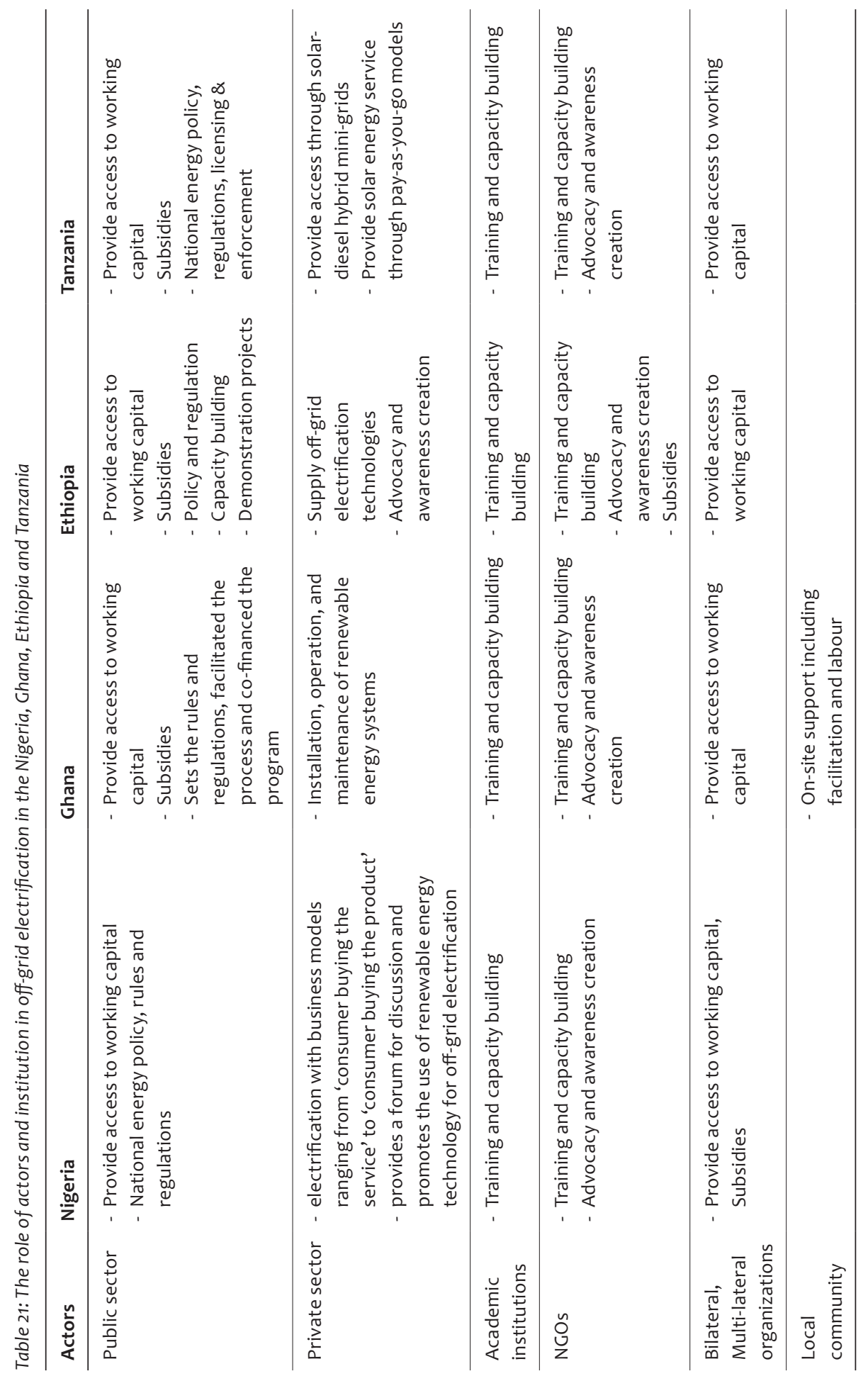


Governments are the dominant actors in electrification projects, although the exact mix of actors differs per country and project. For several decades, electrification has been a top-down supply driven process. In the past couple of decades, the electricity sectors are going through a reform process in which all four countries are unbundling generation, transmission and distribution. Apart from Nigeria, electricity generation in the central grid is the responsibility of the public sector. While Nigeria and Ghana have privatised the distribution of electricity, Ethiopia and Tanzania are yet to involve the private sector in any of the central grid components. Rural energy agencies also play a considerable role in off-grid electrification strategies in rural settlements. Their roles include identifying locations to be electrified, determining the electrifications technology, determining tariffs, providing working capital, and project execution. Several studies emphasise the importance of community engagement and empowerment for wider deployment and sustainability of off-grid electrification systems, but very little community participation is observed in the case-study countries.

Lack of financial capacity is a strong barrier for universal access amplifying the need for strong participation of the private sector. The private sector is gradually growing in the off-grid electricity market. Considering the crucial role of decentralised systems in reaching low-density, low-consumption remote settlements, private sector participation is vital to alleviate the financial limitations through innovative revenue schemes. The number of household and community energy producers (and consumers) is also growing, while rural electrification agencies are being established with the mandate to facilitate rapid electrification, engaging the private sector and producer-consumers. The public sector could play a role by establishing financial and fiscal incentives and eliminating market distortions to harness the private sector potential in delivering fast and reliable electricity services through decentralised systems.

Capital subsidy is one of the most widely adopted policy instruments to help offgrid projects overcome the initial investment barrier. Nigeria, Ghana, Ethiopia and Tanzania have developed regulatory instruments to facilitate the penetration of decentralized systems, including financial incentives (e.g. start-up grants and loan guarantees), fiscal incentives (e.g. exemptions from import duty and/or value 
added tax), and elimination of market distortions (e.g. reducing fossil fuel subsidies). These countries have set up special funds and micro-finance systems to broaden financing channels for off-grid projects, while Tanzania, in addition to the public and bilateral funds, established a crowdfunding for solar-based electrification programs. Operating and maintenance subsidies are seen as essential to sustain project operations over a long period, particularly in the case of extremely remote areas with a poor ability to pay.

Stable and consistent policy and transparency in planning provide good anticipation of future grid extensions which helps the private sector better prepare for change. National electricity policies are designed with the SDGs as the central element, but require better institutional arrangements and human capacity, and greater collaboration between different actors. Inadequate communication between the public and private sectors leads to uncertainty for the private sector while planning investment in decentralised systems, which is especially related to the extent and timing of central grid expansion. In areas where the central grid is to expand in the foreseeable future, decentralised systems could be developed for an eventual integration into the central grid (with higher up-front costs) or as an interim solution with lower standards and costs. While community engagement and empowerment are crucial for wider deployment and sustainability of off-grid electrification systems, there has been very little community participation in the design and development of electrification programs.

\subsubsection{What are the investment and expenditure needs and implications for health, biodiversity, and climate of pathways towards universal access to clean and modern cooking in SSA?}

Nearly 900 million people in SSA rely on traditional biomass with major health and environmental consequences. Incomplete combustion of traditional biomass is linked to over 390 thousand premature deaths in SSA in $2017,35 \%$ of the deaths occurring amongst children under 5 years of age. The use of solid biomass also exerts large pressure on local and regional environments, including deforestation, forest degradation and destruction, and soil degradation and erosion, as well as leading to black carbon emissions and net $\mathrm{CO}_{2}$ emissions if harvested unsustainably. To explore the investment and expenditure needs, as well as, implications for 
health, biodiversity, and climate change of the transition, we developed two sets of scenarios for promoting cooking solutions in SSA in addition to the baseline trend: policy scenarios where specific policy measures are introduced to analyse the effectiveness and consequences of these policies and target scenarios where access to clean cooking solutions for all households in SSA is achieved by 2030.

Implication of different pathways to clean cooking solutions, 2030

Household cooking energy mix
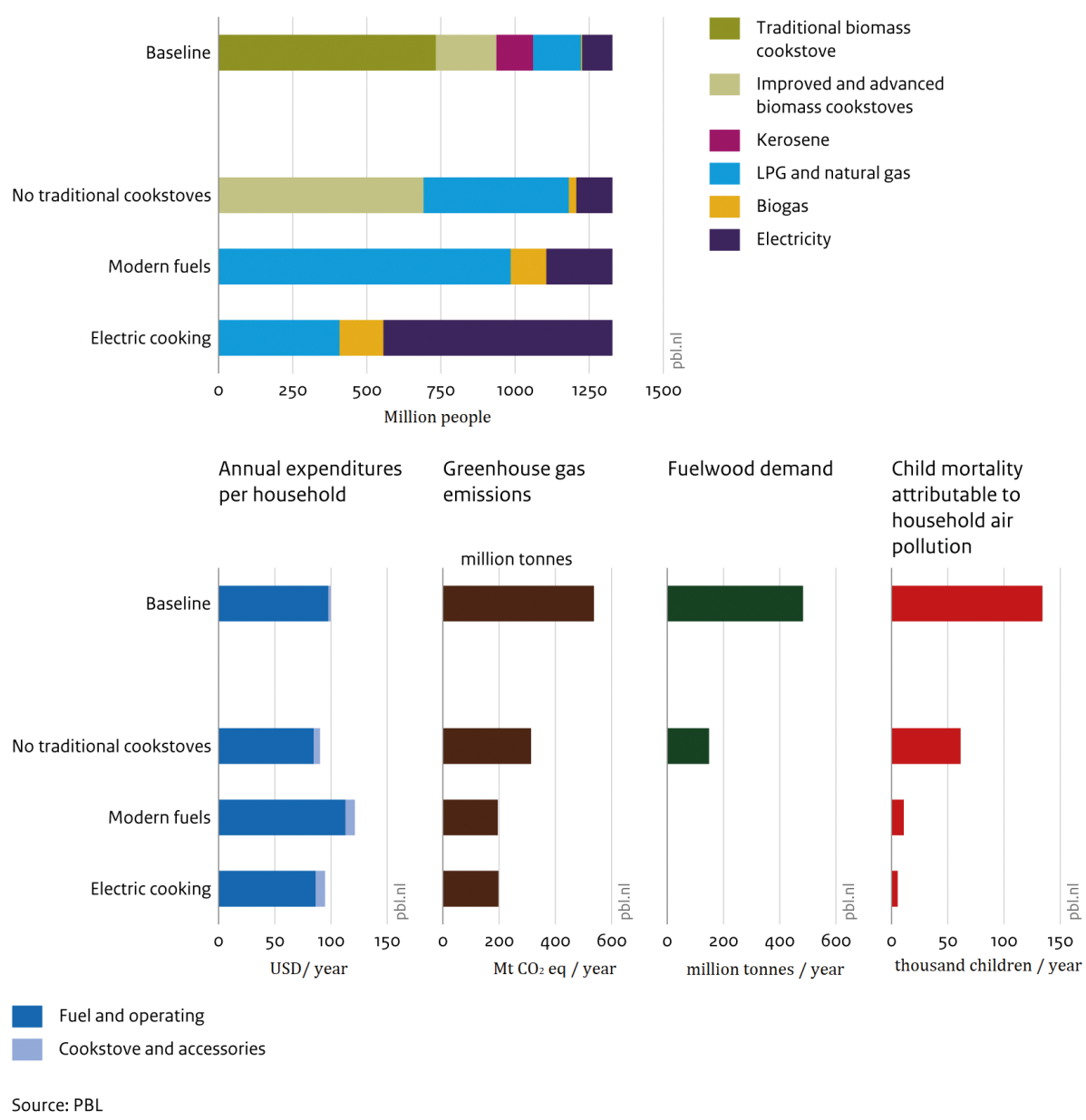

Figure 41: Implications of different pathways to clean cooking solutions in 2030 
Figure 41 presents a summary of the implications of the baseline and target scenarios in 2030. The target scenarios in the figure are: no traditional cookstove scenario - where the use of traditional cookstoves is halted by 2030, modern fuel scenario - where the use of solid biomass and kerosene is completely phased out by 2030, and electric scenario - where, in addition to complete phase out of solid biomass and kerosene, households cooking on electricity will use 50\% less energy due to changes in cooking behaviours. The top figure shows that the baseline development still leaves over 700 million people cooking primarily on traditional biomass cookstoves. Stimulating electric cooking leads to the lowest cooking expenditure for a household on average, lower than the baseline development and considerably lower than stimulating modern fuels in general (bottom figure first from left). Burning of traditional biomass emits black carbon and, if unsustainably harvested, it also releases $\mathrm{CO}_{2}$ into the atmosphere. Halting the use of traditional biomass use could considerably reduce GHG emissions (bottom figure second from left). The inefficiency of traditional biomass cookstoves is demonstrated by the saving in fuelwood demand gained by halting its use (bottom figure second from right). The particulate matters released while burning solid biomass is responsible for ALRI deaths in children under 5 years of age. The benefits of completely banning solid biomass is demonstrated by the large number of lives saved in 2030 (bottom figure first from right).

\section{Thirty million more people could be dependent on traditional biomass cookstoves in}

SSA by 2030. Access to clean and modern energy for cooking is central to social and economic development and environmental protection. Achieving universal access to clean and modern cooking fuels, technologies and services by 2030 is a SDG target. However, our analysis shows that SSA is far from being on track to achieve universal access to clean and modern cooking fuels and technologies by 2030 with the number of people lacking access to clean and modern cooking solutions increasing to 730 million (from 700 million in 2016) if current trends continue. Without supporting policies that improve the affordability and efficiency of clean cooking technologies, as well as an exceptionally rapid installation of modern fuel infrastructure, twothirds of the SSA population will rely on traditional biomass (firewood and charcoal) for decades to come. Improved and advanced biomass cookstoves could, therefore, play an important role as interim-solutions in the transition, especially in rural areas of SSA. 
Phasing out traditional biomass use could lead to up to $17 \%$ lower costs of cooking for households depending on how biomass is acquired. The annual fuel cost for cooking is several times higher than the average annual capital cost for a household. While the capital expenditure ranges from 2-8 USD/hh/year, the fuel expenditure could reach as high as $112 \mathrm{USD} / \mathrm{hh} /$ year. Saving on fuel use, either by changing to more efficient biomass cookstoves or by using less useful energy for cooking by changing to cooking on electricity, could lead to a lower cost of cooking for households. Stimulating behavioural change and promoting efficiency improvements of cookstoves play a pivotal role in facilitating the transition to clean and modern energy for cooking while at the same time lowering the burden on the household. However, depending, the transition from a cheap biomass fuel (sometimes even collected for free) to expensive modern fuels could increase household cooking expenditures despite the efficiency gains.

Phasing out traditional biomass (and kerosene) use could lower child mortality, save hundreds of millions of tons of fuelwood annually, and considerably decrease cooking-related greenhouse gas emissions. Children under 5 years of age in SSA are disproportionately affected by household air pollution. Universal access to clean and modern cooking energy could reduce child mortality rates by up to a hundred thousand in 2030. Moreover, the burning of solid biomass in traditional cookstoves is extremely inefficient and phasing out the use of traditional cookstoves could considerably reduce deforestation and forest degradation and contribute to the reduction of up to $340 \mathrm{Mt} \mathrm{CO}_{2}$ emissions by 2030 (see Figure 41). Unsustainable harvest of fuelwood is contributing to forest degradation and destruction in some parts of SSA. While the total biomass demand in SSA is well below total biomass production, several parts in western Africa and eastern Africa could experience pressure due to higher demand for fuelwood than the local production capacities. The transition towards clean and modern fuels could therefore provide environmental benefits tackling forest degradation, deforestation, soil erosion, and other natural resource impacts resulting from fuelwood collection.

Harnessing the full benefits of the transition requires reliable and affordable supply of modern fuels to prevent reverting back to traditional cookstoves. Even after purchasing the stove, the continued and proper use of the stove can be hindered 
by high fuel cost. Fuel and stove stacking are particular barriers to achieving the full benefits of clean cooking technologies. Stable supplies of affordable clean fuels and energy sources are essential to harness the full benefits of the transition. The transition can be hampered by the cost of purchasing a modern stove, particularly for the rural poor, even if these costs seem relatively low. Addressing this issue requires emphasis on innovative business models and scaling-up of micro-finance with special focus on the low-income population.

\section{Embedding solutions for clean and modern cooking energy access within broader} poverty alleviation and economic development strategies increases synergies. Universal access to clean and modern cooking solutions is inherently cross-sectoral and contributes to achieving other SDGs, for instance SDG3, SDG13, and SDG15. Therefore, creating a cross-sectoral collaboration and coordinating initiatives and policies in various sector of the economy could increase synergies and facilitate faster implementation of the goals. In that context, governments play a role in facilitating the coordination between education, health, energy and climate related programs and processes.

\subsubsection{What are the synergies and trade-offs of integrating policies to achieve goals with respect to access, efficiency and renewable energy in SSA?}

Sustainable Development Goal 7 calls for "affordable, reliable, sustainable and modern energy for all" by 2030 and it has three core targets: ensure universal access to affordable, reliable and modern energy services, increase substantially the share of renewable energy in the global energy mix, and double the global rate of improvement in energy efficiency. As income increases, demand for energy increases amid a growing use of end-use appliances. This increase can be met through increasing the supply while at the same time improving households' energy efficiency. In theory, using more efficient appliances lowers peak demand, resulting in lower generation costs, reduced need for fuel imports, and increased value of decentralized systems. Chapter 6 explores the synergies and trade-offs of the integration quantitatively by looking at the impacts on residential final energy demand, renewable energy shares, saving on investments and avoided energy-userelated residential emissions. Two models with considerable differences in model 
structure and data aggregation, IMAGE and MESSAGE, were employed to better capture uncertainties.
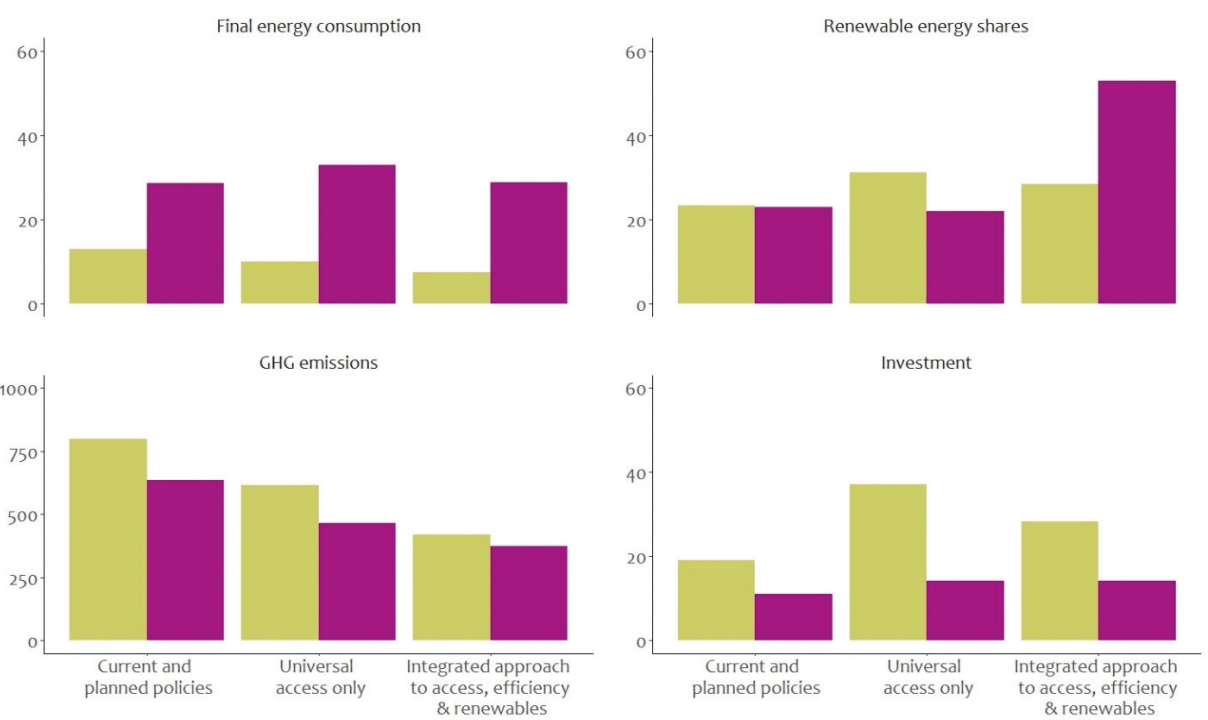

Model IMAGE MESSAGE

Figure 42: Synergies and trade-offs of integrated approach to SDG7 targets in 2030

Figure 42 summarises the results for current and planned policy scenario, solely focusing on universal access and integrating access, efficiency and renewable energy policies. Relative to the current and planned policy scenario, universal access results in a small to no increase in final energy consumption per capita, marginal increase in renewable energy shares, considerable decline in GHG emission driven by efficiency improvements and fuel switch in cooking and at least a doubling of investments in electricity and gaseous fuel infrastructure. Despite the differences in model architecture, per capita useful energy assumption, and assumptions regarding availability of fuels and stoves, the results of both models demonstrate the synergic effect of integrating strategies for the three targets of SDG7. The integration results in lower energy consumption (top left plot), higher renewable energy shares (top right plot), lower GHG emissions (lower left plot) and lower investment requirements (lower right figure) compared to achieving the universal access target alone. 
Despite the relatively low household energy demand, SSA's energy saving potential is significant and is expected to remain untapped without policy change (see Figure 42). Cooking is largely done with inefficient traditional biomass-cookstoves. Other household appliances such as light bulbs, air conditioners and refrigerators are highly inefficient. Switching from traditional biomass cookstoves to efficient biomass and modern fuel cookstoves offers the largest opportunity for reducing household energy demand. Similarly, deploying the most efficient household appliances that are currently on the market enable providing a wide range of services with distributed systems. If policies are integrated, the final energy consumption per capita could be lower by $13-25 \%$ relative to pursuing the universal access target alone. As enduse energy requirements decrease, given the high renewable-energy potential in the region, the opportunity for low-energy density renewable sources to meet energy needs increases. This requires expanding energy efficiency related financial resources, facilitating access to credit and building local capacity for mobilizing capital for energy efficiency programs.

The integration of energy access, renewable energy and energy efficiency policies could considerably lower investment requirements, reduce average household energy expenditure, and improve reliability of systems. The saving achieved in final energy consumption through the adoption of energy efficient household appliances lowers supply requirements. The total saving in electricity consumption while integrating policies for access, efficiency and renewables could reach up to 290 TWh by 2030, reducing peak load and allowing lower system capacity requirements for decentralised renewable-based energy systems. The investment requirement of 14-28 billion USD a year on average is up to $31 \%$ lower than the investment required to solely provide universal access. Avoided investments in additional generation, and in expanding the transmission and distribution network can be invested in additional energy conservation measures. The adoption of energy-efficient household appliances also lowers the household energy demand, thereby reducing energy related household expenditure. This, however, requires targeted policies to protect the poor from increasing energy prices, designing and enforcing of national standards and labelling for household appliances and equipment efficiency to protect consumers, investments in research and development, and facilitating access to finance. 
The integration of policies stimulates the expansion of energy services while reducing the impact on the climate relative to just achieving the universal access target. Linked to projected increases in population and income growth, residential GHG emissions in SSA are expected to grow rapidly as energy demand increases. Integration of the policies to achieve the three SDG7 targets reduces final energy demand, increases renewable energy shares and facilitates expansion of services, while reducing energy-use related residential emissions. Higher reduction in GHG emissions is achieved through the increased implementation of decentralized electrification technologies (as a result of lower demand density), elimination of traditional biomass-cookstoves, increased deployment of improved and advanced biomass-cookstoves, and faster transition to modern fuel cookstoves.

\subsection{Discussion}

Delivering on the goal of universal access to modern energy services in SSA is a tremendous endeavour with significant challenges. While recognizing that there are various pathways to delivering universal access to modern energy services, the overall message of this thesis is the importance of considering synergies and tradeoffs between various policy instruments not only on the wider energy system but also on the social, economic and environmental dimensions. With the help of an IAM, the findings of this research give insight into the broader implications of various policy measures in terms of investment requirements, and health and environmental impacts.

The rapid decline in the costs of renewable energy technologies has been a driving force for the progress towards universal access to electricity in SSA. Decentralised systems, together with innovative marketing techniques, have created new opportunities to provide access to affordable electricity for all households. There is also a positive trend in clean cooking technology innovation, which, together with a growing number of middle classes with disposable incomes and rapid urbanization, is changing the dynamics of the cooking landscape. However, these developments have also created challenges for traditional energy planning. Determining the costs and benefits between various technologies requires extensive computation, making energy system models crucial tools for long-term planning. However, lack of 
infrastructure, high reliance on traditional energy sources, the existence of a large informal sector, and lack of reliable data make modelling the SSA energy system challenging. Most energy system models lack the representation of the unique nature of regional and local circumstances in SSA, a gap that this thesis intended to - at least partly - address.

This thesis uses an extended version of the residential energy model developed by [37] \& [38], integrated within the IMAGE model in chapters 2 - 5 and MESSAGE together with IMAGE in chapter 6 . This work improves upon previous works by adding a host of decentralised systems for electricity access and more solutions for clean cooking. The electrification model consists of a custom-built decision tree for allocating the least-cost electrification technology based on population density, the level of demand, resource availability, and the cost of the technology. We use data on a $0.5^{\circ} \mathrm{X} 0.5^{\circ}$ grid-cell for population size, population density, renewable energy potentials and renewable energy prices, allowing a more detailed representation of demand density, energy resource potentials and technology prices than when only regional dynamics are considered. The computation is made on annual basis taking into consideration the impact of change in the prices of electrification technologies.

The developed methodology allows strategic planning by determining the leastcost option for universal access to electricity and clean cooking decades ahead. The analysis highlights the need for long-term planning to capture the rapidly changing technology prices and the growing demand for energy. The least-cost option is given for a variety of scenarios ranging from tier-1 to tier- 5 for electricity and from allowing improved biomass cookstoves to completely phasing out solid biomass for cooking. This variety allows exploring the impact of scenarios based on governments' priorities and levels of ambition. The thesis also sought to identify the roles of individual and institutional actors and the role of regulations in the transition towards universal electricity access in the region. In addition to IAM, the methodology involved i) workshops conducted in the Netherlands and Ethiopia with actors involved in the region's electricity system, ii) case studies of centralized and decentralized electrification programs and projects in Nigeria, Ghana, Tanzania, and Ethiopia, and iii) a desk study. 
This thesis, however, also has some important limitations. First of all, our analysis is based on a specific set of socio-economic projections. In this thesis, the scenarios are all based on the exogenous assumptions and projections of population growth, economic development, rate of technology change, and rates of urbanization of the Shared Socioeconomic Pathways (SSPS), as implemented in IMAGE. The SSPs are the result of an iterative community process and provide a common framework for the exploration of mitigation policies, impacts, adaptation options and changes to the physical earth system. Most of the analysis in this book is based on the SSP2 scenario because it represents a 'middle-of-the-road' development regarding population and economic growth. As demonstrated in the sensitivity analysis of chapter 5 , these projections are surrounded by large uncertainties, hence, different projections could result in different outcomes in the long term. Faster rates of growth in economic activity, population and urbanisation could lead to higher energy demand affecting the role of centralised and decentralised systems for universal access.

Secondly, in the model framework used, without additional policies, access to electricity is driven by changes in household income level. Critically assessed, however, it is too simplistic to assume a direct link between income and electricity access for a number of reasons: income is distributed in an uneven manner, government budgets are stretched thin, hence, might opt not to invest in electricity infrastructure, several institutional challenges exist as discussed earlier, and technical and geographical limitations exist for grid connections.

Thirdly, data availability is very limited. The underlying data are collected from several sources that often use varying methodologies and inconsistence definitions. The collected data also differ in terms of aggregation level; resource availability is calculated at grid-cell level, electrification rate is derived from national data, and regional average is used for income and household size. This difference in the level of granularity brings its own challenge in upscaling and downscaling. Some assumptions are taken to account for missing data as well. For instance, we assume that everyone that has access in 2010 was connected to the central grid. Obviously, this might skew the result in favour of the central grid. If off-grid systems had considerable share, it could lead to different dynamics in the long-term projections. 
Fourthly, this thesis is based on residential energy demand for lighting, cooking, water heating, space heating and space cooling. We do not include the impact of income-generating activities that households might conduct to support livelihood once they have access to electricity. This implies that the role of the informal economy, which is a significant business activity in most developing countries, is not taken into account to project demand and access. If considered, it could increase the consumption density of a settlement, which might affect the optimal least-cost technology allocation.

Finally, energy access in this thesis is defined as the ability to fulfil household energy services, such as, lighting, cooking, water heating, space heating, space cooling, and appliance use. As such, the thesis equates access to appliance ownership and physical access to specific energy carriers and do not address the impact of other relevant factors, such as household-head gender, household-head age, cultural norm and consumer preferences, education level, access to finance, land tenure and other technical and social aspects, on energy service needs, appliances choices, and affordability. For instance, household-head gender, household-head education level and family-size can impact the choice for clean fuels. According to [195] femaleheaded households and household-heads with higher levels of education are more likely to choose cleaner fuel than male-headed household. Big family size provides a lot of free labour and the family is more likely to depend on traditional biomass such as dung and crop residue. Studies [196] also show that households with access to credit are more likely to switch from traditional fuels to more efficient and cleaner energy. The impact of land tenure on electricity access is also important as it raises several concerns such as the difficulty of estimating energy demand and securing revenues for utility providers from informal settlement dwellers [197]. Though it does not address the bigger human rights issues, decentralized systems could be technically feasible solution to provide access in these situations. Therefore, neglecting the issue of informal settlement might have led to an over estimation of the central grid potential, especially in the Republic of South Africa. However, the financing of the systems still remain uncertain as the urban poor cannot afford the required investment, and the informal status of the houses makes access to credit difficult. 


\subsection{Conclusions}

With the limitations discussed above in mind, the thesis investigates synergies and trade-offs between various policy measures. The results demonstrate that several fuels and technologies, decentralised and centralised, fossil and renewable, traditional and modern, all play vital roles in achieving universal access to clean and modern energy for all in SSA by 2030. However, strategies to achieve this goal should also consider possible trade-offs and synergies with other SDGs and targets within the SDGs, including how they affect greenhouse gas emissions.

\section{Various technologies could contribute to achieving the target to ensure universal} access to reliable and affordable electricity in SSA by 2030 with significant benefits. Universal access to electricity and clean and modern energy for cooking is central to social and economic development and environmental protection. Between now and 2030, policies will need to ensure access to electricity for over 500 million new customers that could improve education, health, security, and productivity. Various technologies, central-grid, mini-grid and standalone, contribute to providing access to electricity while their role depends on the level of ambition set by governments. Due to the low consumption levels, remote settlements and under-developed infrastructure in SSA, to achieve universal electricity access, on-grid systems will need to be complemented with off-grid technologies. While on-grid electricity would be cost-effective in most cases, renewable mini-grid technologies could provide electricity access to over 180 million people, depending on the targeted level of consumption. Decentralized renewable-energy-based systems, largely based on solar photovoltaic technology, can be implemented with relatively low initial investment, gradually scaling up capacity as the level of consumption increases. However, in large parts of western and southern Africa, due to their high population density and relatively high household electricity consumption, the central grid remains the preferred electrification option. In these regions, providing universal electricity access requires major investments in generation capacity and transmission and distribution. At the same time, implementing international climate policy could lead to higher shares for renewable energy-based decentralised systems and make universal access to electricity cheaper. This is an important synergy between climate policy and electricity access. Universal access is projected to require annual investments of US\$27 billion with climate policy and up to US\$33 billion without one. 
Carbon pricing lowers the required investments through efficiency improvements in household appliances and learning in renewable energy technologies. While this increases electricity prices, an important trade-off, it could also be considered an opportunity to move away from fossil fuels and improve energy security.

\section{Several pathways could lead to universal access to clean and modern cooking} fuels and technologies with considerable benefits for human health and the environment. Universal access to clean and modern energy for cooking is also crucial for social and economic development and environmental protection. Our research demonstrates that current trends do not lead to achieving universal access to clean and modern cooking solutions in 2030. Lack of access to clean cooking facilities remains an acute problem in SSA, with nearly a billion people relying on solid biomass and kerosene as their primary cooking fuel. The transition towards universal access to clean and modern cooking energy can be achieved by stimulating adoption of improved and advanced biomass cookstoves, providing subsidies for modern fuels and cookstoves, halting the use of traditional biomass cookstoves, expanding infrastructure for modern fuels, or stimulating behavioural change in cooking traditions and cultures. Phasing out traditional biomass (and kerosene) use could have multiple benefits - decreasing child mortality by a hundred thousand in 2030, reducing forest degradation and deforestation by cutting fuelwood demand by up to $70 \%$, reducing energy-related emissions by as much as $64 \%$, and lowering the average cost of cooking. Achieving the target to ensure universal access to clean and modern cooking solution in 2030 requires considerable investments in stoves and fuels, ranging from 90 to 160 USD/hh/year, of which $93-97 \%$ consists of annual fuel expenditure. The continued and proper use of the stove can be hindered by high fuel cost for modern stoves and studies demonstrate that fuel and stove stacking is a particular barrier to achieving the full benefits of clean cooking technologies. Hence, the focus on accessibility and affordability of modern fuels is crucial to harness the full benefits of the transition. However, though relatively low, the transition can also be hampered by the cost of adopting clean cooking stoves, particularly for the rural poor. This can be tackled by fostering enabling environment for innovative business models and strengthening the supply by attracting more consumer finance and investment from various stakeholders. 
Universal energy access can benefit from integrating policies for the three targets of SDG7 - energy access, energy efficiency and renewable energy. Higher energy efficiency improvements allow for providing a wide range of services with distributed systems, while distributed renewable energy expansion reduces conversion and transmission losses in the region. That way, the integration stimulates the expansion of energy services while reducing the investment requirements and the impact on the climate. Despite the relatively low level of energy consumption, there is a large untapped potential for efficiency improvement in SSA, especially in cooking. Other household appliances in SSA are also typically far less efficient than the best available units on the market. Integration of policies for the three core targets of SDG7 could result in lower final energy consumption per capita, higher renewable energy shares, lower annual infrastructure investment, and lower energy-related residential emission relative to exclusively pursuing the universal access target. The improvement in the efficiency of household appliances could enable the use of minigrid and stand-alone systems to provide energy beyond lamps and radios, to meet demands for cooling, heating, and electric cooking services. With lower cost of end-use service delivery, money saved can be used to finance additional efficiency improvements and/or in the deployment of renewables.

\section{Governance is the essential component of the transition towards universal access} to clean and modern energy. Governance is an enabler to overcome the trade-offs and enhance the synergies between policy measures, actors and their resources. While countries have embraced multiple technologies to achieve the goal of ensuring universal access to affordable, reliable, sustainable and modern energy, solutions are often deployed independently of one another rather than designed as complementary solutions that form part of a cohesive vision for delivering universal access. For instance, a lack of clear electrification plans from governments and complementary policy and regulation to facilitate deployment of multiple energy access technologies could result in fragmented solutions and in many cases stagnated progress. This creates a major challenge in addressing the electricity access gap at scale. Similarly, strategies that promote a single fuel or cookstove use for universal access usually ignore the local economic, cultural, logistic, and other household characteristics and give suboptimal results. While no single recipe for universal energy access exists, the evidence points to some facilitative ingredients 
that are foundational—including the right institutions, strategic planning, strong regulations, and appropriate incentives. Facilitating universal access requires institutions that stimulate innovation in supply technology and business models by establishing a functioning energy market for both service providers and consumers. The institutions in SSA are generally weak and unable to cope with population growth and technology developments. Especially for off-grid systems, stable and consistent policy frameworks, clear technical standards, and certification for new technologies are crucial. It is also important that governments encourage multisectoral coordination and action between various sectors and agencies to harness the full potential of the synergies and manage (or at least anticipate) the trade-offs. Therefore, active involvement of all stakeholders to jointly explore, develop and scale a combination of pathways towards universal access to affordable, reliable, sustainable and modern energy is critical.

\subsection{Further research}

The energy sector has a significant and productive role to play in achieving several of the sustainable development objectives. Access to electricity and clean cooking solutions can be achieved through centralised or decentralised systems, and a multitude of technologies. The appropriate system and technology for electrification and modern cooking energy is determined by various determinants, such as the level of energy demand, the cost of the technology, availability of resources, and availability of infrastructure. Given the financial constraints of developing countries, it is important to explore the pathways with the least additional investment burden to ensure universal access. Identifying the least-cost option for electricity and modern cooking energy is dependent on the determinants mentioned previously and their interactions, making long-term planning challenging. To add to the challenge, the availability and the cost of any technology vary in space and time, making the computational challenges substantial. To address this challenge, energy system models have become important tools for long-term energy planning. Our model is designed to provide insight into these interactions and their role in determining least-cost technologies to support decision making. However, some additional enhancements in our model methodology would improve the quality of the results. 
Involving key actors and institutions in energy system modelling could improve reliability of models while aiding decision-making on an optimal energy mix for universal access. Energy planning involves the participation of various actors concerning the supply as well as the demand of energy in the future. These actors bring their own interest to the table and play a role in a complex decision making and implementation processes. In chapter 4, we qualitatively discussed the importance of governance in achieving the universal access target in SSA, which is usually ignored in model-based studies that focus on cost. We still do not address important policy drivers such as social equity, political economy, and human behaviour or embed the analysis in socio-technical transitions theories. Nevertheless, chapter 4 highlighted the gap between existing and desired institutional structures pointing out the institutional and financial limitation that stifle the transition. The uncertainties about the source of large sums of finance to fund the electrification and expanding modern cooking solution remain unanswered. Given the fact that large parts of rural SSA consume very low amounts of electricity, off-grid technologies are expected to play a crucial role. This increases the importance of private sector investment. Involving actors in determining not only the feasibility of technology and infrastructure choices but also in determining which questions the models should answer could increase the reliability of the models and the feasibility of recommended pathways. A quantitative analysis of the governance impacts on private sector investment that will affect technology distribution for electricity and clean cooking could be a valuable contribution in energy modelling.

\begin{abstract}
A better understanding of the impact of productive uses of energy for households that start small businesses to support their livelihood could add value to long-term energy planning. The electricity demand density of a settlement is a very important component for determining the distribution of systems and technologies. Universal access to electricity in this thesis is defined based on fulfilling the electricity demand for the five residential end-use services. In practice, electricity needs to be available reliably and affordably not only for households to access meaningful services but also for income-generating activities. Productive uses of energy, such as agroprocessing, carpentry, tailoring, welding, looming, and bars and restaurants that use electricity, are also being referred by several developing countries as one of their intended outcomes of their energy access programmes. Research shows
\end{abstract}


that promoting productive uses of energy not only facilitate economic and social development, it can also help to improve the economic and financial sustainability of electrification programmes. Our model only partially addresses the demand for productive uses that can be a significant driver of economic growth and social progress in SSA. Therefore, exploring long-term impacts of productive uses of energy on technology distribution, investment and GHG emissions using a sound methodology is a key step to improving long-term projections.

Adequate modelling of the energy system of developing countries requires recognizing the unique characteristics of the regions and a strong collaboration with local experts. As discussed in the introduction, most energy models are developed in industrialized countries, so that the assumption on future development of the energy system is largely based on the experience from industrialised nations. Our methodology addresses some of the important characteristics of SSA's energy systems, such as differences in levels of consumption, lack of infrastructure, availability of resources, differences in population density, lack of access to electricity, and the dominance of traditional biomass in the energy system. The energy system in developing countries is also characterised by poor performance of the power sector, too low electricity prices, widespread informal economy, non-monetary transactions, corruption, political instability, inadequate investment decisions, and abuse or inadequate use of subsidies, all of which influence the performance of the sector. Though choices have to be made amid data constraints and computational limitations, energy models should address these deficiencies for adequate modelling amid scenario-making of the regional energy future. Nonetheless, there should be no substitute to local knowledge and experience from modellers and other experts in Sub-Sahara African institutes. Establishing a collaboration with local experts and building capacity for energy system modelling could improve the ownership of the results.

\section{A better representation of current and future development in SSA requires} aggregated, updated and harmonized datasets that are adequate, reliable and easily accessible. Models require considerable data to perform their analysis and lack of reliable data is a constraint particularly in developing countries. Beyond a solid methodology to determine the emergence and consumption of productive activities, the role of governance and a better representation of the energy system, 
high resolution gridded data set for access and level of consumption, based on nighttime satellite data, for instance, could add to the unique character of settlements in developing countries and hence improve long-term projections. Geospatial data is also important to monitor variations in electrification status of settlements and differences in consumption levels in order to adjust electrification strategies accordingly. Similarly, reliable, transparent, consistent, and well documented data on cost of electrification and cooking technologies and availability and prices of modern fuels could improve projections for optimal supply mix.

The methodologies developed in this thesis can be further enhanced by addressing the points mentioned above. The IMAGE model is useful to show general trends in global and regional development and related climate impact. The results of the model show the long-term potentials of systems and technologies, giving insight into the important drivers of the energy sector development in a region. Most countries in the regions are at a similar level of socio-economic development and they can benefit from collective actions for sharing energy resources and tackling climate change. The model provides bilateral and multilateral donors a broader view of possible long-term developments of the regional energy sector. The method can be employed to identify the opportunities and pitfalls of policy decisions for energy access, health, and climate goals in order to take advantage of the synergies and limit or manage the trade-offs. The model can also be used by the private sector (and governments) to broadly assess market opportunities for renewable energy sources and decentralized electrification systems at regional level. The results could be useful to direct a specific type of detail research for countries, for instance, potentials for investment in a specific technology or system in a given location. 

8. References 


\section{Chapter 8}

1. Stehfest, E., et al., ntegrated Assessment of Global Environmental Change with IMAGE 3.0: Model description and policy applications. 2014, The Hague: PBL Netherlands Environmental Assessment Agency.

2. van Vuuren, D.P., et al., TIMER 2: Model description and application, in Integrated modelling of global environmental change: An overview of IMAGE 2.4, A.F. Bouwman, T. Kram, and K.K. Goldewijk, Editors. 2006, Netherlands Environmental Assessment Agency (MNP): Bilthoven. p. 39-60.

3. Woltjer, G.B., et al., The MAGNET Model: Module description. 2014, LEI Wageningen UR (University \& Research centre): Wageningen.

4. Kanagawa, M. and T. Nakata, Assessment of access to electricity and the socio-economic impacts in rural areas of developing countries. Energy Policy, 2008. 36(6): p. 2016-2029.

5. Dinkelman, T., The Effects of Rural Electrification on Employment: New Evidence from South Africa. American Economic Review, 2011. 101(7): p. 3078-3108.

6. Kirubi, C., et al., Community-Based Electric Micro-Grids Can Contribute to Rural Development: Evidence from Kenya. World Development, 2009. 37(7): p. 1208-1221.

7. Dagnachew, A.G., et al., Scenario analysis for promoting clean cooking in Sub-Saharan Africa: Costs and benefits. Energy, 2020. 192.

8. IEA, World Energy Outlook 2019. 2019, International Energy Agency. p. 810.

9. IEA, Boosting the Power Sector in Sub-Saharan Africa: China's Involvement. 2016, International Energy Agency Paris.

10. Dagnachew, A.G., et al., The role of decentralized systems in providing universal electricity access in Sub-Saharan Africa - A model-based approach. Energy, 2017. 139: p. 184-195.

11. World Bank. World Development Indicators. 2016 [cited 2019 7-9-2019]; Available from: http://data. worldbank.org/indicator/EG.USE.ELEC.KH.PC.

12. Schlag, N. and F. Zuzarte, Market Barriers to Clean Cooking Fuels in Sub-Saharan Africa: A Review of Literature. 2008, Stockholm Environment Institute.

13. Stanaway, J.D., et al., Global, regional, and national comparative risk assessment of 84 behavioural, environmental and occupational, and metabolic risks or clusters of risks for 195 countries and territories, 1990-2017: a systematic analysis for the Global Burden of Disease Study 2017. The Lancet, 2018. 392(10159): p. 1923-1994.

14. Dagnachew, A.G., et al., Trade-offs and synergies between universal electricity access and climate change mitigation in Sub-Saharan Africa. Energy Policy, 2018. 114(C): p. 12.

15. Mainali, B., et al., Evaluating Synergies and Trade-Offs among Sustainable Development Goals (SDGs): Explorative Analyses of Development Paths in South Asia and Sub-Saharan Africa. Sustainability, 2018. 10(3).

16. UN, Transforming our world: The 2030 agenda for sustainable development. 2015, United Nations.

17. Fuso Nerini, F., et al., Mapping synergies and trade-offs between energy and the Sustainable Development Goals. Nature Energy, 2017. 3(1): p. 10-15.

18. van Soest, H.L., et al., Analysing interactions among Sustainable Development Goals with Integrated Assessment Models. Global Transitions, 2019. 1: p. 210-225. 
19. UN-DESA, Accelerating SDG 7 achievement: Policy briefs in support of the first SDG 7 review at the UN High-Level Political Forum 2018. 2018.

20. McCollum, D.L., et al., Connecting the sustainable development goals by their energy inter-linkages. Environmental Research Letters, 2018.13(3).

21. IEA / UNDP / IRENA, Policy Brief\#1: Achieving Universal Access to Electricity. 2018.

22. Batchelor, S., et al., Two Birds, One Stone-Reframing Cooking Energy Policies in Africa and Asia. Energies, 2019. 12(9).

23. McCollum, D., et al., SDG 7 Ensure Access To Affordable, Reliable, Sustainable And Modern Energy For All, in A Guide To SDG Interactions: From Science To Implementation, D.J. Griggs, et al., Editors. 2017, International Council for Science (ICSU): Paris, France.

24. Mulugetta, Y., E. Ben Hagan, and D. Kammen, Energy access for sustainable development. Environmental Research Letters, 2019. 14(2).

25. McCollum, D., et al., SDG 7 Ensure Access to Affordable, Reliable, Sustainable And Modern Energy for All, in A guide to SDG interactions: from science to implementation, D.J. Griggs, et al., Editors. 2017, International Council for Science: Paris. p. 127-173.

26. Daioglou, V., et al., Integrated assessment of biomass supply and demand in climate change mitigation scenarios. Global Environmental Change, 2019. 54: p. 88-101.

27. Neshat, N., M.R. Amin-Naseri, and F. Danesh, Energy models: Methods and characteristics. Journal of Energy in Southern Africa, 2014. 25(4).

28. Urban, F., R.M.J. Benders, and H.C. Moll, Modelling energy systems for developing countries. Energy Policy, 2007. 35(6): p. 3473-3482.

29. Silva Herran, D. and T. Nakata, Design of decentralized energy systems for rural electrification in developing countries considering regional disparity. Applied Energy, 2012. 91(1): p. 130-145.

30. Ouedraogo, N.S., Africa energy future: Alternative scenarios and their implications for sustainable development strategies. Energy Policy, 2017. 106: p. 457-471.

31. al Irsyad, M.I., et al., Selecting Tools for Renewable Energy Analysis in Developing Countries: An Expanded Review. Frontiers in Energy Research, 2017. 5.

32. Deichmann, U., et al., The economics of renewable energy expansion in rural Sub-Saharan Africa. Energy Policy, 2011. 39(1): p. 215-227.

33. Parshall, L., et al., National electricity planning in settings with low pre-existing grid coverage: Development of a spatial model and case study of Kenya. Energy Policy, 2009. 37(6): p. 2395-2410.

34. Mentis, D., et al., Lighting the World: the first application of an open source, spatial electrification tool (OnSSET) on Sub-Saharan Africa. Environmental Research Letters, 2017. 12(8): p. 085003.

35. Zeyringer, M., et al., Analyzing grid extension and stand-alone photovoltaic systems for the costeffective electrification of Kenya. Energy for Sustainable Development, 2015. 25: p. 75-86.

36. Winkler, H., A. Hughes, and M. Haw, Technology learning for renewable energy: Implications for South Africa's long-term mitigation scenarios. Energy Policy, 2009. 37(11): p. 4987-4996.

37. van Ruijven, B.J., J. Schers, and D.P. van Vuuren, Model-based scenarios for rural electrification in developing countries. Energy, 2012. 38(1): p. 386-397. 


\section{Chapter 8}

38. Daioglou, V., B.J. van Ruijven, and D.P. van Vuuren, Model projections for household energy use in developing countries. Energy, 2012. 37(1): p. 601-615.

39. Ouedraogo, N.S., Modeling sustainable long-term electricity supply-demand in Africa. Applied Energy, 2017. 190: p. 1047-1067.

40. Heinrich, G., et al., Electricity supply industry modelling for multiple objectives under demand growth uncertainty. Energy, 2007. 32(11): p. 2210-2229.

41. Beck, J., et al., A complex systems approach to planning, optimization and decision making for energy networks. Energy Policy, 2008. 36(8): p. 2795-2805.

42. Stehfest, E., et al., Integrated Assessment of Global Environmental Change with IMAGE 3.0: Model description and policy applications. 2014, The Hague: PBL Netherlands Environmental Assessment Agency.

43. Doelman, J.C., et al., Exploring SSP land-use dynamics using the IMAGE model: Regional and gridded scenarios of land-use change and land-based climate change mitigation. Global Environmental Change, 2018. 48: p. 119-135.

44. Lucas, P., et al., Future impacts of environmental factors on achieving the SDG target on child mortality - a synergistic assessment. Global Environmental Change, Submitted.

45. Lucas, P.L., et al., Future impacts of environmental factors on achieving the SDG target on child mortality - a synergistic assessment, in PBL Working paper 24. 2018, PBL Netherlands Environmental Assessment Agency: The Hague.

46. IEA, Energy and Climate Change WEO 2015. 2015.

47. IEA, Africa Energy Outlook-A focus on energy prospects in Sub-Saharan Africa. 2014.

48. Sokona, Y., Y. Mulugetta, and H. Gujba, Widening energy access in Africa: Towards energy transition. Energy Policy, 2012. 47: p. 3-10.

49. Lucas, P.L., et al., Future energy system challenges for Africa: Insights from Integrated Assessment Models. Energy Policy, 2015. 86: p. 705-717.

50. Bazilian, M., et al., Energy access scenarios to 2030 for the power sector in sub-Saharan Africa. Utilities Policy, 2012. 20(1): p. 1-16.

51. Pachauri, S. and A. Brew-Hammond, Energy Access for Development in The Global Energy Assessment- Toward a Sustainable Future, J. Sathaye, Editor. 2012, Cambridge University Press: Cambridge. p. 1401-1458.

52. Mentis, D., et al., A GIS-based approach for electrification planning-A case study on Nigeria. Energy for Sustainable Development, 2015. 29: p. 142-150.

53. Mentis, D., et al., The benefits of geospatial planning in energy access - A case study on Ethiopia. Applied Geography, 2016. 72: p. 1-13.

54. APP, Power, People, Planet: Seizing Africa's Energy and Climate Opportunities 2015, Africa Progress Panel.

55. Scott, A. and P. Seth, The political economy of electricity distribution in developing countries: A review of the literature. 2013, Overseas Development Institute: London. 
56. Ahlborg, H. and L. Hammar, Drivers and barriers to rural electrification in Tanzania and Mozambique - Grid-extension, off-grid, and renewable energy technologies. Renewable Energy, 2014. 61: p. 117124 .

57. Palit, D. and A. Chaurey, Off-Grid Rural Electrification Experiences from South Asia, in Rural Eelectrification Through Decentralized Off-Grid Systems in Developing Countries, S. Bhattacharyya, Editor. 2013, Springer-Verlag: London.

58. DFID, Low Carbon Mini Grids - "Identifying the gaps and building the evidence base on low carbon mini-grids" 2013, Department For International Development

59. IEA, Enery For All: Financing access for the poor. 2011, International Energy Agency: Paris, France.

60. World Bank, Addressing the Electricity Access Gap: Background Paper for the World Bank Group Energy Sector Strategy. 2010, World Bank Group.

61. Hoogwijk, M., On the global and regional potential of renewable energy sources. 2004, Utrecht University.

62. IRENA, Renewable Energy Technologies: Cost Analysis Series- Solar Photovoltaics. 2012.

63. Kemausuor, F., et al., Electrification planning using Network Planner tool: The case of Ghana. Energy for Sustainable Development, 2014. 19: p. 92-101.

64. IEA, Comparative Study On Rural Electrification Policies In Emerging Economies- Keys To Successful Policies. 2010, International Energy Agency.

65. Open Street Maps. Project Power Networks. 2015

66. Bright, E.A., A.N. Rose, and M.L. Urban. Landscan digital raster data. 2013; Available from: http:// www.ornl.gov/landscan/.

67. Fuso Nerini, F., et al., A cost comparison of technology approaches for improving access to electricity services. Energy, 2016. 95: p. 255-265.

68. Rahman, M.M., J.V. Paatero, and R. Lahdelma, Evaluation of choices for sustainable rural electrification indeveloping countries: A multicriteria approach. Energy Policy, 2013. 59: p. 11.

69. Palit, D. and A. Chaurey, Off-grid rural electrification experiences from South Asia: Status and best practices. Energy for Sustainable Development, 2011: p. 266-276.

70. Ibrahim, H., et al. Wind-Diesel hybrid system: energy storage system selection method. in The 12th International Conference on Energy Storage. 2012.

71. Hong, C.-M., T.-C. Ou, and K.-H. Lu, Development of intelligent MPPT (maximum power point tracking) control for a grid-connected hybrid power generation system. Energy, 2013. 50: p. 270-279.

72. Ou, T.-C. and C.-M. Hong, Dynamic operation and control of microgrid hybrid power systems. Energy, 2014. 66: p. 314-323.

73. van Vuuren, D.P., et al., The Shared Socio-economic Pathways: Trajectories for human development and global environmental change. 2017.

74. O'Neill, B.C., et al., The roads ahead: Narratives for shared socioeconomic pathways describing world futures in the 21st century. Global Environmental Change, 2015. 


\section{Chapter 8}

75. van Vuuren, D.P., et al., Energy, land-use and greenhouse gas emissions trajectories under a green growth paradigm. Global Environmental Change, 2016.

76. ESMAP, Beyond Connections: Energy Access Redefined. 2015, The World Bank Group: Washington DC.

77. Bhatia, M. and N. Angelou, Capturing the Multi-Dimensionality of Energy Access. 2016, The World Bank.

78. World Bank, Beyond Connections: Energy Access Redefined. 2015, THE WORLD BANK GROUP.

79. UNFCCC, FCCC/CP/2015/L.9/Rev.1: Adoption of the Paris Agreement. 2015, Paris, France: UNFCCC. 1-32.

80. Hollberg, P., Swarm grids - Innovation in rural electrification, in Department of Energy Systems Analysis. 2015, KTH School of Industrial Engineering and Management.

81. IEA, Africa Energy Outlook. A focus on energy prospects in Sub-Saharan Africa. World Energy Outlook Special report. 2014, International Energy Agency: Paris, France.

82. van Vuuren, D.P., et al., An energy vision: the transformation towards sustainability —interconnected challenges and solutions. Current Opinion in Environmental Sustainability, 2012. 4(1): p. 18-34.

83. IRENA, Renewable Power Generation Costs in 2014. 2015, IRENA: Abu Dhabi.

84. UN-OHRLLS, Role of the private sector in advancing the implementation of the IPOA: Focus on sustainable energy. 2014, United Nations.

85. Pachauri, S., Household electricity access a trivial contributor to $\mathrm{CO}_{2}$ emissions growth in India. Nature Climate Chanage, 2014. 4: p. 4.

86. Sanchez, T. and T. Tozicka, Energy for all 2030: Rural electrification: The role of the public sector and collective action on electricity access for the poor. 2013, Practical Action.

87. Cameron, C., et al., Policy trade-offs between climate mitigation and clean cook-stove access in South Asia. Nature Energy, 2016. 1: p. 15010.

88. Lucas, P.L., et al., Implications of the international reduction pledges on long-term energy system changes and costs in China and India. Energy Policy, 2013. 63: p. 1032-1041.

89. IEA, World Energy Outlook 2015. 2015, IEA: Paris.

90. van Vuuren, D., et al., Energy Supply and Demand, in Integrated Assessment of Global Environmental Change with IMAGE 3.0 - Model description and policy applications, E. Stehfest, et al., Editors. 2014, PBL: The Hague.

91. van Vuuren, D.P., et al., The Shared Socio-economic Pathways: Trajectories for human development and global environmental change. 2017.

92. O'Neill, B.C., et al., A new scenario framework for climate change research: the concept of shared socioeconomic pathways. Climatic Change, 2013. 122(3): p. 387-400.

93. Kc, S. and W. Lutz, The human core of the shared socioeconomic pathways: Population scenarios by age, sex and level of education for all countries to 2100. Global Environmental Change, 2017. 42: p. 181-192. 
94. Dellink, R., et al., Long-term economic growth projections in the Shared Socioeconomic Pathways. Global Environmental Change, 2017. 42: p. 200-214.

95. Jiang, L. and B.C. O'Neill, Global urbanization projections for the Shared Socioeconomic Pathways. Global Environmental Change, 2017. 42: p. 193-199.

96. Van Vuuren, D.P., et al., Energy, land-use and greenhouse gas emissions trajectories under a green growth paradigm. Global Environmental Change, 2017. 42: p. 237-250.

97. Szabo, S., et al., Energy solutions in rural Africa: mapping electrification costs of distributed solar and diesel generation versus grid extension. Environmental Research Letters, 2011. 6(3): p. 034002.

98. IRENA, Rethinking Energy: Accelerating the global energy transformation. 2017, International Renewable Energy Agency: Abu Dhabi.

99. Alstone, P., D. Gershenson, and D.M. Kammen, Decentralized energy systems for clean electricity access. Nature Clim. Change, 2015. 5(4): p. 305-314.

100. Brahmbhatt, M., et al., Africa's New Climate Economy: Economic Transformation and Social and Environmental Change. 2016, New Climate Economy and Overseas Development Institute: London and Washington, DC.

101. IRENA, Prospects for the African Power Sector: Scenarios and strategies for Africa project. 2012, International Renewable Energy Abu Dhabi.

102. Deshmukh, R., J.P. Carvallo, and A. Gambhir, Sustainable Development of Renewable Energy Minigrids for Energy Access: A Framework for Policy Design. 2013, The University of California: Berkeley.

103. Turkson, J. and N. Wohlgemuth, Power sector reform and distributed generation in sub-Saharan Africa. Energy Policy, 2001. 29(2): p. 12.

104. World Bank, Deterring Corruption and Improving Governance in the Electricity Sector. 2009, The World Bank: Washington DC. p. 207.

105. Scott, A., Building Electricity Supplies in Africa for Growth and Universal Access in Background paper for Power, People, Planet: Seizing Africa's energy and climate opportunities. 2015, New Climate Economy: London and Washington, D.C.

106. Joskow, P.L., Introduction to Electricity Sector Liberalization: Lessons Learned from CrossCountry Studies, in Electricity Market Reform: An International Perspective, F.P. Sioshansi and W. Pfaffenberger, Editors. 2006, Elsevier. p. 32.

107. Power, M., et al., The political economy of energy transitions in Mozambique and South Africa: The role of the Rising Powers. Energy Research \& Social Science, 2016. 17: p. 10-19.

108. Newell, P. and J. Phillips, Neoliberal energy transitions in the South: Kenyan experiences. Geoforum, 2016. 74: p. 39-48.

109. Baker, L., P. Newell, and J. Phillips, The Political Economy of Energy Transitions: The Case of South Africa. New Political Economy, 2014.

110. Winkler, H., Renewable energy policy in South Africa: policy options for renewable electricity. Energy Policy, 2005-33(1): p. 27-38.

111. Gyamfi, S., et al., The energy efficiency situation in Ghana. Renewable and Sustainable Energy Reviews, 2018. 82: p. 1415-1423. 


\section{Chapter 8}

112. Aliyu, A.S., A.T. Ramli, and M.A. Saleh, Nigeria electricity crisis: Power generation capacity expansion and environmental ramifications. Energy, 2013. 61: p. 354-367.

113. Azerefegn, T.M., R. Bhandari, and A.V. Ramayya, Techno-economic analysis of grid-integrated PV/ wind systems for electricity reliability enhancement in Ethiopian industrial park. Sustainable Cities and Society, 2020. 53 .

114. Eberhard, A., et al., Independent Power Projects in Sub-Saharan Africa: Lessons from Five Key Countries. Directions in Development. 2016, Washington, DC: World Bank.

115. Wade, J., et al. Local energy governance: communities and energy efficiency policy (3-031-13). in ECEEE 2013 Summer Study - Rethink, renew, restart. 2013. Belambra Les Criques, Toulon/Hyères, France.

116. Lammers, I. and L. Diestelmeier, Experimenting with Law and Governance for Decentralized Electricity Systems: Adjusting Regulation to Reality? Sustainability, 2017. 9(212): p. 14.

117. Tenenbaum, B., et al., From the Bottom Up: How Small Power Producers and Mini-Grids Can Deliver Electrification and Renewable Energy in Africa. 2014, Washington DC: nternational Bank for Reconstruction and Development / The World Bank. 421.

118. Koirala, B.P., et al., Energetic communities for community energy: A review of key issues and trends shaping integrated community energy systems. Renewable and Sustainable Energy Reviews, 2016. 56: p. 722-744.

119. IEA, Energy Access Outlook 2017: From Poverty to Prosperity. 2017, IEA: Paris.

120. Yaqoot, M., P. Diwan, and T.C. Kandpal, Review of barriers to the dissemination of decentralized renewable energy systems. Renewable and Sustainable Energy Reviews, 2016. 58: p. 477-490.

121. Chaurey, A. and T.C. Kandpal, Assessment and evaluation of PV based decentralized rural electrification: An overview. Renewable and Sustainable Energy Reviews, 2010. 14(8): p. 2266-2278.

122. Shi, X., X. Liu, and L. Yao, Assessment of instruments in facilitating investment in off-grid renewable energy projects. Energy Policy, 2016. 95: p. 437-446.

123. Winkler, B., et al., Integrated assessment of renewable energy potential: Approach and application in rural South Africa. Environmental Innovation and Societal Transitions, 2017. 24: p. 17-31.

124. Whitley, S. and L. van der Burg, Fossil fuel subsidy reform in sub-Saharan Africa: from rhetoric to reality. 2015, New Climate Economy.

125. Rai, N., S. Best, and M. Soanes, Unlocking climate finance for decentralized energy access, in Working Paper. 2016, Intenrnational Insitute for Environment and Development: London. p. 45.

126. Bhattacharyya, S.C., Financing energy access and off-grid electrification: A review of status, options and challenges. Renewable and Sustainable Energy Reviews, 2013. 20: p. 462-472.

127. CLEAN, Unlocking access to finance for decentralized energy solutions, in CLEAN Strategy Series. 2015, the Clean Energy Access network.

128. Hussain, M.Z., Financing Renewable Energy Options for Developing Financing Instruments Using Public Fund. 2013, World Bank: Washington DC.

129. Gujba, H., et al., Financing low carbon energy access in Africa. Energy Policy, 2012. 47: p. 71-78. 
130. Tagliapietra, S. and M. Bazilian, The role of international institutions in fostering sub - Saharan Africa's electrification. 2017, Columbia SIPA- Center on Global Energy Policy.

131. Moula, M.M.E., et al., Researching social acceptability of renewable energy technologies in Finland. International Journal of Sustainable Built Environment, 2013. 2(1): p. 89-98.

132. IEA, World Energy Outlook 2018. 2018, IEA: Paris.

133. Karekezi, S., et al., Energy, Poverty and Development, in Global Energy Assessment - Toward a Sustainable Future. 2012, Cambridge University Press: Cambridge, UK andd New York, NY, USA p. 152-190.

134. Bailis, R., et al., The carbon footprint of traditional woodfuels. Nature Climate Change, 2015. 5(3): p. 266-272.

135. OECD/IEA, Worl Energy Outlook 2006. 2006, International Energy Agency: Paris.

136. Bond, T.C., et al., Bounding the role of black carbon in the climate system: A scientific assessment. Journal of Geophysical Research: Atmospheres, 2013. 118(11): p. 5380-5552.

137. Pearson, T.R.H., et al., Greenhouse gas emissions from tropical forest degradation: an underestimated source. Carbon Balance and Management, 2017. 12(1).

138. Pachauri, S., et al., Pathways to achieve universal household access to modern energy by 2030. Environmental Research Letters, 2013. 8(2): p. 024015.

139. Fuso Nerini, F., C. Ray, and Y. Boulkaid, The cost of cooking a meal. The case of Nyeri County, Kenya. Environmental Research Letters, 2017. 12(6): p. 065007.

140. Pachauri, S., N.D. Rao, and C. Cameron, Outlook for modern cooking energy access in Central America. PLoS One, 2018. 13(6): p. e0197974.

141. van Ruijven, B.J., Energy and Development: A Modelling Approach, in Copernicus Institute for Sustainable Development and Innovation, Department of Science, Technology and Society 2008, Utrecht University: Utrecht.

142. Ifegbesan, A.P., I.T. Rampedi, and H.J. Annegarn, Nigerian households' cooking energy use, determinants of choice, and some implications for human health and environmental sustainability. Habitat International, 2016. 55: p. 17-24.

143. Makonese, T., A.P. Ifegbesan, and I.T. Rampedi, Household cooking fuel use patterns and determinants across southern Africa: Evidence from the demographic and health survey data. Energy \& Environment, 2018. 29(1): p. 20.

144. Masera, O.R., R. Díaz, and V. Berrueta, From cookstoves to cooking systems: the integrated program on sustainable household energy use in Mexico. Energy for Sustainable Development, 2005. IX(1).

145. Hooper, L.G., et al., Traditional cooking practices and preferences for stove features among women in rural Senegal: Informing improved cookstove design and interventions. PLoS One, 2018. 13(11): p. e0206822.

146. Quinn, A.K., et al., An analysis of efforts to scale up clean household energy for cooking around the world. Energy for Sustainable Development, 2018. 46: p. 1-10. 


\section{Chapter 8}

147. Smeets, B., et al. Sub-Saharan Africa continues to depend on inefficient cooking technologies. McKinsey Energy Insights 2017 [cited 2017 September]; Available from: https://www. mckinseyenergyinsights.com/insights/sub-saharan-africa-continues-to-depend-on-inefficientcooking-technologies/.

148. Casteleyn, H., Clean cooking in sub-Saharan Africa: modeling the cooking fuel mix to 2050, in Division of Energy and Climate Studies, Department of Energy Technology, School of Industrial Engineering and Management. 2017, KTH Royal Institute of Technology.

149. de Boer, H.S. and D. van Vuuren, Representation of variable renewable energy sources in TIMER, an aggregated energy system simulation model. Energy Economics, 2017. 64: p. 600-611.

150. Lucas, P.L., et al., Future impacts of environmental factors on achieving the SDG target on child mortality—A synergistic assessment. Global Environmental Change, 2019. 57.

151. van Ruijven, B.J., et al., Long-term model-based projections of energy use and $\mathrm{CO}_{2}$ emissions from the global steel and cement industries. Resources, Conservation and Recycling, 2016. 112: p. 15-36.

152. van Sluisveld, M.A.E., et al., Exploring the implications of lifestyle change in $2^{\circ} \mathrm{C}$ mitigation scenarios using the IMAGE integrated assessment model. Technological Forecasting and Social Change, 2016. 102: p. 309-319.

153. Zubi, G., et al., Development and assessment of a solar home system to cover cooking and lighting needs in developing regions as a better alternative for existing practices. Solar Energy, 2017. 155: p. 7-17.

154. UN, Energy for a Sustainable Future. 2010, United Nations: New York.

155. Kaygusuz, K., Energy services and energy poverty for sustainable rural development. Renewable and Sustainable Energy Reviews, 2011. 15(2): p. 936-947.

156. World Bank, Clean and improved cooking in Sub-Saharan Africa : a landscape report. 2014, World Bank Group: Washington, D.C.

157. Daioglou, V., Residential Energy Use Scenarios, in Department of Geosciences. 2010, Utrecht University: Utrecht.

158. Jeuland, M.A. and S.K. Pattanayak, Benefits and costs of improved cookstoves: assessing the implications of variability in health, forest and climate impacts. PLoS One, 2012. 7(2): p. e30338.

159. Jeuland, M. and J.-S.T. Soo, Analyzing the costs and benefits of clean and improved cooking solutions. 2016, Sanford School of Public Policy and Duke Global Health Institute.

160. FAO, Sustainable woodfuel for food security A smart choice: green, renewable and affordable Working paper. 2017, Food and Agriculture Organization of the United Nations: Rome.

161. IPCC. 2006 IPCC Guidelines for National Greenhouse Gas Inventories. 2006; Available from: https:// www.ipcc-nggip.iges.or.jp/public/2006gl/vol2.html.

162. IPCC, Working Group III Contribution to the Fifth Assessment Report of the Intergovernmental Panel on Climate Change, in Mitigation of Climate Change 2014, ntergovernmental Panel on Climate Change: New York, NY, USA.

163. Santos, M.J., et al., Modeling the Effects of Future Growing Demand for Charcoal in the Tropics. Frontiers in Environmental Science, 2017. 5. 
164. Wilson, D.L., et al., Avoided emissions of a fuel-efficient biomass cookstove dwarf embodied emissions. DevelopmentEngineering, 2016. 1: p. 8.

165. Drigo, R., et al., Pan-tropical analysis of woodfuel supply, demand and sustainability. 2014, Yale School of forestery and environmental studies.

166. Morrissey, J., Africa: A guide for advocates and policy makers: Part 2: Addressing energy poverty, in Oxfam's Research Backgrounders, K. Pfeifer, Editor. 2017, Oxfam.

167. Hou, B.-D., et al., Cooking fuel choice in rural China: results from microdata. Journal of Cleaner Production, 2017. 142: p. 538-547.

168. Karimu, A., J.T. Mensah, and G. Adu, Who Adopts LPG as the Main Cooking Fuel and Why? Empirical Evidence on Ghana Based on National Survey. World Development, 2016. 85: p. 43-57.

169. Kelebe, H.E., et al., Determinants for adoption decision of small scale biogas technology by rural households in Tigray, Ethiopia. Energy Economics, 2017. 66: p. 272-278.

170. Toonen, H.M., Adapting to an innovation: Solar cooking in the urban households of Ouagadougou (Burkina Faso). Physics and Chemistry of the Earth, Parts A/B/C, 2009. 34(1-2): p. 65-71.

171. Mekonnen, A. and G. Köhlin, Determinants of Household Fuel Choice in Major Cities in Ethiopia, in Environment for Development. 2008, School of Business, Economics and Law at University of Gothenburg: Göteborg.

172. Shen, G., et al., Factors influencing the adoption and sustainable use of clean fuels and cookstoves in China -a Chinese literature review. Renewable and Sustainable Energy Reviews, 2015. 51: p. 741750.

173. Nlom, J. and A. Karimov, Modeling Fuel Choice among Households in Northern Cameroon. Sustainability, 2015.7(8): p. 9989-9999.

174. van der Kroon, B., Climbing the African energy ladder: internal and external factors influencing household demand for improved cookstoves and modern fuels in sub-Saharan Africa. 2016, Vrije Universiteit Amsterdam.

175. Malla, S. and G.R. Timilsina, Household Cooking Fuel Choice and Adoption of Improved Cookstoves in Developing Countries: A Review, in Policy Research Working Paper. 2014, The World Bank.

176. UN, The Paris Agreement. 2015, UNFCCC.

177. Koskimäki, P.-L., Africa could take a leap to energy efficiency: What lessons could Sub-Saharan countries learn from European energy efficiency policy implementation? Energy for Sustainable Development, 2012.16(2): p. 189-196.

178. World bank, EE+EA : enhancing the World Bank's energy access investments through energy efficiency 2015, World Bank Group: Washington, D.C.

179. IEA, Capturing the Multiple Benefits of Energy Efficiency. 2014, International Energy Agency: Paris, France.

180. Pachauri, S., D. Ürge-Vorsatz, and M. LaBelle, Synergies between Energy Efficiency and Energy Access Policies and Strategies. Global Policy, 2012. 3(2): p. 187-197.

181. Nilsson, M., et al., Mapping interactions between the sustainable development goals: lessons learned and ways forward. Sustain Sci, 2018. 13(6): p. 1489-1503. 


\section{Chapter 8}

182. Huppmann, D., et al., The MESSAGE Integrated Assessment Model and the ix modeling platform (ixmp): An open framework for integrated and cross-cutting analysis of energy, climate, the environment, and sustainable development. Environmental Modelling \& Software, 2019. 112: p. 143-156.

183. Fricko, O., et al., The marker quantification of the Shared Socioeconomic Pathway 2: A middle-ofthe-road scenario for the 21st century. Global Environmental Change, 2017. 42: p. 251-267.

184. Messner, S. and M. Strubegger, User's Guide for MESSAGE 111. 1995, IIASA: Laxenburg, Austria.

185. Pachauri, S., et al., Pathways to achieve universal household access to modern energy by 2030. Environmental Research Letters, 2013. 8.

186. Poblete-Cazenave, M. and S. Pachauri, A structural model of cooking fuel choices in developing countries. Energy Economics, 2018. 75: p. 449-463.

187. Cameron, C., et al., Policy trade-offs between climate mitigation and clean cook-stove access in South Asia. Nature Energy, 2016. 1(1): p. 15010.

188. Ang, B.W., Asean energy demand: Current trends and future outlook. 1989.

189. Riahi, K., et al., The Shared Socioeconomic Pathways and their energy, land use, and greenhouse gas emissions implications: An overview. Global Environmental Change, 2017. 42: p. 153-168.

190. Asian Development Bank, Energy efficiency developments and potential energy savings in the greater Mekong subregion. 2015, Asian Development Bank: Mandaluyong City, Philippines.

191. de la Rue du Can, S., et al., Energy Efficiency Roadmap for Uganda: Making Energy Efficiency Count. 2017, Power Africa under Lawrence Berkeley National Laboratory

192. Letschert, V.E. and M.A. McNeil, Potential Savings for Cote d'Ivoire, Ghana, Nigeria and Senegal from BUENAS modeling. 2012, Ernest Orlando Lawrence Berkeley National Laboratory.

193. IEA, Africa Energy Outlook 2019, in World Energy Outlook Special Report. 2019.

194. African Union. Agenda 2063: The Africa We Want. 2015 [cited 202014 September ]; Available from: https://au.int/agenda2063/sdgs.

195. Rahut, D.B., et al., Wealth, education and cooking-fuel choices among rural households in Pakistan. Energy Strategy Reviews, 2019. 24: p. 236-243.

196. Twumasi, M.A., et al., The impact of credit accessibility on rural households clean cooking energy consumption: The case of Ghana. Energy Reports, 2020. 6: p. 974-983.

197. Kovacic, Z., et al., Probing uncertainty levels of electrification in informal urban settlements: A case from South Africa. Habitat International, 2016. 56: p. 212-221.

198. Pelland, S., et al., Nemiah Valley Photovoltaic-Diesel Mini-Grid: System Performance and Fuel Saving Based on One Year of Monitored Data. IEEE Transactions on Sustainable Energy, 2012. 3(1): p. 167175 .

199. World Bank, Technical and Economic Assessment of Grid, Mini-Grid and Off-Grade Electrification Technologies 2006, The International Bank for Reconstruction and Development / The World Bank Group p. 155. 
200. Taliotis, C., et al., An indicative analysis of investment opportunities in the African electricity supply sector - Using TEMBA (The Electricity Model Base for Africa). Energy for Sustainable Development, 2016. 31: p. 50-66.

201. IRENA, Africa 2030: Roadmap for a renewable energy future. 2015, IInternational Renewable Energy Agency.

202. Veileder, Cost base for small-scale hydropower plants. 2012.

203. Veileder, Cost base for hydropower plants. 2012.

204. Bondeau, A., et al., Modelling the role of agriculture for the 20th century global terrestrial carbon balance. Global Change Biology, 2007. 13(3): p. 679-706.

205. Biemans, H., et al., Effects of precipitation uncertainty on discharge calculations for main river basins. Journal of Hydrometeorology, 2009. 10(4): p. 1011-1025.

206. Rost, S., et al., Agricultural green and blue water consumption and its influence on the global water system. Water Resources Research, 2008. 44(9).

207. Gerten, D., et al., Terrestrial vegetation and water balance - hydrological evaluation of a dynamic global vegetation model. Journal of Hydrology, 2004. 286(1): p. 249-270.

208. Lehner, B., K. Verdin, and A. Jarvis, New global hydrography derived from spaceborne elevation data. Eos, Transactions, AGU, 2008. 89(10): 93-94.

209. Bekele, G. and G. Tadesse, Feasibility study of small Hydro/PV/Wind hybrid system for off-grid rural electrification in Ethiopia. Applied Energy, 2012. 97: p. 5-15.

210. NREL, Distributed Solar PV for Electricity System Resiliency: Policy \& Regulatory Considerations. 2014, National Renewable Energy Laboratory.

211. Ibrahim, H., et al., Wind-Diesel hybrid system: energy storage system selection method in Innostock 2012: The 12th International Conference on Energy Storage. 2012: Lleida, Spain.

212. Levin, T. and V.M. Thomas, Can developing countries leapfrog the centralized electrification paradigm? Energy for Sustainable Development, 2016. 31: p. 97-107.

213. Chaurey, A. and T.C. Kandpal, Assessment and evaluation of PV based decentralized rural electrification: An overview. Renewable and Sustainable Energy Reviews, 2010. 14: p. 13.

214. Chaurey, A. and T.C. Kandpal, A techno-economic comparison of rural electrification based on solar home systems and PV microgrids. Energy Policy, 2010. 38(6): p. 11.

215. IEA, Africa Energy Outlook. 2014, IEA: Paris. p. 242.

216. Mainali, B., Sustainability of rural energy access in developing countries, in Department of Energy Technology/ Energy and Climate Studies. 2014, KTH Royal Institute of Technology: Stockholm.

217. de Boer, H.S. and D. van Vuuren, Representation of variable renewable energy sources in TIMER, an aggregated energy system simulation model. Energy Economics, 2016.

218. Kemausuor, F., et al., Electrification planning using Network Planner tool: The case of Ghana. Energy for Sustainable Development, 2014. 19: p. 10.

219. Kc, S. and W. Lutz, The human core of the shared socioeconomic pathways: Population scenarios by age, sex and level of education for all countries to 2100. Glob Environ Change, 2017. 42: p. 181-192. 


\section{Chapter 8}

220. Bruce, N.G., K. Aunan, and E.A. Rehfuess, Liquefied Petroleum Gas as a Clean Cooking Fuel for Developing Countries: Implications for Climate, Forests, and Affordability, in Materials on Development Financing, C.C.C.a. Energy, Editor. 2017, KfW Development Bank: Frankfurt am Main.

221. World Bank Group, Clean and improved cooking in Sub-Saharan Africa : a landscape report. 2014, World Bank Group: Washington, D.C.

222. IPCC, Emission Factors for Greenhouse Gas Inventories. 2014, Intergovernmental Panel on Climate Change (IPCC).

223. Balmer, M., Energy poverty and cooking energy requirements: The forgotten issue in South African energy policy? Journal of Energy in Southern Africa, 2007. 18(3).

224. Brown, E., et al., eCook: What behavioural challenges await this potentially transformative concept? Sustainable Energy Technologies and Assessments, 2017(22): p. 10.

225. Messner, S. and M. Strubegger, User's Guide for MESSAGE III. 1995, International Institute for Applied Systems Analysis. p. 160.

226. van Vuuren, D.P., et al., Timer model description, in Integrated modelling of global environmental change. An overview of IMAGE 2.4, A.F. Bouwman, T. Kram, and K.K. Goldewijk, Editors. 2006, Netherlands Environmental Assessment Agency (MNP): Bilthoven.

227. Poblete-Cazenave, M. and S. Pachauri, 'A simulation-based estimation model of household electricity demand and appliance uptake'. in progress, IIASA.

228. de la Rue du Can, S., et al., Energy Efficiency Indicators Methodology Booklet. 2010, Ernest Orlando Lawrence Berkeley National Laboratory.

229. Belzer, D., A Comprehensive System of Energy Intensity Indicators for the U.S.: Methods, Data and Key Trends. 2014, Pacific Northwest National Laboratory: Richland, Washington.

230. EEA. Intensity of final energy consumption in Europe. 2019 [cited 2020 June]; Available from: https:// www.eea.europa.eu/data-and-maps/indicators/final-energy-consumption-intensity-5.

231. Amankwah, D., W. Juan, and Y. Haizhen, Analysis of Household Energy Efficiency in developing countries using the Long Energy Alternative Planning System (Case Study: Ghana). Journal of Energy and Natural Resource Management, 2016.3(2): p. 11. 
References

8 

Annex A

Annex B

Annex C

Annex D

Annex E

Summary

Samenvatting

वीक्मरS

Acknowledgements

Curriculum Vitae

List of publications 


\section{Annex A: Supplementary information - Chapter 2 Model description of off-grid technologies}

Detailed cost components of the chosen electrification technologies such as the cost of high voltage (HV) lines, medium voltage (MV) lines, low voltage lines (LV), transformers, household connection and metering, diesel fuel per litre, diesel generators, solar panels, BOS, wind energy system, storage technologies, and associated recurring annual costs (operation and maintenance) are required by the model. The model also needs interest rate per year to be used to determine the discounted costs for each technology option. These data requirements are discussed in detail below. The following formula are used to calculate the required system capacity (1), the levelized cost of electricity (2) and the cost of the distribution network per KWh (3).

The total capacity of the mini-grid technology i at a grid-cell level $\left(M_{\mathrm{i}, \text { cap,c }}\right)$ depends on the annual electricity consumption of the grid-cell $\left(E_{t, c}\right)$, the capacity factor of the technology $\left(C_{i}\right)$, annual hours of operation and the distribution loss (Loss ${ }_{\text {dis }}$ ):

$$
M G_{i, c a p, c}=\frac{E_{t, c}}{\left(C F_{i} * \text { Annual load hours }\right) *\left(1-\text { Loss }_{\text {dis }}\right)}
$$

The levelized cost of electricity generation $\left(L C O E_{g}\right)$ for all alternative technologies are calculated according to the following formulae:

$$
L C O E_{g}=\frac{\sum_{i=1}^{m}\left[\text { Annuity }_{i} * I_{i}+C_{F C, i}+\beta_{i} I_{i}\right]}{\sum_{i=1}^{m} E_{i}}
$$

Where $i=\quad$ the power generating technology $(1,2, \ldots ., m)$,

$m=\quad$ the total number of power-plants

$E_{i}=$ the annual electricity output (kWh)

Annuity $=\quad$ Present value annuity factor $=\frac{1-(1+r)^{-1}}{r}$

$I_{i}=\quad$ the capital cost of plant $i$ (USD),

$C_{\mathrm{FC}, \mathrm{i}}=\quad$ the fuel cost (USD/MJ) $=E_{i} * \emptyset_{H R, i} * P_{\text {fuel }}$

$\emptyset_{H R, i}=\quad$ the heat rate of plant $i$ measured in (MJ per kWh) 


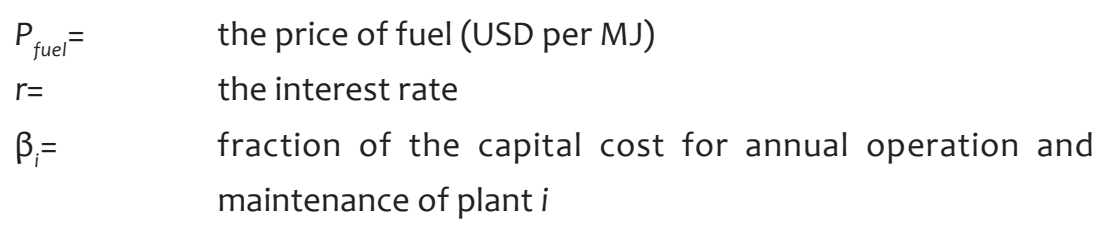

The capital cost $\left(I_{i}\right)$ includes the initial investment cost of power plants including all components, replacement cost of the components, and the interest payment during construction.

The required transmission and distribution network is calculated according to the methodology discussed in van Ruijven, Schers [37]. Then, the cost of distribution and household wiring and metering $\left(\ln v_{\text {tot,c }}\right)$ is calculated as follows:

$$
\ln v_{t o t, c}=\ln v_{w \& m, c}+\ln v_{i n t, c}+\ln v_{E x t, c}
$$

Where; $I n v_{w \& m, c}$ is the cost of household wiring and metering for the total number of households in a grid-cell (USD)

$$
\begin{aligned}
& \operatorname{Inv}_{\text {int, } \mathrm{c}} \quad \text { is the cost of the internal component of electrification for a } \\
& \text { grid-cell which includes the costs of low-voltage line network } \\
& \text { for a grid-cell (USD) } \\
& \ln v_{E x t, c} \quad \text { is the cost of the external component of grid extension } \\
& L C O E_{\text {dis }, c}=\frac{\sum_{i=1}^{m}\left[\text { Annuity }_{i} * \text { Inv }_{i, t o t, c}\right]}{\sum_{i=1}^{m} E_{i}}
\end{aligned}
$$

\section{Diesel Generator Mini-grid}


Table 22: Input variables, descriptions and assumptions[32, 198, 199]

\begin{tabular}{lll}
\hline Variables & Description & Values \\
\hline $\begin{array}{lll}\text { Diesel Generator Hours of } \\
\text { Operation }\end{array}$ & $\begin{array}{l}\text { The Annual hours of operation for the } \\
\text { generator in hours per year }\end{array}$ & $\begin{array}{l}\text { According to Multi- } \\
\text { tier framework }\end{array}$ \\
Diesel Generator Life time & $\begin{array}{l}\text { The technical lifetime of a diesel generator } \\
\text { and its components }\end{array}$ & 20 years \\
Diesel Price & Price of Diesel fuel in US\$2005 per MJ & TIMER \\
Diesel Generator Fuel & Consumed diesel fuel per kwh produced & $0.266-0.303$ litres \\
Consumption per kwh & energy & kwh-1 \\
Diesel Fuel Energy Content & The energy content of diesel fuel & 38.29 MJ liter \\
Diesel Generator Efficiency & The efficiency of the generator & $35-45 \%$ \\
Capacity Factor & The Generator capacity factor & $80-90 \%$ \\
O\&M cost & Diesel Generator Operation and Maintenance & $5 \%$ \\
\hline
\end{tabular}

The mini-grid diesel generator effective capacity required for a grid cell can be calculated according to formulae (1). The levelized cost of electricity generation for diesel generator mini-grid is calculated according to formulae (2) and the distribution cost from formulae (3).

\section{Solar PV Mini-grid}

Solar mini-grid refers to large scale solar photovoltaic system connected to the mini-grid transmission network. The cost of providing solar mini-grid involves: (i) the cost of the PV units, (ii) the cost of distribution network, (iii) the cost of wiring \& metering at the household, (iv) battery storage system, (v) the operation $\&$ maintenance cost and (vi) BOS and battery replacement costs.

For a PV system on an isolated grid, security of supply is usually a primary concern. Therefore, the storage is an integral element of a well-functioning solar mini-grid system. In our model, we assume a storage capacity enough to provide a day of autonomy at 50\% discharge. 
Table 23: Input variables, descriptions and assumptions for Solar PV mini-grid [58, 67, 200]

\begin{tabular}{lll}
\hline Variables & Description & Values \\
\hline $\begin{array}{l}\text { Average Daily } \\
\text { Irradiation }\end{array}$ & $\begin{array}{l}\text { Solar irradiation in watt per m² daily } \\
\text { average }\end{array}$ & Data from Hoogwijk [61] \\
PV BOS Cost & The BOS Cost & 20-75\% of the Panel prices \\
PV Lifetime & The technical life time of PV panel & 25 Years \\
PV BOS Lifetime & PV component technical lifetime & 15 years \\
Storage kwh per system & The PV battery kilowatt-hours per PV & 1 \\
kilowatt & component kilowatt & \\
Battery Lifetime & The technical lifetime of the storage battery & 8 years \\
Peak Solar Irradiance & The peak solar irradiance & $1000 \mathrm{~W} \mathrm{~m}^{-2}$ \\
O\&M cost & Solar PV system Operation and & $1-4 \%$ \\
& Maintenance Cost &
\end{tabular}

The PV mini-grid actual system capacity required for a grid cell can be calculated according to formulae (1). The size of the array depends not only on the daily peak demand but also the Average Daily Irradiation at the grid cell. The levelized cost of electricity generation with solar mini-grid for a grid cell is calculated according to formulae (2). Finally, the levelized cost of electricity generation and distribution for Solar mini-grid is calculated according to the formulae (3).

\section{Wind Power Mini-grid}

The wind power mini-grid system in our model consists of a power generation unit, a storage system and a distribution network. The wind data, including the capacity factor and cost per kilowatt capacity for grid cells is taken from TIMER. The average monthly capacity factor for the wind power system used in our model ranges from 0.15 to 0.24 . Again, for Wind power system on an isolated grid, uncertainty of supply is a concern. Therefore, it is important to design the system to store excess wind energy generated when demand is low and dispatch when needed. A storage capacity enough to provide one day of electricity during interruptions at $50 \%$ discharge is included. 
Annex A

Table 24: Input variables, descriptions and assumptions for Wind power mini-grid [61, 200, 201]

\begin{tabular}{llc}
\hline Variables & Description & Value \\
\hline Wind load factor & The average power generated, divided by the rated peak power & $0.15-0.25$ \\
Wind system lifetime & The technical life time of wind turbine system & 25 years \\
Storage kwh per & The battery kilowatt-hours per wind system component kilowatt & 1 \\
system kilowatt & & 8 years \\
Battery Lifetime & The technical lifetime of the storage system & $3-5 \%$ \\
O\&M cost & Solar PV system Operation and Maintenance Cost &
\end{tabular}

The wind power mini-grid actual system capacity required for a grid cell can be calculated according to formulae (1). The levelized cost of electricity generation with solar mini-grid for a grid cell is calculated according to formulae (2). Finally, the levelized cost of electricity generation and distribution for wind power mini-grid is calculated according to the formulae (3).

\section{Small-hydro Power}

Small-hydro power plants have been evaluated for every $10 \mathrm{~km}$ on every river with a discharge lower that $50 \mathrm{~m}^{3} \mathrm{~s}^{-1}$, with the exception of protected areas. On these locations, high-resolution (3") Hydro SHEDS topographic data was used to find realistic dam dimensions (maximum dam height of $30 \mathrm{~m}$ ). To assess the cost effectiveness of these locations, we used a variety of highly local spatial data to feed a cost model with cost equations that have been based on Norwegian and US hydropower tenders and contracts. These methods are used by the hydropower industry as planning tools to calculate foreseeable contractor and supplier cost of projects in early planning stages. The cost components are listed in Table 25. 
Table 25: Input variables, descriptions and assumptions for mini-hydro systems[202, 203]

\begin{tabular}{|c|c|c|}
\hline Cost components 1 & Description & Value \\
\hline $\operatorname{Dam}\left(\mathrm{NOK}_{2010}\right)^{2}$ & The cost of civil works & $\left(1590 D_{H}^{2}+7807 D_{H}+1392\right) * D_{L}$ \\
\hline Turbine $\left(\$_{2005}\right)^{3}$ & The cost of turbines & $1.1943 P^{0.7634} 10^{6}$ \\
\hline Power Station $\left(\mathrm{NOK}_{2010}\right)^{4}$ & The costs of the power station & $-0.0006 v^{2}+0.67 v-6.95$ \\
\hline $\begin{array}{l}\text { Electro-technical } \\
\text { equipment }\left(\mathrm{NOK}_{2010}\right)^{2}\end{array}$ & The cost of electro- technical equipment & $3.9142 P^{0.6622}$ \\
\hline Fish passage $\left(\$_{2002}\right)^{5}$ & $\begin{array}{l}\text { The cost to provide fish passage facilities } \\
\text { at the dam }\end{array}$ & $1.3 e^{6} P^{0.56}$ \\
\hline Miscellaneous ${ }^{6}$ & Miscellaneous & $-38.795 \log Q+309.89 P$ \\
\hline Loss of agricultural land & $\begin{array}{l}\text { The value of inundated agricultural land } \\
\text { area based on rain fed production and } \\
\text { global commodity prices }\end{array}$ & $\begin{array}{l}\text { Data from World Bank or FAO } \\
\text { stat. }\end{array}$ \\
\hline Displacement cost & $\begin{array}{l}\text { The cost of relocating people from the } \\
\text { reservoir }\end{array}$ & $\begin{array}{l}\text { Number of displaced people } \\
\text { multiplied by } 2 \text { times the GDP } \\
\text { from the country of the dam } \\
\text { location. }\end{array}$ \\
\hline Owner's cost & $\begin{array}{l}\text { Interest rates, preliminary feasibility } \\
\& \text { engineering studies, environmental } \\
\text { studies \& permitting, legal fees, } \\
\text { insurance costs, }\end{array}$ & $20 \%$ \\
\hline O\&M costs & $\begin{array}{l}\text { Operation \& maintenance cost as a \% of } \\
\text { annualized investments }\end{array}$ & $2 \%$ \\
\hline
\end{tabular}

The sum of the cost components is divided by the energy production that depends on the discharge, head and a load factor using the following equation:

$$
E_{R P}=\rho \cdot g \cdot\left(Z_{1}-Z_{2}\right) \cdot Q_{D} \cdot h r s \cdot L F_{R P} \cdot \eta_{\text {ror }}
$$

1 All costs are converted to $\$ 2010$, for NOK2010 to $\$ 2010$ the exchange rate on $1 / 1 / 2010$ of 0.1725 is used, for $\$ 2005$ to $\$ 2010$ the inflation rate of 1.09 is used, for $\$ 2002$ to $\$ 2010$ the inflation rate of 1.24 is used, for $\$ 2013$ to $\$ 2010$ the inflation rate of 0.99 is used

$2 D_{H}$ is the dam height, $D_{L}$ is the dam length.

$3 \mathrm{P}$ is the turbine capacity (MW)

$4 \mathrm{~V}$ is the flow rate (design discharge or a result of Eq. 4 and 5), minimum investment 20 million NOK2010

5 P is turbine capacity $(\mathrm{kW})$

$6 \mathrm{P}$ is the turbine capacity (MW) and Q is the discharge (design discharge or a result of Eq. 4 and 5 
Where $\rho$ is the density of water $\left(\mathrm{kg} \mathrm{m}^{-3}\right)$, g the gravitational acceleration $\left(9.8 \mathrm{~m} \mathrm{~s}^{-2}\right)$, $Z_{1}$ is the headwater elevation ( $\left.m\right), Z_{2}$ is the tail water elevation $(m), Q_{D}$ the design discharge $\left(\mathrm{m}^{3} \mathrm{~s}^{-1}\right)$, hrs the hours per year, LF the yearly load factor and $\eta_{\text {ror }}$ the waterto-wire efficiency (70\%). The monthly discharge maps were developed by combining available lower resolution $\left(0.5^{\circ}\right)$ monthly runoff data from the hydrological LPJml model [204-207] with 15" area accumulation and drainage directions maps available from the Hydro SHEDS project [208]. The energy potential and the generation price expressed in $\$ \mathrm{kWh}^{-1}$ were aggregated to a 0.5 -degree map to compare with other options.

\section{Hybrid systems: Solar-diesel generator \& Wind -diesel generator}

Hybrid systems provide a high level of energy reliability by using a combination of diverse generation sources, reducing the risk of outages[209]. These systems combine two or more energy conversion devices, or two or more fuels, that when integrated overcome limitations inherent in either [210]. On days where both sunlight and wind are limited or not available, the capacity difference needs to be made up in some manner, such as diesel Generator.

In our model, we have included two types of hybrid mini-grid systems. These hybrid systems are autonomous electricity generating systems using PV Solar systems or wind turbines in combination with diesel generators to obtain a maximum contribution by the intermittent Solar and wind resource to the total power produced. This way we can reduce fossil fuel consumption and reduce system operating costs (by avoiding storage requirements) and environmental impacts (by reducing fossil fuel use). The Solar-Diesel hybrid system utilizes the solar energy resource during daytime and diesel Generator at night. Wind-Diesel hybrid system is designed to have a medium level penetration with the wind system providing half the energy demand and the diesel Generator generating power to meet the rest of the energy demand. The medium penetration level is chosen to reduce complexity of the system, hence the cost of the system. Low \& medium penetration systems are mature technologies, while high penetration systems still face several problems [211]. High penetration systems may require advanced power control systems as discussed in Hong, Ou [71] for microgrid hybrid wind- photovoltaic- fuel cell based power supply system and in Ou and Hong [72] for a system containing solar power, 
wind power, and a diesel-engine. The component parameters of the hybrid systems in our model are presented in Table 26, Table 27 and Table 28.

\section{Solar Home systems}

A stand-alone PV System can be defined as an off-grid-system with one or more solar PV modules serving an independent user. Classical Solar Home Systems generally cover a power output of up to 250 watt-peak.

Table 26: System specific input variables, descriptions and assumptions [32, 58, 67, 200]

\begin{tabular}{lll}
\hline Variables & Description & Value \\
\hline Average Daily Irradiation & Solar irradiation in watt per m² daily average & Data from Hoogwijk [61] \\
PV BOS Cost & The BOS Cost & 20-75\% of the Panel prices \\
PV Lifetime & The technical life time of PV panel & 15 years \\
PV BOS Lifetime & PV component technical lifetime & 15 years \\
PV Battery kwh per PV & The PV battery kilowatt-hours per PV component & 1 \\
kilowatt & kilowatt & \\
Peak Solar Irradiance & The peak solar irradiance & $1000 \mathrm{~W} \mathrm{~m}^{-2}$ \\
O\&M cost & Solar PV system Operation and Maintenance Cost & $1-4 \%$ \\
\hline
\end{tabular}

The cost of the stand-alone solar home system includes: (i) the cost of the PV units, (ii) the cost of wiring \& metering at the household, (iii) storage system cost, (iv) the operation and maintenance cost and (v) replacement costs.

The capacity of the stand-alone technology i for a household $\left(S t A l_{i, c a p, c}\right)$ depends on the annual electricity consumption of the household $E_{t, h h}$, the annual load hours and the capacity factor of the technology $\left(C_{i}\right)$ as given in formulae (4):

$$
S t A l_{i, \text { cap }, c}=\frac{E_{t, h h}}{\left(C F_{i} * \text { Annual load hours }\right)}
$$

\section{Diesel Generator}

Similarly, a distributed diesel Generator can serve both rural and urban electricity demand at individual household levels. The costs of the system include: (i) the cost 
of the Generator, (ii) the cost of wiring \& metering at the household, and (iii) the operation and maintenance cost. The stand-alone diesel generator effective capacity required for households can be calculated from formulae (4) given above. The levelized cost of electricity generation for stand-alone diesel generator is calculated according to formulae (2).

Table 27: System specific input variables, descriptions and assumptions [32, 58]

\begin{tabular}{lll}
\hline Variables & Description & Value \\
\hline Diesel Generator Life time & $\begin{array}{l}\text { The technical lifetime of a diesel generator and its } \\
\text { components }\end{array}$ & 20 years \\
Diesel Price & Price of Diesel fuel in US\$2005 per MJ & TIMER \\
Diesel Generator Fuel & Consumed diesel fuel per kwh produced energy & $0.266-0.303$ litres \\
Consumption per kwh & & $\mathrm{kwh}^{-1}$ \\
Diesel Fuel Energy Content & The energy content of diesel fuel & $38.29 \mathrm{MJ} \mathrm{liter}^{-1}$ \\
Diesel Generator Efficiency & The efficiency of the generator & $35-45 \%$ \\
Capacity Factor & The Generator capacity factor & $80-90 \%$ \\
O\&M cost & Diesel Generator Operation and Maintenance Cost & $5 \%$ \\
\hline
\end{tabular}

\section{Key parameter assumptions}

Table 28, Table 29 and Table 30 provide the range of parameter values used in our model

Table 28: Assumptions on cost components of electricity networks in SSA [32, 67, 200, 212]

\begin{tabular}{lll}
\hline Variables & \multicolumn{1}{c}{ Cost (USD) } \\
\cline { 2 - 3 } & Low range & High range \\
\hline HV transmission lines (132 kV line) & $28000 \$ \mathrm{~km}^{-1}$ & $90000 \$ \mathrm{~km}^{-1}$ \\
MV transmission lines (33 kV line) & $9000 \$ \mathrm{~km}^{-1}$ & $23000 \$ \mathrm{~km}^{-1}$ \\
LV transmission lines & $5000 \$ \mathrm{~km}^{-1}$ & $10600 \$ \mathrm{~km}^{-1}$ \\
Transformers & $5000 \$ \mathrm{~km}^{-1}$ & $35000 \$ \mathrm{~km}^{-1}$ \\
Metering and wiring & $100 \$ \mathrm{HH}^{-1}$ & $250 \$ \mathrm{HH}^{-1}$ \\
\hline
\end{tabular}


Table 29: Electricity generation technologies parameters and assumption[58]

\begin{tabular}{lccc}
\hline \multicolumn{1}{c}{ Variables } & \multicolumn{2}{c}{ Investment cost (USD) } & \multirow{2}{*}{$\begin{array}{c}\text { O\&M Cost (as \% of } \\
\text { investment cost) }\end{array}$} \\
\cline { 2 - 3 } & Low range & High range & \\
\hline Diesel Generator Mini-grid & $500 \$ / \mathrm{kw}$ & $1500 \$ / \mathrm{kw}$ & $5 \%$ \\
PV system Mini-grid (Panel \& BOS) & $3000 \$ / \mathrm{kwp}$ & $5000 \$ / \mathrm{kwp}$ & $1-4 \%$ \\
Mini-Hydro system & $8000 \$ / \mathrm{kw}$ & $13300 \$ / \mathrm{kw}$ & $2 \%$ \\
Wind system Mini-grid & $2000 \$ / \mathrm{kwp}$ & $6000 \$ / \mathrm{kwp}$ & $3-5 \%$ \\
Diesel Generator Stand-alone & $500 \$ / \mathrm{kw}$ & $1500 \$ / \mathrm{kw}$ & $5 \%$ \\
PV system Stand-alone (Panel \& BOS) & $3600 \$ / \mathrm{kwp}$ & $6000 \$ / \mathrm{kwp}$ & $1-4 \%$ \\
Storage Cost & $150 \$ / \mathrm{kwh}$ & $200 \$ / \mathrm{kwh}$ & $\mathrm{n} / \mathrm{a}$ \\
\hline
\end{tabular}

Table 30: Model parameters and assumptions [2, 37, 69, 213-216]

\begin{tabular}{ll}
\hline Variables & Value \\
\hline The economic life time of all technologies & 20 years \\
The real discount rate & $10 \%$ \\
Transmission \& distribution loss for mini-grids & $10 \%$ \\
\hline
\end{tabular}


Annex A

\section{Regional grouping}

Table 31: Regional grouping

\begin{tabular}{|c|c|c|c|c|c|c|c|c|}
\hline \multicolumn{9}{|c|}{ Regions } \\
\hline \multicolumn{4}{|c|}{ Western \& central Africa } & \multicolumn{2}{|c|}{ Eastern Africa } & \multicolumn{2}{|c|}{$\begin{array}{l}\text { Rest of Southern } \\
\text { Africa }\end{array}$} & $\begin{array}{l}\text { Republic of } \\
\text { South Africa }\end{array}$ \\
\hline 1. & Benin & 2. & Burkina Faso & 1. & Burundi & 1. & Angola & South Africa \\
\hline 3. & Cameroon & 4. & Cape Verde & 2. & Comoros & 2. & Botswana & \\
\hline 5. & CAR & 6. & Chad & 3. & Djibouti & 3. & Lesotho & \\
\hline 7. & Congo Dem Rep & 8. & Congo Rep & 4. & Eritrea & 4. & Malawi & \\
\hline 9. & Cote d'Ivoire & 10. & Equatorial Guinea & 5. & Ethiopia & 5. & Mozambique & \\
\hline 11. & Gabon & 12. & Gambia & 6. & Kenya & 6. & Namibia & \\
\hline 13. & Ghana & 14. & Guinea-Bissau & 7. & Madagascar & 7. & Swaziland & \\
\hline 15. & Liberia & 16. & Mali & 8. & Mauritius & 8. & Tanzania & \\
\hline 17. & Mauritania & 18. & Niger & 9. & Reunion & 9. & Zambia & \\
\hline 19. & Nigeria & 20. & Sao Tome \& Principe & 10. & Rwanda & 10. & Zimbabwe & \\
\hline 21. & Senegal & 22. & Sierra Leone & 11. & Seychelles & & & \\
\hline \multirow{3}{*}{\multicolumn{2}{|c|}{ 23. St. Helena }} & 24. & Togo & 12. & Somalia & & & \\
\hline & & & & & Sudan & & & \\
\hline & & & & 14. & Uganda & & & \\
\hline
\end{tabular}

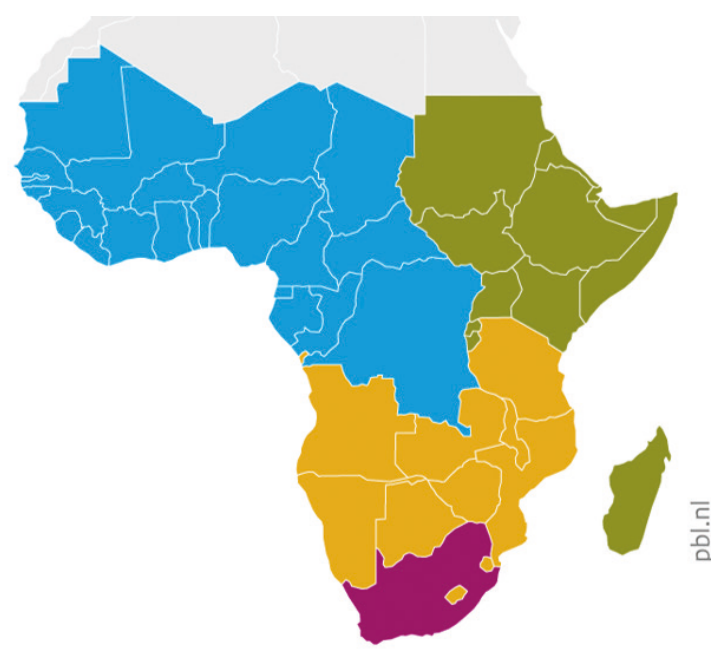

Western $\&$ central Africa

Eastern Africa

Republic of South Africa

Rest of southern Africa Source: PBL

Figure 43: Regional grouping of SSA 


\title{
Annex B: Supplementary information - Chapter 3 IMAGE-TIMER model
}

\begin{abstract}
IMAGE is an integrated assessment model framework that simulates global and regional environmental consequences of changes in human activities [1]. The model is a simulation model, i.e. changes in model variables are calculated on the basis of the information from the previous time-step. The model includes a detailed description of the energy and land-use system and simulates most of the socio-economic parameters for 26 regions and most of the environmental parameters, depending on the variable, on the basis of a geographical grid of 30 by 30 min or 5 by $5 \mathrm{~min}$ (respectively around $50 \mathrm{~km}$ and $10 \mathrm{~km}$ at the equator). The model has been designed to analyses large-scale and long-term interactions between human development and the natural environment and to identify response strategies to global environmental change based on assessment of options for mitigation and adaption.

IMAGE is a framework with a modular structure, with some components linked directly to the model code of IMAGE, and others connected through soft links (where models run independently with information exchange via data files). The IMAGE framework is structured around to the causal chain of key global sustainability issues and comprises two main systems:1) the human or socio-economic system that describes the long-term development of human activities relevant for sustainable development; and 2) the earth system that describes changes in natural systems, such as the carbon and hydrological cycle and climate. The two systems are linked through emissions, land-use, climate feedbacks and potential human policy responses.

Important inputs to the model are descriptions of the future development of so-called direct and indirect drivers of global environmental change: Exogenous assumptions on population, economic development, lifestyle, policies and technology change form a key input into the energy system model TIMER [2] and the food and agriculture system model MAGNET [3].
\end{abstract}

Box 1: IMAGE model description [75]

\section{The residential electrification model}

The residential electrification model is a multi-year bottom-up model that determines the least-cost electrification technology on $0.5^{\circ} \times 0.5^{\circ}$ grid-cell basis. The model distinguished between three electrification options: (a) extending the central grid; (b) mini-grid systems (photovoltaic panels, diesel generator, wind power, mini-hydro, and hybrid technologies); and (c) stand-alone systems (diesel generators and Solar Home Systems). For a full description of the model and the data used see Dagnachew, Lucas [10].

The least cost calculations are based on grid-cell data on the costs of electricity generation for different technologies, technical potentials of renewable energy sources, cost of transmission and distribution networks, and the distance of a gridcells population from existing high-voltage power lines, population density, and household electricity demand. The model uses the levelized cost of electricity (LCOE) 
to make cost comparison across the different system and technology options. The total LCOE of a system is the combination of LCOEs of electricity generation, transmission system and distribution network. The transmission system is required only for the central grid, while both the central grid and mini-grid systems require a distribution network. Stand-alone systems are installed close to the load, so they require neither a transmission system nor a distribution network. The LCOE for power generation $\left(L C O E_{g}\right)$ for different technologies is calculated according to the following formulae:

$$
L C O E_{g}=\frac{\sum_{i=1}^{m}\left[\text { Annuity } * I_{i}+C_{F C, i}+\beta_{i} I_{i}\right]}{\sum_{i=1}^{m} E_{i}}
$$

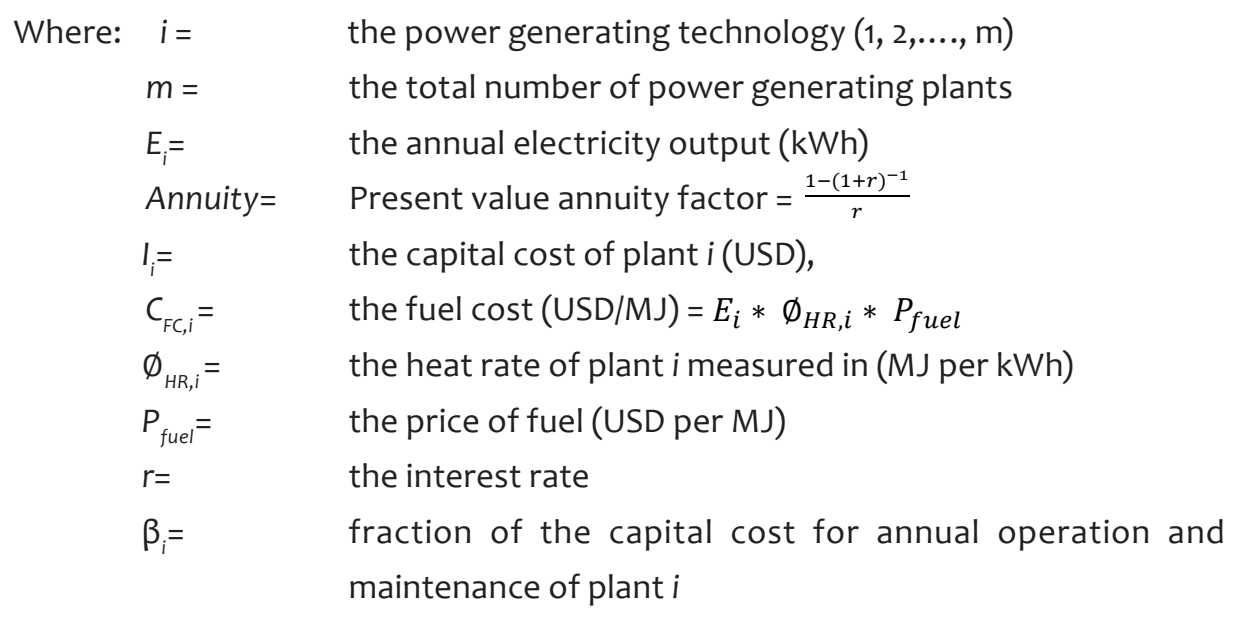

The required transmission system \& distribution network for a grid cell is calculated according to the methodology discussed in van Ruijven et.al., [37]. The cost of the transmission systems becomes relevant while choosing between central grid and mini-grid systems that is discussed below. The levelized cost of the distribution network $\left(\operatorname{LCOE}_{n}\right)$ is the same for both central grid and mini-grid. $L C O E_{n}$ is calculated according to formula 2 .

$$
L C O E_{n}=\frac{\text { Annuity } * I n v_{n}}{\sum_{i=1}^{m} E_{i}}
$$


Where: $\quad \ln v_{n}=$ the cost of the required distribution network for a grid-cell (USD)

Accordingly, the LCOE for delivery of electricity (generation and distribution) from a system $\left(\operatorname{LCOE}_{d}\right)$ is given as:

$$
L C O E_{d}=L C O E_{g}+L C O E_{n}
$$

$L_{C O E}$ of the grid-based technologies are calculated within the IMAGE-TIMER model [217]. The model calculates LCOEs of off-grid technologies based on total system cost, life time and technical potential of the technology [10]. Technical potentials of renewable technologies per grid-cell are based on Hoogwijk [61] and Dagnachew, Lucas [10]. The costs of transmission and distribution lines, transformers and household metering and wiring are taken from the literature [32, 67]. The distance from existing power lines is the population weighted distance in 2010, based on power line data from Open street Maps [65] and gridded population data from Landscan [66]. Population density is based on Landscan data for 2010, with future projections based on van Vuuren et al. (2007). Household electricity demand is either determined in the IMAGE-TIMER model [38] or based on exogenous assumptions.

The least-cost technology is based on two main model decisions: 1) selecting between grid-extension and off-grid electrification; and for off-grid electrification 2) selecting between mini-grid and stand-alone options (Figure 44).

The first decision is made based on $\mathrm{LCOE}_{d}$ of the central grid and off-grid technologies, and the population-weighted distance of the grid-cell from existing power lines. If the $L C O E_{d}$ of the central grid (generation and distribution) is lower than that of the off-grid options, the choice between central grid and mini-grid system depends on the distance of the grid cell from the existing power line. Grid extension is favourable if the distance from the power line does not exceed a certain threshold value. This value is represented by the Economical Distance Limit (EDL) [218]:

$$
E D L=\frac{\left(L C O E_{\text {alt }}-L C O E_{c g}\right) * \sum_{t=\text { Baseyear }}^{\text {Baseyear }+ \text { Lifetime }} E_{t(t)}}{C_{H V \& M V}} \mathrm{~km}
$$


Where: $L C O E_{c g}=\quad$ the levelized costs of electricity generation per grid-cell from centralized power plants (USD per kWh)

$\mathrm{LCOE}_{a \mid t}=\quad$ the levelized costs of electricity generation per grid-cell for off grid electrification (USD per kWh)

$E_{t(t)}=\quad$ the total annual electricity consumption per grid-cell ( $k W h$ per year)

$C_{\text {HV\&MV }}=\quad$ the cost of transmission network (high-voltage and mediumvoltage lines) required to a grid-cell to the central power grid (USD per km)

The EDL is the critical distance between households/communities and the main power lines for which the total LCOE (generation, transmission and distribution) of grid extension are greater than $L C E O_{d}$ (generation \& distribution) for off-grid electricity supply [64]. If the distance to the existing power lines is larger than the EDL, off-grid electrification is more cost-effective.

The second decision is based on the $\mathrm{LCEO}_{d}$ of the off-grid technologies, population density and household electricity demand. Stand-alone systems are the least-cost systems, only if the average demand density is lower than $37500 \mathrm{KWh} \mathrm{km²}$ per year. This demand density is a factor of population density and electricity demand per capita. For example, if the grid-cell has a population density less than 250 person per $\mathrm{km}^{2}$ (equivalent to about 50-100 households per $\mathrm{km}^{2}$ ) and electricity demand is less than $150 \mathrm{kWh}$ per person per year, stand-alone is favoured over other systems [58, 67]. To reduce the revenue risk of stand-alone technologies, within $50 \mathrm{~km}$ distance from existing power lines, mini-grids are always selected as the least cost option. 
Decision tree to determine the lowest-cost electrification system

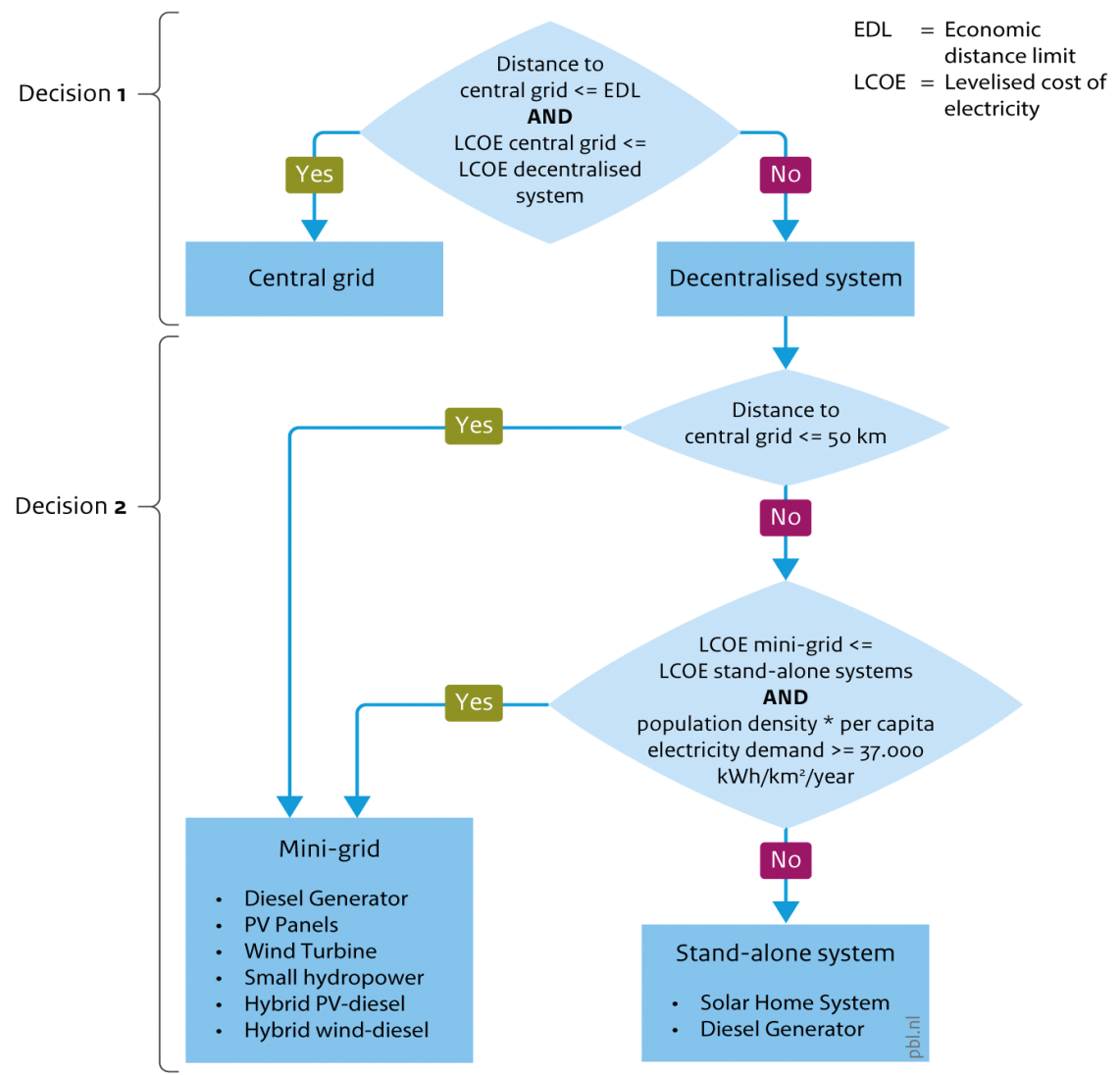

Source: PBL

Figure 44: Decision-tree for the least-cost options [10]

\section{Shared Socio-economic Pathways}

The SSPs are global pathways describing the future evolution of key aspects of society, designed to span a relevant range of uncertainty in societal futures. O'Neill, Kriegler [74] described the SSP narratives, qualitative descriptions of future changes in demographics, human development, economy and lifestyle, policies and institutions, technology, and environment and natural resources. The narratives are intended as a description of plausible future conditions at the level of large world regions that can serve as a basis for integrated scenarios of emissions and land use, as well as climate impact, adaptation and vulnerability analyses. Along with the qualitative storylines, the developers of the SSPs have produced quantitative 
projections for population by age, sex, and education [219], urbanization [95] and economic development [94] for over 200 countries.

SSP1 (Sustainability): This scenario assumes a future that is moving toward a more sustainable path, with educational and health investments accelerating the demographic transition, leading to a relatively low world population. The emphasis is on strengthening human wellbeing.

SSP2 (Continuation): This is the middle-of-the-road scenario in which trends typical of recent decades continue, with some progress toward achieving development goals, reductions in resource and energy intensity, and slowly decreasing fossil fuel dependency. Development of low-income countries is uneven, with some countries making good progress, while others are left behind.

SSP3 (Fragmentation): The scenario portrays a world separated into regions characterized by extreme poverty, pockets of moderate wealth, and many countries struggling to maintain living standards for rapidly growing populations. The emphasis is on security at the expense of international development.
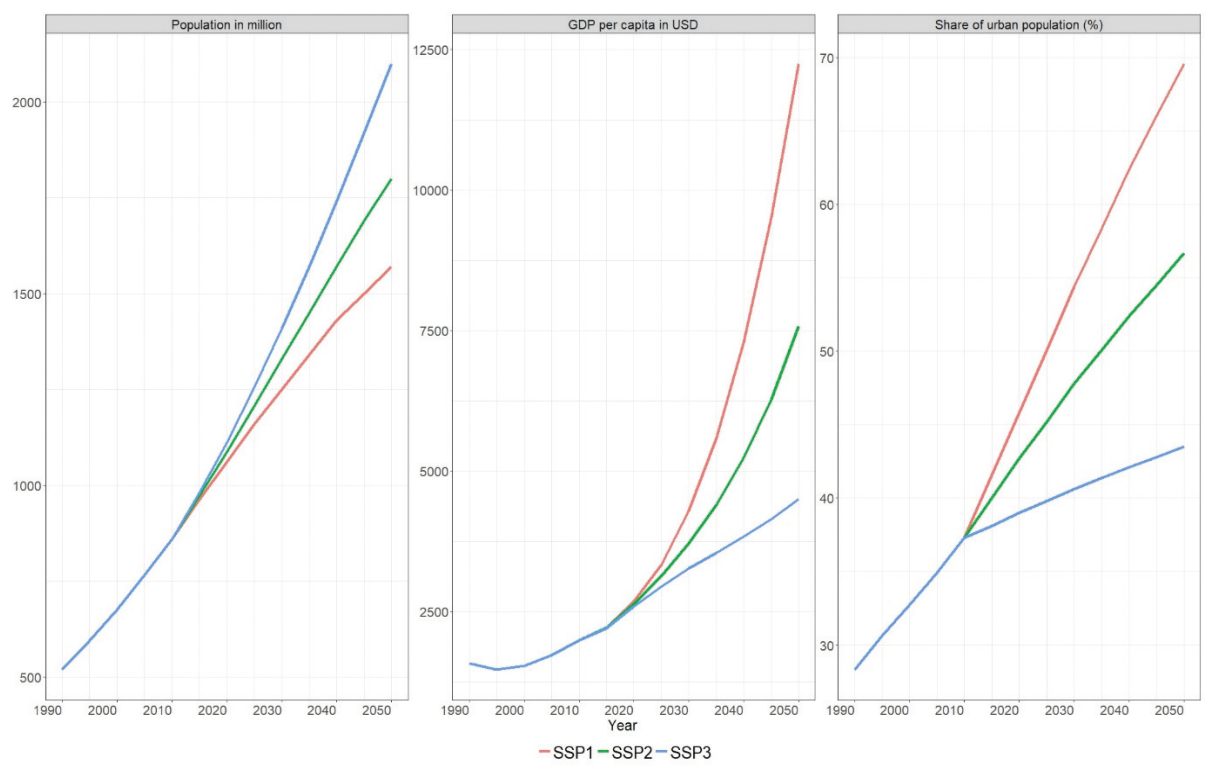

Figure 45: SSA population growth, GDP per capita growth and urbanization in the three SSP projections 


\section{Annex C: Supplementary information - Chapter 4 Expert workshop \\ Methodology Description}

Since the development of the narratives for the future of the electricity sector in SSA require local, regional and international knowledge, expert workshops were organized in Utrecht, the Netherlands and Addis Ababa, Ethiopia. The overall objective of the workshop is to bring experts from different disciplines together to draft scenario narratives for plausible future pathways for providing universal access to electricity in SSA. The workshop participants include policy makers, researchers, financers, modellers, energy service providers, Non-Government Organizations and the private sector. Participants for the Utrecht workshop are identified through academic and research networks in the Netherlands. The participants of the Addis Ababa workshop are selected from a large number of participants at the first African Sustainable Development Forum organized by the Horn of Africa Regional Environment Centre and Network (HOAREC\&N). The participants came from various countries and play various roles in the region's electricity system. The combination of international and local experts provided the advantage of capturing the key trends while at the same time decreasing the likelihood of bias towards a particular point of view. The Utrecht workshops followed the world-café model setting that provided a venue for thorough discussions and capture the uncertainty and variability in future scenarios. The Addis Ababa workshop involved deep discussions with the information gathered at the first workshop serving as the entry point for the discussion. Several iterative steps were followed to develop the narratives:

a. Brainstorming session to identify key actors, their roles driving forces and key uncertainties that will affect universal access to electricity in SSA

b. Categorising the factors according to their importance in the electricity system, their power of influence and the uncertainties involved

c. The focus was put on the factors and actors according to their importance, influence and uncertainty.

d. Based on the above focus, the factors and actors were put in a matrix according to the increasing role of top-down governance structures at the $y$-axis and the dominance of centralized electrification systems on the $x$-axis. 
e. Based on this categorization of actor, driving forces and uncertainties, the four storylines were narrated.

\section{List of organizations represented in workshops}

\begin{tabular}{|c|c|}
\hline Utrecht Workshop & Addis Ababa Workshop \\
\hline Dutch ministry of foreign affaires & (B) Energy \\
\hline CIRED & Arsi NCEDA \\
\hline Clingendael & Climate \& development knowledge network \\
\hline ECN & Ethiopia Stifting Solarenergie-Solar Energy Foundation \\
\hline EfD University of Gothenburg & EXIM Bank of India \\
\hline FMO & French Development Agency \\
\hline Foundation Rural Energy Services & HoA-REC\&N \\
\hline HIVOS & MHP Energy Technology, GIZ \\
\hline HOAREC & Nigeria Youth \\
\hline IEA & Regional Electrification consultants \\
\hline IRENA & SNV \\
\hline IVM & Solar Energy Foundation \\
\hline KtH & Sunny Simons \\
\hline Philips & The Eminence Media \\
\hline RVO and $B Z$ & University of Sussex \\
\hline \multicolumn{2}{|l|}{ SEI Kenya office } \\
\hline \multicolumn{2}{|l|}{ SNV } \\
\hline \multicolumn{2}{|l|}{ Trinomics } \\
\hline \multicolumn{2}{|l|}{ Triodos Bank } \\
\hline \multicolumn{2}{|l|}{ TUE } \\
\hline \multicolumn{2}{|l|}{ Twente University } \\
\hline \multicolumn{2}{|l|}{ UNEP/DTU Copenhagen } \\
\hline \multicolumn{2}{|l|}{ University of Cape town- ERC } \\
\hline \multicolumn{2}{|l|}{ University of Durham } \\
\hline \multicolumn{2}{|l|}{ University of Sussex } \\
\hline World Bank & \\
\hline
\end{tabular}




\section{Stakeholder interviews \\ Methodology description}

The overall purpose of the interviews was to identify key actors and challenges in the electricity system in SSA and regulatory instruments employed to address those challenges. Accordingly, the stakeholder interviews were designed to obtain information on the electricity system in SSA from key individuals/ organizations that are involved in the sector under various capacities.

The stakeholder interviews were conducted between August and October 2017 in Nigeria, Ghana, Ethiopia and Tanzania. After identifying the projects, actors including national governments, regional/state governments, local governments, key financial institutions, civil society organizations, academic institutions, consumers and the private sector were approached for interviews. The initial process resulted in a long list of actors involved in the sector and we prioritised the ones that play a crucial role in the sector. For this, we consulted two experts in each country which have extensive knowledge of the electricity sector, its actors, and the power of those actors to influence policy. Following that, we applied snowball sampling to identify and include actors deemed important by respondents. The snowballing helped to identify actors that play important roles in centralized and decentralised systems. This process provided an extensive list of actors in the electricity sector in the countries under consideration.

The interviews were semi-structured open-ended, and were based on predetermined questions, which allowed stakeholders to share the requested information (the supplementary text presents the interview questions). In developing the question, we tried to identify the most appropriate way to obtain the necessary information together with local experts, given the cultural context. The interview questions were tested with non-priority stakeholders in each country. 


\section{Interview protocol}

\section{Project/program details:}

Name:

Capacity/size:

Location:

Population served by the project:

Project start and completion date:

Total cost of the project:

Main source of energy:

\section{Actor details}

Name ${ }^{1}$ :

Type $^{2}$ :

Position/role in the project/program:

Responsibility:

\begin{tabular}{|c|c|}
\hline Questions & Purpose \\
\hline $\begin{array}{l}\text { Can you describe your organization } 3 \text { ? What is its core business? what } \\
\text { does it do? }\end{array}$ & $\begin{array}{l}\text { Tasks, engagement } \\
\text { reason }\end{array}$ \\
\hline When did you start working in this project/program? & Engagement period \\
\hline How active are you in this project/program? What role do you play? & Responsibility \\
\hline What do/did you plan to achieve with this project/ program? & $\begin{array}{l}\text { Expectations, } \\
\text { desired objective }\end{array}$ \\
\hline $\begin{array}{l}\text { Are you familiar with the SDGs (universal energy access target)? How do } \\
\text { you relate your goal with this target? Do you believe universal energy } \\
\text { access is feasible? }\end{array}$ & $\begin{array}{l}\text { Ambitions related } \\
\text { to SDGs }\end{array}$ \\
\hline Who are the actors/stakeholders in this project/program? & Relation with actors \\
\hline Who do you think are the most crucial actors in the project/program? Why? & Relation with actors \\
\hline With which actor(s) do you have frequent communication? & Relation with actors \\
\hline
\end{tabular}

1 Probably not always possible (eg in the case of community), so improvise

2 There will be a list of stakeholder types to choose from

3 Try to define that word 'organization' based on the type of stakeholder defined above 


\section{Interview protocol (continued)}

\begin{tabular}{ll}
\hline Questions & Purpose \\
\hline What is the most common channel of communication? & Relation with actors \\
$\begin{array}{l}\text { What is your assessment of the regulatory framework with relation to } \\
\text { the project? }\end{array}$ & $\begin{array}{l}\text { Adequacy of } \\
\text { frameworks }\end{array}$ \\
$\begin{array}{l}\text { Do you think there are actors missing in the project? Which ones? What } \\
\text { roles should they play? }\end{array}$ & $\begin{array}{l}\text { Relation with actors } \\
\text { What is/was the most challenging situation/ bottleneck you faced in this }\end{array}$ \\
$\begin{array}{l}\text { project/program? } \\
\text { How did you solve that challenge? Did you involve other actors for that? }\end{array}$ & $\begin{array}{l}\text { Cesources } \\
\text { What are the most important policies, legislations or procedures for the }\end{array}$ \\
$\begin{array}{l}\text { project? Are there subsidies, penalties, feed-in-tariffs, etc. that stimulate } \\
\text { or hinder this project? }\end{array}$ & $\begin{array}{l}\text { Important laws, } \\
\text { legislations, } \\
\text { procedures and } \\
\text { authorities }\end{array}$ \\
$\begin{array}{l}\text { Are there still crucial barriers limiting the reach of the project/program? } \\
\text { In your opinion, what makes/ can make the program successful? }\end{array}$ & $\begin{array}{l}\text { Challenges, resources } \\
\text { In your opinion, what can make the program fail? }\end{array}$ \\
\hline
\end{tabular}

\section{List of organizations represented in interviews}

\begin{tabular}{|c|c|c|c|}
\hline Ethiopia $n=18$ & Ghana $n=30$ & Nigeria $n=21$ & Tanzania $\mathrm{n}=31$ \\
\hline $\begin{array}{l}\text { Addis Ababa } \\
\text { University }\end{array}$ & $\begin{array}{l}\text { Donor Agencies/World } \\
\text { Bank }\end{array}$ & $\begin{array}{l}\text { Ac energy consult - energy } \\
\text { researcher }\end{array}$ & $\begin{array}{l}\text { ECHO East Africa } \\
\text { Impact Centre-Smart } \\
\text { Biogas Network }\end{array}$ \\
\hline Direct solar & Energy Commission (EC) & Ac energy consults & End-users \\
\hline EEP & Energy Commission (EC) & Council for renewable energy Nigeria & Gadgetronix Net \\
\hline EEU & $\begin{array}{l}\text { Ghana-Netherlands } \\
\text { WASH Program (GNWP) }\end{array}$ & $\begin{array}{l}\text { Covenant university physical } \\
\text { planning and development }\end{array}$ & Mobisol \\
\hline End-users & GTS Engineering Services & $\begin{array}{l}\text { EKO electricity distribution } \\
\text { company }\end{array}$ & $\begin{array}{l}\text { Off-grid electric } \\
\text { Tanzania Ltd. (ZOLA) }\end{array}$ \\
\hline METEC & Safi Sana & $\begin{array}{l}\text { EKO electricity distribution } \\
\text { company }\end{array}$ & $\begin{array}{l}\text { TAREA (Tanzania } \\
\text { Renewable Energy } \\
\text { Association) }\end{array}$ \\
\hline
\end{tabular}




\section{List of organizations represented in interviews (continued)}

\begin{tabular}{|c|c|c|c|}
\hline Ethiopia $n=18$ & Ghana $\mathrm{n}=30$ & Nigeria $\mathrm{n}=\mathbf{2 1}$ & Tanzania $\mathrm{n}=31$ \\
\hline $\begin{array}{l}\text { Selam } \\
\text { vocational } \\
\text { training } \\
\text { centre }\end{array}$ & Africano Electro Limited & End-users & \\
\hline SIGMA & Arthur Energy Advisors (AEA) & Energy commission of Nigeria & \\
\hline Solar Energy & Ashaiman Municipal & Energy department - united nations & \\
\hline Foundation & Assembly (AshMA) & industrial development organization & \\
\hline \multirow[t]{16}{*}{ UEAP } & Black star energy & IKEJA electricity distribution company & \\
\hline & Chessing Global & Independent mini grid installers - & \\
\hline & Technologies & RUBITEC & \\
\hline & $\begin{array}{l}\text { Electricity Company of } \\
\text { Ghana (ECG) }\end{array}$ & Installers - KOKUN integrated. & \\
\hline & End-users & Lagos state electricity board & \\
\hline & $\begin{array}{l}\text { Ghana Energy Development } \\
\text { and Access Project (GEDAP) }\end{array}$ & Mini grid installer - CETENERGY & \\
\hline & International Fertilizer & Mini grid maintenance team - & \\
\hline & Development Centre(IFDC) & CETENERGY & \\
\hline & Solar Light Company & Nigerian bulk electricity regulatory & \\
\hline & Limited & commission & \\
\hline & Suka Energy & $\begin{array}{l}\text { Nigerian electricity management } \\
\text { services agency }\end{array}$ & \\
\hline & Tino Solutions & $\begin{array}{l}\text { Nigerian institute of electrical and } \\
\text { electronics engineers }\end{array}$ & \\
\hline & Tradeworks & Power for all & \\
\hline & $\begin{array}{l}\text { Trama Tecno Ambiental } \\
\text { (TTA) }\end{array}$ & $\begin{array}{l}\text { Renewable energy association of } \\
\text { Nigeria }\end{array}$ & \\
\hline & Wilkins Engineering Limited & Rural electrification agency & \\
\hline & & Transmission company of Nigeria & \\
\hline
\end{tabular}




\section{Annex D: Supplementary information - Chapter 5 Model description}

In this section, we present details of the Residential energy model global (REMG), which is the core of our methodology to determine future energy demand and the role of different fuels and technologies for cooking. The detail description and working principles of other components of the methodology can be found in various literatures; IMAGE [42], TIMER [149], IMAGE-Landmanagement [43] and GISMO [150]. REMG is part of TIMER, while TIMER, IMAGE-Landmanagement and GISMO are all components of IMAGE.

REMG is a bottom up residential energy simulation model that describes the demand and supply of energy for different end-use functions, such as lighting, water heating, space heating/cooling, appliances and cooking. The future residential energy demand is determined by focusing on the energy demand for a specific-end use function and the demand drivers like population size, household expenditure, population density, household size and climate. The model also recognizes the impact of heterogeneity in income groups and urban-rural divisions on household energy demand. The relationships between the drivers and end-use demand is presented in Figure 46. In all subsequent figures and equations, the subscript ' $R$ ' denotes regional variation, ' $\mathrm{p}$ ' denotes urban/rural class difference, ' $q$ ' denotes income quintile, and 'a' different appliances.

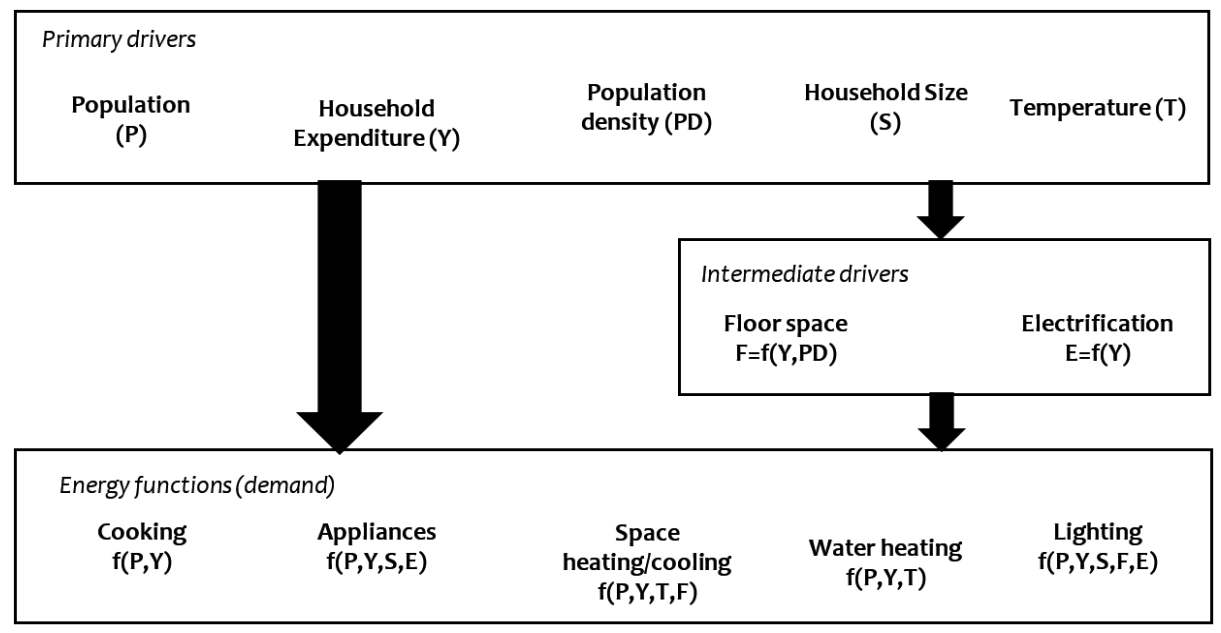

Figure 46: Relationship between drivers and energy functions [38] 
The model determines energy demand for the end-use functions at the household level, using five income quintiles for both rural and urban settlements. Once the energy demand for each end-use function is determined, the model assigns energy carriers based on the relative cost of the fuel and the corresponding technology. The choice for energy carrier is made from the available fuel-technology combinations shown in Table 32. Note that, in addition to the fuels mention in Table 32, TIMER also describes more advanced fuels like hydrogen and modern bio-energy. However, given the time frame of our simulation, we opted not to include them in REMG runs.

Table 32: Energy carriers available for each end-use function

\begin{tabular}{|c|c|c|c|c|c|}
\hline \multicolumn{6}{|c|}{ End-use function } \\
\hline & Cooking & $\begin{array}{l}\text { Appliances and } \\
\text { space cooling }\end{array}$ & Space heating & Water heating & Lighting \\
\hline \multirow{9}{*}{ ల్ } & Coal & Electricity & Coal & Coal & Kerosene \\
\hline & Traditional biomass & & Traditional biomass & Traditional biomass & Electricity \\
\hline & Kerosene & & Kerosene & Kerosene & \\
\hline & Liquide petroleum gas & & Liquide petroleum gas & Liquide petroleum gas & \\
\hline & Natural gas & & Natural gas & Natural gas & \\
\hline & Modern bioenergy & & Modern bioenergy & Modern bioenergy & \\
\hline & Modern biomass & & Secondary heat & Secondary heat & \\
\hline & Electricity & & Electricity & Electricity & \\
\hline & & & Hydrogen & Hydrogen & \\
\hline
\end{tabular}

The household energy demand for the five end-use functions are determined in terms of useful energy (UE). Useful energy is the energy that households need to provide for energy services, adjusted for conversion efficiency between energy carriers excluding losses in the use of energy products. In chapter 5, we specifically focus on cooking end-use function.

In developing regions, cooking often represents the most significant end-use function. Daioglou, van Ruijven [38] analysed a large number of literature for useful energy demand for cooking and found estimates in the range of 0.77 to $7.22 \mathrm{MJ}$ UE/cap/ day. Most of the data was clustered around 1.5 and 3.5 MJ UE/cap/day, and found no 
statistically significant relationship between household energy demand for cooking and income or geographical region. Therefore, similar to Daioglou, van Ruijven [38], we assume that all households in the region have an average static consumption of 3 MJ ue/cap/day. The household cooking energy demand $u e_{h h}$ is a function of household size $\mathrm{HH}_{\text {size }}$ and useful energy per capita ue capita . It is expressed as:

$$
u e_{\text {hh }}=H_{\text {sizex }} \text { ue } e_{\text {capita }}
$$

Once the useful energy demand is determined, the model simulates which cooking fuel/technology are used in order to meet the demand. The available energy carriers for cooking end-use function is presented in Table 32. The regional fuel allocation for cooking is dictated by four key dynamics: 1) A multinomial logit allocation based on relative costs, 2) Income based perceived costs accounting for aspects such as behaviour and accessibility 3 ) the consumer discount rate of the different income classes indicating upfront cost barriers and 4) stock turnover delays. The multinomial logit function used to allocate fuel shares (FS) for each energy carrier (EC) based on relative costs $(C)$ is expressed as:

$$
F S_{R, p, q, E C}=\frac{e^{-\lambda C_{R, p, q, E C}}}{\sum_{E C=1}^{E C_{t o t}} e^{-\lambda C_{R, p, q, E C}}}
$$

The total annual costs of each energy option in equation (2) are the sum of annualized capital costs (CC), fuel price (price) and fuel-specific penalties ( $P$ ):

$$
C_{p, q, E C(t)}=\frac{C D R_{p, q(t)}}{1-\left(1+C D R_{p, q(t)}\right)^{L T} E C} \times C C_{E C}+\frac{u e_{p, q(t)}}{E f f_{E C}} \times \text { price }_{p, q, E C(t)}+P_{p, q, E C(t)}
$$

Where CDR is the consumer discount rate. The discount rate, the perceived costs and the multinomial logit model represent the dynamics of the concept of the energy ladder. This equation also takes into consideration the impact of other variables, such as fuel prices. Access to electricity, which determines the use of electricity for a cooking is determined with in the electrification model discuss in Dagnachew, Lucas [10]. The energy transition is simulated by introducing additional factors that determine the cost in equation (2). 
The annualized capital costs are a function of the assumed consumer discount rates. The discount rate is income dependent to simulate the effect that up-front capital investments are more feasible for richer households than for poor. According to Daioglou, van Ruijven [38], applied discount rates for fuel choices are much higher for low income households (up to $80 \%$ ) due to the high cost of capital for the poor. With this logic, in our model, discount rates are assumed to decrease with income, hence, annualized costs also decrease with income. Second, there is an income dependent disadvantage-factor to represent the importance of perceived (nonmonetary) negative images of cheap but dirty fuels like biomass and coal (i.e. time spent collecting biomass, indoor smoke, etc....). This phenomenon indirectly results in a behaviour similar to the energy ladder while also accounting for fuel staking, as the market shares are determined by fraction and heterogeneity (income class and urban/rural population).

The non-monetary costs represent the fact that fuel choice is not only the product of economic factors alone; especially in poorer households where cultural aspects, lack of awareness on advantages of cleaner fuels, and the opportunity cost of traditional biomass play important roles. It is assumed that the non-monetary costs for traditional fuels (i.e. biomass, kerosene) increase with income. This follows the logic that with increasing income, factors like employment/education and the value of time, change - leading to more 'rational' behaviour. This results in decreased attractiveness for less convenient fuels like solid biomass, coal and kerosene, while the attractiveness for cleaner fuels like electricity and natural gas increase. Market distortion, such as consumer preferences and infrastructure barriers, are also represented with an additional factor included to calibrate the modelled market shares to historic observations.

Equation (2) determines the market shares of cooking fuels and technologies, hence, investments in new capital stock, while a vintage stock depends on the lifetime of the cookstoves. Effectively, this builds time-lag in fuel switching (as only new capital responds to changes in circumstances) and prevents energy transitions happening overnight. 
Finally, each cooking fuel or technology has its own final conversion efficiency. The household final energy demand for cooking is a function of the technical efficiency $t_{n}$ and the capital stock $c$ of the technology $i$, and it is expressed as

$$
e^{f}=\sum_{i=1}^{n} \frac{U E D^{h h} X C_{i}}{t_{\eta} i}
$$

\section{Technology and cost assumptions}

Important assumptions include the conversion efficiencies of the fuels and technology related indoor air pollution (hereby focusing on $\mathrm{PM}_{2.5}$ concentration). Table 33 presents efficiency improvement and PM2.5 concentration projections to 2050. The traditional biomass cookstove includes various self-made cookstoves ranging from three-stone fire to basic mud stoves, and we assume that the use of three-stone fire declines in the future, hence, the increase in efficiency.

Table 33: Assumptions on efficiencies and health effects of different cooking technologies in 2050. Conversion efficiencies are based on [155, 220]; health effects based on World Bank Group [221].

\begin{tabular}{|c|c|c|c|}
\hline \multirow[t]{2}{*}{ Fuel } & \multirow[t]{2}{*}{ Cookstove technology } & \multirow{2}{*}{$\begin{array}{l}\begin{array}{l}\text { Conversion } \\
\text { efficiency (\%) }\end{array} \\
2050\end{array}$} & \multirow{2}{*}{$\begin{array}{l}\text { 24-hour PM2.5 } \\
\text { concentrations }\left(\mu \mathrm{g} / \mathrm{m}_{3}\right) \\
2050\end{array}$} \\
\hline & & & \\
\hline \multirow[t]{2}{*}{ Traditional biomass } & Traditional cookstove & $20^{4}$ & 500 \\
\hline & Improved cookstove & 40 & 75 \\
\hline Modern biomass & Advanced cookstove & 65 & 35 \\
\hline Coal & Improved coal cookstove & 25 & 75 \\
\hline Kerosene & Kerosene stove & 55 & 20 \\
\hline LPG & Single or double burner & 70 & 5 \\
\hline Natural gas & Gas stove & 66 & 0 \\
\hline Biogas & Gas stove \& digester & 65 & 0 \\
\hline Electricity & Electric/induction & 90 & 0 \\
\hline
\end{tabular}

4 Traditional biomass cookstove includes various self-made cookstoves ranging from three-stone fire to basic mud stoves, and we assume that the use of three-stone fire declines in the future 
The GHG emissions from cookstoves vary depending on the fuel type used and the cookstove efficiency. The emissions from coal, biomass, kerosene, LPG, and natural gas are calculated based on the emission factors given in Table 34 and the total energy input required to produce the desired amount of useful energy. The table gives the global warming potentials of the different emissions covered in this study used to convert those emissions to $\mathrm{CO}_{2}$ equivalent.

Table 34: Energy content and GHG emission factors of fuels [161, 222]

\begin{tabular}{|c|c|c|c|c|c|c|}
\hline Fuel & $\begin{array}{l}\text { Energy } \\
\text { content }\end{array}$ & $\begin{array}{l}\text { CO2 emission } \\
\text { in } 2016 \\
(\mathrm{~kg} / \mathrm{GJ})\end{array}$ & $\begin{array}{l}\mathrm{CH}_{4} \text { as } \mathrm{CO}_{2 \mathrm{e}} \\
(\mathrm{GWP} 2 \mathrm{O}=72) \\
(\mathrm{kg} / \mathrm{GJ})\end{array}$ & $\begin{array}{l}\mathrm{N} 2 \mathrm{O} \text { as } \mathrm{CO}_{2 \mathrm{e}} \\
(\mathrm{GWP} 2 \mathrm{O}=289) \\
(\mathrm{kg} / \mathrm{GJ})\end{array}$ & $\begin{array}{l}\mathrm{BC} \text { as CO2e } \\
(\mathrm{GWP} 20=900) \\
(\mathrm{kg} / \mathrm{GJ})\end{array}$ & $\begin{array}{l}\mathrm{CO} \text { as CO2e } \\
(\mathrm{GWP} 20=-46) \\
(\mathrm{kg} / \mathrm{GJ})\end{array}$ \\
\hline Coal & $46 \mathrm{MJ} / \mathrm{kg}$ & 101 & 21.60 & 0.43 & 118.90 & -3.69 \\
\hline $\begin{array}{l}\text { Firewood, } \\
\text { air dried (15\% } \\
\text { moisture) }\end{array}$ & $16 \mathrm{MJ} / \mathrm{kg}$ & $0-112^{1}$ & 21.60 & 1.16 & 96.74 & -14.17 \\
\hline Charcoal & $30 \mathrm{MJ} / \mathrm{kg}$ & 121 & 14.40 & 0.29 & 96.74 & -14.17 \\
\hline Kerosene & $43 \mathrm{MJ} / \mathrm{kg}$ & 72 & 0.22 & 0.17 & 55.19 & -0.79 \\
\hline $\begin{array}{l}\text { Liquefied } \\
\text { Petroleum Gas } \\
\text { (LPG) }\end{array}$ & $45.5 \mathrm{MJ} / \mathrm{kg}$ & 63 & 0.07 & 0.03 & 3.92 & $-0,42$ \\
\hline Natural gas & $38 \mathrm{MJ} / \mathrm{m}^{3}$ & 56 & 0.36 & 0.03 & 0.00 & $-0,001$ \\
\hline Bio-gas & $22.8 \mathrm{MJ} / \mathrm{m}^{3}$ & 0 & 0.72 & 0.17 & 3.91 & $-0,42$ \\
\hline Electricity & $3.6 \mathrm{MJ} / \mathrm{kWh}$ & $70-250 \mathrm{~kg} / \mathrm{GWh}$ & & & & \\
\hline
\end{tabular}

The amount of useful energy needed for cooking is an important assumption for determining the technology choice. The amount of energy that a household requires for cooking has been the subject of numerous studies. Balmer [223] found that in households that have access to modern cooking fuel and technology, the cooking fuel consumption is in the range of 2 to $3 \mathrm{MJ} /$ capita/day. Based on a field study in Nyeri County in Kenya, Fuso Nerini, Ray [139] arrived at the conclusion that one 'standard' meal for a household of four members needs 3.64 MJ of energy. Similarly, the UN assumes an average cooking energy requirement of 50kgoe per person per year, which is equivalent to $5.8 \mathrm{MJ}$ per person per day [154]. On the other hand, Zubi, Spertino [153] estimate that a 3 litre multi-cooker needs just $0.6 \mathrm{kWh}$ per day to cook a lunch and dinner for a household of six, which equivalent to 0.36 
$\mathrm{MJ} / \mathrm{capita}$ /day. This range in cooking energy needs makes it difficult to estimate location specific energy demand. Moreover, Daioglou, van Ruijven [38] found no statistically significant relationship between energy for cooking and income or geographical region. Hence, a constant value of $3 \mathrm{MJ} / \mathrm{capita} /$ day of useful energy for all households and regions is used. The uncertainty in the impact of useful energy demand on cooking energy mix is addressed in the analysis further down.

The capital and annual costs of cooking technologies are also important assumption in our model. Figure 47 presents assumed current and future average capital cost (stove and accessory costs) and the annual average operating cost (fuel and maintenance costs) of the cooking fuel and technology combinations included in the model. These costs can differ per region and settlement. The values provided in the figure are averages across the whole of SSA.

For all cooking solutions, except for biogas, the annual operating costs are higher than the initial capital costs for purchasing the cookstove and accessories. Especially kerosene and electricity have high operating costs, followed by LPG. The annual operating costs for biogas are close to zero, but the initial capital costs of the digester are high. Traditional cookstoves, kerosene and coal are assumed to be matured technologies and therefore are assumed not to decrease further in price. LPG and natural gas cookstoves are also relative matured technologies and therefore are assumed to have a relatively modest annual cost decline of $1 \%$ until 2050. For the other cooking technologies electricity, improved and advanced cookstoves and biogas an average annual capital cost decline of $2 \%$ is assumed. 
Capital and operating expenditure of cooking technologies in Sub-Saharan Africa

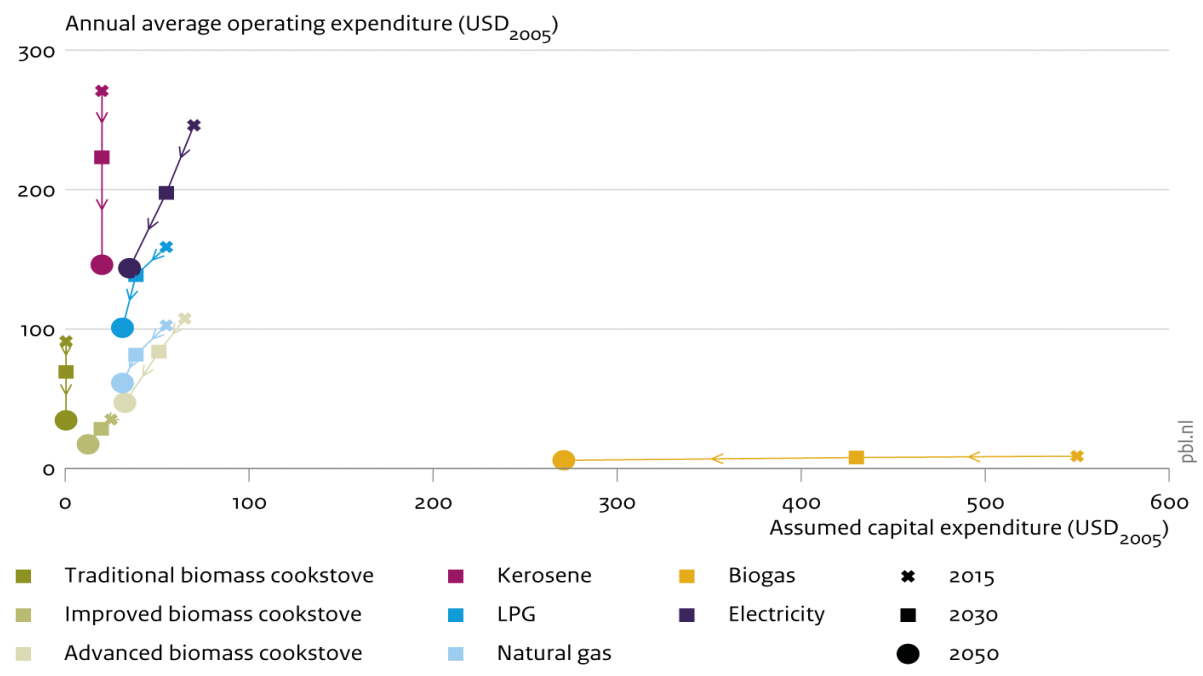

Figure 47: Assumed capital costs and annual average operating cost of cooking technologies [157-159]

\section{Scenario descriptions}

Table 35: A detail description of the scenarios in the study

\begin{tabular}{lll}
\hline $\begin{array}{l}\text { Scenario } \\
\text { set }\end{array}$ & $\begin{array}{l}\text { Scenario } \\
\text { name }\end{array}$ & Short description \\
\hline $\begin{array}{l}\text { Baseline } \\
\text { scenario }\end{array}$ & Baseline & $\begin{array}{l}\text { Reference scenario without specific policies to stimulate clean cooking } \\
\text { under SSP1, SSP2 \& SSP3 socio-economic projections. }\end{array}$ \\
\hline $\begin{array}{l}\text { Policy } \\
\text { scenarios }\end{array}$ & $\begin{array}{l}\text { Cookstove } \\
\text { subsidy }\end{array}$ & $\begin{array}{l}\text { A 50\% subsidy on the retail prices of improved and advanced cookstoves, } \\
\text { but no subsidy on fuel. The focus in this scenario is therefore to promote } \\
\text { improved and advanced cookstoves to address the households with the } \\
\text { worst cooking methods }\end{array}$ \\
& $\begin{array}{l}\text { Biogas } \\
\text { digester } \\
\text { subsidy }\end{array}$ & $\begin{array}{l}\text { A 50\% subsidy on the retail price of biogas digesters. Biogas digesters } \\
\text { could transform abundant agriculture and domestic wastes to biogas } \\
\text { which can be used for cooking in rural areas. Biogas technology is very } \\
\text { attractive for rural settlements since the fuel source is produced locally, } \\
\text { the fuel is typically free and abundant, saves time spent on fuel collection, } \\
\text { the gas burns efficiently and has almost no pollution. }\end{array}$ \\
\end{tabular}


Table 35: A detail description of the scenarios in the study (continued)

\begin{tabular}{|c|c|c|}
\hline $\begin{array}{l}\text { Scenario } \\
\text { set }\end{array}$ & $\begin{array}{l}\text { Scenario } \\
\text { name }\end{array}$ & Short description \\
\hline $\begin{array}{l}\text { Policy } \\
\text { scenarios } \\
\text { (continued) }\end{array}$ & $\begin{array}{l}\text { Enhanced } \\
\text { fuel } \\
\text { distribution }\end{array}$ & $\begin{array}{l}\text { A fraction of LPG and (liquid) natural gas required for cooking is provided } \\
\text { by infrastructure support or subsidy ( } 40 \% \text { in urban areas and } 100 \% \text { in rural } \\
\text { areas). The weak supply chain and the high and often fluctuating price } \\
\text { of fuel has limited the diffusion rate of LPG and natural gas for cooking } \\
\text { in SSA. In addition, the initial capital costs of stove and components and } \\
\text { deposit for the cylinder has made LPG beyond the reach of the (rural) } \\
\text { poor, which suggests that an innovative business model or some form of } \\
\text { financial support could help improving access. The same can be said about } \\
\text { natural gas. To address these concerns, we have explored the role of LPG } \\
\text { and natural gas when the supply chain is subsidized by the government } \\
\text { and/or other players in the sector under a distribution program. }\end{array}$ \\
\hline
\end{tabular}

Target No All households that rely on solid biomass in combination with traditional

scenarios traditional cookstove have switched to cleaner cooking technologies by 2030. Like cookstoves the other target scenarios, there is not so much a narrative behind this scenario; instead, the scenario should be regarded as providing insight in what would be needed in terms of technologies, capital costs, and fuel expenditures to completely remove the dirtiest of cooking methods by 2030 - and what the potential effect would be on health and biodiversity.

Modern In addition to the measures in the no traditional cookstove scenario, the use fuel of solid biomass, kerosene and coal for cooking will be eliminated by 2030 .

Electric The use of solid biomass, kerosene and coal for cooking will be eliminated cooking by 2030. Households cooking on electricity will use $50 \%$ less energy due to changes in cooking behaviours. This assumption is reinforced by the declining price of off-grid renewable energy technologies making them competitive to cooking with charcoal or firewood [224]. This scenario could be interpreted as a change to less energy-intensive preparation of food for those households that cook on electricity, or an increased usage of more pre-cooked foods for those households. Indeed, there is some evidence that alternative electric cooking methods can lead to much lower energy use. Zubi et al. (2017), for instance, discuss the option of an efficient electric multi-cooker that can run on solar-home-systems and requires just $0.36 \mathrm{MJ} /$ capita/day to cook lunch and dinner, while Batchelor (2015) estimates a higher electricity demand of $1.2 \mathrm{MJ} /$ capita/day.

\section{Detailed results}

\section{Cooking energy mix beyond 2030}

Amid a rapid population growth, economic development and urbanization, the cooking energy mix changes considerably towards 2050. After 2030, a significant decrease in the population using traditional cookstoves is projected under baseline. Traditional biomass cookstoves are mainly replaced by improved cookstoves and LPG. In general, a transition away from solid biomass can be faster in urban areas than 
in rural areas, as a result of higher income levels, longer supply chains for fuelwood and charcoal, and more developed markets of modern cooking fuels in urban areas. Under baseline, just $12 \%$ of the population is projected to still use traditional cookstoves, most of them living in rural areas. By 2050, under the Enhanced fuel distribution subsidy scenario, traditional cookstove use reduces to $7 \%$, from $12 \%$ in the baseline. A similar decrease takes place in the biogas digester scenario. In the Cookstove subsidy scenario, the use of traditional cookstoves is practically phased out completely by 2050. Of the policy scenarios, the Enhanced fuel distribution scenario shows the strongest and fastest decline of biomass use with $85 \%$ of the population cooking with LPG or natural gas. At the same time, however, in this scenario, LPG and natural gas displace the very clean alternatives electricity and biogas.

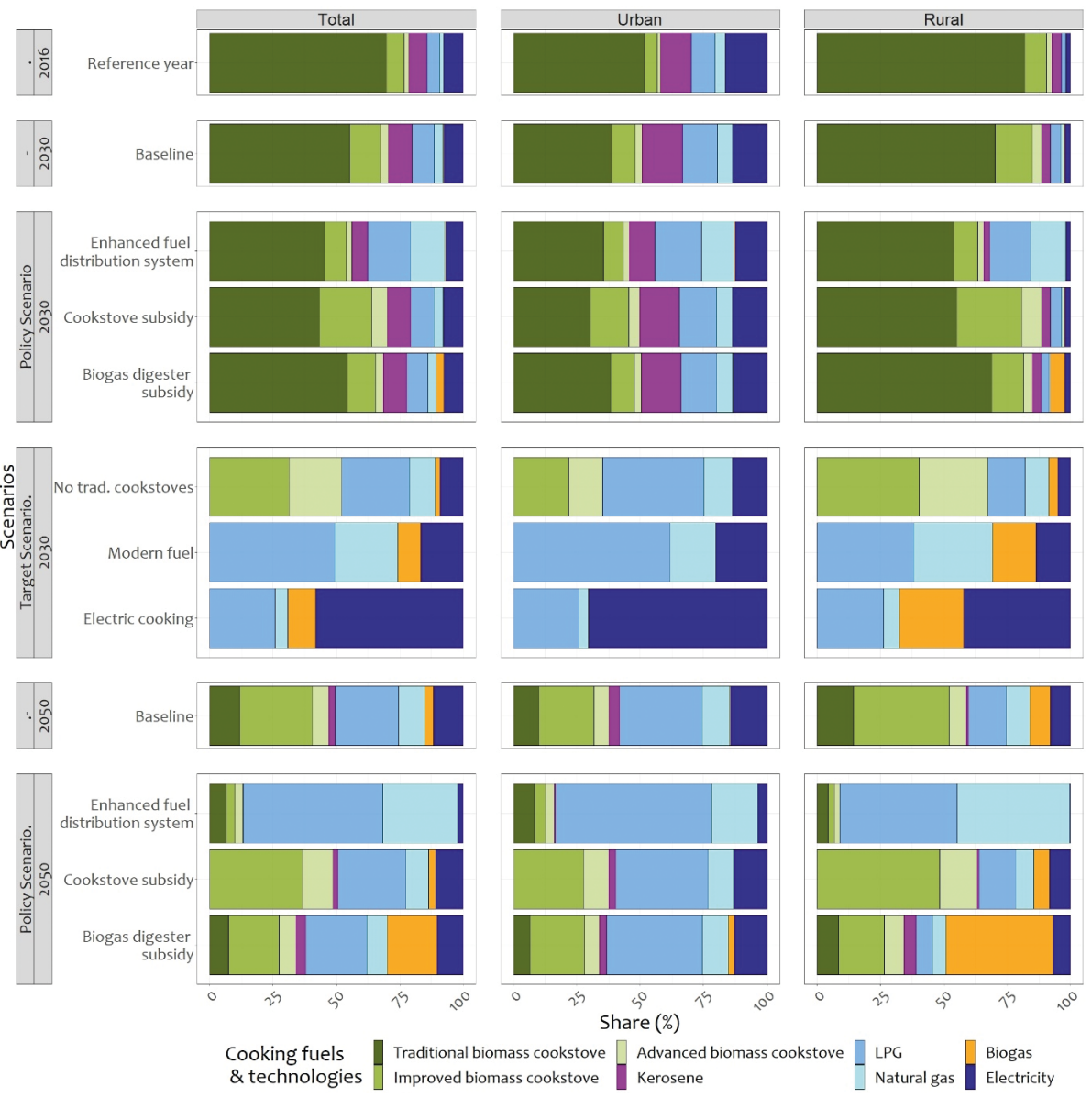

Figure 48: Cooking energy mix SSA under various scenarios projected to 2030 and 2050 


\section{Annual capital expenditure}

The cumulative annual expenditure between 2016-2030 amounts to 8.4 billion USD in the baseline scenario. All the policy scenarios show a slightly higher cumulative capital expenditure (USD 9-12 billion) since the policies stimulate a switch to a cleaner cooking technology relative to baseline. The cumulative investment in target scenarios is threeto four-fold the investment in the baseline as achieving the SDG target requires large investments in cleaner cooking technologies at a higher pace. The capital expenditure in the period 2030-2050 in baseline and policy scenarios is four times the investment in the previous period. These scenarios, except for the Cookstove subsidy scenario, will not eliminate solid biomass from the cooking mix by 2050.

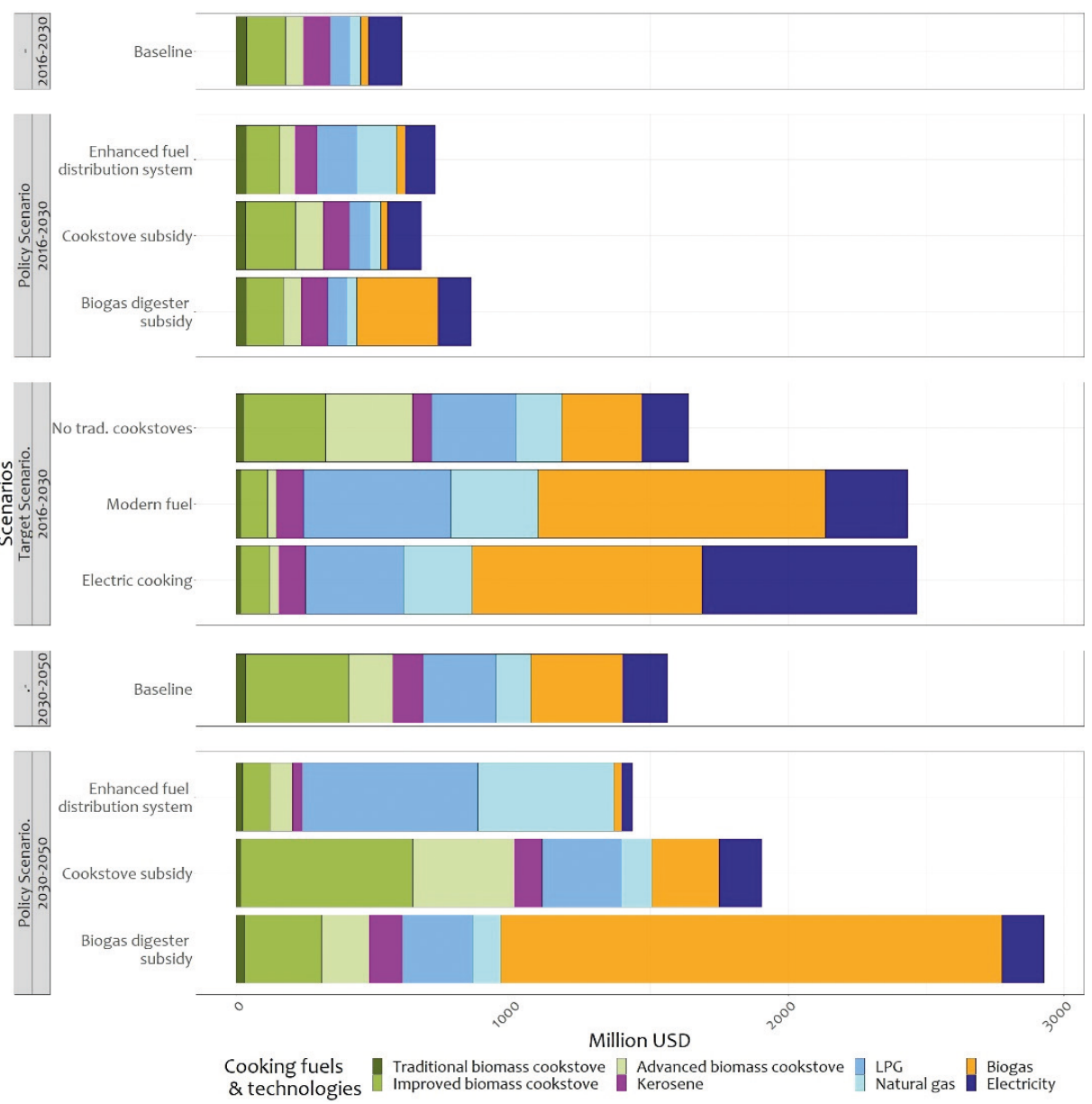

Figure 49: Projected annual capital costs (including subsidies) for stoves and accessories in SSA 


\section{Annual fuel expenditure}

Annual fuel expenditures in SSA under all the scenarios by far exceed the capital investment requirements. In 2030, the total fuel expenditure in the baseline scenario is higher than the 2016 expenditures (USD 29 billion vs USD 23 billion). This is because the efficiency improvements gained under the baseline are cancelled out by the increase in population. The policy scenarios also show similar amount of fuel expenditure as in the baseline in the range of USD 28-29 billion in 2030. By 2050, the enhanced fuel distribution scenario has the highest fuel expenditure as biomass is largely displaced by the relatively expensive fuels LPG and natural gas.

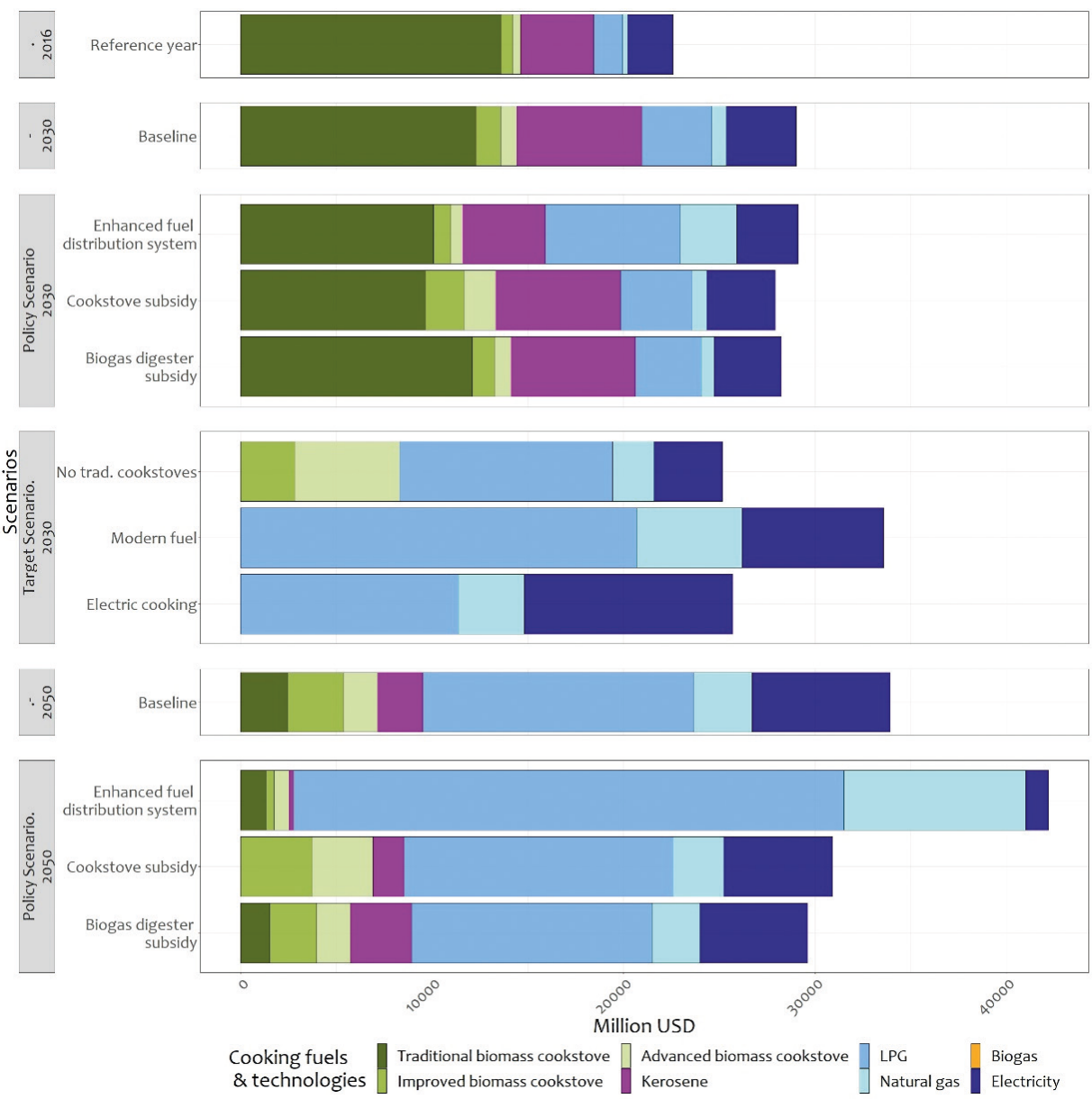

Figure 50: Annual cooking fuel expenditure in SSA under various scenarios 


\section{Sensitivity analysis}

\section{Useful energy demand}

Energy demand has a very small impact on cooking fuel and technology distributions. Figure 51 shows the energy mix of the high-energy-demand scenario (useful energy demand $=6 \mathrm{MJ} /$ capita/day) and the low-energy-demand scenario (useful energy demand $=0.36 \mathrm{MJ} /$ Capita/day). As can be seen in Figure 51, the only obvious difference between the scenarios in 2030 is that the highest demand level stimulate biogas digester as the higher energy demand makes it slightly more competitive. In 2050, high useful energy demand makes LPG and biogas attractive, while with low useful energy demand large portion of the population rely on tradition and improved biomass cookstoves.

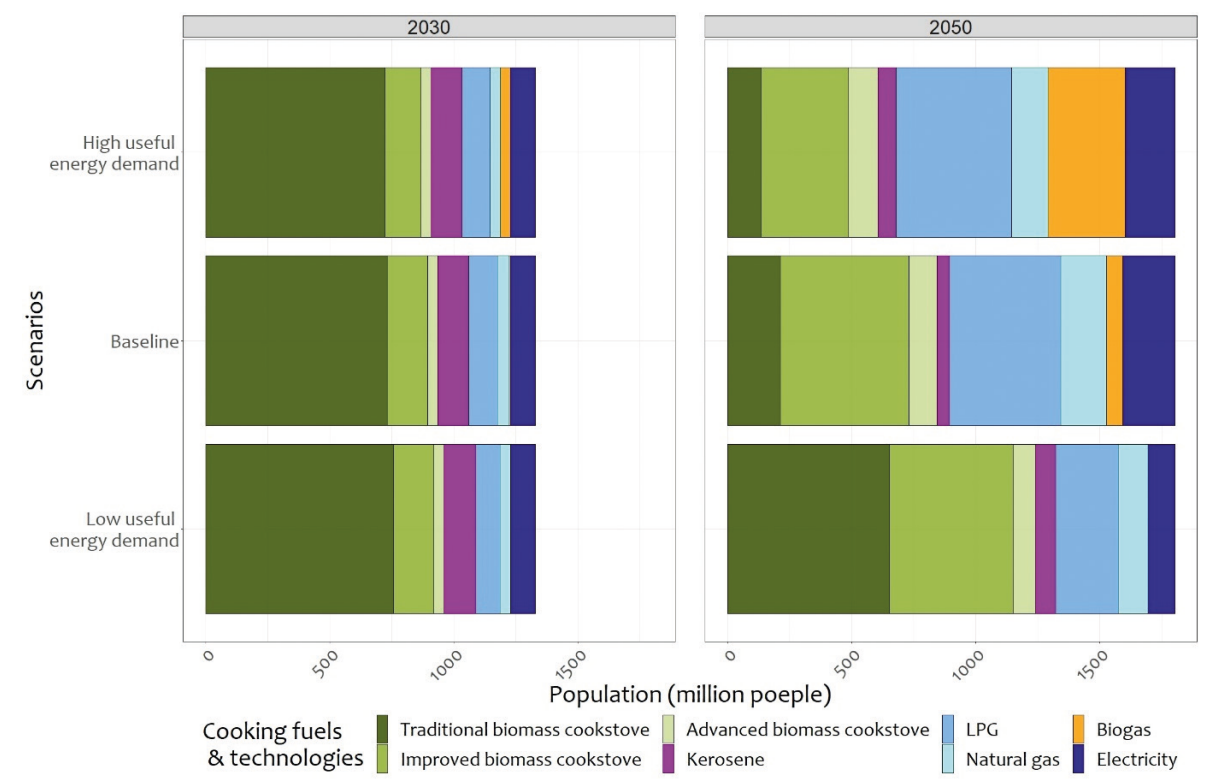

Figure 51: The impact of useful energy demand on cooking energy mix

\section{Socio-economic assumptions}

Under all socioeconomic developments, only a moderate switch away from traditional cookstoves is projected by 2030 without additional policies (Figure 52). As the population and GDP projections do not diverge strongly by 2030, the demand for fuelwood and total GHG emissions differ only slightly among three socioeconomic scenarios. Although the share of solid biomass used in traditional cookstoves is projected to decline gradually, strong population growth offsets efforts to increase 
access to modern cooking facilities, resulting in an increase in the absolute number of people cooking on traditional cookstoves. The share of the population relying on solid biomass on traditional cookstoves declines from $70 \%$ in 2010 to $53-58 \%$ in 2030 , leaving 660-820 million people relying on traditional biomass cookstoves. This is in line with the IEA projection that with continuation of current policies, almost 820 million people do not have access to clean cooking by 2040 [132].

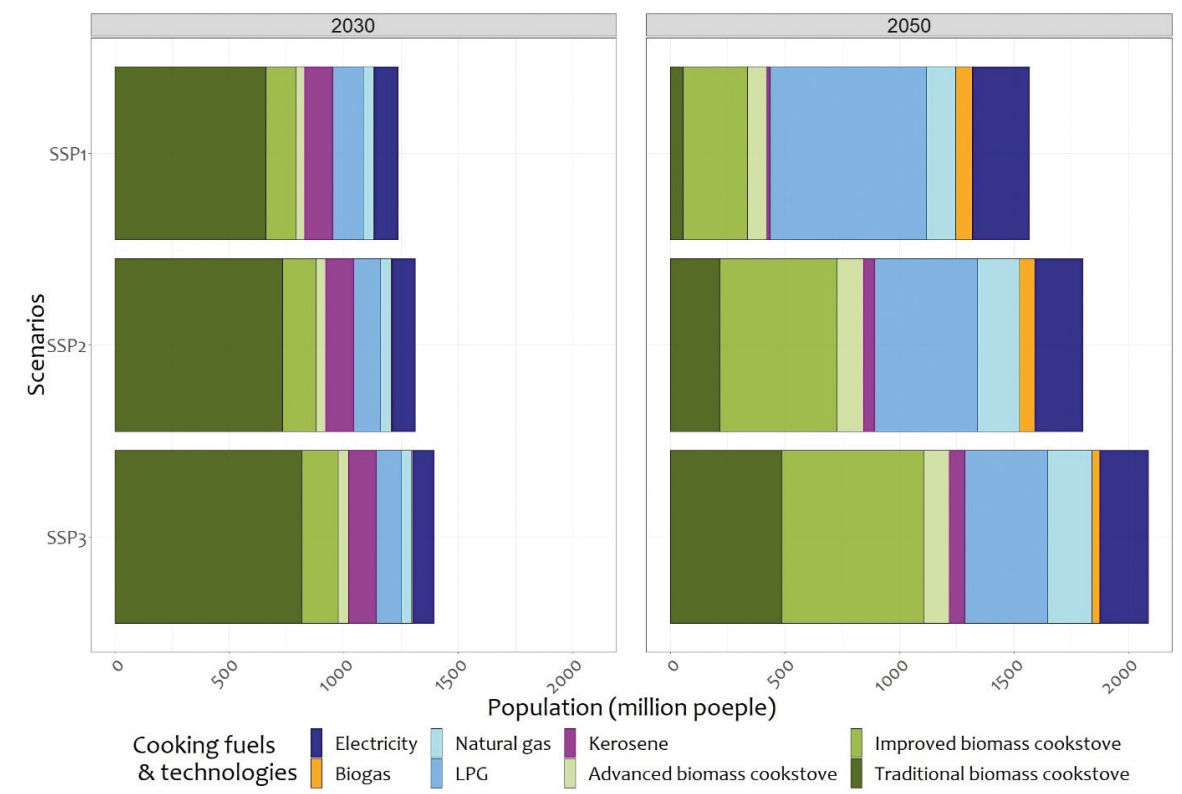

Figure 52: The impact of uncertainties in socio-economic drivers on cooking fuel and technologies

After 2030, a significant decrease in the population using traditional cookstoves is projected under all three socio-economic projections. Traditional biomass cookstoves are mainly replaced by improved cookstoves and LPG. This rapid decrease can be attributed to i) efficiency improvements of modern fuel-based technologies and improved and advanced cookstoves, ii) urbanization, and iii) the increase in household income. Under SSP1, traditional cookstoves are projected to be almost completely phased out by 2050 , while under the $\mathrm{SSP}_{3}$, a quarter of the population is projected to still use traditional cookstoves, most of them living in rural areas. In the latter scenario, economic development and urbanization rates are relatively low, implying slow modern fuel infrastructure development, inability to pay for more expensive fuels and/or higher upfront stove costs, and low awareness about the benefits of modern cooking fuels. 


\section{Annex E: Supplementary information - Chapter 6 Model descriptions}

IMAGE is a simulation model that represents interactions between human and natural systems to assess environmental issues and sustainability challenges [42]. MESSAGE, on the other hand, is a systems engineering optimization model used for the planning of medium to long-term energy systems, analysing climate change policies, and developing scenarios, for national or global regions [225]. Both models include a detailed description of the energy and land-use system and simulate socio-economic and environmental parameters. They provide a framework for representing an energy system with all its interdependencies from resource extraction, imports and exports, conversion, transport, and distribution, to the provision of energy end-use services such as appliances, lighting, space conditioning, industrial production processes, and transportation. In IMAGE the simulations are done in a single year time steps, while MESSAGE simulates on 5- or 10-year timesteps until 2100. Important inputs to the models are descriptions of the future development of direct and indirect drivers of global environmental change.

The TIMER energy-system simulation model [226] and IMAGE-LandManagement [43] form the core of the IMAGE model. The TIMER model describes demand and supply of key energy carriers for 26 world regions [226]. The household energy model (REMG) and the Sub-Saharan Electrification model form part of TIMER model. REMG is a stylized bottom-up simulation model, which describes energy demand for several end-use functions (i.e. cooking, appliances, space heating and cooling, water heating, and lighting), based on a set of physical drivers [38]. By relating these end-use functions to economic development, the model is able to analyse changes in energy demand, and energy use and the fuel mix for five income classes, for both rural and urban households. Similarly, the SSA electrification model determines the least-cost option for electrification based on a set of variables at a grid-cell (30min $\mathrm{X}$ 3omin) level. The choice between the technologies is based on the proximity of the grid-cell to an existing power line, the household electricity demand, the population density of the grid-cell, and the cost and availability of local energy resources.

The MESSAGE-Access model is a standalone residential energy choice and demand model linked to MESSAGE for the projections of useful or final energy demand. 
In the model, households choose fuels and appliances for different end-uses according to their preferences for consumption of other household goods and each of the available options. Several versions of the Access model have been used for scenario analysis over the years. The first version was used in similar study also comparing results of MESSAGE-Access and IMAGE-TIMER for the Sub-Saharan Africa and the South and Pacific Asia regions [138], whereas the second version was used to analyse trade-offs between mitigation and clean cooking targets in South Asia [187], and policies towards full clean cooking energy access in Central America [140]. Here we use the third version of the Access model, which consists of a structural econometrics model, where choices and demand for fuels and appliances are estimated based on observed patterns and vary among households [186, 227]. In particular, households optimally choose appliances, stoves and the amount of energy consumed for different end-uses, as well as their consumption of other goods, based on their preferences and their budget. Preference parameters for the households are estimated using simulation-based estimation methods on a large micro dataset comprised of households from different representative countries of the Sub-Saharan region.

The electrification model within TIMER considers eight off-grid electrification options (mini-grid and stand-alone technologies) for electrification, in addition to extending the central grid. MESSAGE only assumes access through the central grid extension. Both IMAGE-TIMER and MESSAGE- Access models allow assessing electrification in both rural and urban areas, but whereas IMAGE-TIMER assumes five income groups [10, 28], MESSAGE- Access assumes a continuous income distribution. The energy carriers in these models include coal, traditional biomass (in combination with traditional, improved and advanced cookstoves), kerosene, LPG, natural gas and electricity $[38,186]$. Additionally, TIMER considers biogas for cooking as an important option in the transition towards modern cooking fuels, especially in rural SSA. This alternative is not included in Access due to data limitations, as none of the micro datasets used to estimate the model possess information on biogas adoption. SSA is a single aggregate region in MESSAGE, but microdata from several individual nations representative of different sub-regions is used to estimate choices in the Access model. The IMAGE-TIMER distinguishes four sub-regions in SSA: western \& 
central Africa, eastern Africa, the Republic of South Africa, and the rest of southern Africa.

The major difference between the models lies on their assumptions of cooking energy demand in the region. While IMAGE-TIMER assumes a fixed amount of $3 \mathrm{MJ} /$ capita/day for cooking for all households irrespective of regions or income, the MESSAGE-Access model assumes that households freely decide their levels of consumption of fuels and other household goods based on the available alternatives, market prices and income in line with what is observed in micro data from household surveys from the region. The cooking end-use service is by far the dominant energy end-use in SSA households. As a result, it largely determines the overall residential energy demand, energy mix, and residential sector emissions.

Table 36: Residential demand modelling and characterization in IMAGE-TIMER and MESSAGE-Access

\begin{tabular}{|c|c|c|}
\hline Model characteristics & IMAGE-TIMER & MESSAGE- Access \\
\hline $\begin{array}{l}\text { Regional } \\
\text { disaggregation }\end{array}$ & $\begin{array}{l}\text { SSA divided into } 4 \text { regions, } 0.5 \times 0.5 \\
\text { resolution for demand and supply analysis }\end{array}$ & $\begin{array}{l}\text { Whole region simulated based on } \\
\text { individual country aggregates }\end{array}$ \\
\hline Type model & Simulation model & Structural econometrics model \\
\hline Time steps & Annual & Decennial (MESSAGE) \\
\hline $\begin{array}{l}\text { Household } \\
\text { disaggregation }\end{array}$ & $\begin{array}{l}\text { Urban and rural divide and five income } \\
\text { classes }\end{array}$ & $\begin{array}{l}\text { Large number of random draws } \\
\text { from joint distributions to match } \\
\text { data from surveys }\end{array}$ \\
\hline $\begin{array}{l}\text { Household } \\
\text { electricity demand }\end{array}$ & $\begin{array}{l}\text { Bottom-up based on appliance } \\
\text { ownership driven by income }\end{array}$ & $\begin{array}{l}\text { Indirect utility maximization driven } \\
\text { by a set of household characteristics }\end{array}$ \\
\hline $\begin{array}{l}\text { Household cooking } \\
\text { energy demand }\end{array}$ & $\begin{array}{l}3 \mathrm{MJ} / \text { capita/day for all households and } \\
\text { regions }\end{array}$ & Utility maximization model \\
\hline $\begin{array}{l}\text { Energy carriers } \\
\text { for electricity } \\
\text { production }\end{array}$ & $\begin{array}{l}\text { Solar, wind, wave, hydro, nuclear, coal, } \\
\text { coal with CCS, oil, oil with CCS, natural } \\
\text { gas, natural gas with CCS, biomass, } \\
\text { biomass with CCS, other renewables }\end{array}$ & $\begin{array}{l}\text { Biomass (w/wo ccs), coal (w/wo } \\
\text { ccs), oil (w/wo ccs), gas (w/wo } \\
\text { ccs), geothermal, hydro, nuclear, } \\
\text { solar, wind, other renewables }\end{array}$ \\
\hline
\end{tabular}


Annex E

Table 36: Residential demand modelling and characterization in IMAGE-TIMER and MESSAGE-Access (continued)

\begin{tabular}{|c|c|c|}
\hline Model characteristics & IMAGE-TIMER & MESSAGE- Access \\
\hline \multirow[t]{9}{*}{ Appliances } & Television & Air conditioner \\
\hline & VCR/DVD & Fan \\
\hline & PC & Water Heater \\
\hline & Washing machine & Refrigerator \\
\hline & Dryer & Television \\
\hline & Air conditioner & Washing Machine \\
\hline & Fan & Electric heater \\
\hline & Microwave & Kerosene heater \\
\hline & Dish washer & \\
\hline \multirow[t]{2}{*}{ Lighting } & Kerosene & Kerosene \\
\hline & incandescent light bulb (standard and halogen) & Electricity \\
\hline \multirow{8}{*}{$\begin{array}{l}\text { Cooking / Water } \\
\text { heating }\end{array}$} & Traditional biomass stove & Traditional biomass stove \\
\hline & Improved biomass stove & Improved biomass stove \\
\hline & Advanced biomass stove & Advanced biomass stove \\
\hline & Kerosene stove & Kerosene stove \\
\hline & LPG stove & Gas stove \\
\hline & Natural gas stove & Electric stove \\
\hline & Biogas stove & \\
\hline & Electric stove & \\
\hline \multirow[t]{5}{*}{ Space heating } & Coal heater & Electric \\
\hline & Traditional biomass heater & Biomass \\
\hline & LPG heater & Other (LPG, Kerosene) \\
\hline & Natural gas heater & \\
\hline & Electricity heater & \\
\hline Space cooling & $\mathrm{Ac} / \mathrm{fan}$ & AC/fan \\
\hline
\end{tabular}

\section{Targets and indicators}

We analyse the scenarios in terms of various indicators discussed in detail below:

1. Universal access to electricity is achieved when everyone in SSA has access to reliable electricity services. The household electricity demand is based on historical observations discussed in van Ruijven, Schers [37] and ranges from $200 \mathrm{kwh}$ in rural eastern-Africa to $3500 \mathrm{kwh}$ in urban RSA in 2030. The share of people with access to electricity (\%) is chosen as an indicator. 
2. Access to clean fuels and technologies for cooking is defined as halting the use of traditional biomass cookstoves and kerosene. The share of the population cooking on improved and advanced biomass cookstoves, LPG, natural gas, biogas, and electricity is considered as having access to clean cooking fuels and technologies. The share of people with access to clean and sustainable energy for cooking (\%) is used as an indicator.

3. The annual rate of change in the average energy intensity of the residential sector indicates the energy savings achieved in the sector owing to various measures. Energy efficiency can relate to supply-side and demand-side efficiency. For the purpose of this study, we focus on demand-side efficiency improvements.

- Activity measures in the residential sector include population size [228], number of households $[228,229]$ or floor area of occupied housing units [229]. Based on the chosen activity, the final energy intensity can be presented as energy consumption per capita (MJ/capita), energy consumption per household $(\mathrm{MJ} / \mathrm{HH})$, or energy consumption per unit of dwelling area $\left(\mathrm{MJ} / \mathrm{m}^{2}\right)$. In line with EEA [230], we have chosen to use population as activity to assess how residential energy use on a per capita basis is evolving.

- The final energy intensity is calculated as:

$\mathrm{FEI}_{\mathrm{t}}=\frac{\text { Residnetial } F E C_{t}}{\text { Number of people }}$,

where $\quad \mathrm{FEI}_{t}$ is the residential final energy intensity at time $t$ and $\mathrm{FEC}_{\mathrm{i}}$ is the final energy consumption at time $t$

4. Substantially increasing the share of renewable energy in the energy mix: for this target, we consider the share of renewable energy in the final energy mix of residential energy consumption without solid biomass. The change in the share of renewable energy in the final energy supply of SSA between 2010 and 2030 demonstrates the potential developments of renewable energy sources in electricity, cooking and heating in the region.

Synergies and trade-offs of integrating energy access, efficiency and renewables policies are assessed in terms of impacts on household FEC, capital investment and 
operating expenditure of providing access to clean and modern energy services, and energy use related residential sector emissions in SSA.

\section{Data and assumptions}

Table 37: Historic and SSP2 projection for socio-economic indicators

\begin{tabular}{|c|c|c|c|c|c|c|}
\hline \multirow{2}{*}{ Region } & \multicolumn{2}{|c|}{$\begin{array}{l}\text { Population } \\
\text { (million people) }\end{array}$} & \multicolumn{2}{|c|}{$\begin{array}{l}\text { GDP per capita PPP } \\
\text { (USD) }\end{array}$} & \multicolumn{2}{|c|}{$\begin{array}{l}\text { Urbanization rate } \\
\text { (\%) }\end{array}$} \\
\hline & 2010 & 2030 & 2010 & 2030 & 2010 & 2030 \\
\hline Western \& central Africa & 415.7 & 655.8 & 1586.5 & 3400.2 & 43.7 & 55.1 \\
\hline Eastern Africa & 266.9 & 402.7 & 1227.6 & 2406.1 & 23.5 & 33.1 \\
\hline Republic of South Africa & 51.6 & 58.9 & 9252.4 & 16407.2 & 61.7 & 71.5 \\
\hline Rest of Southern Africa & 144.2 & 211.1 & 1943.8 & 3681.6 & $34 \cdot 9$ & 46.2 \\
\hline SSA & 878.5 & 1328.4 & 1986.0 & 3720.6 & 37.2 & 47.8 \\
\hline
\end{tabular}

Table 38: current status of and future targets for energy consumption in SSA

\begin{tabular}{|c|c|c|c|c|c|}
\hline \multirow[t]{2}{*}{ Appliance } & \multirow{2}{*}{$\begin{array}{l}\text { Baseline } \\
{[192,231]}\end{array}$} & \multirow{2}{*}{$\begin{array}{l}\text { Implementation } \\
\text { in model - annual } \\
\text { energy consumption }\end{array}$} & \multicolumn{3}{|c|}{ Energy saving potentials } \\
\hline & & & Uganda [191] & $\begin{array}{l}\text { ECOWAS } \\
\text { countries [192] }\end{array}$ & $\begin{array}{l}\text { Vietnam } \\
\text { [190] }\end{array}$ \\
\hline Washing machine & $92 \mathrm{kwh} / \mathrm{year}$ & $75 \mathrm{kwh} /$ year & - & $30.3 \%$ & $40.1 \%$ \\
\hline Fans & $48 \mathrm{kwh} /$ year & $11.3 \mathrm{kwh} /$ year & $30 \%-60 \%$ & $53.0 \%$ & $21.9 \%$ \\
\hline Incandescent lamp & $70 \mathrm{kwh} /$ year & $14 \mathrm{kwh} /$ year & $50 \%-67 \%$ & $75.0 \%$ & $65.9 \%$ \\
\hline Refrigerator & 386 kwh/year & 296 kwh/year & $40 \%-60 \%$ & $64.8 \%$ & $45 \cdot 3 \%$ \\
\hline Air conditioner & $373.3 \mathrm{kwh} /$ year & 366 kwh/year & $15 \%-35 \%$ & $44.0 \%$ & $28.1 \%$ \\
\hline TV & $100 \mathrm{kwh} /$ year & $20.7 \mathrm{kwh} /$ year & $40 \%-55 \%$ & $41.3 \%$ & $20.8 \%$ \\
\hline Microwave & 270 kwh/year & $19.7 \%$ & - & - & $19.7 \%$ \\
\hline Electric cookstove & $900 \mathrm{kwh} /$ year & $5.0 \%$ & - & - & $5.0 \%$ \\
\hline Biomass cookstove & Current & 2030 Baseline & 2030 ACC-EFF & & \\
\hline - Improved & $30 \%$ & $35 \%$ & $40 \%$ & & \\
\hline - Advanced & $40 \%$ & $52.5 \%$ & $65 \%$ & & \\
\hline
\end{tabular}




\section{Summary}

Access to electricity and clean cooking solutions are important prerequisites for human development. This was acknowledged by the global community through the adoption of the Sustainable Development Goals (SDGs), in which SDG7 aims to ensure access to affordable, reliable, sustainable and modern energy for all by 2030. The SDGs are integrated, indivisible and interlinked goals, hence, a silo-approach that focuses on a specific goal or sector will deliver sub-optimal results and may undermine the systemic nature of the challenges. The three targets of SDG7, to ensure universal access to affordable, reliable and modern energy services, to increase substantially the share of renewable energy in the global energy mix, and to double the global rate of improvement in energy efficiency, interact strongly with other SDGs. Several studies [1-3] have shown interlinkages between SDG7 and other SDGs.

Currently, more than 600 million people in sub-Saharan Africa (SSA) have no access to electricity and over 900 million people rely on traditional biomass for cooking. If we follow historical trends, about 515 million people still lack access to electricity and over 700 million people rely on traditional biomass for cooking in 2030. People who lack access to modern forms of energy are trapped in a reinforcing cycle with insufficient means to improve their living conditions and basic services. They also spend a significant share of their income on expensive, unhealthy, unsafe, time consuming and inefficient forms of energy. Hence, affordable and reliable access to modern forms of energy is the key to breaking this cycle.

In this context, working out the best way to provide universal access to clean, modern and sustainable energy while minimizing the social, economic and environmental impacts is a key challenge that policy makers in SSA are facing. The rapid decline in the price of renewable energy technologies has been a driving force for the progress towards universal access to electricity in SSA. There is also a positive trend in clean cooking technology innovation, which, together with a growing number of middle classes with disposable incomes and rapid urbanization, is changing the dynamics of the cooking landscape. However, these developments have also created challenges for traditional energy planning. Determining the cost and benefits between various technologies requires extensive computation, making 
energy system models crucial tools for long-term planning. However, most energy models were built and used in industrialised countries, and they ignore the unique characteristics of SSA, such as lack of infrastructure, high reliance on traditional energy sources, the existence of large informal sector, and lack of reliable data. It is not only the energy system characteristics but also the central question that the models aim to address that are different for developed and developing countries. The main question in developed countries is how to reduce emissions without affecting the energy services. In developing countries, the focus lies on providing access to modern energy for all and preferably with renewable energy.

This research employs an extended version of the residential energy model presented in [4] and [5] embedded within an integrated modelling framework, to partly address the unique characteristics of SSA. The model includes a custom-made decision module that determines the least-cost technology option for settlements based on various local socio-economic characteristics. Over the years, this research used various versions of the residential energy model and applied several scenarios for universal access to electricity and clean cooking solutions. Using this model, we have analysed synergies and trade-offs between providing universal energy access and climate change and health, as well as between the other two targets of SDG7 (improving efficiency and increasing renewable energy). In addition, we have identified the barriers for electricity access and relevant actors, institutions, and regulations in SSA through stakeholder interviews and workshops, with a focus on off-grid systems. The overall aim of this study is to explore synergies and trade-offs of pathways to achieve SDG7. The study has several limitations, such as, failure to account the role of the informal sector, uncertainties in socio-economic projections, the simplistic assumption of a direct link between income and electricity access, limited availability of proper data, and failure to include the impact of factors like household-head gender, age, education level and cultural preferences.

Delivering on the goal of universal access to modern energy services in SSA is a tremendous endeavour with significant challenges. While recognizing that there are various pathways to delivering universal access to modern energy services, the overall message of this thesis is the importance of considering synergies and tradeoffs between various policy instruments not only on the wider energy system but 
also on the social, economic and environmental dimensions. The results demonstrate that several fuels and technologies, decentralised and centralised, fossil and renewable, traditional and modern, all play vital roles in achieving universal access to clean and modern energy for all in SSA by 2030. However, strategies to achieve this goal should also consider possible trade-offs and synergies with other SDGs and targets within the SDGs, including how they affect greenhouse gas emissions.

To achieve universal electricity access, on-grid systems will need to be complemented with off-grid technologies. Between now and 2030, policies will need to ensure access to electricity for over 500 million new customers. While on-grid electricity would be cost-effective in most cases, renewable mini-grid technologies could provide electricity access to a large number of people, depending on the targeted level of consumption. If governments target a minimum level of access that is enough to light two bulbs, charge a phone and play a radio, off-grid systems could provide access to more than 65 percent of the newly connected population. Especially in poor, sparsely populated rural settlements in SSA, off-grid systems including mini-grids and stand-alone systems - could play a vital role in providing electricity at a reasonable cost. Decentralized renewable-energy-based systems, largely based on solar photovoltaic technology, can be implemented with relatively low initial investment, gradually scaling up capacity as the level of consumption increases. However, in large parts of western and southern Africa, due to their high population density and relatively high household electricity consumption, the central grid remains the preferred electrification option. In that case, providing universal electricity access requires major investments in generation capacity and transmission and distribution.

An important synergy between climate policy and electricity access is that implementing international climate policy could make universal access to electricity cheaper. This is because increasing energy efficiency, which is an important strategy for climate change mitigation, could reduce the overall demand. Universal access is projected to require annual investments of US\$27 billion with climate policy and up to US\$33 billion without one. Carbon pricing lowers the required investments through efficiency improvements in household appliances and learning in renewable energy technologies. While this increases electricity prices, an important trade- 
off, it could also be considered an opportunity to move away from fossil fuels and improve energy security.

Universal energy access is not only about electricity. Access to clean and modern energy for cooking is also central to social and economic development, and environmental protection. Lack of access to clean cooking facilities remains acute in SSA with nearly a billion people relying on solid biomass and kerosene as their primary cooking fuel. The choice of clean cooking solution depends on economic factors and availability of resources and infrastructure. Improved and advanced biomass cookstoves play a prominent role in the transition towards universal access to clean and modern energy in SSA. Phasing out traditional biomass (and kerosene) use has multiple benefits: it saves lives, reduces forest degradation and deforestation, reduces energy related emissions, and can even lower the cost of cooking. However, though relatively low compared to the required investment in electricity access, the transition can be hampered by the cost of adopting clean fuels and devices, particularly for the rural poor. And after purchasing the device, the continued and proper use of the stove can be hindered by high fuel costs for modern technologies depending on how biomass is acquired. Hence, the focus on accessibility and affordability of modern fuels is crucial to harness the full benefits of the transition.

Universal energy access can benefit from integrating policies for the three targets of SDG7, energy access, energy efficiency and renewable energy. Higher energy efficiency improvements allow for providing a wide range of services with distributed systems, while distributed renewable energy expansion reduces conversion and transmission losses in the region. That way, the integration stimulates the expansion of energy services while reducing the investment requirements and the impact on the climate. Despite the relatively low level of energy consumption, there is a large potential for efficiency improvement in SSA, especially in cooking. Other household appliances in SSA are also typically far less efficient than the best available units on the market. The improvement in the efficiency of household appliances could enable the use of mini-grid and stand-alone systems to provide energy beyond lamps and radios, to meet demands for cooling, heating, and electric cooking services. 
With lower cost of end-use service delivery, money saved can be used to finance additional efficiency improvements and/or in the deployment of renewables.

Governance is an essential component of the transition towards universal access to clean and modern energy for all, as an enabler to overcome the trade-offs and enhance the synergies between policy measures, actors and their resources. While countries have embraced multiple technologies to achieve the goal, solutions are often deployed independently of one another rather than designed as complementary solutions that form part of a cohesive vision for delivering universal access. Lack of clear electrification plans from governments and complementary policy and regulation to facilitate deployment of multiple energy access technologies could result in fragmented solutions and in many cases stagnated progress. While no single recipe exists, the evidence points to some facilitative ingredients that are foundational. Especially for off-grid electrification systems, stable and consistent policy frameworks, clear technical standards, and certification for new technologies are crucial. For clean cooking, stable supplies of affordable clean fuels and energy sources are essential to enable the adoption of clean household energy. It is also important that governments encourage multi-sectoral coordination and action between various sectors and agencies to harness the full potential of the synergies and manage (or at least anticipate) the trade-offs. 


\section{Samenvatting}

Toegang tot elektriciteit en schone kookmethoden zijn belangrijke voorwaarden voor menselijke ontwikkeling. Dit werd erkend door de wereldwijde gemeenschap via de goedkeuring van de Sustainable Development Goals (SDG's), waarin SDG7 tot doel heeft om in 2030 toegang tot betaalbare, betrouwbare, duurzame en moderne energie voor iedereen te voorzien. De SDG's zijn geïntegreerde, ondeelbare en onderling verbonden doelen. Een silobenadering die zich richt op een specifiek doel of een specifieke sector zal tot suboptimale resultaten leiden omdat dan geen rekening wordt gehouden met de systemische aard van de uitdagingen. De drie doelstellingen van SDG7, universele toegang tot betaalbare, betrouwbare en moderne energiediensten, vergroten van het aandeel hernieuwbare energie in de mondiale energiemix en verdubbeling van de snelheid van de verbetering van energie-efficiëntie verbeterd op mondiaal niveau, hebben sterke wisselwerkingen met andere SDG's. Verschillende onderzoeken hebben de onderlinge verbanden tussen SDG7 en andere SDG's aangetoond.

Momenteel hebben meer dan 600 miljoen mensen in sub-Sahara Afrika (SSA) geen toegang tot elektriciteit en zijn meer dan 900 miljoen mensen afhankelijk van traditionele biomassa om te koken. Als historische trends doorzetten, hebben ongeveer 515 miljoen mensen nog steeds geen toegang tot elektriciteit en zijn meer dan 700 miljoen mensen afhankelijk van traditionele biomassa om te koken in 2030. Mensen die geen toegang hebben tot moderne vormen van energie zitten vast in een zich versterkende cyclus: een groot deel van het inkomen wordt aan dure, ongezonde, onveilige, tijdrovende en inefficiënte vormen van energie besteed, waardoor onvoldoende middelen overblijven om het levensonderhoud en basisvoorzieningen te verbeteren. Betaalbare en betrouwbare toegang tot moderne vormen van energie is de sleutel om deze cyclus te doorbreken.

In deze context is het vinden van de beste manier om universele toegang tot schone, moderne en duurzame energie te bieden en tegelijkertijd de sociale, economische en milieueffecten tot een minimum te beperken, een belangrijke uitdaging voor beleidsmakers in SSA. De snelle daling van de prijs van hernieuwbare energietechnologieën is een drijvende kracht geweest voor het verbeteren van toegang tot elektriciteit in SSA. Er is ook een positieve trend in de innovatie van schone kooktechnologieën, die, samen met een groeiende middenklasse met een relatief hoog 
besteedbaar inkomen en snelle verstedelijking, leidt tot veranderingen in kookmethoden. Deze ontwikkelingen leiden echter ook tot uitdagingen voor energieplanning. Het bepalen van de kosten en baten tussen verschillende technologieën vereist uitgebreide berekeningen door energiesysteemmodellen. Deze modellen geven cruciale informatie voor langetermijnplanning. De meeste energiemodellen zijn echter gebouwd en gebruikt in ontwikkelde landen en negeren de unieke kenmerken van SSA, zoals een gebrek aan infrastructuur, een grote afhankelijkheid van traditionele energiebronnen, het bestaan van een grote informele sector en een gebrek aan betrouwbare data. Niet alleen de kenmerken van het energiesysteem, maar ook de vraag die in de modellen centraal staan, zijn verschillend voor ontwikkelde en ontwikkelingslanden. De belangrijkste vraag in ontwikkelde landen is hoe de uitstoot van broeikasgassen kan worden verminderd zonder de energiediensten te beïnvloeden, terwijl in ontwikkelingslanden de focus ligt op toegang tot moderne energie voor iedereen, bij voorkeur met hernieuwbare energie.

Dit onderzoek maakt gebruik van het residentiële energiemodel gepresenteerd in [4] en [5], welke is uitgebreid om rekening te houden met belangrijke karakteristieken van SSA. Het energiemodel is ingebed in een geïntegreerd modelleerraamwerk en bevat een op maat gemaakte beslissingsmodule die de goedkoopste technologieoptie voor nederzettingen bepaalt op basis van verschillende lokale sociaaleconomische kenmerken. In dit onderzoek zijn in de loop der jaren verschillende versies van het residentiële energiemodel gebruikt en zijn verschillende scenario's ontwikkeld voor universele toegang tot elektriciteit en schoon koken. Met behulp van dit model hebben we synergieën en compromissen geanalyseerd tussen het verstrekken van universele toegang tot energie en klimaatverandering en gezondheid, en tussen de andere twee doelstellingen van $\mathrm{SDG} 7$ (het verbeteren van energie-efficiëntie en het verhogen van het aandeel hernieuwbare energie). Daarnaast hebben we de belemmeringen voor toegang tot elektriciteit en relevante actoren, instellingen en regelgeving in SSA geïdentificeerd via interviews met belanghebbenden en workshops, met de nadruk op off-grid systemen. Het algemene doel van deze studie is om synergieën en compromissen te verkennen van paden om SDG7 te bereiken. De studie heeft verschillende beperkingen, zoals onzekerheden in sociaaleconomische projecties, de simplistische veronderstelling van een rechtstreeks verband tussen inkomen en toegang tot elektriciteit, beperkte beschikbaarheid van de juiste gegevens en het niet meenemen van factoren zoals het geslacht, de leeftijd, opleidingsniveau van het gezinshoofd en culturele voorkeuren. 
Het bereiken van universele toegang tot moderne energie in SSA is een enorme uitdaging. Er zijn verschillende manieren om universele toegang tot moderne energiediensten te bieden. De algemene boodschap van dit proefschrift is om de synergieën en afwegingen tussen verschillende beleidsinstrumenten mee te nemen in beleidsbeslissingen; niet alleen op het bredere energiesysteem maar ook op sociale, economische en milieudimensies. De resultaten tonen aan dat verschillende brandstoffen en technologieën, gedecentraliseerd en gecentraliseerd, fossiel en hernieuwbaar, traditioneel en modern, allemaal een cruciale rol spelen bij het bereiken van toegang tot schone en moderne energie voor iedereen in SSA in 2030. Bij het bedenken van strategieën om dit doel te bereiken moeten echter ook mogelijke compromissen en synergieën met andere SDG's en doelstellingen binnen de SDG's worden meegenomen, inclusief hoe deze de uitstoot van broeikasgassen beïnvloeden.

Om universele toegang tot elektriciteit te verkrijgen, on-grid-systemen moeten worden aangevuld met off-grid-technologieën. Tussen nu en 2030 moet het beleid ervoor zorgen dat meer dan 500 miljoen mensen toegang krijgen tot elektriciteit. Hoewel elektriciteit op het net in de meeste gevallen kosteneffectief is, zouden hernieuwbare mini-grid technologieën toegang tot elektriciteit kunnen bieden aan een groot aantal mensen, afhankelijk van het beoogde elektriciteitsverbruik. Als regeringen een minimumniveau van toegang nastreven, voldoende om twee lampen aan te steken, een telefoon op te laden en een radio af te spelen, kunnen offgrid-systemen toegang bieden aan meer dan 65 procent van de nieuw aangesloten bevolking. Vooral in arme, dunbevolkte, landelijke nederzettingen in SSA kunnen off-grid-systemen - zowel mini-grids en stand-alone systemen - een cruciale rol spelen bij het leveren van elektriciteit tegen een redelijke prijs. Gedecentraliseerde systemen op basis van hernieuwbare energie, grotendeels gebaseerd op zonneenergie, kunnen met relatief lage initiële investeringen worden geïmplementeerd, waardoor de capaciteit geleidelijk toeneemt naarmate het verbruik toeneemt. In grote delen van westelijk en zuidelijk Afrika blijft het centrale net echter vanwege de hoge bevolkingsdichtheid en relatief hoge elektriciteitsverbruik de voorkeursoptie voor elektrificatie. Het verstrekken van universele toegang tot elektriciteit vergt daar grote investeringen in opwekkingscapaciteit en transmissie en distributie. 
Een belangrijke synergie tussen klimaatbeleid en elektriciteitstoegang is dat internationaal klimaatbeleid universele toegang tot elektriciteit goedkoper kan maken. Dit komt doordat het verbeteren van energie-efficiëntie een belangrijke strategie is om de klimaatverandering te beperken, wat leidt tot een lagere vraag naar energie. Voor universele toegang in SSA zijn naar verwachting jaarlijkse investeringen nodig van 27 miljard dollar met klimaatbeleid en tot 33 miljard dollar zonder klimaatbeleid. Het beprijzen van $\mathrm{CO}_{2}$ leidt weliswaar tot hogere elektriciteitsprijzen, maar verlaagt de vereiste investeringen door efficiëntieverbeteringen in huishoudelijke apparaten en snellere kostendalingen van hernieuwbare energie.

Universele toegang tot energie gaat niet alleen over elektriciteit. Toegang tot schone en moderne energie om te koken speelt ook een cruciale rol voor sociale en economische ontwikkeling en milieubescherming. Gebrek aan toegang tot schone kookfaciliteiten blijft een acuut probleem in SSA, waar bijna een miljard mensen biomassa en kerosine als hun primaire kookbrandstof gebruiken. De keuze voor een schone kookmethode hangt af van economische factoren en beschikbaarheid van middelen en infrastructuur. Verbeterde en geavanceerde biomassa-kooktoestellen spelen een prominente rol in de overgang naar universele toegang tot schone en moderne energie in SSA. Het uitfaseren van het traditionele gebruik van biomassa (en kerosine) heeft meerdere voordelen: het verlagen van kindersterfte, het verminderen van bosdegradatie en ontbossing, het verminderen van energiegerelateerde emissies en het kan zelfs de kosten van koken verlagen. Hoewel de benodigde investeringen voor universele toegang tot moderne kookmethoden relatief laag zijn ten opzichte van de benodigde investeringen voor universele toegang tot elektriciteit, kunnen deze worden belemmerd door de kosten van het gebruik van schone brandstof en apparatuur, met name voor de armen op het platteland. Zelfs na aankoop van het apparaat kan het blijvende en juiste gebruik van het kooktoestel worden belemmerd door hoge brandstofkosten. Daarom is de focus op toegankelijkheid en betaalbaarheid van moderne brandstoffen cruciaal om de voordelen van de transitie ten volle te benutten.

Integratie van beleid voor het halen van de drie doelstellingen van SDG7 (gericht op energietoegang, energie-efficiëntie en hernieuwbare energie) heeft diverse 
voordelen. Door hogere energie-efficiëntieverbeteringen kan een breed scala aan diensten worden geleverd met off-grid systemen, terwijl off-grid uitbreiding van hernieuwbare energie de conversie- en transmissieverliezen in de regio vermindert. Op die manier stimuleert het verbeteren van efficiëntie de uitbreiding van energiediensten terwijl de investeringsvereisten en de impact op het klimaat worden verminderd. Ondanks het relatief lage energieverbruik is er een groot potentieel voor efficiëntieverbetering bij SSA, vooral bij koken. Andere huishoudelijke apparaten in SSA zijn doorgaans ook veel minder efficiënt dan de best beschikbare apparaten op de markt. De verbetering van de efficiëntie van huishoudelijke apparaten zou het gebruik van mini-grid en stand-alone systemen mogelijk kunnen maken om energie te leveren die verder gaat dan lampen en radio's, om te voldoen aan de vraag naar koeling, verwarming en elektrisch koken. Het bespaarde geld door lagere kosten voor eindgebruik kan worden gebruikt om extra efficiëntieverbeteringen en / of de inzet van hernieuwbare energiebronnen te financieren.

Governance is een essentieel onderdeel van de overgang naar universele toegang tot schone en moderne energie voor iedereen. Goede governance is noodzakelijk om tot compromissen te komen en synergieën tussen beleidsmaatregelen, actoren en hun middelen te versterken. Hoewel landen meerdere technologieën hebben omarmd om SDG7 doelen te bereiken, worden oplossingen vaak onafhankelijk van elkaar ingezet in plaats van ontworpen als complementaire oplossingen die deel uitmaken van een samenhangende visie voor het leveren van universele toegang. Het ontbreken van duidelijke elektrificatieplannen van regeringen en aanvullend beleid en regelgeving om de inzet van meervoudige energietoegangstechnologieën te vergemakkelijken, zou kunnen leiden tot gefragmenteerde oplossingen en in veel gevallen tot stagnerende vooruitgang. Hoewel er geen vast recept bestaat, kunnen er wel enkele fundamentele aanbevelingen worden gedaan. Vooral voor off-grid elektrificatiesystemen zijn stabiele en consistente beleidskaders, duidelijke technische normen en certificering voor nieuwe technologieën cruciaal. Voor schoon koken is een stabiele aanvoer van betaalbare schone brandstoffen en energiebronnen essentieel om de toepassing van schone huishoudelijke energie mogelijk te maken. Het is ook belangrijk dat regeringen multisectorale coördinatie en actie tussen verschillende sectoren en agentschappen aanmoedigen om het volledige potentieel van de synergieën te benutten en de compromissen te beperken. 


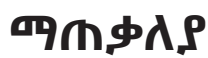

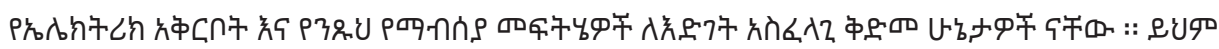

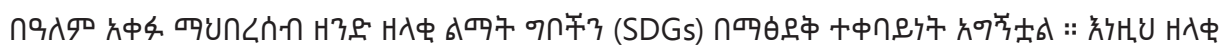

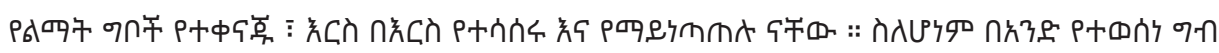

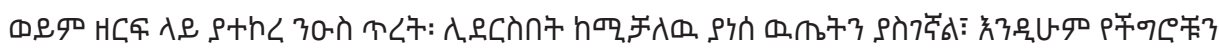

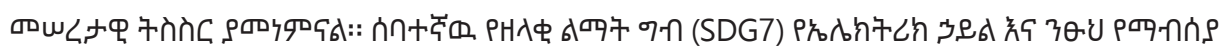

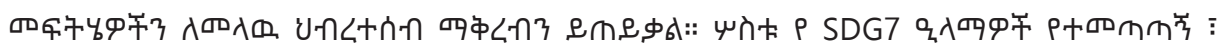

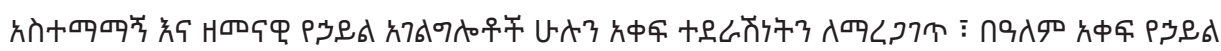

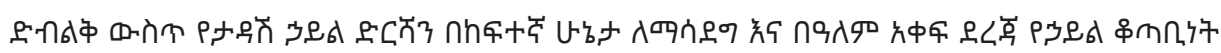

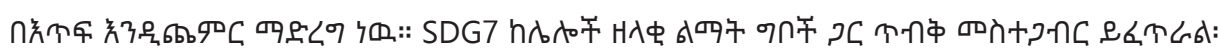

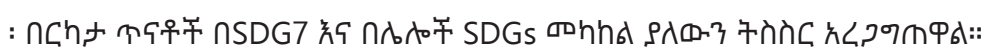

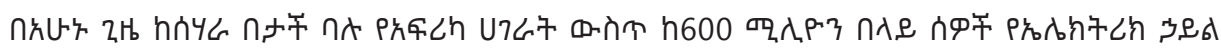

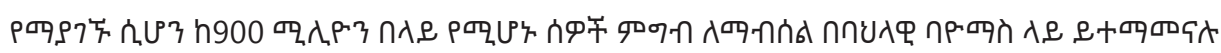

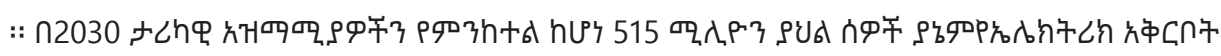

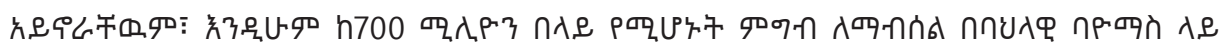

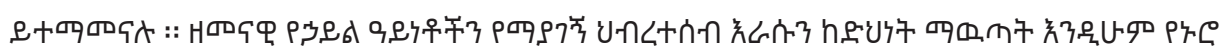

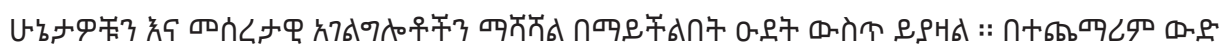

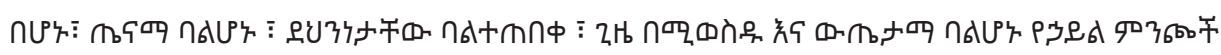

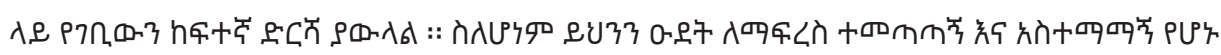

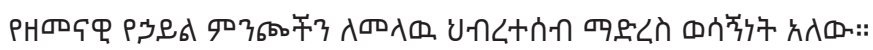

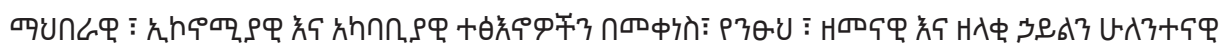

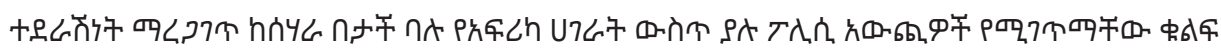

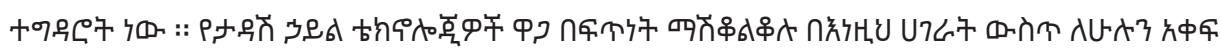

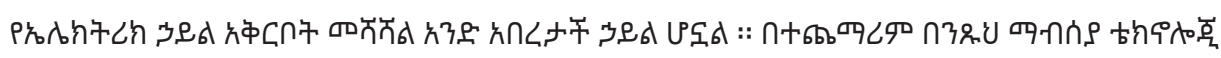
б一⿻

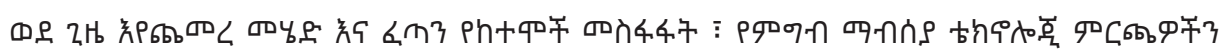

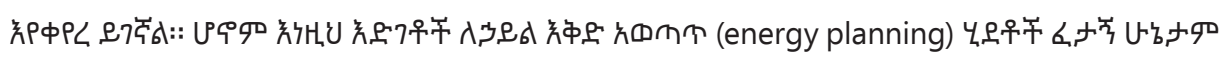
бr ene

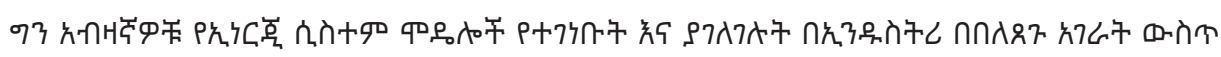

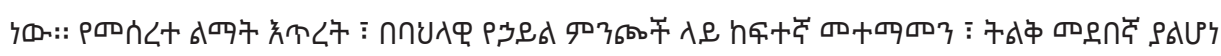




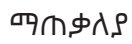

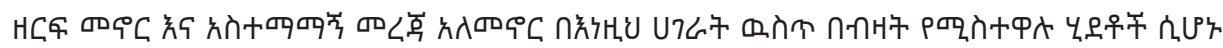

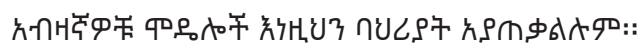

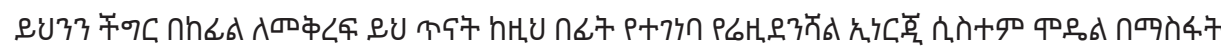

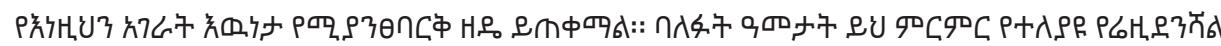

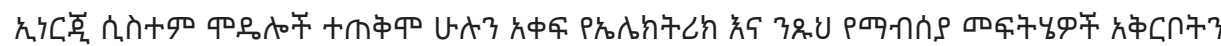

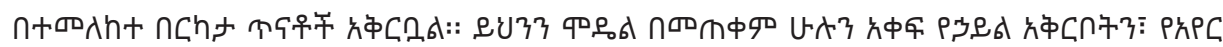

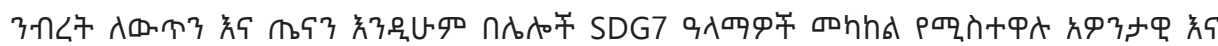

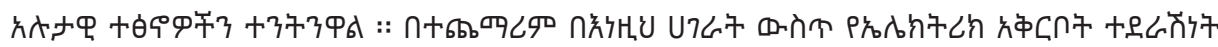

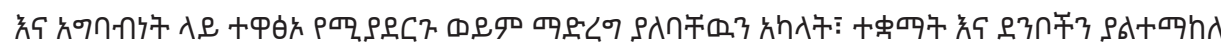

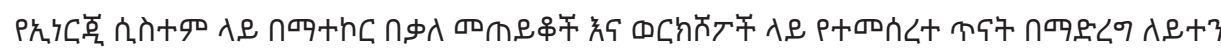
久中

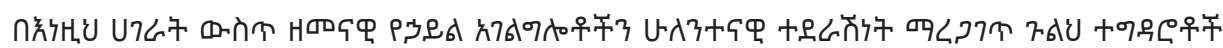

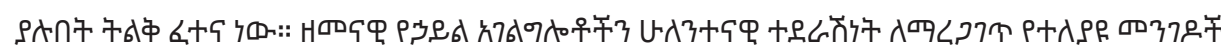

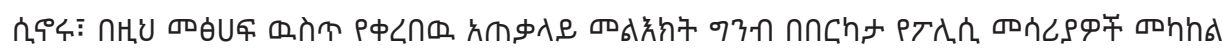

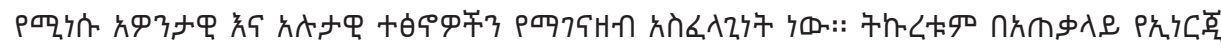

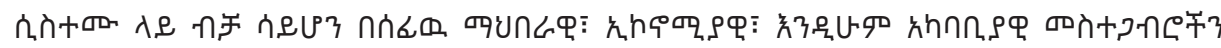

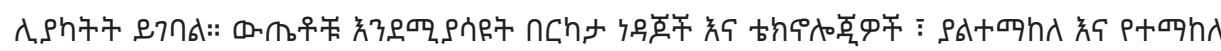

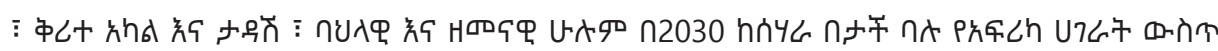

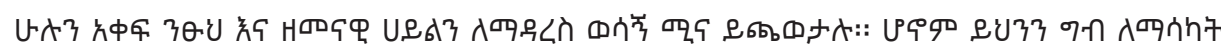

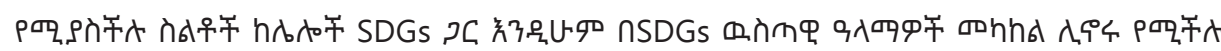

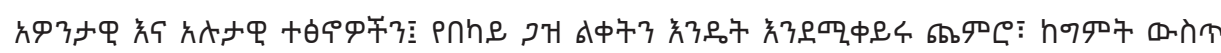

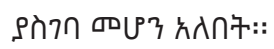

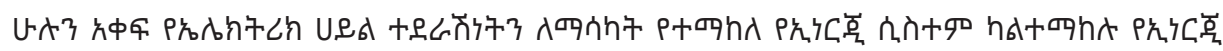

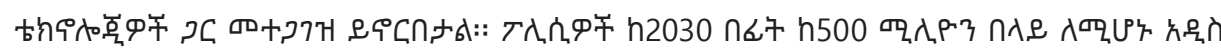

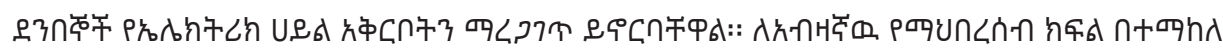

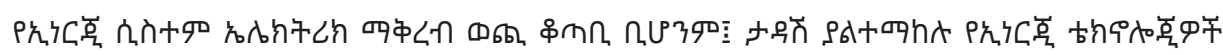

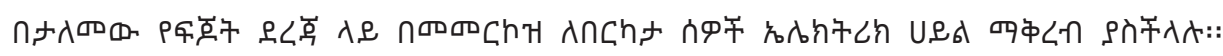

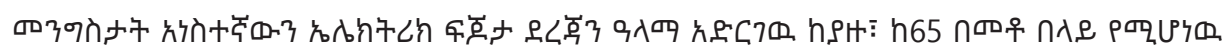

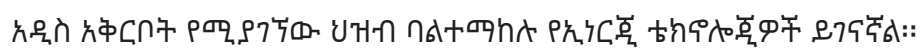




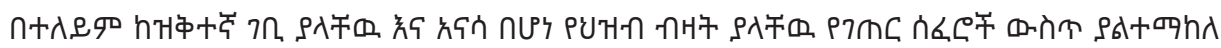

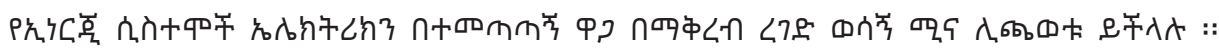

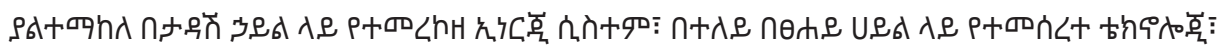

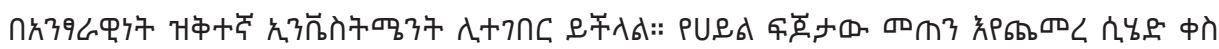

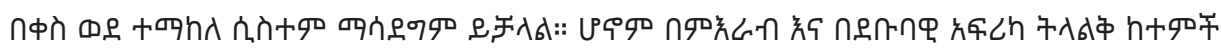

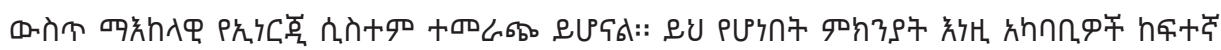

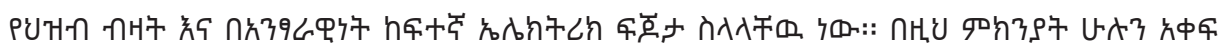

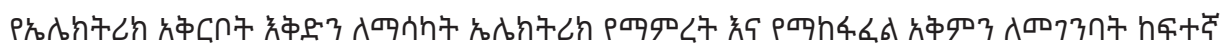

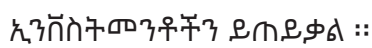

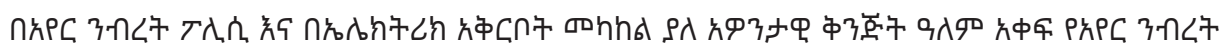

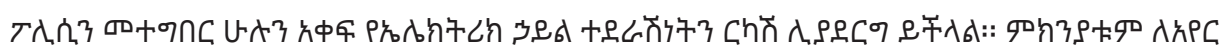

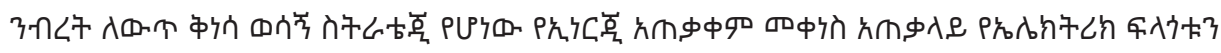

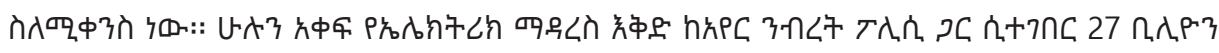

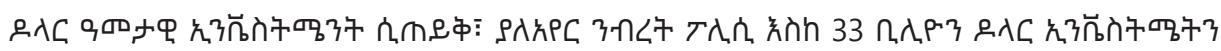
еद.

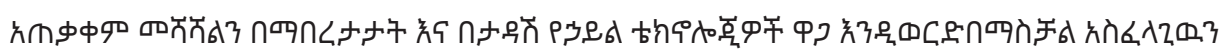

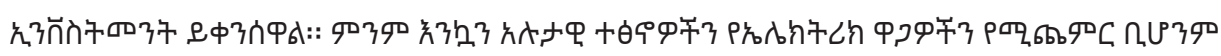

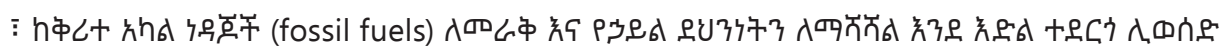
e年入d:

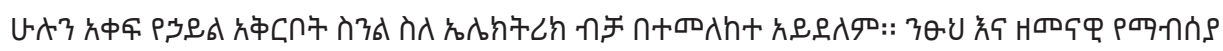

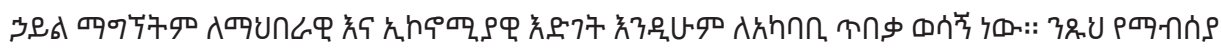

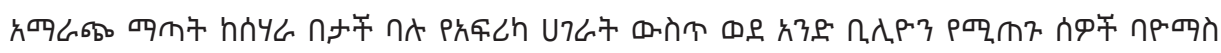

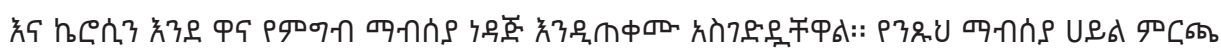

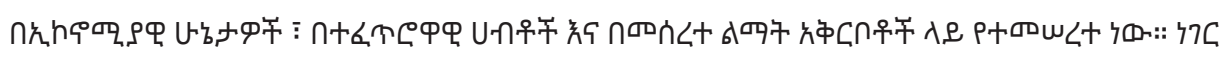

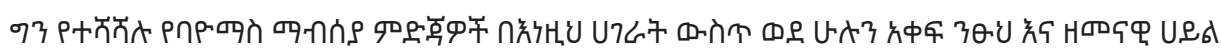

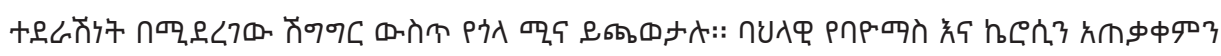

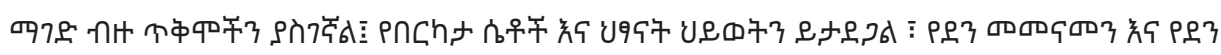

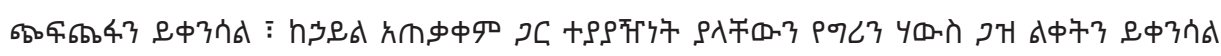

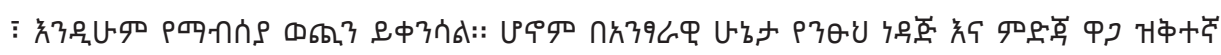

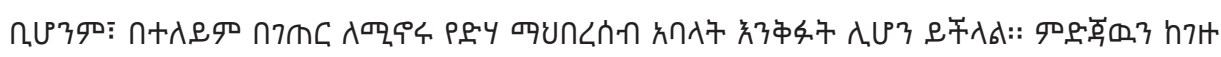

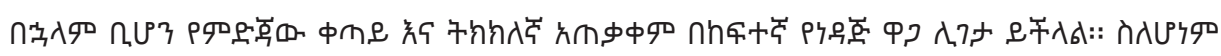

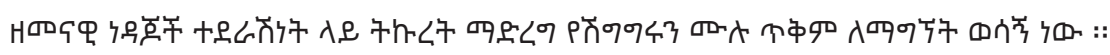


$\operatorname{anm} \phi \lambda \rho$

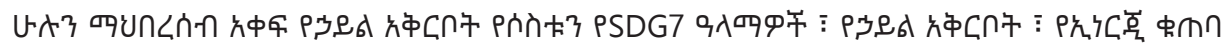

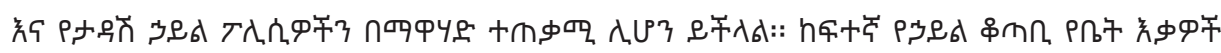

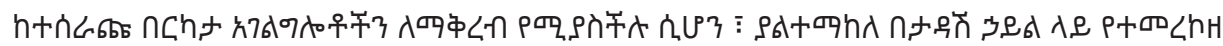

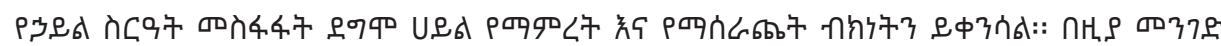

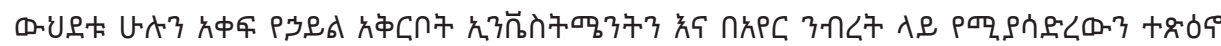

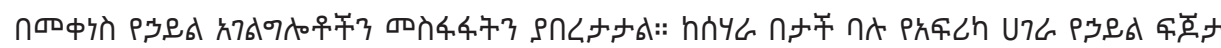

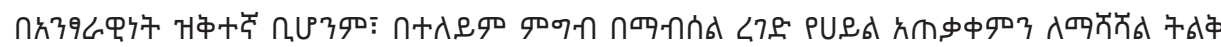

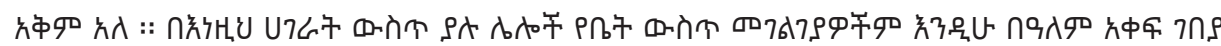

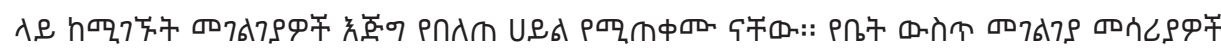

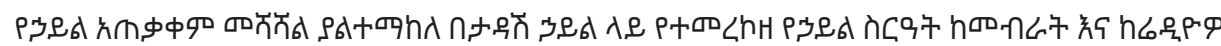

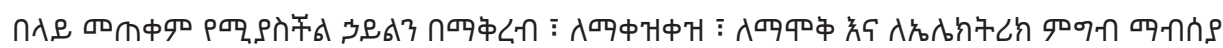

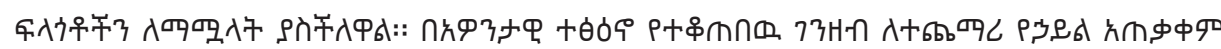

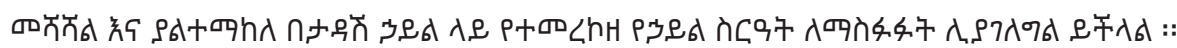

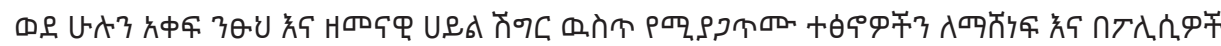

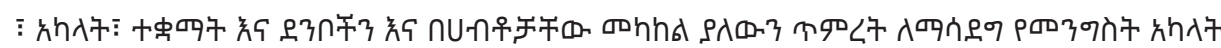

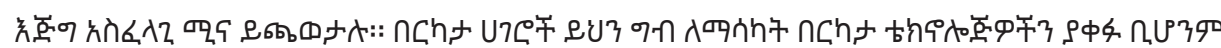

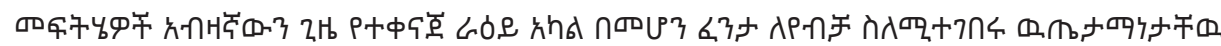

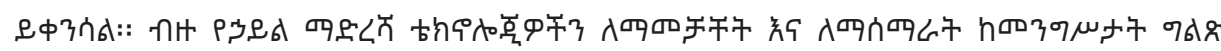

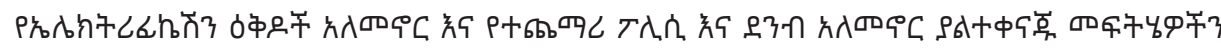

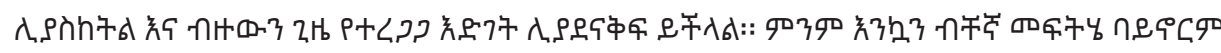

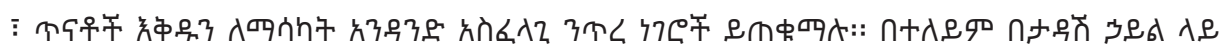

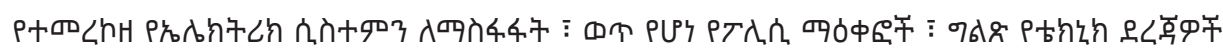

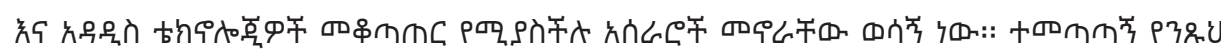
识焉

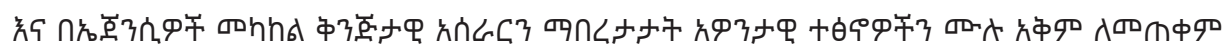

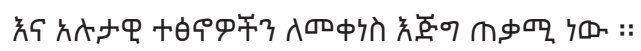




\section{Acknowledgements}

This thesis is an upshot of collaborations and interactions with people of different professional backgrounds. I had the privilege of working among purpose driven individuals who inspired me to go deeper, to persevere and finally to publish these findings. I am indebted to all, near and far, who encouraged me in the process and gave me the much-needed boost when I needed it. Without their support, guidance and patience, this journey would have been an insurmountable task. It is a pleasure to thank those who made these valuable contributions. I am especially grateful to my supervisors - Detlef van Vuuren and Andries Hof, for their patience and vision.

Detlef, thank you for your inspirational support during this process, you have undoubtedly helped me shape the thesis to this quality. You have given me insightful comments at every stage of the process. I am blessed to have my thesis supervised by such a knowledgeable man.

And Andries, who has been the co-supervisor of this thesis, thank you very much for all the insightful comments and encouragement throughout this research work. Your comments and critical view on the smallest details of the thesis have been exceptional. You helped me see the bigger picture of the work we are doing. I cannot have imagined having a better advisor and mentor.

My sincere thanks also goes to Paul Lucas, for his patience and dedication while introducing me to the details of the IMAGE-TIMER model. Without his help, this thesis would have been improbable. My gratitude extends to the past and present heads of the department of climate, air and energy (KLE) at PBL, Pieter Boot, Tom Kram, and Martine Uyterlinde, for providing me with the opportunity and resources to pursue this $\mathrm{PhD}$. I would also like to thank everyone that provided valuable contributions to this thesis and enlighten this work with their experience and perspectives. It goes without saying that my deepest gratitude extends to my colleagues at PBL, and especially at KLE. Likewise, I am grateful for all the support I received from Utrecht University. Also worth a mention is the valuable collaboration with my (briefly) former colleagues at the energy program of IIASA. 
I would also like to thank my family. Ethan AG Ruijsink and Liya AG Ruijsink, having you is the best thing that happened to me, your energy always carries me forward. Saskia Ruijsink, thank you for your support and sacrifices throughout this process. Mlungisi Nkala, you have been there all the way, my brother, thank you. My parents, my family and friends in the Netherlands, Ethiopia, and around the world, thank you for all the support and encouragement over the years. It is always impossible to mention all, therefore, whoever has contributed to this thesis, one way or another, forgive me for not mentioning your name and accept my heartily praise.

This thesis benefitted from the funding by the Dutch Ministry of Foreign Affairs, through its Directorate-General of Trade and International Cooperation and the European Horizon 2020 research programme CD-LINKS [grant agreement No 642147]. 


\section{Curriculum Vitae}

Anteneh Getnet Dagnachew was born on the 17th of October 1981 in Addis Ababa, Ethiopia. Early on, he followed in his father's footsteps into technical education. Here he obtained a diploma in auto mechanics and a bachelor's degree in construction technology (with distinction). In 2006 he moved to the Netherlands and attended IHS, Erasmus University in Rotterdam where he graduated with an M.Sc. degree in Urban Management and development - specializing in Environment and Infrastructure (with distinction) in 2007. After working in the field for a couple of years, mostly as a freelance consultant, he attended Utrecht University, where he graduated with an M.Sc. degree in sustainable development - Energy and resources in 2013. After graduation, he returned to freelance consulting for two years before joining PBL Netherland Environmental Assessment Agency. At PBL, he extended the global residential energy model and adapted the methodology to reflect the situation on the ground in Sub-Saharan Africa. The model is used for exploring energy access challenges and opportunities in Sub-Saharan Africa in the context of the sustainable development goals. He also conducted his PhD research at Utrecht University and PBL between 2016 and 2021. In 2019, he spent three months at the International Institute for Applied Systems Analysis (IIASA) exploring the methodological differences between IMAGE and MESSAGE-Access Integrated Assessment Models for energy access research in developing countries. His research work has resulted in various publication, most of which have been presented in international conferences. 


\section{List of publications}

\section{Publication used in this thesis}

Dagnachew, A. G., Lucas, P. L., Hof, A. F., Gernaat, D. E., de Boer, H.-S. \& van Vuuren, D. P. 2017. The role of decentralized systems in providing universal electricity access in Sub-Saharan Africa-A model-based approach. Energy, 139, 184-195.

Dagnachew, A. G., Lucas, P. L., Hof, A. F. \& van Vuuren, D. P. 2018. Trade-offs and synergies between universal electricity access and climate change mitigation in Sub-Saharan Africa. Energy Policy, $114,355-366$.

Dagnachew, A. G., Hof, A. F., Roelfsema, M. R. \& van Vuuren, D. P. 2020. Actors and governance in the transition toward universal electricity access in Sub-Saharan Africa. Energy Policy, 143, 111572.

Dagnachew, A. G., Hof, A. F., Lucas, P. L. \& van Vuuren, D. P. 2020. Scenario analysis for promoting clean cooking in Sub-Saharan Africa: Costs and benefits. Energy, 192, 116641.

Dagnachew, A. G., Poblete-Cazenave, M., Pachauri, S., Hof, A., van Ruijven, B., \& van Vuuren, D. (2020). Integrating energy access, efficiency and renewable energy policies in Sub-Saharan Africa: a model-based analysis. Environmental Research Letters.

\section{Other publications}

Lucas, P. L., Dagnachew, A. G. \& Hof, A. F. 2017. Towards universal electricity access in Sub-Saharan Africa: A quantitative analysis of technology and investment requirements. PBL Netherlands Environmental Assessment Agency, The Hague.

Dagnachew, A. G., Lucas, P. L., Hof, A. F., van Vuuren, D. P. 2018. Opportunities and challenges in achieving universal electricity access in sub-Saharan Africa. Oxford Energy Forum. September (115).

Dagnachew, A. G., Lucas, P. L., van Vuuren, D. P. \& Hof, A. F. 2019. Towards Universal Access to Clean Cooking Solutions in Sub-Saharan Africa. PBL Netherlands Environmental Assessment Agency, The Hague.

Dagnachew, A. G., Hof, A. F., Lucas, P. L. \& van Vuuren, D. P. 2019. Insight into Energy Scenarios: A comparison of key transition indicators of $2 \mathrm{C}$ scenarios. PBL Netherlands Environmental Assessment Agency, The Hague.

Hof, A. F. \& Dagnachew, A. G. 2020. Paris-aligned energy transition pathways for India. PBL Netherlands Environmental Assessment Agency, The Hague.

Falchetta, G., Dagnachew, A. G., Hof, A. F., Milne, D., Submitted. The role of regulatory, market and governance risk for electricity access investment in sub-Saharan Africa Energy for Sustainable Development. 


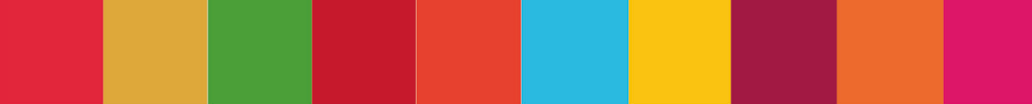

